\title{
1 Widely used catalysts in biodiesel production: A review
}

2 Bishwajit Changmai, ${ }^{1}$ Chhangte Vanlalveni, ${ }^{2}$ Avinash Prabhakar Ingle,${ }^{3}$ Rahul

3 Bhagat, ${ }^{4}$ Lalthazuala Rokhum ${ }^{1,5 *}$

$4 \quad{ }^{l}$ Department of Chemistry, National Institute of Technology Silchar, Silchar, 788010

$5 \quad{ }^{2}$ Department of Botany, Mizoram University, Tanhril, Aizawl, Mizoram, 796001, India

$6{ }^{3}$ Department of Biotechnology, Engineering School of Lorena, University of Sao Paulo,

7 Lorena, SP, Brazil

$8{ }^{4}$ Department of Biotechnology, Government Institute of Science, Aurangabad, Maharashtra, 9 India

$10{ }^{5}$ Department of Chemistry, University of Cambridge, Lensfield Road, Cambridge CB2 1EW, 11 UK.

*Email: rokhum@che.nits.ac.in and/or lalthazualarokhum@gmail.com

\section{Contents}

1. Introduction

2. (Trans)esterification

3. Biodiesel

4. Feedstock for biodiesel production

4.1.1 Edible plant oil

4.1.2 Non-edible plant oil

4.1.3 Waste cooking oil

4.1.4 Animal fats

4.1.5 Algae oil

5. Characterization of catalysts and biodiesel

6. Homogeneous catalyst

6.1. Base catalyst

6.2. Acid catalyst

7. Heterogeneous catalyst

7.1. Base catalyst

7.1.1. Alkaline earth metal oxides

7.1.2. Transition metal oxide

7.1.3. Zeolite

7.1.4. Supported catalysts 
7.1.5. Hydrotalcite

7.1.6. Mixed metal oxides

7.1.7. Bio-waste based catalyst

7.1.7.1. Waste shells

7.1.7.1.1. Eggshell

7.1.7.1.2. Mollusk shell and other seashells

\subsubsection{Ashes of biomass}

\subsection{Acid catalysts}

7.2.1. Sulfated catalyst

7.2.2. Ion-exchange resin

\subsubsection{Mixed metal oxides}

\subsubsection{Sulfonated carbon-based catalyst}

\subsection{Enzyme catalyst}

\subsection{Bifunctional solid catalyst}

\section{Biodiesel production processes}

9. Catalyst comparison

10. Conclusions and outlook

Acknowledgement

References

\section{Abstract}

An ever-increasing energy demand and environmental problems associated with exhaustible fossil fuels have led to the search for an alternative renewable source of energy. In this context, biodiesel has attracted attention worldwide as an alternative to fossil fuel for being renewable, non-toxic, biodegradable, carbon-neutral; hence eco-friendly. Despite homogeneous catalyst has its own merits, currently, much attention has been paid to chemically synthesize heterogeneous catalysts for biodiesel production as it can be tuned as per specific requirement, easily recovered, thus enhance reusability. Recently, biomass-derived heterogeneous catalysts have risen to the forefront of biodiesel productions because of their sustainable, economical and eco-friendly nature. Further, nano and bifunctional catalysts have emerged as a powerful catalyst largely due to their high surface area and potential to convert free fatty acids and triglycerides to biodiesel, respectively. This review highlighted the latest synthesis routes of various types of catalysts including acidic, basic, bifunctional and nanocatalysts derived from different chemicals as well as biomass. In addition, the impacts of 
different methods of preparation of catalysts on the yield of biodiesel are also discussed in details.

\section{Highlights}

- Biodiesel has attracted immense attention as a potential substitute for fossil fuels.

- Esterification and transesterification reactions to produce biodiesel are discussed.

- Effects of various reaction parameters in biodiesel production processes are highlighted.

- Review on the different characterization techniques employed in biodiesel production processes.

- Acid, basic and bifunctional catalysts employed in biodiesel productions are highlighted.

- Different sources, methods of preparation and activities of catalysts are reviewed.

Keywords: Biodiesel, Homogeneous catalyst, Heterogeneous catalyst, Characterization, Fatty acid methyl esters, Renewable energy

\section{Graphical abstract:}

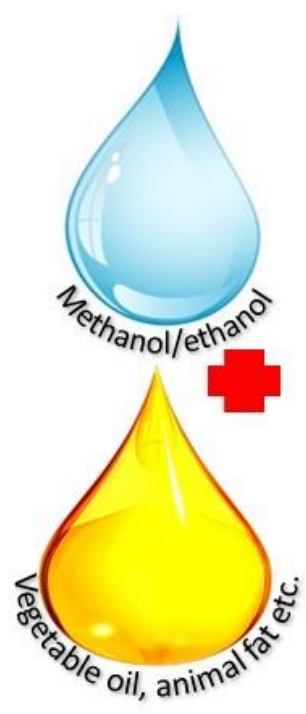

91

92

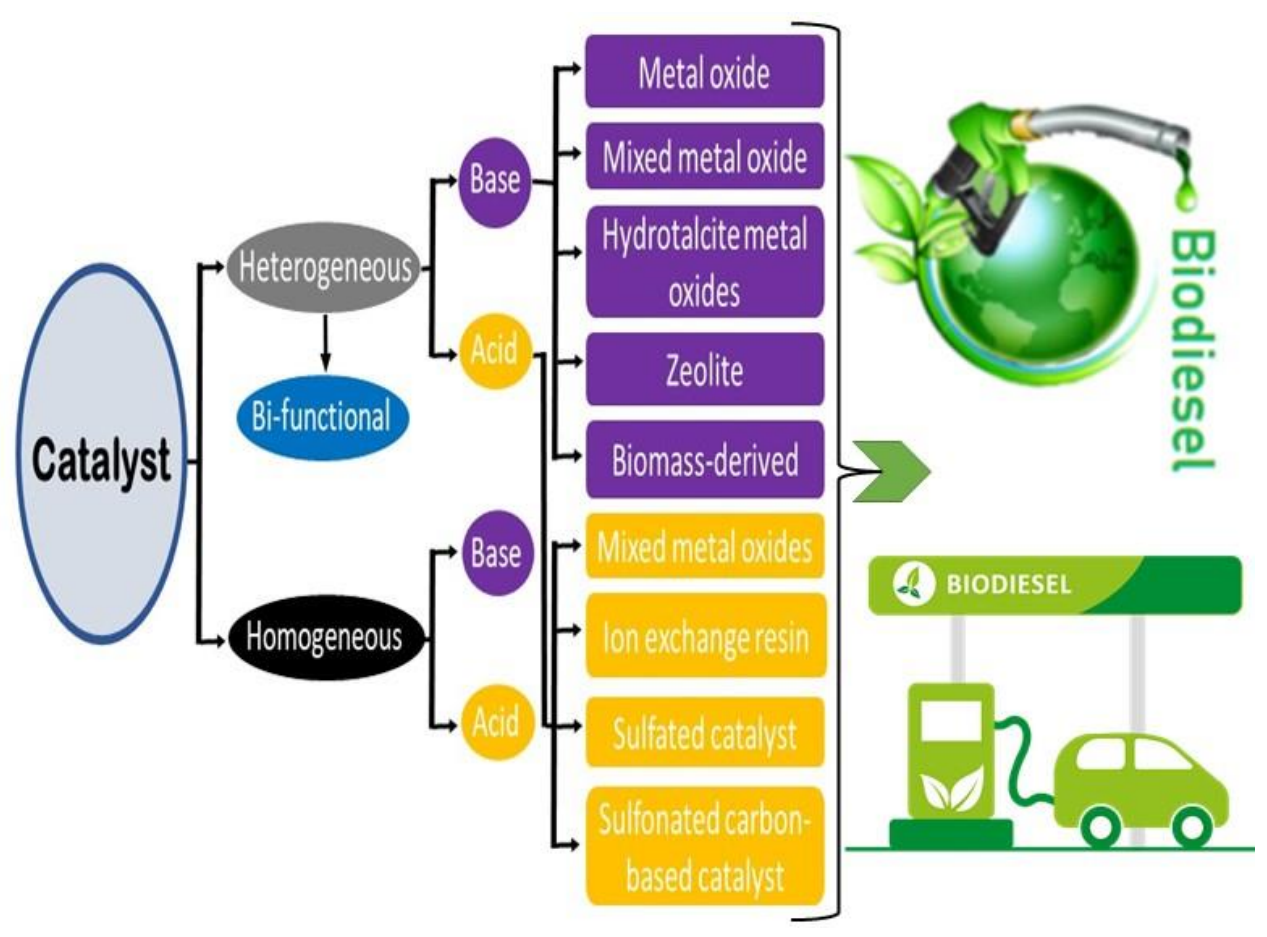




\section{Introduction}

The exponential growth of the world's population coupled with the high standard of living has resulted in a steep increase in energy consumption., ${ }^{1,2}$ The world's total primary energy consumed (TPEC), which is over $150,000,000 \mathrm{GW}$ h in the year 2015, is estimated to rise by a triggering $57 \%$ in $2050^{3}$. Currently, the transportation of goods and services, which is the major contributor to the global economy, primarily rely on non-renewable fossil fuels. In total primary energy consumption, $80 \%$ of the energy consumed is associated with petroleum resources. Amongst these, $54 \%$ is consumed in the transportation sector ${ }^{4}$. It has been predicted that energy consumption in the transportation section will increase with an average rate of 1.1 $\%$ per year. As a result, the high energy consumption of non-renewable petroleum-based fuel to fulfil increasing energy demand of human society has led to an ecological imbalance, excess greenhouse gas emission, acid rain, global warming and drastic decline in fossil fuel reserves. These negative factors associated with excessive consumption and exhaustible nature of fossil fuels compel scientific communities to look out for an alternative energy source. 5, 6

Biofuels are an excellent source of energy and widely seen as a potential substitute for fossil fuels. They are prepared from renewable sources such as plants, municipal wastes, agricultural crops, agricultural and forestry by-product. ${ }^{7}$ Over the last few decades, biofuel such as biodiesel has gained significant attention as an alternative fuel in the research field because of its sustainable and environment-friendly nature. Biodiesel has exhibited properties similar to conventional fossil fuels (petro-diesel) and has some properties better than petro-diesel such as high combustion efficiency, high flash point, high cetane number, lower $\mathrm{CO}_{2}$ emission, lower sulfur content and better lubrication. ${ }^{8,9}$ The high flash point of biodiesel (423 K), as compared to petrodiesel $(337 \mathrm{~K})$, makes it non-flammable and non-explosive resulting in easy and safe handling, storage, and transportation. Additionally, it can be directly used in the automotive engine without any additional alteration. ${ }^{10}$ It is estimated that biodiesel demand will increase to double or triple by the year $2020 .{ }^{11}$ In the light of this, in the last decades, much attention has been paid to research on biodiesel production with an intension make it more sustainable and economical. An increasing interest in biodiesel is validated by the number of research paper publications in this area as shown in Figure 1. Statistical data analysis in Figure 1 depicted the increasing trend of published research papers in the field of biodiesel. These data were collected in February 2020 from "SciFinder Database" using the keyword "biodiesel". From a meagre 157 publications in the year 1993, it has exponentially increased to 3725 publications during its peak in 2014. 


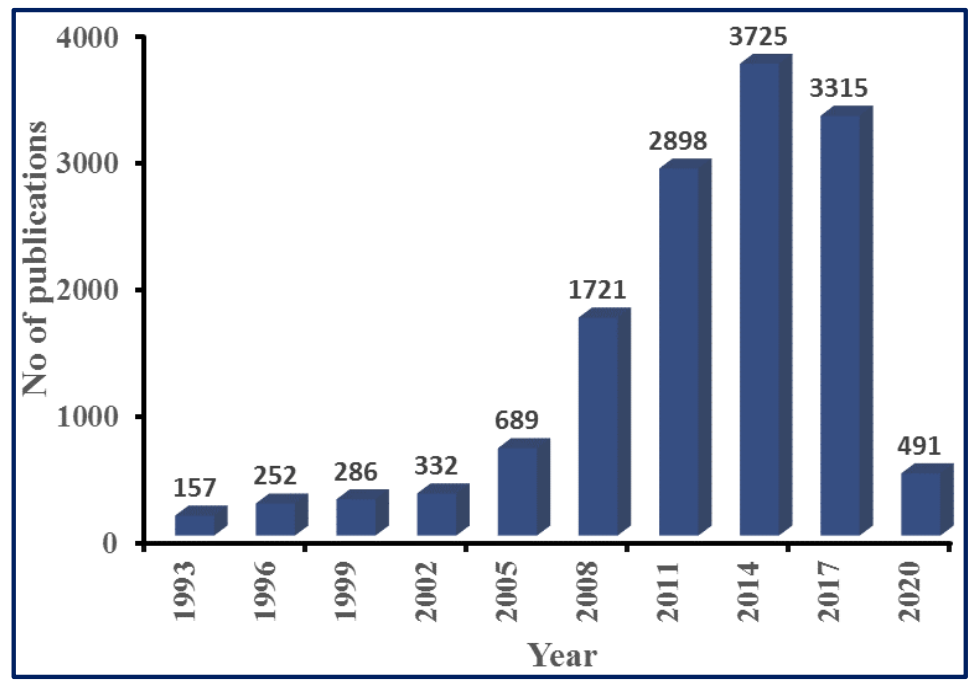

Figure 1: Publications per year for biodiesel during the period 1993 to Feb 2020 (Data collected from SciFinder Database)

\section{2. (Trans)esterification}

Transesterification or alcoholysis is a process to produce biodiesel in which edible/nonedible oils or triglyceride (TG) and alcohol have undergone nucleophilic reaction to form fatty acid methyl ester (FAME) and glycerol as a byproduct. ${ }^{12}$ The transesterification reaction is illustrated in Scheme 1. Three sequential reversible reactions occurred in the transesterification process; i) conversion of triglyceride to diglyceride, ii) diglyceride conversion to monoglyceride, and finally, iii) monoglyceride conversion to glycerol. An ester is formed in each conversion steps, thus one TG molecule produced three molecules of ester. Transesterification reaction can efficiently convert triglyceride of vegetable oil into FAME, also called biodiesel, as depicted in Scheme 1. However, esterification reaction, a reaction between carboxylic acids and alcohols to afford esters. ${ }^{13-15}$ is essential to converts all free fatty acids (FFA) of vegetable oil into biodiesel as shown in Scheme 2. These transesterification and esterification reactions are usually carried out in the two-pots procedure. Usually, the high FFA content of vegetable oil is first converted to esters (FAME) via esterification reaction by employing acid catalyst followed by transesterification reaction using a basic catalyst to converts triglycerides to FAME. However, (trans)esterification reactions (or simultaneous transesterification and esterification) in one-pot is highly desirable to convert both triglycerides and FFA of vegetable oil (with high FFAs) to FAME to reduce time and cost of biodiesel production. The different routes to synthesized biodiesel are outlined in Figure 2. 


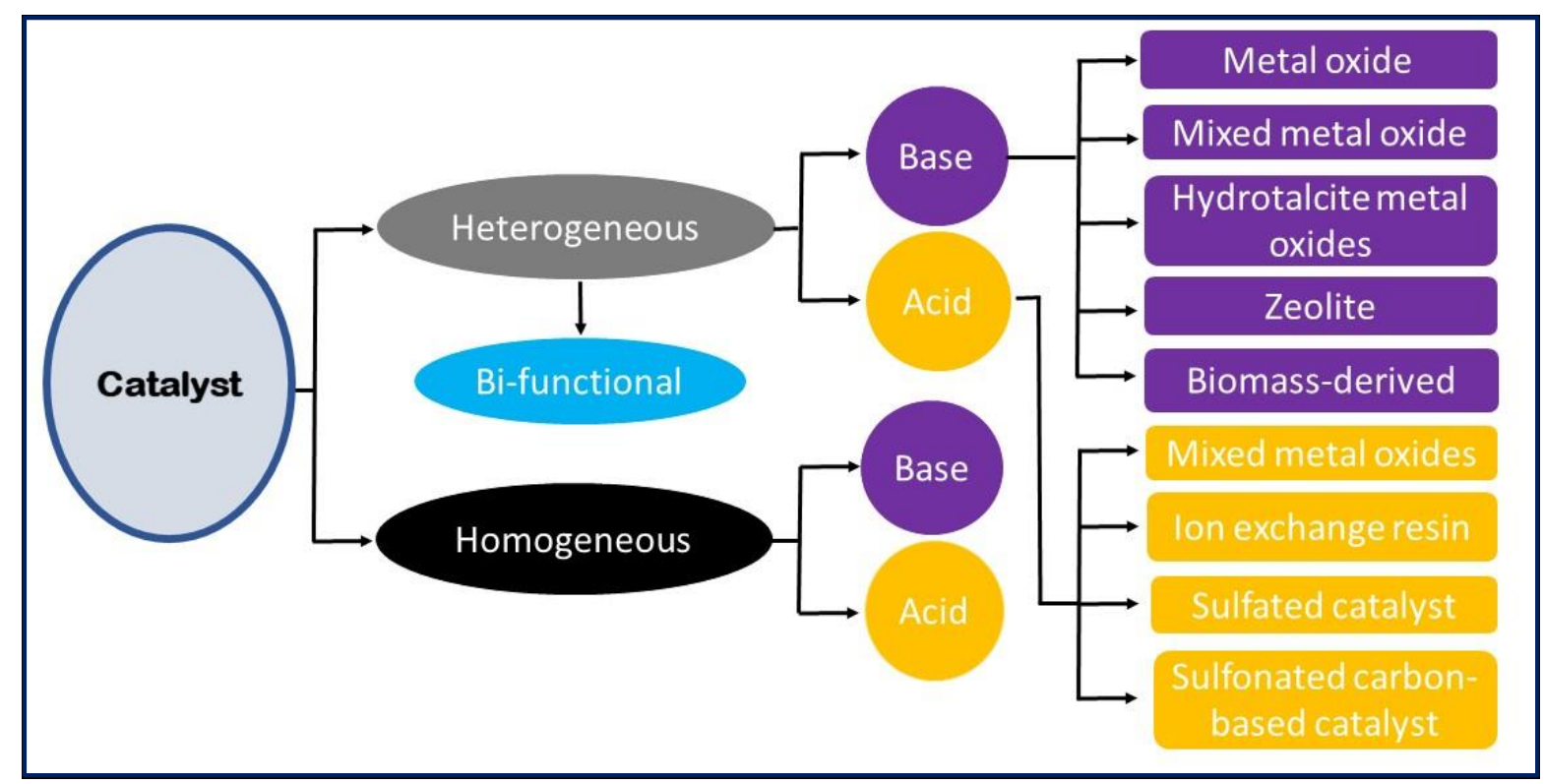

Figure. 2: Catalyst classification for biodiesel synthesis

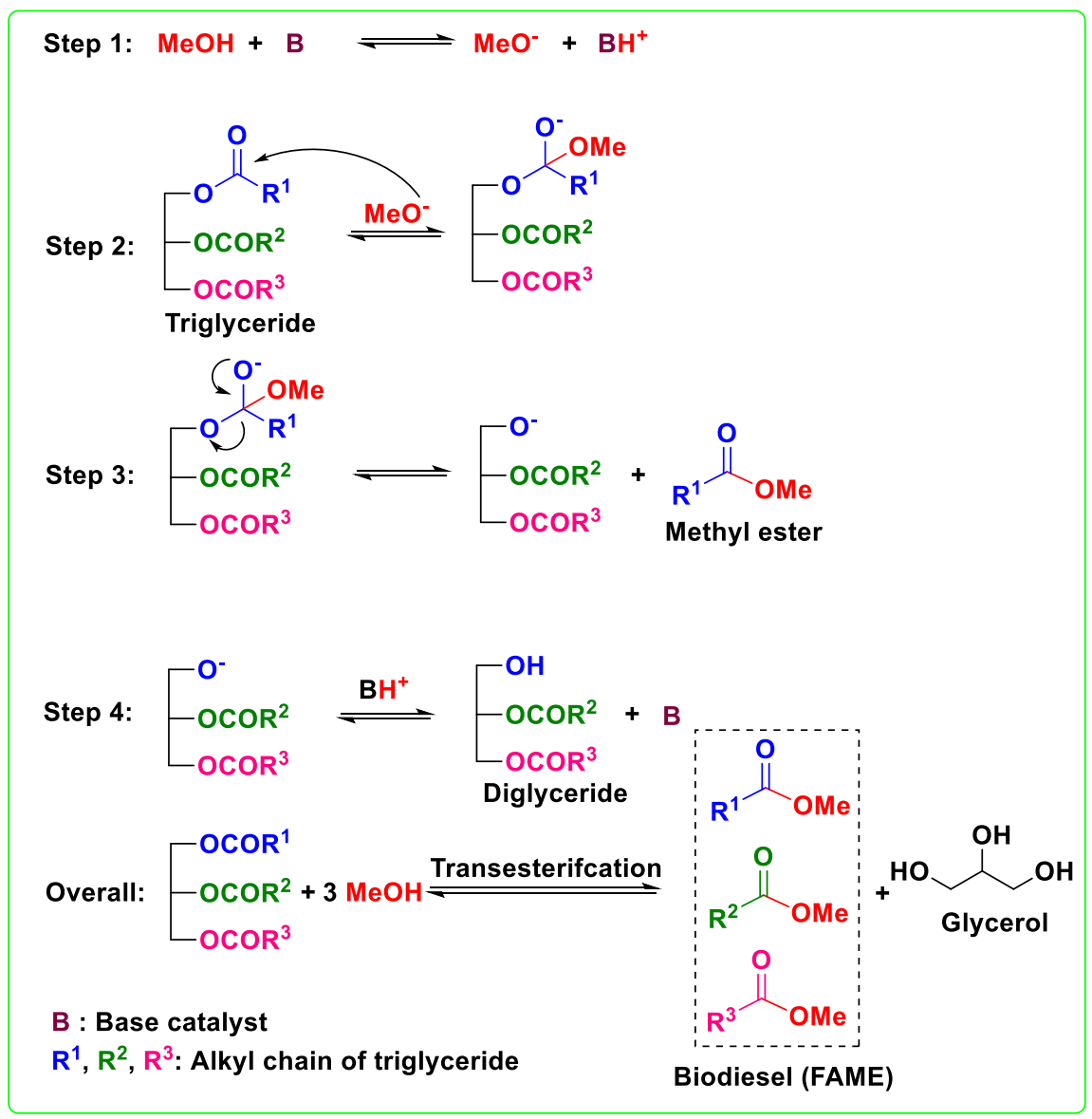

Scheme 1: Base-catalyzed reaction mechanism for transesterification of TGs of vegetable oil to biodiesel. 


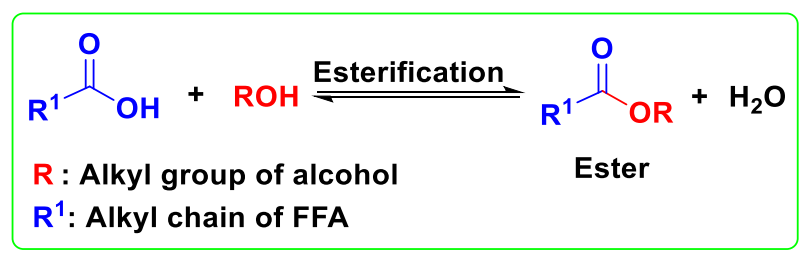

Scheme 2: Acid-catalyzed esterification of FFA content of vegetable oil to biodiesel

\section{Biodiesel}

American Society for Testing and Materials (ASTM) described biodiesel as a monoalkyl ester produced from edible/non-edible oils or animal fats. ${ }^{16}$ Vegetable oils or animal fats comprise of mainly triacylglycerol (TAG) which is an ester of fatty acids (FA) and glycerol. The physicochemical properties of vegetable oils and animal fats are greatly influenced by the compositions of the TAG which further often dictates the quality of biodiesel produced from these resources. FA are classified broadly into two groups: i) saturated FA which has carboncarbon single bond, and ii) unsaturated FA which comprises of at least one carbon-carbon double bond. The FA most widely found in vegetable oils are oleic acid (18:1), palmitic acid (16:0), linoleic acid (18:2), and linolenic acid (18:3), stearic acid (18:0), palmitoleic acid (16:1), myristic acid (14:0), arachidic acid (20:0). Besides these FA, a trace amount of phospholipids, tocopherols, carotenes, sulphur compounds, and water are also found in vegetable oils. ${ }^{17,18}$

\section{Feedstocks for biodiesel production}

The feedstocks for production of biodiesel are mainly edible ${ }^{18-20}$ and non-edible vegetable oils, ${ }^{21-23}$ waste cooking oils ${ }^{24,25}$ and animal fats including tallow, ${ }^{25}$ yellow grease, ${ }^{26}$ lard, ${ }^{27}$ chicken fat ${ }^{28-30}$ and by-products from the production of Omega-3 fatty acids from fish oil. $^{31,32}$ Algae are another promising feedstocks for biodiesel which have a high potential to replace edible oil due to their availability in a pond, sewage water or in shallow ocean water without dislodging land used for food production. ${ }^{32-34}$ In worldwide, $31 \%$ biodiesel is produced from palm oil, $27 \%$ from soybean oil and $20 \%$ from rapeseed oil. ${ }^{35}$ Different countries used various feedstock based on their local availability. The major feedstocks used in various countries are listed in Table 1. The feedstocks cost alone contributed $75 \%$ of biodiesel cost. ${ }^{36}$ Thus, proper selection of feedstocks for biodiesel is necessary to reduce the overall cost of biodiesel production. Ironically, utilization of edible oils (sunflower, rape, soy, etc.) as feedstocks for biodiesel, called the first-generation biofuels, resulted in food versus fuel 
177 problem and also disturbed the agricultural farmland allocation. ${ }^{27,37}$ In Malaysia, the edible 178 palm oil price has increased by $70 \%$ due to its uses as feedstock in biodiesel industry. ${ }^{38}$ In this regard, to mitigate the problem associated with food versus fuel nexus and high cost of firstgeneration biodiesel, currently, non-edible oil are largely targeted as a biodiesel feedstock. Another problem associated with first-generation biofuels is their remarkably higher cost than fossil fuels. Hence, to bring the cost of biodiesel, utilization of non-edible oil as biodiesel feedstocks is highly relevant. Non-edible oil of more than 300 species are available in South Asia. India has abundant amount (approximately 1 million tons per year) of such non-edible oils. Pongamia Pinnata (Karanja) and Jatropha curcas oils (JCO) were identified as the most promising feedstocks by the Government of India. However, in India's biodiesel program, Jatropha has got prominence over Karanja due to its less gestation period. If properly managed, non-edible crops planted in different parts of the world has the potential to reduce our dependence on fossil fuel for energy sources and edible oil as biodiesel feedstocks.

Biodiesel has been widely used biofuels in the European Union (EU) and $49 \%$ of biodiesel were produced from rapeseed oil in 2015 in EU. ${ }^{39}$ With the increasing uses of waste cooking oil (WCO), recycled vegetable oils and palm oils, the share of rapeseed oil in biodiesel production decreased from $72 \%$ in 2008. To reduce our dependency on edible oil and reduce the price of biodiesel, EU has raised the share of WCO to $2^{\text {nd }}$ position after rapeseed oil in 2015. ${ }^{40}$ The top five biodiesel producer in EU are Germany, France, Spain, Netherlands, and Poland. Germany is the largest biodiesel producer in EU and its production capacity increased from 3.2 billion litres in 2010 to 3.8 billion litres in $2014 .{ }^{41}$

Table 1: Countrywise feedstocks used for biodiesel production.

\begin{tabular}{ll}
\hline Country & Feedstock \\
\hline India & Jatropha/ Pongamia Pinnata (Karanja)/ \\
& Soybean/ Rapeseed/ Sunflower \\
Argentina & Soybeans \\
Brazil & Soybeans/ Palm oil/ Castor/ Cotton oil \\
France & Rapeseed/ Sunflower \\
Peru & Palm/ Jatropha \\
Germany & Rapeseed \\
Spain & Linseed oil/ Sunflower \\
Italy & Rapeseed/ Sunflower
\end{tabular}




$\begin{array}{ll}\text { Turkey } & \text { Sunflower/ Rapeseed } \\ \text { Greece } & \text { Cottonseed } \\ \text { Sweden } & \text { Rapeseed } \\ \text { Norway } & \text { Animal fats } \\ \text { China } & \text { Jatropha/ Waste cooking oil/ Rapeseed } \\ & \text { oil } \\ \text { Indonesia } & \text { Palm oil/ Jatropha/ Coconut } \\ \text { Japan } & \text { Waste cooking oil } \\ \text { Malaysia } & \text { Palm oil } \\ \text { Philippines } & \text { Coconut/ Jatropha oil } \\ \text { Bangladesh } & \text { Rubber seed/ Pongamia Pinnata oil } \\ \text { Pakistan } & \text { Jatropha oil } \\ \text { Thailand } & \text { Palm/ Jatropha/ Coconut oil } \\ \text { Iran } & \text { Palm/ Jatropha/ Castor/ Algae oil } \\ \text { Singapore } & \text { Palm oil } \\ \text { Ghana } & \text { Palm oil } \\ \text { Zimbabwe } & \text { Jatropha oil } \\ \text { Kenya } & \text { Castor oil } \\ \text { Mali } & \text { Jatropha oil } \\ \text { UK } & \text { Rapeseed/waste cooking oil } \\ \text { Ireland } & \text { Frying oil/ Animal fat } \\ \text { Canada } & \text { Rapeseed/ Animal fat/ Soybean oil } \\ \text { Mexico } & \text { Animal fat/ Waste Oil } \\ \text { USA } & \text { Soybeans/ Waste oil/ Peanut } \\ \text { Australia } & \text { Jaba }\end{array}$

Wide types of feedstocks such as edible plant oils, non-edible oils, waste cooking oils, animal fats, and algal oil have been considered for the synthesis of biodiesel, and are discussed below: 
Soybean oil, ${ }^{42}$ sunflower oil, ${ }^{43}$ rapeseed oil,${ }^{44}$ and palm oil ${ }^{45}$ are widely utilized as a biodiesel feedstock in numerous nations, for example, Argentina, Brazil, Indonesia, Europe, US, Malaysia etc. At present, an estimated $95 \%$ of the worlds' total biodiesel is produced from sunflower oil, rapeseed oil, and palm oil. ${ }^{46}$ Various types of edible oils exploited as feedstocks for the production of biodiesel are recorded in Table 2.

Table 2. Different forms of edible oils utilized to produce biodiesel.

\begin{tabular}{llll}
\hline No. & $\begin{array}{l}\text { Edible oil for } \\
\text { biodiesel production }\end{array}$ & Plant source & $\begin{array}{l}\text { The botanical name of the } \\
\text { plant source }\end{array}$ \\
\hline 1 & Sunflower oil & Sunflower & $\begin{array}{l}\text { Helianthus annuus } \\
\text { Brassica napus }\end{array}$ \\
3 & Rapeseed oil & Rape & Glycine max \\
4 & Soybean oil & Soybean & Elaeis guineensis \\
5 & Palm oil & Mesocarp of oil palm & Cocos nucifera \\
\hline
\end{tabular}

\section{2 Non-edible plant oils}

Recently, non-edible plant oils have been increasingly considered as another promising potential feedstock for biodiesel attributable to their high oil content and low cost. In addition, unlike edible oils, it does not pose 'food versus fuel' problem as they can be grown in barren and arid regions which are not suitable for agriculture. Further, non-edible oil plants can grow under harsh conditions and hardly need any attention; thus, reducing the cost involved in cultivation and potentially reduced the cost of biodiesel. ${ }^{47,48}$ Some of the commonly investigated non-edible plant oils for biodiesel production include Jatropha curcas, Pongamia glabra (Karanja), Madhuca indica (Mahua), Azadirachta indica (neem), Moringa oleifera (moringa seed), Calophyllum inophyllum, Salvadora oleoides (Pilu), Nicotiana tabacum (tobacco), cottonseed oil, Eruca Sativa Gars, terebinth, rubber seed oil, desert date, Acrocomia aculeate (macaúba), Crambe abyssinica (hochst), linseed oil, rubber seed oil, Sapium sebiferum (chinese tallow), Sapindus mukorossi (soapnut), Euphorbia tirucalli (milk bush), Calophyllum inophyllum (polangafish oil, Jojoba, leather pre-fleshings, apricot seed, Pistacia chinensis Bunge Seed, sal oil, Moringa oleifera and croton megalo-carpus. Amongst all these oil plants, Jatropha curcas, Pongamia glabra (karanja), Madhuca indica (Mahua), Azadirachta indica (neem) are commercially available and most largely used in biodiesel production. ${ }^{49}$ 


\section{3 Waste cooking oil}

Biodiesel production from WCO can partially substitute fossil fuels as well as can solve the energy crisis and environmental pollution. Moreover, WCO is cheaper than fresh vegetable oils, consequently, lessen the expense incurred for biodiesel synthesis. WCO can be grouped into two classifications based on their FFA content if the FFA content is $>15 \%$, then it is called brown grease, otherwise, it is named 'yellow grease'. Annually billion tons of WCO is generated throughout the world. In EU, it is estimated that around 0.7-1 MT WCO were collected per year. Among 80,000 tons of WCO, around 65,000 tons were collected from UK only, basically originating from commercial restaurants and food processing industries. Therefore, disposal of WCO is a major concern which otherwise contaminates water and environment at large. Although some portions of WCO oil were used in the production of soap, major parts of WCO were usually dumped into the river and landfills. In the light of this, the production of biodiesel from WCO not only reduced the cost of biodiesel but also resolved the disposal problem of $\mathrm{WCO}$ and minimized environmental pollution.

\section{4 Animal fats}

Animal fats are another feedstock for biodiesel production that have the potential to reduce the cost of biodiesel. This type of feedstock includes lard, tallow and chicken fat. However, due to the presence of a high quantity of saturated fatty acids, it has some shortcomings both in chemical and physical properties such as poor cloud point, poor pour point and so forth. At the same time, its high saturation level has various advantages such as high cetane number, high oxidation stability etc. Moreover, animal fats are more favourable biodiesel feedstocks as compared to vegetable oils due to their low price.

\section{5 Algal oil}

Currently, microalgae are viewed as one of the most promising feedstocks for the industrial-scale synthesis of biodiesel. Biodiesel production from algal oil is highly sustainable as several strains of microalgae can double in size within hours; thereby have the capacity to create a large number of litres of biodiesel per hectare every year. ${ }^{50}$ Additionally, as several microalgal strains can be grown on non-arable land in a saline water medium, their mass cultivating doesn't compete with food production. 


\section{Characterization of catalysts and biodiesel}

Several analytical techniques are employed to characterize both catalysts and FAME produced. Each analytical techniques will be discussed in the upcoming sections as and when relevant. As a preliminary study, Fourier transform infrared spectroscopy (FT-IR) is usually employed to detect the presence of various functional groups in the catalyst, while X-ray diffraction (XRD) can be employed to investigate the crystallinity and qualitative detection of elements present in the catalyst. The surface morphology, particle size and the structure of the catalysts can be investigated using Scanning electron microscopy (SEM) and Transmission electron microscopy (TEM). The chemical compositions are investigated using Energydispersive X-ray spectroscopy (EDX). X-ray fluorescence (XRF) is commonly used for quantitative detection of metal oxides and X-ray photoelectron spectroscopy (XPS) analyses are routinely performed for the quantitative measurement of the elements present in the catalyst and also provide the chemical state information of the catalyst. Surface area, pore volume and pore diameter are usually measured by Brunauer-Emmett-Teller (BET) analysis, whereas the thermal stability of the catalysts is analyzed using thermogravimetric analysis (TGA). The acidity, as well as basicity of the catalysts, are usually investigated using $\mathrm{NH}_{3}$ and $\mathrm{CO}_{2}$ temperature-programmed desorption (TPD) analyses. In addition, basicity and acidity of the catalyst can be visualized by Hammett indicators tests and acid-base titration methods. Valuable information about the degree of carbonization and/or aromatization of carbonaceous material used as a catalyst can be obtained using solid-state magic-angle spin-nuclear magnetic resonance (MAS NMR). Likewise, the successful conversion of biodiesel feedstocks to FAME is confirmed using different analytical techniques. Usually, NMR analysis is used as a confirmation tool to identify the formation of FAME. Despite not common, FT-IR analysis can also be used to identify the FAME formation. The chemical components of FAME along with their respective percentage are usually identified using gas chromatography-mass spectroscopy (GC-MS) technique. In addition, ${ }^{1} \mathrm{H}$ NMR spectra can be used to give concrete information about the purity of FAME and percentage conversion of vegetable oil to FAME using Knothe and Kenar equation (1).

$$
\% \text { Conversion }=100 \times \frac{2 A_{M e}}{3 A_{C_{2}}}
$$

Here, $A_{M e}$ and $A_{\mathrm{CH}_{2}}$ are the integration values of methoxy protons and methylene protons of FAME respectively. 


\section{Homogeneous catalyst:}

The homogeneous catalysts utilized for the transesterification reaction are classified into two groups such as i) base catalysts, for example, $\mathrm{NaOH}$ and $\mathrm{KOH}$ and ii) acid catalysts such as sulphuric, sulphonic, hydrofluoric, and hydrochloric acids.

\section{1 Base catalyst:}

Homogeneous base catalysts are most widely investigated in the transesterification of vegetable oil to FAME as they are cheap and easily accessible. Till date, several homogenous base catalysts have been utilized for the synthesis of FAME e.g., $\mathrm{KOH}, \mathrm{NaOH}, \mathrm{NaOCH}_{3}$ etc. as shown in Table 3. The uses of $\mathrm{NaOH}$ and $\mathrm{KOH}$ as catalyst showed excellent catalytic activities towards biodiesel production such as minimum reaction time, high biodiesel yield and occurred at ambient temperature and pressure. However, this process has some certain limitations like water is formed as a byproduct, which reduces biodiesel yield. Other than $\mathrm{KOH}$ and $\mathrm{NaOH}$, sodium methoxide and potassium methoxide gives better biodiesel performance as water is not formed in these processes. An alkaline catalyst is not suitable for transesterification of vegetable oils with high FFA content (>2 wt. \%). However, it is fit for refined vegetable oils with low FFA content (ranging from less than 0.5 wt. \% to less than 2 wt. \%).

Dmytryshyn et al. ${ }^{51}$ examined the transesterification of various vegetable oil such as canola oil, green seed canola oil from heat-harmed seeds, handled waste fryer oil and natural waste fryer oil with methanol to afford FAME using $\mathrm{KOH}$ catalyst, and reported a biodiesel yield of 51-87\% under the optimum reaction conditions. In another study, $\mathrm{KOH}$ was exploited to convert crude rubber oil and palm oil mixture to biodiesel in $98 \%$ yield under the optimum reaction conditions. The vegetable oil was esterified using acid catalyst prior to a basecatalyzed transesterification process, to get low FFA content vegetable oil. ${ }^{52}$ Similarly, KOH was utilized as a catalyst for the transformation of soybean oil to FAME in $96 \%$ yield. ${ }^{53}$ Roselle oil ${ }^{34}$ rapeseed oil, ${ }^{54}$ frying oil, ${ }^{55,56}$ used olive oil, ${ }^{57}$ palm kernel ${ }^{58}$ and duck tallow ${ }^{59}$ were also successfully transesterified to FAME using KOH catalyst. Karmee et al. ${ }^{60}$ reported the transesterification of Pongamia pinnata to FAME in $92 \%$ conversion using base catalyst $\mathrm{KOH}$. Interestingly, the utilization of tetrahydrofuran (THF) as a co-solvent increased the conversion to $95 \%$.

Meng et $a l .{ }^{23}$ detailed an exceptionally high activity of $\mathrm{NaOH}$ towards biodiesel production from WCO with high FFA in $89.8 \%$ conversion under the optimized reaction settings. The high FFA substance of WCO was reduced by a pre-esterification process with sulphuric acid. Similarly, waste cooking/frying oil, ${ }^{61,62}$ canola oil, ${ }^{63}$ sunflower oil,,${ }^{64}$ palm oil ${ }^{65}$ 
and cotton seed oil ${ }^{66}$ were converted to biodiesel using $\mathrm{NaOH}$ as a homogeneous catalyst. Furthermore, $\mathrm{NaOCH}_{3}{ }^{67,68}$ was evaluated as a catalyst for transesterification of rice bran oil to FAME by Rashid et al. ${ }^{67}$ where $83.3 \%$ biodiesel yield was observed in 60 min under the optimum reaction conditions.

Table 3: Distinctive homogeneous base catalysts utilized for biodiesel production.

\begin{tabular}{|c|c|c|c|c|c|}
\hline No. & Catalyst & Feedstock & ${ }^{a}$ Conditions & Yield $(\%)$ & Ref. \\
\hline 1. & $\mathrm{KOH}$ & Vegetable oil & $6: 1,1,25,40$ & $51-87$ & 51 \\
\hline 2. & $\mathrm{KOH}$ & Crude rubber/palm oil & $8: 1,2,55,300$ & 98 & 52 \\
\hline 3. & $\mathrm{KOH}$ & Soybean oil & $6: 1,1,60,60$ & 96 & 53 \\
\hline 4. & $\mathrm{KOH}$ & Roselle oil & $8: 1,1.5,60,60$ & 99.4 & 36 \\
\hline 5. & $\mathrm{KOH}$ & Rapeseed & $6: 1,1,65,120$ & $95-96$ & 54 \\
\hline 6. & $\mathrm{KOH}$ & Frying oil & $12: 1,1,60,120$ & 72.5 & 55 \\
\hline 7. & $\mathrm{KOH}$ & Waste Frying oil & $6: 1,1,65,60$ & 96.15 & 56 \\
\hline 8. & $\mathrm{KOH}$ & Used olive oil & $12: 1,1.26,25,90$ & 94 & 57 \\
\hline 9. & $\mathrm{KOH}$ & Palm kernel & $6: 1,1,60,60$ & 96 & 58 \\
\hline 10. & $\mathrm{KOH}$ & Duck tallow & $6: 1,1,65,180$ & 83.6 & 59 \\
\hline 11 & $\mathrm{KOH}$ & Pongamia pinnata & $10: 1,1,60,90$ & $92^{b}$ & 60 \\
\hline 12. & $\mathrm{NaOH}$ & Waste cooking oil & $6: 1,1,50,90$ & $89.8^{b}$ & 23 \\
\hline 13. & $\mathrm{NaOH}$ & Waste frying oil & $4.8: 1,0.6,65,60$ & 98 & 61 \\
\hline 14. & $\mathrm{NaOH}$ & Waste frying oil & $7.5: 1,0.5,50,30$ & 96 & 62 \\
\hline 15. & $\mathrm{NaOH}$ & Canola oil & $6: 1,1,45,15$ & 98 & 63 \\
\hline 16. & $\mathrm{NaOH}$ & Sunflower & $6: 1,1,60,120$ & 97.1 & 64 \\
\hline 17. & $\mathrm{NaOH}$ & Refined palm oil & $6: 1,1,60,30$ & 95 & 65 \\
\hline 18. & $\mathrm{NaOH}$ & Cotton seed oil & $6: 1,1,60,60$ & 97 & 66 \\
\hline 19. & $\mathrm{NaOCH}_{3}$ & Soybean oil & $6: 1,0.6,60,60$ & -97 & 53 \\
\hline 20. & $\mathrm{NaOCH}_{3}$ & Rice bran & $7.5: 1,0.88,55,60$ & 83.3 & 67 \\
\hline 21 & $\mathrm{NaOCH}_{3}$ & Waste cooking oil & $6: 1,0.75,65,90$ & 96.6 & 68 \\
\hline
\end{tabular}

\section{2 Acid catalyst:}


Base catalysts are usually preferred over acid catalysts as they are more reactive and low cost. However, base catalysts may react with FFA present in the feedstock during transesterification, bringing about soap formation by saponification, which may consume the catalyst and diminish its reactivity. Meanwhile, acidic catalyst is neutral to the FFA and henceforth shows better outcomes for transesterification or esterification of vegetable oils or fats having a high amount of FFA ( $\geq 2$ wt. \%). Generally, acid catalysts are utilized to bring down the FFA content in WCO and animal fats by means of esterification prior to transesterification using base catalyst ${ }^{5}$. Several acids such as $\mathrm{H}_{2} \mathrm{SO}_{4}, \mathrm{HCl}, \mathrm{H}_{3} \mathrm{PO}_{4}$ and sulfonated acids were mostly utilized for the (trans)esterification of vegetable oils ${ }^{36}$ However, acid-catalyzed biodiesel production has some major limitations such as slow reaction rate (4000 times slower than the rate of base-catalyzed transesterification) and require high alcohol to oil molar ratio. ${ }^{69-71}$ Moreover, it has environmental and corrosive related problems. ${ }^{69}$ Because of these demerits, acid-catalyzed biodiesel synthesis is not very popular and is less examined. Some reported literature of acid-catalyzed biodiesel production and their results are listed in Table 4.

Wang et al. ${ }^{70}$ examined the biodiesel synthesis from WCO and reported a $90 \%$ yield.. Moreover, Miao et al. ${ }^{72}$ examined the conversion of soybean oil to biodiesel using trifluoroacetic acid catalyst and reported $98.4 \%$ biodiesel yield at optimal reaction conditions . Similarly, various edible/non-edible oils such as WCO, ${ }^{73}$ soybean oil, ${ }^{71}$ zanthoxylum bungeanum ${ }^{74}$ and tobacco seed oil ${ }^{75}$ were used for biodiesel production using sulfuric acid. Moreover, trifluoroacetic acid was utilized as a homogeneous acid catalyst for the esterification/transesterification of soybean oil to biodiesel. ${ }^{72}$ The catalyst brought about a high biodiesel yield of $98.4 \%$ under the optimum reaction conditions. From the above discussion, it was observed that an acid-catalyzed esterification/transesterification reactions usually require drastic reaction conditions such as high $\mathrm{M} / \mathrm{O}$ molar ratio, catalyst loading, temperature and long reaction time as compared to base-catalyzed transesterification reactions.

Table 4: Different acidic homogeneous catalysts utilized for biodiesel synthesis.

\begin{tabular}{llllll}
\hline No. & Catalyst & Feedstock & ${ }^{a}$ Conditions & Yield (\%) & Ref. \\
\hline 1. & $\mathrm{H}_{2} \mathrm{SO}_{4}$ & Chicken/mutton & $30: 1,1.25 / 2.5$, & $99.01 \pm 0.71 /$ & 25 \\
& & tallow & $50 / 60,1440$ & $93.21 \pm 5.07$ & \\
2. & $\mathrm{H}_{2} \mathrm{SO}_{4}$ & WCO & $20: 1,4,95,600$ & 90 & 70 \\
3. & $\mathrm{H}_{2} \mathrm{SO}_{4}$ & Used frying oil & $3.6: 1,0.1,65,40$ & 79.3 & 73
\end{tabular}




$\begin{array}{llllll}\text { 4. } & \mathrm{H}_{2} \mathrm{SO}_{4} & \text { Soybean oil } & 6: 1,3,60,2880 & 98 & 71 \\ \text { 5. } & \mathrm{H}_{2} \mathrm{SO}_{4} & \begin{array}{l}\text { Zanthoxylum } \\ \text { bungeanum }\end{array} & 24: 1,2,60,80 & 98 & 74 \\ & & & & \\ \text { 6. } & \mathrm{H}_{2} \mathrm{SO}_{4} & \text { Tobacco seed oil } & 18: 1,1,60,25 & 91 & 75 \\ \text { 7. } & \mathrm{C}_{2} \mathrm{HF}_{3} \mathrm{O}_{2} & \text { Soybean oil } & 20: 1,2 \mathrm{M}, 120,98.4 & 72 \\ & & & 300 & & \end{array}$

${ }^{a}$ Methanol-to-oil molar ratio, catalyst loading (wt. \%), temperature $\left({ }^{\circ} \mathrm{C}\right)$, reaction time $(\mathrm{min})$.

\section{Heterogeneous catalysts}

Although homogeneous catalyst has its own advantages such as high reactivity and low cost, its utilization in the production of biodiesel is accompanied by several shortfalls such as low quality of glycerol produced, the catalyst cannot be regenerated and the lengthy process involves in the purification of biodiesel; thereby makes the whole process labour-intensive and uneconomical. Hence, in recent years, the heterogeneous catalyst has attracted immense attention for biodiesel production as it can be tailored to match specific requirement, easily recovered and reused for several cycles of catalytic reaction, thereby potentially bring down the labour involved and cost of biodiesel.

Unlike homogeneous catalysts, heterogeneous catalysts mostly appear in a solid form, thus the reaction mixture and the catalyst are in a different phase. In heterogeneous catalyzed reactions, the catalyst surface is the main site for reaction to occurs. ${ }^{76}$ The following advantages of utilizing a solid catalyst in transesterification make the process green: i) Catalyst can be reused, ii) very minimal amount of wastewater generated during the process, iii) glycerol separation from the final mixture (glycerol, biodiesel and catalyst) is much easier, iv) high purity glycerol is obtained.

Heterogeneous catalysts have several advantages over a homogeneous catalyst such as simple separation, recyclability and reusability. Moreover, solid catalysts are eco-friendly, less toxic, minimum corrosion and reduced energy intake. Thus, solid catalysts provide an efficient and economical pathway for biodiesel production. ${ }^{12,77,78}$ Heterogeneous or solid catalysts can be grouped into two categories: i) basic and ii) acidic heterogeneous catalysts. Nowadays, researchers have developed several heterogeneous catalysts, which can promote esterification and transesterification reactions simultaneously in one reaction vessel (one-pot). These type of catalysts are mostly utilized for biodiesel synthesis from the vegetable oils or animal fats having a high amount of FFA without the requirement of additional pretreatment step to reduce the FFA content. ${ }^{12}$ 


\subsection{Base catalysts:}

In recent years, basic heterogeneous catalysts have been most widely investigated as it can overcome the constraints associated with homogeneous basic catalysts and shows excellent catalytic activity under mild reaction conditions. However, these catalysts are suitable only for biodiesel feedstock with low FFA content, otherwise, catalysts will react with the FFA to produce soap by means of saponification reaction, which make separation of biodiesel from glycerol tedious, thereby diminished biodiesel yield. Several solid base catalysts reported in the literature such as alkaline metal oxide, transition metal oxides, mixed metal oxides, hydrotalcites, zeolites, biomass-based catalyst are discussed comprehensively in this section.

\subsubsection{Alkaline earth metal oxides:}

Oxides of alkaline earth metal are one of the most widely studied catalysts for biodiesel synthesis due to their insolubility in methanol and low toxicities. The basicity of alkaline earth metal oxides follows the order: $\mathrm{MgO}<\mathrm{CaO}<\mathrm{SrO}<\mathrm{BaO} . \mathrm{MgO}$ is almost inactive towards the transesterification reaction. ${ }^{79,80}$ Among all alkaline earth metal oxides, $\mathrm{CaO}$ is most widely utilized in FAME production as it is highly basic, insoluble in alcohol, non-toxic, cheap and easily available. ${ }^{81}$ However, it is very sensitive to FFA content and forms undesirable byproducts via saponification and also lost its activity in the process. ${ }^{82}$ Despite its high activity, $\mathrm{SrO}$ is less studied in transesterification reactions as it is very sensitive to the atmospheric moisture and reacts with $\mathrm{CO}_{2}$ and water to form $\mathrm{SrCO}_{3}$ and $\mathrm{Sr}(\mathrm{OH})_{2}$. Table 5 shows the activity of various alkaline metal oxide towards biodiesel production.

Kouzu et al. ${ }^{82}$ examined the transesterification of soybean oil using $\mathrm{CaO}$ catalyst and reported a high biodiesel yield of $95 \%$ under the optimized reaction conditions. Granados et al. ${ }^{83}$ found that $\mathrm{CaO}$ calcined at $700{ }^{\circ} \mathrm{C}$ showed very high activity towards biodiesel production from sunflower oil and attained $94 \%$ biodiesel yield. Furthermore, the transesterification of rapeseed oil was reported by Kawashima et al. ${ }^{84}$ where $\mathrm{CaO}$ was pretreated with methanol to form $\mathrm{Ca}\left(\mathrm{OCH}_{3}\right)$, which acted as an initiator for the transesterification reaction. A high biodiesel yield of $90 \%$ was observed using the optimized reaction conditions. In another work, SrO catalyzed transesterification of soybean oil has been reported by Liu et al. ${ }^{85}$ The catalyst showed excellent activity with a high yield of $95 \%$ at $70{ }^{\circ} \mathrm{C}$ and $30 \mathrm{~min}$ time. The catalyst is highly stable and can be reused for 10 successive cycles.

Ultrasonic-assisted biodiesel synthesis from palm oil was reported using diverse metal oxides such as $\mathrm{CaO}, \mathrm{BaO}$ and $\mathrm{SrO} .{ }^{86}$ The activity of the catalyst in ultrasonic-assisted biodiesel synthesis was compared with the traditional magnetic stirring process and found that ultrasonic 
process showed $95.2 \%$ of yield using $\mathrm{BaO}$ within 60 min reaction time, which otherwise take 3-4 $\mathrm{h}$ in conventional stirring process. Similarly, ultrasonic-assisted transesterification using $\mathrm{CaO}$ and $\mathrm{SrO}$ resulted in an increase in biodiesel yield from $5.5 \%$ to $77.3 \%$ and $48.2 \%$ to $95.2 \%$ respectively. These findings show the advantages of using ultrasonication in the field of chemical synthesis particularly in the field of biodiesel synthesis. The authors also investigated the influence of ultrasonic amplitude on the biodiesel synthesis from palm oil and observed that $50 \%$ ultrasonic amplitude displayed the best result in terms of biodiesel yield. Catalyst reusability test revealed that the catalytic activity of $\mathrm{BaO}$ decreased drastically, especially in the ultrasonic process during the reusability test, which was mainly due to catalyst leaching. The reaction set-up is depicted in Figure 3.

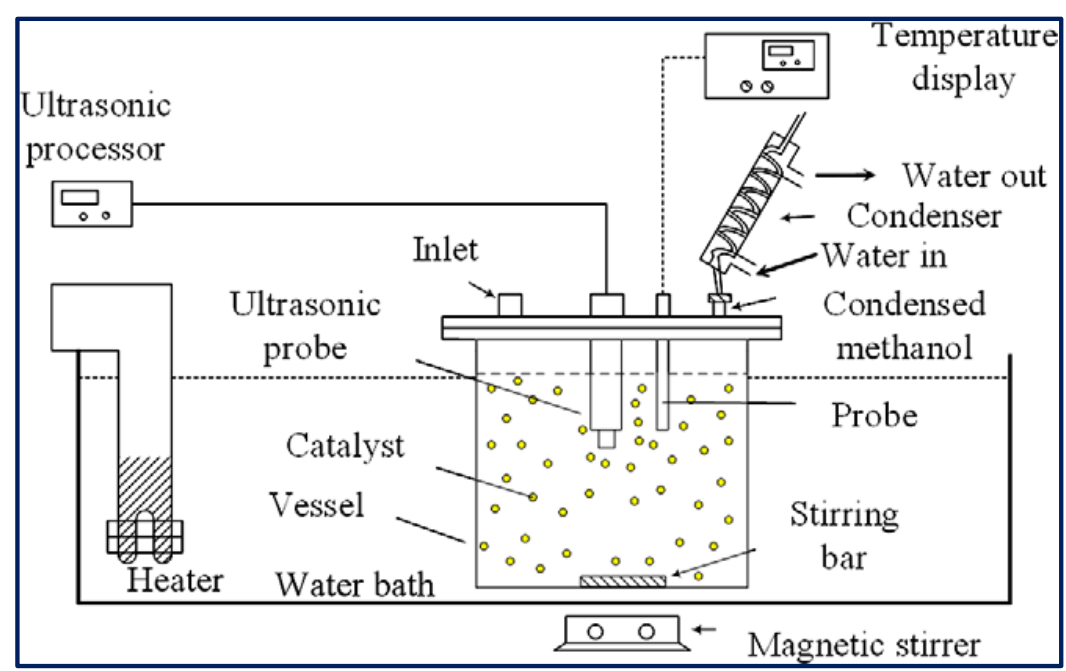

Figure 3: Schematic portrayal of experimental set up for ultrasonic-assisted transesterification reaction. Reproduced from ref. [86].

445 Table 5: Different alkaline earth metal oxide catalyzed biodiesel production under various 446 reaction conditions.

\begin{tabular}{llllll}
\hline No. & Catalyst & Feedstock & ${ }^{a}$ Conditions & Yield (\%) & Ref. \\
\hline 1 & $\mathrm{CaO}$ & Soybean oil & $12: 1,8,65,180$ & 95 & 82 \\
2 & $\mathrm{CaO}$ & Sunflower oil & $13: 1,3,60,120$ & 94 & 83 \\
3 & $\mathrm{CaO}$ & Rapeseed oil & $3.8: 1,0.7,60,160$ & 90 & 84 \\
4 & $\mathrm{SrO}$ & Soybean oil & $6: 1,3,70,30$ & 95 & 85 \\
5 & $\mathrm{BaO}$ & Palm oil & $9: 1,3,65,60$ & 95.2 & 86 \\
\hline
\end{tabular}




\subsubsection{Transition metal oxides:}

Despite the high reactivity of alkaline earth metal oxides, they have some serious drawbacks such as low reusability and high sensitivity towards moisture that reduced their catalytic efficacy. To overcome these inherent drawbacks, metal oxides of $\mathrm{Zn}, \mathrm{Ti}, \mathrm{Zr}$ and $\mathrm{Zn}$ are widely investigated in transesterification reactions as they are easily available, highly stable and showed excellent catalytic activities. ${ }^{87-89}$ To date, numerous transition metal oxide-based catalysts have been reported in the field of biodiesel synthesis from vegetable oil as depicted in Table 6. da Silva et al. ${ }^{90}$ reported $\mathrm{Cu}$ (II) and $\mathrm{Co}(\mathrm{II})$ impregnated on chitosan catalyst for FAME synthesis from soybean oil. The adsorption process for $\mathrm{Cu}(\mathrm{II})$ on chitosan is better than Co(II). However, Co(II)@chitosan showed higher biodiesel yield (94.01\%) as compared to $\mathrm{Cu}(\mathrm{II}) @$ chitosan $(88.82 \%)$ using the optimal reaction conditions. In another work, Jitputti et al. ${ }^{87}$ investigated $\mathrm{ZrO}_{2}, \mathrm{ZnO}, \mathrm{SO}_{4}{ }^{2-} / \mathrm{SnO}_{2}, \mathrm{SO}_{4}{ }^{2-} / \mathrm{ZrO}_{2}, \mathrm{KNO}_{3} / \mathrm{KL}$ zeolite and $\mathrm{KNO}_{3} / \mathrm{ZrO}_{2}$ for the FAME synthesis from the crude palm kernel oil and crude coconut oil, and found that $\mathrm{SO}_{4}{ }^{2-} / \mathrm{ZrO}_{2}$ catalyst displays the highest reactivity for both the oils with biodiesel yield of 90.30 $\%$ and $86.30 \%$ respectively. The decreasing order of the catalyst activity towards biodiesel synthesis from crude kernel oil is $\mathrm{SO}_{4}{ }^{2-} / \mathrm{ZrO}_{2}>\mathrm{SO}_{4}{ }^{2-} / \mathrm{SnO}_{2}>\mathrm{ZnO}>\mathrm{KNO}_{3} / \mathrm{ZrO}_{2}>\mathrm{KNO}_{3} / \mathrm{KL}$ zeolite $>\mathrm{ZrO}_{2}$ and for the crude coconut oil is $\mathrm{SO}_{4}{ }^{2-} / \mathrm{ZrO}_{2}>\mathrm{SO}_{4}{ }^{2-} / \mathrm{SnO}_{2}>\mathrm{ZnO}>\mathrm{KNO}_{3} / \mathrm{KL}$ zeolite $>\mathrm{KNO}_{3} / \mathrm{ZrO}_{2}>\mathrm{ZrO}_{2}$.

Meanwhile, Baskar et al. ${ }^{91}$ used $\mathrm{Mn}$-doped $\mathrm{ZnO}$ nanomaterial for the conversion of Mahua oil to biodiesel and observed that catalyst calcined at $600{ }^{\circ} \mathrm{C}$ showed highest biodiesel yield of $97 \%$ under the optimum reaction conditions. The kinetic investigation of the reaction revealed that $181.91 \mathrm{~kJ} / \mathrm{mol}$ activation energy is necessary for biodiesel synthesis from Mahua oil utilizing $\mathrm{Mn}$-doped $\mathrm{ZnO}$ catalyst. The prepared $\mathrm{Mn}$-doped $\mathrm{ZnO}$ catalyst was seen as a cluster and spherical in shape as depicted in Figure 4 A. FI-TR analysis was performed to confirm the formation of biodiesel. Absorption bands at 1744 and $1703 \mathrm{~cm}^{-1}$ demonstrated CO stretching of methyl esters in Mahua oil and biodiesel respectively. The main spectrum region that allows for chemical discrimination between Mahua oil and produced biodiesel is in the range $1500-900 \mathrm{~cm}^{-1}$ also called known as fingerprint region. Figure $4 \mathrm{~B}$ revealed the symmetric and asymmetric stretching of alkyl regions at 1376, 1463, 2852, $2922 \mathrm{~cm}^{-1}$ and CO group of lactones and esters at $1735 \mathrm{~cm}^{-1}$. Moreover, the stretching band of $\mathrm{CO}$ group of typical esters at around $1703 \mathrm{~cm}^{-1}$ was observed in Figure 4C. In light of this FT-IR bands, the product obtained after transesterification of Mahua oil using Mn-doped Zno catalyst was confirmed as biodiesel. 
$\mathrm{Na}_{2} \mathrm{MoO}_{4}$ has been synthesized and investigated as a catalyst in transesterification of

483

484

485

486

487

488

489

490

491

492

493

494

495

496

497

498

499

500

501

502

503 soybean oil by Nakagaki et al. ${ }^{92}$ The catalyst displayed high activity towards the transesterification reaction and afforded biodiesel yield of $95.6 \%$. The high reactivity of the catalyst is due to the acid sites of $\mathrm{Mo}(\mathrm{VI})$, which can polarize $\mathrm{O}-\mathrm{H}$ bond easily. Correspondingly, Serio et al. ${ }^{93}$ also reported the high reactivity of vanadyl phosphate-based catalyst in the biodiesel synthesis from soybean oil. Regardless of the low surface area, the high reactivity of the catalyst is attributed to the structural/surface morphologies. Biodiesel yield of $\geq 88 \%$ was recorded using the optimal reaction conditions. The dehydrated product of the catalyst $\mathrm{VOPO}_{4} \cdot 2 \mathrm{H}_{2} \mathrm{O}$ can be converted to $\mathrm{VOPO}_{4}$ simply by calcination at $400-500{ }^{\circ} \mathrm{C}$.

\section{.}

.



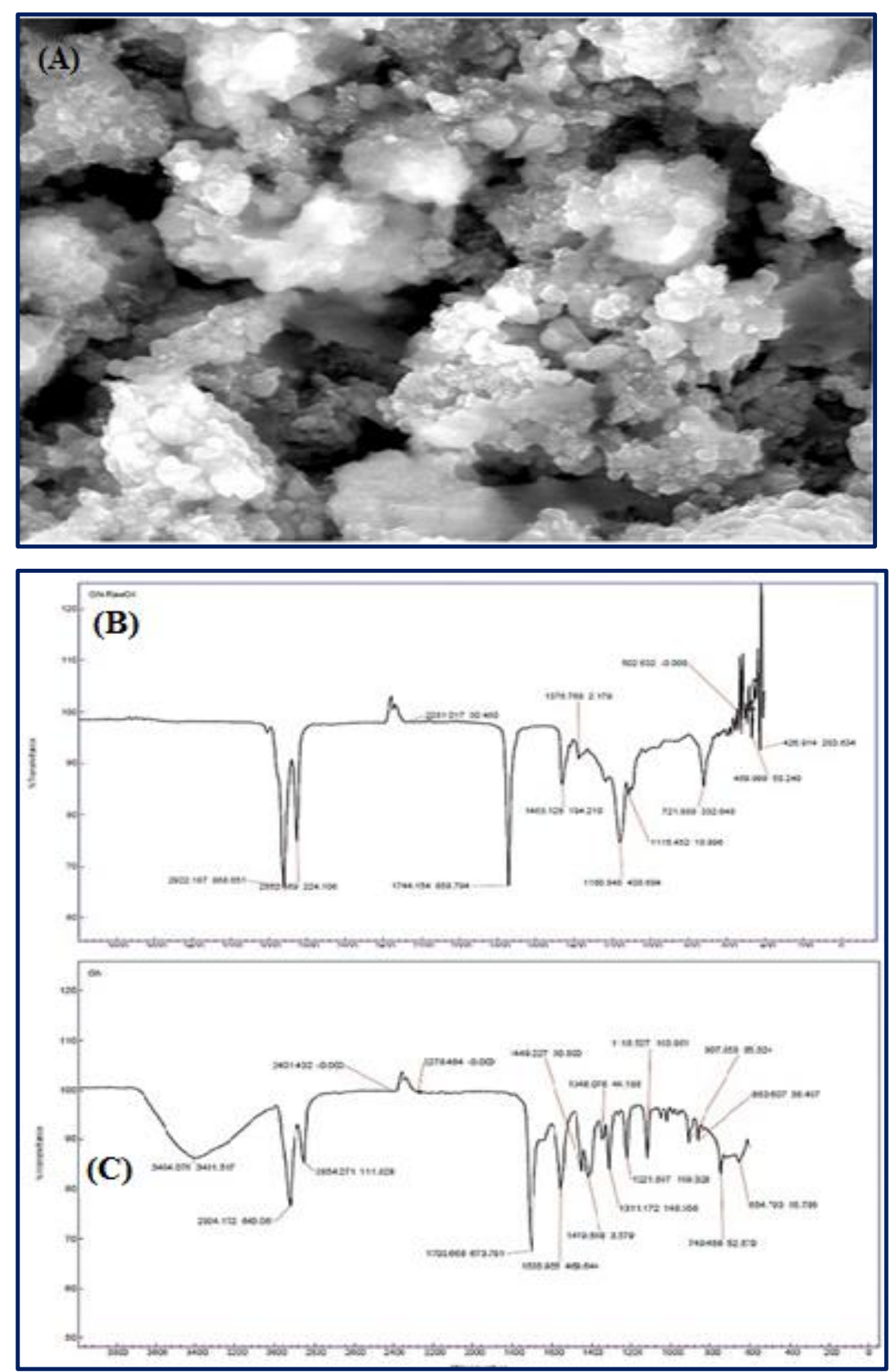

Figure 4: SEM image (A) and FT-IR spectrum (B, C) of Mn-doped $\mathrm{ZnO}$ nanomaterial. Reproduced from ref. [92]. 
511 Table 6: Various transition metal oxide catalyzed biodiesel production under different reaction 512 conditions.

\begin{tabular}{|c|c|c|c|c|c|}
\hline No. & Catalyst & Feedstocks & ${ }^{a}$ Conditions & Yield $(\%)$ & Ref. \\
\hline 1 & $\mathrm{Cu}(\mathrm{II}) @$ chitosan & Soybean oil & $1: 5^{c}, 2,70,180$ & 88.82 & 90 \\
\hline 2 & Co(II)@chitosan & Soybean oil & $1: 5^{c}, 2,70,180$ & 94.01 & 90 \\
\hline 3 & $\mathrm{SO}_{4}^{2-/ Z \mathrm{ZO}_{2}}$ & Crude palm & $6: 1,3,200,60$ & 90.30 & 87 \\
\hline 4 & $\mathrm{SO}_{4}{ }^{2-} / \mathrm{ZrO}_{2}$ & $\begin{array}{l}\text { kernel oil } \\
\text { Crude coconut } \\
\text { oil }\end{array}$ & $6: 1,3,200,60$ & 86.30 & 87 \\
\hline 5 & Mn doped $\mathrm{ZnO}$ & Mahua oil & $7: 1,8,50,50$ & 97 & 91 \\
\hline 6 & $\mathrm{Na}_{2} \mathrm{MoO}_{4}$ & Soybean oil & $54: 1,3,120,180$ & 95.6 & 92 \\
\hline 7 & Vanadyl phosphate & Soybean oil & $0.88: 2,0.5,180,60$ & $\geq 88$ & 93 \\
\hline
\end{tabular}

513

514

515

516

517

518

519

520

521

522

523

524

525

526

527

528

529

530

531

532

533

${ }^{a}$ Methanol-to-oil molar ratio, catalyst loading (wt. \%), temperature $\left({ }^{\circ} \mathrm{C}\right)$, reaction time $(\mathrm{min})$. ${ }^{c} \mathrm{~W} / \mathrm{W}$

\subsubsection{Zeolites}

Zeolites are crystalline aluminosilicates that possess microporous structure. ${ }^{94}$ It can exist in different structural morphology depending on their synthesis process and reaction conditions such as Si/Al molar ratio, pour sizes and proton exchange levels. The wide opportunity for structural modification of zeolites makes them an excellent catalyst for various acid-base reactions. Recently, zeolites are intensively investigated in the field of biodiesel production due to their shape selectivity and acidic character. Normally, zeolites are moderately active for the esterification reaction, however, by increasing the pore size and varying the $\mathrm{Si} / \mathrm{Al}$ ratio, the catalytic properties can be improved. Moreover, zeolites can incorporate various metal ions such as $\mathrm{Na}^{+}, \mathrm{K}^{+}, \mathrm{Mg}^{2+}$ etc., which are mainly responsible for its basic nature. ${ }^{95}$ Table 7 shows various reported zeolite catalysts employed in biodiesel synthesis.

In 2007, NaX zeolite loaded with various concentration of $\mathrm{KOH}$ was synthesized and reported as a catalyst in FAME production from soybean oil. ${ }^{96}$ Catalyst loaded with $10 \% \mathrm{KOH}$ followed by heating at $393 \mathrm{~K}$ for $3 \mathrm{~h}$ gave the best result with $85.6 \%$ yield under the optimized reaction conditions. Shu et al. ${ }^{97}$ prepared La/zeolite beta using $\mathrm{La}\left(\mathrm{NO}_{3}\right)_{3}$ as a precursor via ion exchange technique and exploited in FAME production from soybean oil. They reported that La/zeolite beta has higher stability and catalytic activity towards FAME production compared to zeolite beta catalyst. A yield of $48.9 \%$ was obtained using La/zeolite beta under the 
optimized reaction conditions such as 14.5:1 M/O molar ratio, 0.011 wt. \% catalyst loading, $60^{\circ} \mathrm{C}$ and $4 \mathrm{~h}$ time. In the year 2008, Ramos et al. ${ }^{98}$ studied three zeolites such as mordenite, beta and $\mathrm{X}$ for the conversion of sunflower oil biodiesel. They examined the effect of different loaded/stacked metals on such zeolites. Zeolite X showed the best catalytic activity as it has a higher number of super basic sites which is absent in other zeolites. Effect of binder, sodium bentonite, on the catalytic reactivity of such zeolites was tested, where $\mathrm{X}$ zeolite was agglomerated and thus catalytic activity reduced slightly. A high yield of $93.5 \%$ and $95.1 \%$ of FAME was obtained at $60{ }^{\circ} \mathrm{C}$ with and without binder, respectively. In another report, Wu et al. ${ }^{99}$ synthesized a series of $\mathrm{CaO}$ supported on zeolites such as NaY, $\mathrm{KL}$ and NaZSM-5 via microwave irradiation and utilized in biodiesel synthesis from soybean oil. They reported that supported $\mathrm{CaO}$ showed better result compared to the naked $\mathrm{CaO}$ as supported catalyst have a high surface area, porosity and basic strength. Accordingly, the best result was exhibited by $\mathrm{NaY}$ supported $\mathrm{CaO}(30 \% \mathrm{CaO}$ loaded on $\mathrm{NaY}$ ) under the optimized reaction conditions.

Strontium nanocatalyst supported on ZSM-5 by incipient wetness impregnation method was prepared and applied in biodiesel synthesis from sunflower oil. ${ }^{100}$ The authors reported the effect of calcination temperature and Sr/ZSM-5, Ba-Sr/ZSM-5 mass ratios. Ba-Sr/ZSM-5 (Ba 4 wt. \% to the Sr weight and Sr 6 wt. \% to the ZSM-5 weight exhibited the best performance with $87.7 \%$ yield under optimal conditions. In the meantime, Narkhede et al. ${ }^{101}$ synthesized a series of 12-tungstosilicic acid, $\mathrm{SiW}_{12}$ (10-40 wt. \%) impregnated on zeolite $\mathrm{H} \beta$ and applied it in biodiesel synthesis from soybean oil. Interestingly, SEM image of the $30 \% \mathrm{SiW}_{12} / \mathrm{H} \beta$ (Figure 5b) is similar with the pure zeolite $\mathrm{H} \beta$ (Figure 5a) and revealed that framework structure of $\mathrm{H} \beta$ was retained even after the impregnation of $\mathrm{SiW}_{12}$ and suggested that $\mathrm{SiW}_{12}$ was homogeneously distributed in the framework structure of $\mathrm{H} \beta$ zeolite. They reported a 95 $\%$ yield of FAME under the optimized reaction conditions. 

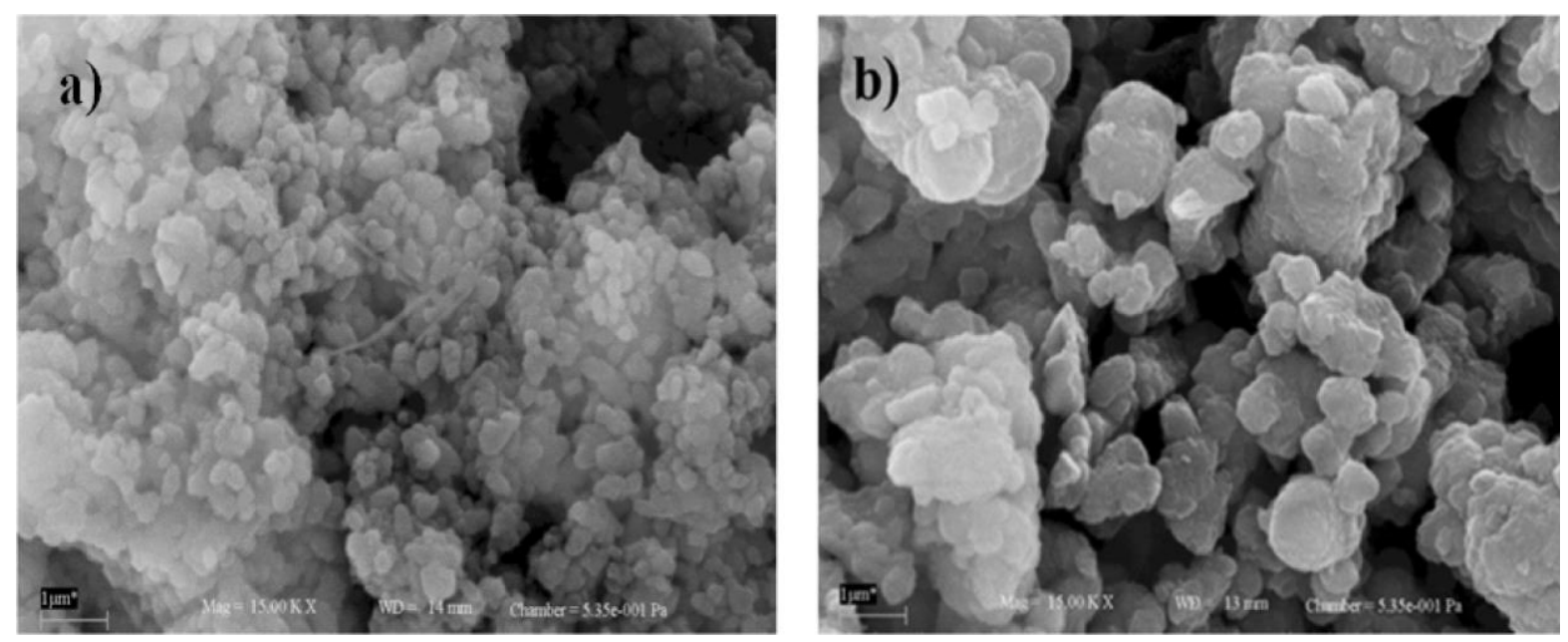

Figure 5: SEM micrographs of (a) $\mathrm{H} \beta$ and (b) $30 \% \mathrm{SiW}_{12} / \mathrm{H} \beta$. Reproduced from ref 101.

559

560

561

562

563

564

565

566

567

568

569

570

571

572

573

574

575

576

577

578

579

580

581

In 2012, Babajide et al. ${ }^{102}$ synthesized a zeolite derived from fly ash and then ionexchanged with $\mathrm{K}$ to form $\mathrm{FA} / \mathrm{K}-\mathrm{X}$ zeolite, which was then applied in biodiesel synthesis from sunflower oil. They reported a high yield of $83.53 \%$ under the optimized reaction conditions. Similarly, Manique et al. ${ }^{103}$ prepared zeolite (sodalite) derived from coal fly ash via the hydrothermal process and utilized in biodiesel synthesis from soybean oil. The developed sodalite has a definite surface area of $10 \mathrm{~m}^{2} / \mathrm{g}$. They also reported a maximum conversion of $95.5 \%$ soybean oil usingthe optimized reaction conditions . Recently, Al-Jammal et al. ${ }^{104}$ prepared zeolite derived from zeolite tuft followed by impregnation of a series of $\mathrm{KOH}$ (1-6 $\mathrm{M}$ ) and heated at $80{ }^{\circ} \mathrm{C}$ for $4 \mathrm{~h}$ to form $\mathrm{KOH} /$ zeolite catalyst and finally utilized in biodiesel synthesis from waste sunflower oil. The catalyst (1-4 M) KOH/zeolite exhibited a biodiesel yield of $96.7 \%$ under the reaction conditions: $11.5: 1 \mathrm{M} / \mathrm{O}$ molar ratio, catalyst amount of $6 \mathrm{wt}$. $\%$ w.r.t. oil, $50{ }^{\circ} \mathrm{C}$ temperature and reaction time of $2 \mathrm{~h}$.

In the same vein, Du et al. ${ }^{105}$ developed $\mathrm{La}_{2} \mathrm{O}_{3}$ impregnated on $\mathrm{NaY}$ zeolite catalyst having a spherical shape with 3-5 mm size and utilized it in biodiesel synthesis from castor oil. In addition, they explored the impact of calcination temperature in the range of $600-1000{ }^{\circ} \mathrm{C}$ on biodiesel yield and observed that the catalyst calcined at $800{ }^{\circ} \mathrm{C}$ showed the best result. They also revealed that the incorporation of surfactant improved the dispersion of $\mathrm{La}_{2} \mathrm{O}_{3}$ and pore size of zeolite. The XRD pattern of the pure zeolite $\mathrm{NaY}$ and the catalyst $\mathrm{La}_{2} \mathrm{O}_{3} / \mathrm{NaY}$ zeolite calcined in the temperature range of $600-1000{ }^{\circ} \mathrm{C}$ is displayed in Figure 6 . The XRD pattern of the pure zeolite (Figure 6a) and the catalyst calcined at $600{ }^{\circ} \mathrm{C}$ (Figure 6b) and 800 ${ }^{\circ} \mathrm{C}$ (Figure 6c) are almost same and revealed that the crystallinity of the zeolite NaY does not change upon the incorporation of $\mathrm{La}_{2} \mathrm{O}_{3}$. However, on increasing the temperature to $1000{ }^{\circ} \mathrm{C}$, 
582

583

584

the XRD pattern (Figure 11e) showed no characteristic peaks of zeolite, suggests that at high calcination temperature, the crystallinity of the zeolite is lost.

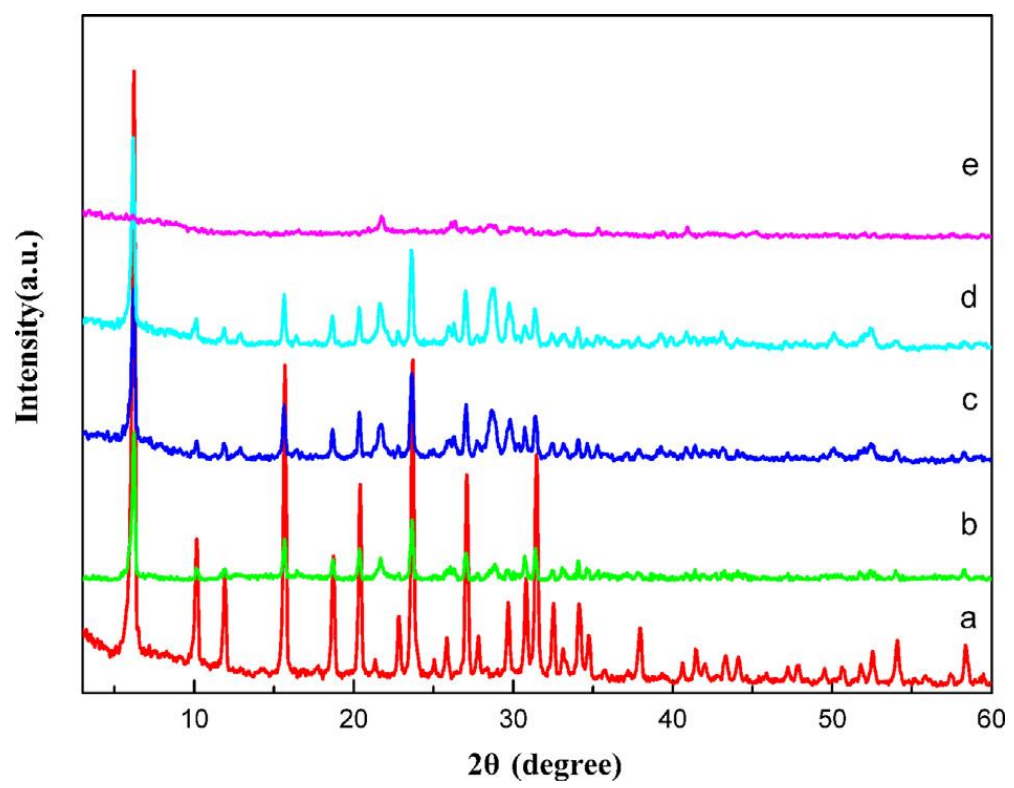

Figure 6: XRD pattern of pure zeolite (a), $\mathrm{La}_{2} \mathrm{O}_{3} / \mathrm{NaY}-600$ (b), $\mathrm{La}_{2} \mathrm{O}_{3} / \mathrm{NaY}-800$ (C), S-La $\mathrm{O}_{3} / \mathrm{NaY}-800$ (d), $\mathrm{La}_{2} \mathrm{O}_{3} / \mathrm{NaY}-1000$ (e). Reproduced from ref. [105].

585

586 Table 7: Different zeolite catalyzed FAME production under various reaction conditions.

\begin{tabular}{llllll}
\hline No. & Catalyst & Feedstocks & ${ }^{a}$ Conditions & $\begin{array}{l}\text { Yield } \\
(\%)\end{array}$ & Ref. \\
& & & & \\
\hline 1 & KOH@NaX zeolite & Soybean oil & $10: 1,3,65,480$ & 85.6 & 96 \\
2 & La/zeolite beta & Soybean oil & $14.5: 1,0.011, \quad 60$, & 48.9 & 97 \\
& & & 240 & & \\
3 & Zeolite X & Sunflower oil & $6: 1,10,60,420$ & 95.1 & 98 \\
4 & CaO@NaY zeolite & Soybean oil & $9: 1,3,65,180$ & 95 & 99 \\
5 & Ba-Sr/ZSM-5 & Sunflower oil & $9: 1,3,60,180$ & 87.7 & 100 \\
6 & H4[W12SiO40]@zeolite & Soybean oil & $4: 1,0.2,65,480$ & 95 & 101 \\
& H $\beta$ & & & & \\
7 & FA/K-X zeolite & Sunflower oil & $6: 1,3,60,480$ & 83.53. & 102 \\
8 & Sodalite & Soybean oil & $12: 1,4,65,120$ & 95.5 & 103 \\
9 & KOH/zeolite & Waste & $11.5: 1,6,50,120$ & 96.7 & 104 \\
& & sunflower oil & & &
\end{tabular}




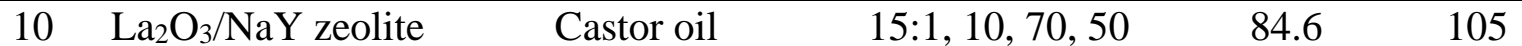

${ }^{a}$ Methanol-to-oil molar ratio, catalyst loading (wt. \%), temperature $\left({ }^{\circ} \mathrm{C}\right)$, reaction time (min).

\subsubsection{Supported catalyst}

To increase the stability and reusability of alkaline earth metal oxides, catalyst support

591

592

593

594

595

596

597

598

599

600

601

602

603

604

605

606

607

608

609

610

611

612

613

614

615 plays an important role as they can reduce the mass transfer limitation and provide a high surface area with high porosity, where metals are anchored. ${ }^{106}$ Till now several catalyst support such as alumina, silica, $\mathrm{ZnO}$ and $\mathrm{ZrO}_{2}$ had been proposed for the production of FAME. Alumina is extensively employed as catalyst supports for various basic or acidic compounds exploited as a solid catalyst in esterification/transesterification reactions. ${ }^{107}$ Several alumina supported catalysts employed in the transesterification reaction for biodiesel synthesis as shown in Table 8. In 2006, Xie et al. ${ }^{108}$ investigated the potential of KI loaded on $\mathrm{Al}_{2} \mathrm{O}_{3}$ support catalyst for biodiesel synthesis from soybean oil. They prepared a series of $\mathrm{KI} @ \mathrm{Al}_{2} \mathrm{O}_{3}$ catalysts by changing the KI amount and investigated their catalytic activities. They observed that catalyst loaded with $35 \% \mathrm{KI}$ and calcined at $773 \mathrm{~K}$ showed highest FAME conversion of 96 $\%$ against all other catalysts under the optimal reaction conditions. In another study, potassium oxide loaded on alumina derived from various potassium salts such as $\mathrm{KNO}_{3}, \mathrm{KOH}, \mathrm{KF}$, $\mathrm{KI}$ and $\mathrm{K}_{2} \mathrm{CO}_{3}$ were compared and found that $\mathrm{KF} @ \mathrm{Al}_{2} \mathrm{O}_{3}$ showed the best result compared to other catalysts, because of the generation of new phase $\mathrm{K}_{2} \mathrm{O}$ on the surface of alumina and as result basicity of the catalyst increases. ${ }^{109}$ In addition, Ma et al. ${ }^{110}$ reported the synthesis of FAME via transesterification of rapeseed oil using $\mathrm{K} @ \mathrm{KOH} @ \mathrm{Al}_{2} \mathrm{O}_{3}$ catalyst. The formation of Al-O$\mathrm{K}$ composite enhanced the basicity of the catalyst, thereby catalytic efficiency. They investigated catalytic activity by varying the amount of $\mathrm{K}$ and $\mathrm{KOH}$ and found that 7.5 and 20 wt. \% (w.r.t. alumina) of $\mathrm{K}$ and $\mathrm{KOH}$, respectively displayed the highest activity with $84.52 \%$ biodiesel yield. Moreover, Chen et al. ${ }^{111}$ reported biodiesel production from soybean oil using $\mathrm{K} @ \gamma-\mathrm{Al}_{2} \mathrm{O}_{3}$ catalyst in a rotating packed bed (RPB) reactor. The schematic representation of RPB model is displayed in Figure 7. The main advantage of RPB reactor is that it provides efficient mixing of three immiscible reactants such as oil, methanol and the catalyst. A high yield of $96.4 \%$ was reported using the optimal reaction conditions. 


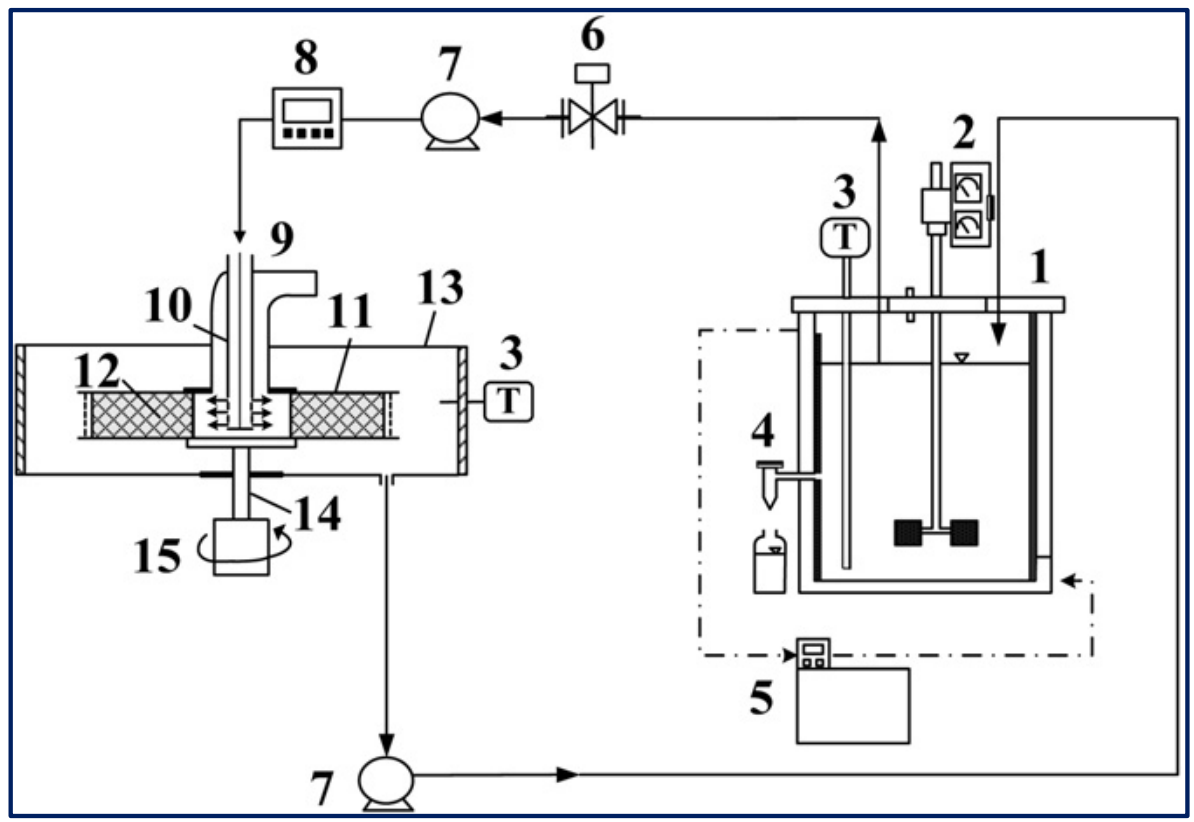

Figure 7: RPB experimental apparatus utilized for heterogeneously catalyzed transesterification reaction. Components: (1) CSTR reactor; (2) stirrer; (3) thermocouples; (4) sample port; (5) thermostat; (6) control valve; (7) pumps; (8) flow-meter; (9) RPB reactor; (10) stationary liquid distributor; (11) packed-bed rotator; (12) K/g-Al2O3 catalyst; (13) housing case; (14) rotor shaft; (15) motor. Reproduced from ref. [111].

Zhang et al. ${ }^{112}$ synthesized KOH impregnated modified alumina catalyst for biodiesel synthesis from microalgae oil. Firstly, the alumina was modified with Lanthanum and barium to increase its surface area, possess desired pore volume and pore distribution and finally impregnation of $\mathrm{KOH}$ on the modified alumina to form the desired catalyst. They reported that $25 \% \mathrm{KOH}$ (w.r.t. modified alumina) impregnated on modified alumina and calcined at $550{ }^{\circ} \mathrm{C}$ for $4 \mathrm{~h}$ showed the best activity towards the transesterification reaction with $97.7 \%$ biodiesel yield under the ideal reaction conditions. Umdu et al. ${ }^{113}$ synthesized $\mathrm{CaO} @ \mathrm{Al}_{2} \mathrm{O}_{3}$ via the solgel method and conducted a transesterification reaction of microalgae (Nannochloropsis oculata) oil to produce biodiesel. The catalyst has higher reactivity than the bare $\mathrm{CaO}$, which was almost inactive towards transesterification of the desired microalgae. The alumina was loaded with 80 wt. $\%$ (w.r.t. $\left.\mathrm{Al}_{2} \mathrm{O}_{3}\right) \mathrm{Ca}\left(\mathrm{NO}_{3}\right)_{2} .4 \mathrm{H}_{2} \mathrm{O}$ and calcined at $500{ }^{\circ} \mathrm{C}$ for $6 \mathrm{~h}$ to form 80 wt.\% $\mathrm{CaO} @ \mathrm{Al}_{2} \mathrm{O}_{3}$ that possessed the highest catalytic activity with $97.5 \%$ biodiesel yield. In addition, Zabeti et al. ${ }^{114}$ synthesized a $\mathrm{CaO} @ \mathrm{Al}_{2} \mathrm{O}_{3}$ catalyst using calcium acetate via calcination at $718{ }^{\circ} \mathrm{C}$ for biodiesel synthesis from palm oil. They have used Response Surface 
Table 8: Different aluminium supported solid catalyst for biodiesel production.

\begin{tabular}{llllll}
\hline No. & Catalyst & Feedstock & ${ }^{a}$ Conditions & Yield (\%) & Ref. \\
\hline 1 & $\mathrm{KI} @ \mathrm{Al}_{2} \mathrm{O}_{3}$ & Soybean oil & $15: 1,2,65,480$ & 96 & 108 \\
2 & $\mathrm{~K} @ \mathrm{KOH} @ \mathrm{Al}_{2} \mathrm{O}_{3}$ & Rapeseed oil & $9: 1,4,60,60$ & 84.52 & 110 \\
3 & $\mathrm{~K} @ \gamma-\mathrm{Al}_{2} \mathrm{O}_{3}$ & Soybean oil & $24: 1,10.6,60,60$ & 96.4 & 111 \\
4 & $\mathrm{KOH} / \mathrm{La}-\mathrm{Ba}_{-} \mathrm{Al}_{2} \mathrm{O}_{3}$ & Microalgae & $\mathrm{NR}, 25,60,180$ & $97.7^{b}$ & 112 \\
5 & $\mathrm{CaO} @ \mathrm{Al}_{2} \mathrm{O}_{3}$ & Nannochloropsis & $30: 1,2,50,240$ & 97.5 & 113 \\
& & oculata & & & \\
6 & $\mathrm{CaO} @ \mathrm{Al}_{2} \mathrm{O}_{3}$ & Palm oil & $12: 1,6,65,300$ & 98.64 & 114 \\
\hline
\end{tabular}

636

${ }^{a}$ Methanol-to-oil molar ratio, catalyst loading (wt. \%), temperature $\left({ }^{\circ} \mathrm{C}\right)$, reaction time (min).

637

638

639

640

641

642

643

644

645

646

647

648

649

650

651

652

653

654

Methodology (RSM) in association with Central Composite Design (CCD) to determine the optimum reaction conditions such as $\mathrm{M} / \mathrm{O}$ molar ratio, catalyst amount, reaction temperature and reaction time. Biodiesel yield of $98.64 \%$ was obtained under the optimum reaction conditions.

${ }^{b}$ Conversion

NR: Not reported

Apart from alumina, there are several materials which are used as catalyst support such as $\mathrm{SiO}_{2}, \mathrm{ZrO}_{2}$ and activated carbon (AC) (Table 9). In 2010, Samart et al. ${ }^{115}$ conducted transesterification reaction using $\mathrm{CaO}$ impregnated on mesoporous $\mathrm{SiO}_{2}$ catalyst for FAME production. They also investigated the influence of $\mathrm{CaO}$ amount and reported that 15 wt. \% $\mathrm{CaO}$ (w.r.t. $\mathrm{SiO}_{2}$ ) loading showed the maximum yield of $95.2 \%$. In addition, the synthesis of FAME from palm oil using a $\mathrm{CaO}$ impregnated on bimodal meso-macroporous $\mathrm{SiO}_{2}$ support catalyst was reported by Witoon et al. ${ }^{116}$. They investigated the influence of $\mathrm{CaO}$ loading and pellet size on biodiesel conversion and also compared with unimodal $\mathrm{SiO}_{2}$ supported $\mathrm{CaO}$ catalyst. $\mathrm{CaO}$ in 40 wt.\% $\mathrm{CaO} @ \mathrm{SiO}_{2}$ were highly aggregated on the surface of the mesoporous $\mathrm{SiO}_{2}$, hence increases the surface basicity; while $\mathrm{CaO}$ in 30 wt. \% $\mathrm{CaO} @ \mathrm{SiO}_{2}$ were highly dispersed inside the mesopore of the silica support, accordingly 40 wt.\% $\mathrm{CaO} @ \mathrm{SiO}_{2}$ showed higher FAME yield compared to 30 wt. \% CaO@ $\mathrm{SiO}_{2}$. They also reported that the catalyst with pellet size $335 \mu \mathrm{m}$ showed a maximum yield of $92.45 \%$. Moreover, Wu et al. ${ }^{117}$ reported catalysts consisting of three different potassium compounds ( $\mathrm{KAc}, \mathrm{K}_{2} \mathrm{CO}_{3}$ and $\mathrm{K}_{2} \mathrm{SiO}_{3}$ ) impregnated on mesoporous $\mathrm{SiO}_{2}$ such as AlSBA-15 and SBA-15 for the production of FAME 
from JCO. Three potassium salts with different concentration were impregnated on AlSBA-15 and SBA-15 and found that the basicity lies in the order of 35 wt. \% $\mathrm{K}_{2} \mathrm{SiO}_{3} @ \mathrm{AlSBA}-15>35$ wt.\% $\mathrm{K}_{2} \mathrm{CO}_{3} @ \mathrm{AlSBA}-15$ > 35 wt.\% KAc@AlSBA-15 and thus 30 wt.\% $\mathrm{K}_{2} \mathrm{SiO}_{3}$ showed highest yield of $95.7 \%$ under the optimized reaction conditions.

The concept of AC-based catalyst is an attempt towards the development of a novel alternative to homogeneous alkaline in the form a heterogeneous catalyst. These kinds of catalysts have pulled in a lot of consideration from the scientific community because the uses of carbon as catalysts not only makes them reusable in the production process but also greatly reduce the formation of the soap and increases glycerol purity. ${ }^{118}$ To date, different kinds of activated carbon-based catalysts have been developed and successfully exploited in biodiesel production, some of them are briefly discussed here (Table 18). Narowska et al. ${ }^{118}$ proposed the development of a novel carbon-based catalyst to replace alkaline homogeneous catalyst as a solid catalyst which has the potential to be reused multiple times, eliminating various limitations associated with other traditional catalysts. In this context, the authors demonstrated the preparation of FAME from corn oil via transesterification utilizing $\mathrm{KOH}$ supported on activated carbon catalyst. The result showed that the highest yield (92 wt. \%) of FAME was recorded using optimal reaction conditions. These finding indicated that activated carbonsupported catalysts can be promisingly employed in the transesterification of the waste corn oil using methanol.

Previously, Buasri et al. ${ }^{119}$ reported calcium oxide impregnated on AC catalyst in the synthesis of highly pure FAME from waste cooking palm oil through continuous transesterification of FFA. After optimization of various reaction, a maximum FAME yield (94 $\%$ ) was accomplished. In another study, Konwar et al. ${ }^{120}$ also synthesized AC-supported calcium oxide from Turbonilla striatula shell and further, their applicability as a catalyst has been investigated in biodiesel synthesis from vegetable oil. It was reported that the catalyst displayed more than $90 \%$ oil conversion under the optimized reaction conditions. Moreover, this approached is economically viable due to easy recoverability of the catalyst. The catalyst was utilized for five progressive reactions cycles with minimum activity loss.

Hameed et al. ${ }^{121}$ examined a solid catalyst KF supported on AC for biodiesel synthesis from WCO. They designed a composite rotatable reactor to optimize the reaction parameters and obtained $83 \%$ methyl ester yield. In 2010, Baroutian et al. ${ }^{122}$ studied FAME synthesis in a packed bed membrane reactor (PBMR) from palm oil using a solid catalyst of $\mathrm{KOH}$ supported on AC generated from palm shell (Figure 8). They also investigated the impact of reaction parameters using RSM. The highest biodiesel yield of $98.03 \%$ was reported using the catalyst 
689 with optimized reaction conditions. In addition, Li et al. ${ }^{123}$ reported in situ synthesis of $690 \mathrm{~K}_{2} \mathrm{CO}_{3} @ \mathrm{KFA}$ via mixing of $\mathrm{K}_{2} \mathrm{CO}_{3}$ and kraft lignin (KF) succeeded by calcination at $800{ }^{\circ} \mathrm{C}$ 691 and utilized the catalyst in biodiesel synthesis from rapeseed oil. They also investigated the 692 influence of reaction parameters on the FAME production and reported that a maximum yield 693 of $99.6 \%$ under the optimized reaction conditions.

694 Further, Buasri et al. ${ }^{124}$ conducted a synthesis process where a solution of KOH was 695 mixed with activated carbon (AC) originated from coconut shell to form KOH@ AC and used 696 this catalyst in biodiesel synthesis from WCO. The authors claimed that the synthesized 697 catalyst has extraordinary catalytic reactivity and showed $86 \%$ biodiesel yield under the 698 optimized reaction conditions. Similarly, Wan et al. ${ }^{125}$ examined a solid base catalyst $699 \mathrm{CaO} @ \mathrm{AC}$ for FAME synthesis from palm oil. RSM was utilized to investigate the impact of 700 reaction parameters on biodiesel synthesis. A maximum yield of $80.98 \%$ was reported under 701 the optimal reaction conditions and also claimed that the catalyst can retain its activity even 702 after two cycles. Recently, Fadhil et al. ${ }^{126}$ conducted a transesterification reaction of bitter 703 almond oil to produce biodiesel using KAc impregnated on activated carbon originated from 704 the waste of polyethyleneterphathalte. A maximum yield of $93.21 \%$ with high purity was 705 reported. The authors claimed that the catalyst showed excellent reactivity towards biodiesel 706 synthesis compared to other reported solid base catalyst as the catalyst showed a very high 707 yield in very low optimal reaction conditions. Moreover, according to the authors, the catalyst 708 has great stability as it can be reused for 6 cycles. 


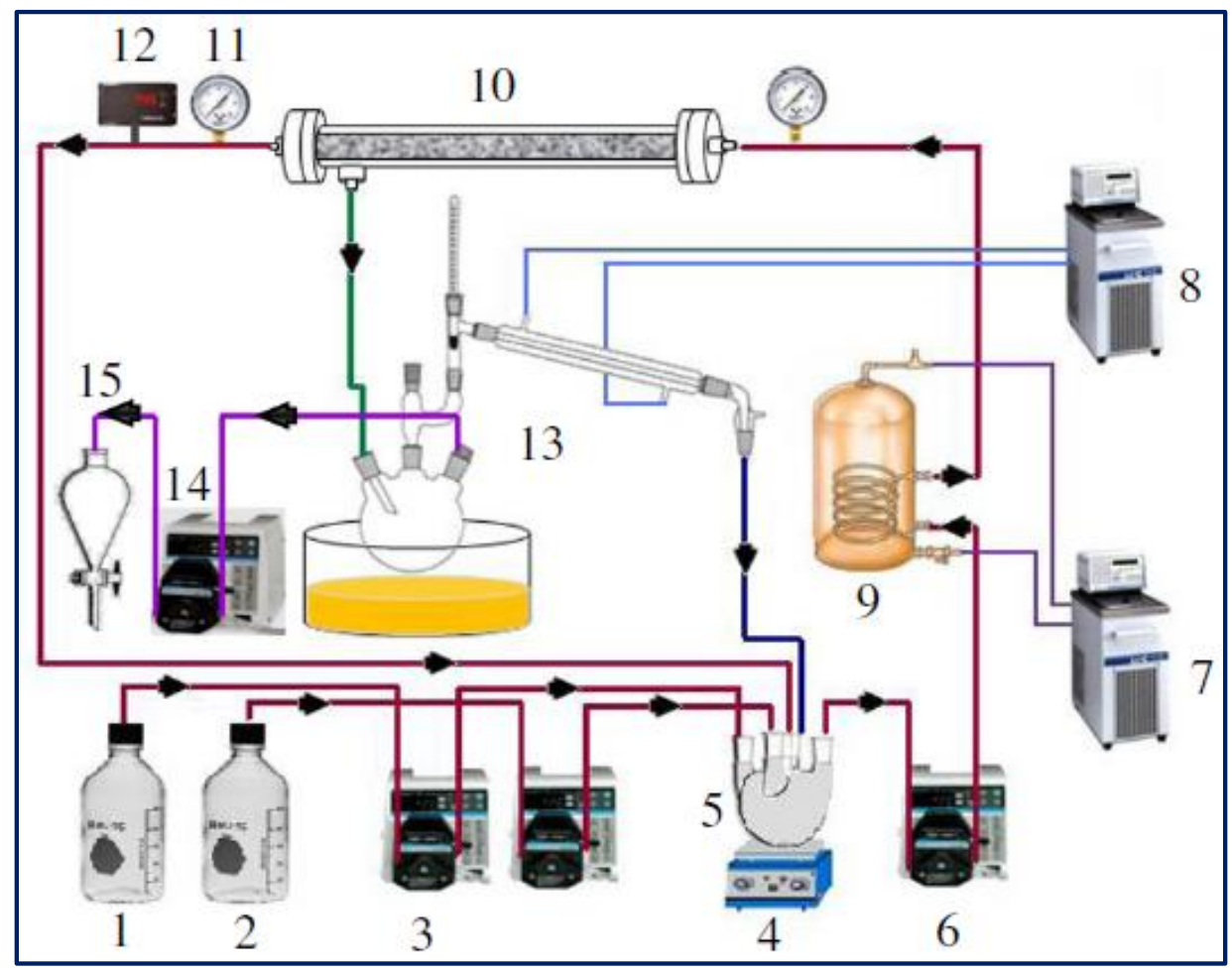

Figure 8: Schematic diagram of PBMR for FAME synthesis. Components: (1) palm oil; (2) methanol; (3) crude material siphon; (4) magnetic stirrer; (5) blending vessel; (6) flowing siphon; (7) boiling water flowing; (8) water chiller; (9) wound thermal exchanger; (10) ceramic membrane; (11) pressure check; (12) temperature indicator; (13) methanol recuperation unit; (14) siphon; (15) isolating funnel. Reproduced from ref. [122].

Liu et al. ${ }^{127}$ examined a solid base catalyst $\mathrm{KF} / \mathrm{CaO} / \mathrm{AC}$ calcined at $500{ }^{\circ} \mathrm{C}$ for $5 \mathrm{~h}$ for the conversion of soybean oil to biodiesel. The authors claimed that the main catalytic role was 713 played by $\mathrm{K}_{2} \mathrm{O}$ and $\mathrm{KCaF}_{3}$ that are present in the catalyst. The catalyst demonstrated high yield of $99.9 \%$ only in $20 \mathrm{~min}$. Nonetheless, they reported that the catalyst is highly sensitive towards water contents in methanol and oleic acid. Therefore it is necessary to use anhydrous oil and methanol to overcome this problem. In conclusion, from all these above-mentioned studies a collective inference can be drawn that activated carbon-based catalysts will be the next generation novel alternative to traditionally available catalysts for efficient transesterification of different oils.

In the meantime, the application of zinc oxide supported silver nanoparticles $(\mathrm{ZnO} @ \mathrm{Ag}$ NPs) as a solid catalyst for the conversion of palm oil to FAME was reported by Laskar et al. ${ }^{128}$ The transformation of palm oil to FAME was confirmed using NMR analysis and 10 
components of FAME were identified using GC-MS technique, with methyl octadecanoate (C18:0) being the major component. Mixture with different ratio of $\mathrm{Ag}$ on $\mathrm{ZnO}$ were prepared, where 10 wt.\% $\mathrm{ZnO} @ \mathrm{Ag}$ was found to be the most active catalyst producing $96 \%$ FAME under optimum reaction conditions. In the recent past, Taslim et al. ${ }^{129}$ also demonstrated the efficacy of low-cost AC-based catalyst developed from candlenut shell (an agricultural waste) through the impregnation of $\mathrm{KOH}$ for biodiesel production from WCO. The results obtained has shown that the yield of biodiesel up to $96.65 \%$ using optimized reaction conditions.

Table 9: Different solid supported catalyst for biodiesel synthesis.

\begin{tabular}{|c|c|c|c|c|c|}
\hline No. & Catalyst & Feedstocks & ${ }^{a}$ Conditions & $\begin{array}{l}\text { Yield } \\
(\%)\end{array}$ & Ref. \\
\hline 1. & $\mathrm{CaO} / \mathrm{SiO}_{2}$ & Soybean oil & $16: 1,5,60,480$ & 95.2 & 115 \\
\hline 2. & $\begin{array}{l}\mathrm{CaO} / \mathrm{SiO}_{2} \\
\text { (bimodal) }\end{array}$ & Palm oil & $12: 1,5,60,240$ & 94.15 & 116 \\
\hline 3. & $\mathrm{~K}_{2} \mathrm{SiO}_{3} @ \mathrm{AlSBA}-$ & Jatropha oil & $9: 1,15.30,60,180$ & 95.7 & 117 \\
\hline 4. & $\mathrm{KOH} / \mathrm{AC}$ & Corn oil & $3: 1,0.75,62.5,60$ & 92 & 118 \\
\hline 5. & $\mathrm{CaO} / \mathrm{AC}$ & WCO & $25: 1, \mathrm{NR}, 60,480$ & 94 & 119 \\
\hline $\begin{array}{l}6 . \\
7 .\end{array}$ & $\mathrm{CaO} / \mathrm{AC}$ & Vegetable oil & $40: 111,120,420$ & $>90$ & 120 \\
\hline 8. & $\mathrm{KF} / \mathrm{AC}$ & WCO & $8.85: 1,3,175,60$ & 83 & 121 \\
\hline 9. & $\mathrm{KOH} / \mathrm{AC}$ & Palm oil & $\begin{array}{l}24 ; 1,30.3,64.1, \\
60\end{array}$ & 98.03 & 122 \\
\hline 10. & $\mathrm{~K}_{2} \mathrm{CO}_{3} @ \mathrm{KFA}$ & Rapeseed oil & $15: 1,3,65,120$ & 99.6 & 123 \\
\hline 11. & KOH@AC & WCO & $25: 1, N R, 60,120$ & 86.3 & 124 \\
\hline 12. & $\mathrm{CaO} @ \mathrm{AC}$ & Palm oil & $15: 1,5.5,190,81$ & 80.98 & 125 \\
\hline 13. & $\mathrm{KAc} / \mathrm{AC}$ & $\begin{array}{l}\text { Bitter almond } \\
\text { oil }\end{array}$ & $9: 1,2.50,65,150$ & 93.21 & 126 \\
\hline 14. & $\mathrm{KF} / \mathrm{CaO} / \mathrm{AC}$ & Soybean oil & $12: 1,2.1,65,20$ & 99.9 & 127 \\
\hline 15. & Ag@ZnO & Palm oil & $10: 1,10,60,60$ & 96 & 128 \\
\hline 16. & $\mathrm{KOH} / \mathrm{AC}$ & WCO & $12: 1,3,60,120$ & 96.65 & 129 \\
\hline
\end{tabular}




\subsubsection{Hydrotalcite:}

Recently, hydrotalcites have attracted interest as a solid catalyst in the transesterification reactions due to their tunable properties and excellent performance. They belong to the layered double hydroxide (LDH) family. The general formula of hydrotalcite is $\left[\mathrm{M}_{\mathrm{n}}{ }^{2+} \mathrm{M}_{\mathrm{m}}{ }^{3+}(\mathrm{OH})_{2(\mathrm{n}+\mathrm{m})}\right]^{\mathrm{m+}}\left[\mathrm{A}^{\mathrm{x}-}\right]_{\mathrm{m} / \mathrm{x}} \cdot \mathrm{yH}_{2} \mathrm{O}$, where $\mathrm{M}^{2+}$ is a divalent metal e.g., $\mathrm{Ca}^{2+}, \mathrm{Zn}^{2+}, \mathrm{Mg}^{2+}$ etc., $\mathrm{M}^{3+}$ is a trivalent metal, most frequently $\mathrm{Al}^{3+}$, whereas $\mathrm{A}^{\mathrm{x}-}$ is an anion with $\mathrm{x}$ in the range of $0.1-0.5^{130,131}$. Table 10 shows various reported hydrotalcite catalysts employed in the biodiesel synthesis from different feedstocks. Navajas et al. ${ }^{132}$ prepared $\mathrm{Mg} / \mathrm{Al}$ hydrotalcite with composition within the range of $1.5-5$ by co-precipitation method and applied it in the conversion of sunflower oil to biodiesel. The basicity of the catalyst increased with the increase in $\mathrm{Mg} / \mathrm{Al}$ molar ratio and degree of rehydration. They reported a $96 \%$ conversion of oil to FAME (92\% yield) utilizing the rehydrated hydrotalcite under the optimal reaction conditions.

Zeng et al. ${ }^{133}$ reported $\mathrm{Mg}$-Al hydrotalcite with various $\mathrm{Mg} / \mathrm{Al}$ molar ratio and used them as a heterogeneous catalyst for the transesterification of soybean oil. The hydrotalcite calcined at $773 \mathrm{~K}$ and 3:1 $\mathrm{Mg}$ to $\mathrm{Al}$ molar ratio exhibited the highest catalytic activity with $90.5 \%$ conversion of oil. Recently, Ma et al. ${ }^{134}$ investigated a heterogeneous catalyst Mg-Al hydrotalcite in the production of biodiesel from WCO. They mentioned that the catalyst with $\mathrm{Mg} / \mathrm{Al}$ molar ratio 3:1 and calcined at $500{ }^{\circ} \mathrm{C}$ have a high surface area, excellent crystallinity and mesoporous structure, subsequently showed excellent activity. They also reported $95.2 \%$ FAME yield under the optimized reaction condition. In the same manner, Zeng et al. ${ }^{135}$ prepared $\mathrm{Mg} / \mathrm{Al}-\mathrm{CO}_{3}$ with $\mathrm{Mg} / \mathrm{Al}$ molar ratio of 4:1 via urea method and compared their structures and catalytic activities with those prepared by co-precipitation for the biodiesel synthesis from microalgae oil. They studied the crystal size and surface basicity of all the prepared hydrotalcites and reported that the crystal size of the hydrotalcites prepared using urea method is greater than as-synthesized ones. They also reported that the mixed oxide of the hydrotalcite prepared via urea method showed the highest catalytic reactivity with the maximum conversion of $90.30 \%$.

Further, Mg-Al hydrotalcite loaded with $1.5 \% \mathrm{~K}$ was prepared and used as a catalyst for the synthesis of biodiesel from palm oil. ${ }^{136}$ A maximum $86.6 \%$ yield was reported usingthe optimized reaction conditions. . They also studied the effect of the synthesized biodiesel on six types of elastomers such as NBR, HNBR, NBR/PVC, acrylic rubber, co-polymer FKM, and terpolymer FKM, which are commonly found in the fuel system. For testing, the elastomers were immersed in B10 (10 \% biodiesel in diesel) and found that only terpolymer FKM and co- 
polymer FKM showed a slight change in the properties. Thus, concluded that B10 is compatible with the diesel engines without any modification. In another work, Liu et al. ${ }^{137}$ prepared $\mathrm{Zn}$ Al hydrotalcite within the temperature range of $413-773 \mathrm{~K}$ to form dehydrated $\mathrm{Zn}$-Al hydrotalcite and $\mathrm{Zn}-\mathrm{Al}$ mixed oxides and used both the catalysts in the transesterification reaction in a fixed-bed reactor. The $\mathrm{OH}$ groups in the dehydrated $\mathrm{Zn}$ - $\mathrm{Al}$ is responsible for the high basicity of the catalyst. However, $\mathrm{Mn}^{+}-\mathrm{O}^{2-}$ pairs and isolated $\mathrm{O}^{2-}$ anions are the main basic sites in $\mathrm{Zn}-\mathrm{Al}$ metal oxides. Furthermore, they compared the catalytic activity of both dehydrated Zn-Al HT and Zn-Al oxides and found that the dehydrated HT calcined at $473 \mathrm{~K}$ showed highest catalytic activity and stability towards biodiesel synthesis with a maximum yield of $76 \%$ at $140{ }^{\circ} \mathrm{C}$ for $1 \mathrm{~h}$. Similarly, a heterogeneous base catalyst, KF/Ca-Al was developed for the biodiesel production from palm oil. ${ }^{138}$ The catalyst was prepared from layered double hydroxides of $\mathrm{Ca}-\mathrm{Al}$, where the introduction of $\mathrm{KF}$ enhanced the catalytic activity. It was observed that 100 wt. \% loading of KF decreased particle size of catalyst as shown by the SEM image of KF/Ca-Al (Figure 9). The authors also reported biodiesel yield of $97.14 \%$ under the optimized reaction conditions. Besides, biodiesel production from poultry fats was reported by using a solid base catalyst, $\mathrm{Mg}$-Al hydrotalcite. ${ }^{139}$ The influence of calcination temperature for the preparation of catalyst was investigated and disclosed that the catalyst calcined at $550{ }^{\circ} \mathrm{C}$ showed the maximum catalytic activity. Moreover, the authors detailed that rehydration of the catalyst before the transesterification reaction and preferential adsorption of TAGs on the surface of the catalyst reduced the catalytic activity.

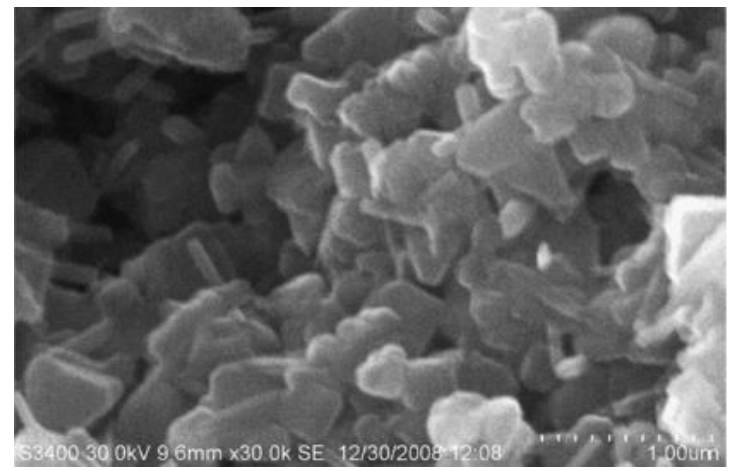

Figure 9: SEM image of $\mathrm{KF} / \mathrm{Ca}-\mathrm{Al}$.

Reproduced from ref. [138].

Helwani et al. ${ }^{140}$ synthesized $\mathrm{Mg}$-Al hydrotalcite via combustion method using saccharose for biodiesel synthesis from JCO. SEM image of the catalyst calcined at $850{ }^{\circ} \mathrm{C}$ displays a lamellar microstructure with closely packed flakes (Figure 10). The catalyst calcined 
793

794

795

796

797

at $850{ }^{\circ} \mathrm{C}$ and recrystallized with $20 \%$ saccharose fuel showed the best reactivity with $75.2 \%$ biodiesel conversion under the optimized reaction conditions. A layered double hydroxide of zinc hydroxide nitrate was also reported for FAME synthesis from palm oil. ${ }^{141}$ The catalyst showed excellent reactivity towards the transesterification reaction with $96.5 \%$ biodiesel yield.

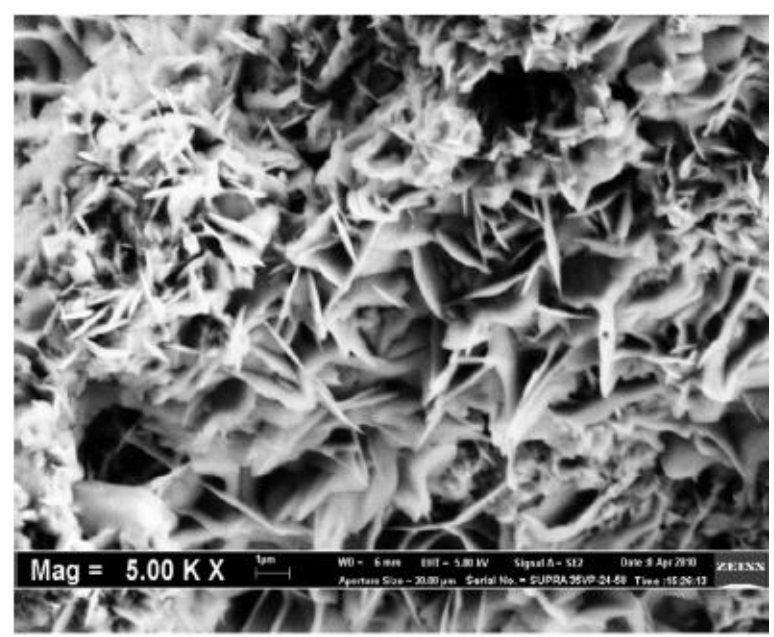

Figure 10: SEM image of Mg-Al HT calcined at $850{ }^{\circ} \mathrm{C}$ Reproduced from ref. [140].

798

799

Table 10: Different hydrotalcite catalyzed FAME production under various reaction 800 conditions.

\begin{tabular}{|c|c|c|c|c|c|}
\hline No. & Catalyst & Feedstocks & ${ }^{a}$ Conditions & $\begin{array}{l}\text { Yield } \\
(\%)\end{array}$ & Ref. \\
\hline 1 & $\mathrm{Mg}-\mathrm{Al} \mathrm{HT}$ & Sunflower oil & $48: 1,2,60,480$ & 92 & 132 \\
\hline 2 & $\mathrm{Mg}-\mathrm{Al} \mathrm{HT}$ & Soybean oil & $6: 1,1.5,65,240$ & 90.5 & 133 \\
\hline 3 & $\mathrm{Mg}-\mathrm{Al} \mathrm{HT}$ & WCO & $6: 1,1.5,80,150$ & 95.2 & 134 \\
\hline 4 & $\mathrm{Mg} / \mathrm{Al}-\mathrm{CO}_{3}$ & Microalgae oil & $6.4: 1,1.7,66,240$ & 90.3 & 135 \\
\hline 5 & $\mathrm{~K} / \mathrm{Mg}-\mathrm{Al} \mathrm{HT}$ & Palm oil & $30: 1,7,100,360$ & 86.6 & 136 \\
\hline 6 & Zn-Al HT & Soybean oil & $26: 1, \mathrm{NR}, 140,60$ & 76 & 137 \\
\hline 7 & $\mathrm{KF} / \mathrm{Ca}-\mathrm{Al}$ & Palm oil & $12: 1,5,65,300$ & 97.98 & 138 \\
\hline 8 & Mg-Al HT & Poultry fat & $30: 1,10,120,120$ & 75 & 139 \\
\hline 9 & Mg-Al HT & Jatropha oil & $30: 1,5,160,240$ & 93.4 & 140 \\
\hline 10 & $\begin{array}{l}\mathrm{Zn}_{5}(\mathrm{OH})_{8}\left(\mathrm{NO}_{3}\right)_{2} \\
.2 \mathrm{H}_{2} \mathrm{O}\end{array}$ & Palm oil & $6: 1,2,140,120$ & 96.5 & 141 \\
\hline
\end{tabular}


$\mathrm{NR}=$ Not reported

\subsubsection{Mixed metals oxides:}

Mixed metal oxides provide exceptionally fascinating properties especially when each component differs from one another. The basic idea of synthesizing the mixed metal-oxide catalysts is to increase the basic or acid strength, surface area, and stability of these catalysts when compared with single metal oxides. Henceforth, a series of highly efficient, reusable, and stable solid catalysts were prepared. For example, a combination of two metal oxides can show acid-base properties or some unique properties irrespective of their individual properties. ${ }^{142}$ The basicity of metals increases as it becomes less electronegative down the group. In the meantime, the highly basic metal oxides those formed with alkaline and alkaline earth metals are usually carbonated in air, and hence are inert. Hence, strong basicity can be achieved only after a high temperature treatment to obtain a carbonate-free metal oxide surface, making the process highly energy demanding. ${ }^{143}$ Interestingly, mixed metal oxides with high reactivity can be obtained at a much lower temperature making it highly demanded in catalysis. To date, several mixed metal oxides have been reported in transesterification reactions and are listed in Table 11.

Kawashima et al. ${ }^{144}$ investigated various calcium-containing catalysts-CaTiO 3 , $\mathrm{CaMnO}_{3}, \mathrm{Ca}_{2} \mathrm{Fe}_{2} \mathrm{O}_{5}, \mathrm{CaZrO}_{3}$, and $\mathrm{CaO}-\mathrm{CeO}_{2}$ in the biodiesel production from rapeseed oil. Among these, $\mathrm{CaO}-\mathrm{CeO}_{2}$ showed excellent results (approximately $90 \%$ yield) with high stability compared to other calcium-containing heterogeneous catalysts under the optimized reaction conditions. The catalyst can be reused for 7 times with a high yield of $>80 \%$ in each time. Sun et al. ${ }^{145}$ also prepared $\mathrm{La}_{2} \mathrm{O}_{3}$ loaded $\mathrm{ZrO}_{2}$ catalyst by varying $\mathrm{La}_{2} \mathrm{O}_{3}$ amount from 728 wt. $\%$ and investigated for the synthesis of biodiesel. 21 wt. $\% \mathrm{La}_{2} \mathrm{O}_{3}$ loading on $\mathrm{ZrO}_{2}$ and calcined at $600{ }^{\circ} \mathrm{C}$ demonstrated the highest catalytic activity towards biodiesel production from sunflower oil. The authors proposed a model for the preparation of the catalyst, where $\mathrm{La}\left(\mathrm{NO}_{3}\right)_{3}$ was impregnated on the surface of $\mathrm{ZrO}_{2}$ followed by drying to form a film of $\mathrm{La}\left(\mathrm{NO}_{3}\right)_{3}$, which upon calcination forms the $\mathrm{La}_{2} \mathrm{O}_{3} / \mathrm{ZrO}_{2}$ composite, resulting in a decrease in particle size due to $t / m$ phase transition (Figure 11). A high oil conversion of $96 \%$ and 84.9 $\%$ FAME yield was observed under optimal reaction conditions. They reported an excellent activity of catalyst prepared by 21 wt. \% loaded $\mathrm{La}_{2} \mathrm{O}_{3}$ and calcined at $600{ }^{\circ} \mathrm{C}$. 


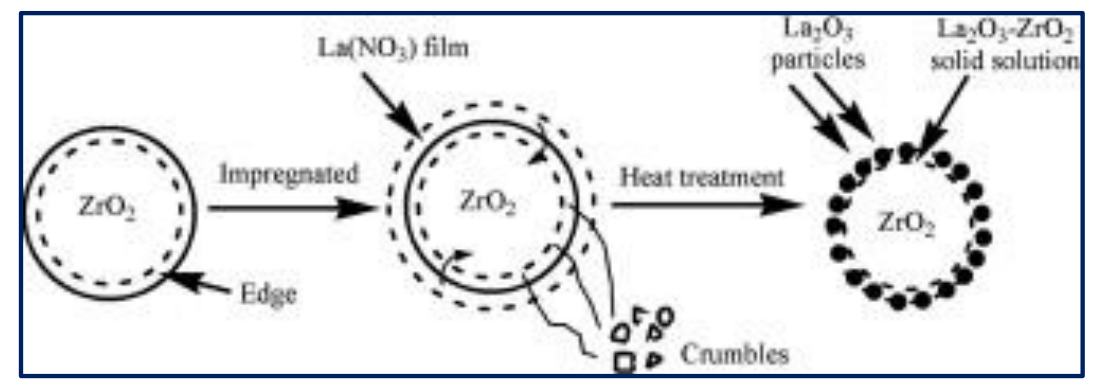

Figure 11: Proposed model for the solid-state reaction on the catalyst surface. Reproduced from ref. [145].

Wen et al. ${ }^{146}$ obtained $\mathrm{TiO}_{2}-\mathrm{MgO}$ catalyst via the sol-gel method and employed it in the FAME synthesis from WCO. Substitution of Ti to the Mg lattice led to defects in the surface of the catalyst, enhanced both the activity and stability of the catalyst. It was revealed that the catalyst with 1:1 Ti to Mg molar ratio and calcined at $923 \mathrm{~K}$ is the most active one in FAME synthesis. Biodiesel yield of $92.3 \%$ was observed utilizing the catalyst MT-1-923 using the optimal reaction conditions. Similarly, $\mathrm{SrO} / \mathrm{SiO}_{2}$ and $\mathrm{SrO} / \mathrm{CaO}$ has been synthesized and their catalytic activity was compared with naked $\mathrm{SrO}$ in transesterification of olive oil by Chen $e t$ $a l .{ }^{147}$ Although naked SrO showed very good catalytic activity and afforded $82 \%$ yield in just 15 min, biodiesel yield shrunk to $68.9 \%$ when the reaction was performed for $3 \mathrm{~h}$. They reported that the reason for the unusual decreased in biodiesel yield was due to reverse reaction between FAME and glycerol, which showed that the catalyst not only catalyzed the forward reaction but also catalyzed the reverse reaction as well. On the contrary, modification of SrO with $\mathrm{SiO}_{2}$ and $\mathrm{CaO}$ provided an excellent activity as well as high stability. They observed that around $95 \%$ conversion was obtained at $65{ }^{\circ} \mathrm{C}$ using $\mathrm{SrO} / \mathrm{SiO}_{2}$ and $\mathrm{SrO} / \mathrm{CaO}$ in 10 and $20 \mathrm{~min}$ respectively. However, they reported that on decreasing the reaction temperature to $45{ }^{\circ} \mathrm{C}$, $\mathrm{SrO} / \mathrm{CaO}$ showed only $20.20 \%$ conversion as compared to $\mathrm{SrO} / \mathrm{SiO}_{2}$, which showed $76.9 \%$ conversion. Thus, $\mathrm{SrO} / \mathrm{SiO}_{2}$ displayed better reactivity towards transesterification of olive oil than $\mathrm{SrO} / \mathrm{CaO}$ and possessed high tolerance to the water content and FFA of biodiesel feedstocks.

In the recent past, Madhuvilakku et al. ${ }^{148}$ developed $\mathrm{TiO}_{2}-\mathrm{ZnO}$ nanocatalyst and utilized in FAME synthesis from palm oil. Arrangement of deformities on the catalyst surface as a result of the substitution of $\mathrm{Ti}$ on $\mathrm{Zn}$ grid improved the reactivity and stability of the prepared catalyst. They recorded $92 \%$ biodiesel yield was acquired under the optimized reaction conditions. Similarly, a series of $\mathrm{ZnO}-\mathrm{La}_{2} \mathrm{O}_{3}$ catalyst have been examined in the biodiesel synthesis from waste oil by Yan et al. ${ }^{149}$ Incorporation of La promoted dispersion of $\mathrm{ZnO}$ and improved acidic-basic sites, thereby increased catalytic activity towards both 
transesterification and esterification reactions. The molar ratio of 3:1 $\mathrm{Zn}$ to La showed the highest activity towards biodiesel production. A high $96 \%$ yield was reported under the optimal reaction conditions. The authors also reported that the catalyst can endure FFA and water contents and thus allowed direct conversion of waste oil to FAME. In another work, transesterification of palm kernel oil to produce biodiesel has also been reported using a mixed metal oxide solid base catalyst $\mathrm{CaO}-\mathrm{ZnO} .{ }^{150}$ Upon incorporation of $\mathrm{Zn}$ to the $\mathrm{CaO}$ phase, the particle size of the catalyst has decreased and has reduced the calcination temperature required for the decomposition of carbonates to its oxides. Lowering of calcination temperature for the decomposition of $\mathrm{CaCO}_{3}$ upon the incorporation of $\mathrm{Zn}$ can be explained by particle size reduction coupled with a loss of $\mathrm{H}_{2} \mathrm{O}$ and $\mathrm{CO}_{2}$ from the zinc carbonate. The schematic representation for the decomposition of $\mathrm{CaCO}_{3}$ and formation of $\mathrm{CaO}-\mathrm{ZnO}$ mixed metal oxides is displayed in Scheme 3. It is well known that decarbonisation is a reversible process, which mostly depends on atmospheric $\mathrm{CO}_{2}$, particle size and composition. The dissociation of $\mathrm{CO}_{2}$ normally occurs in the outer surface (Scheme 3A). Moreover, upon calcination, the evolved

$873 \mathrm{CO}_{2}$ may form a layer on the surface of the material during the continuous disjunction of inner particles, generated a possibility for recarbonation of $\mathrm{CaO}$ to $\mathrm{CaCO}_{3}$ (Scheme $3 \mathrm{~B}$ ). However, incorporation of $\mathrm{ZnCO}_{3}$ resulted in the formation of voids due to its decomposition to zinc oxide. The resulting voids facilitated heat transfer to the interior particles and evaporation of

877 the gaseous compounds. Moreover, due to the small particle size of the $\mathrm{CaO}-\mathrm{ZnO}$, the diffusion 878 distance of $\mathrm{CO}_{2}$ decreased, thus calcination temperature also decreased. 


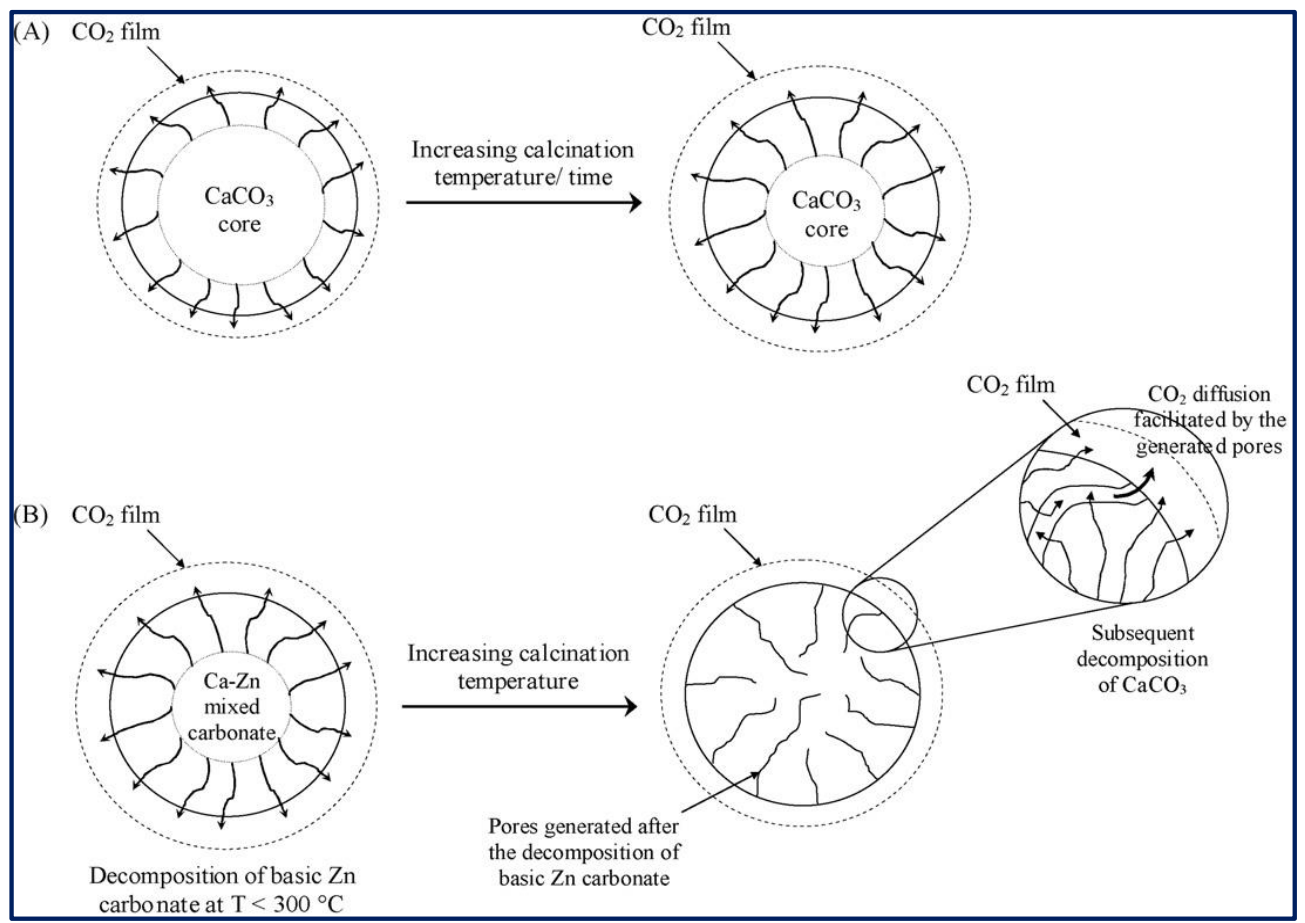

Scheme 3: Proposed models for $\mathrm{CaCO}_{3}$ decomposition to $\mathrm{CaO}(\mathrm{A})$ and mixed precipitate of Ca-Zn Reproduced from ref. [150].

Among solid base catalysts, solid $\mathrm{ZrO}_{2}$ catalysts become popular because of their environmentally benign nature and economic viability for biodiesel production. Till date, different types of $\mathrm{ZrO}_{2}$ catalysts have been developed for use in biodiesel production. In this line, Su et al. ${ }^{151}$ synthesized microporous solid base $\mathrm{MgO}-\mathrm{ZrO}_{2}$ composites and utilized them as effective heterogeneous catalysts in biodiesel synthesis. They claimed that such microporous catalysts are of great significance as the presence of porous materials in the preparation of these catalysts provided the ability to interact with atoms, ions, molecules.

Recently, Ibrahim et al. ${ }^{152}$ examined the influence of different support materials like $\mathrm{Al}_{2} \mathrm{O}_{3}, \mathrm{Fe}_{2} \mathrm{O}_{3}, \mathrm{TiO}_{2}$ and $\mathrm{SiO}_{2}$ on physicochemical properties and efficacy of $\mathrm{ZrO}_{2}$ solid catalysts commonly used in biodiesel synthesis. From the results obtained it was revealed that $\mathrm{ZrO}_{2}$ supported on $\mathrm{SiO}_{2}$ showed the highest conversion rate due to comparatively high surface area and a high number of Lewis acid sites. In another study, Faria et al. ${ }^{153}$ developed nanosized catalyst mixed metal oxides $\mathrm{SiO}_{2} / \mathrm{ZrO}_{2}$ catalyst prepared via sol-gel strategy and examined its reactivity in the synthesis of biodiesel from soybean oil. It was observed that this catalyst displayed promising reactivity and gave $96.2 \pm 1.4 \%$ biodiesel yield after $3 \mathrm{~h}$ of reaction time. In addition, the catalyst can be reused for 6 progressive cycles with little drop in activity. In 2008, Albuquerque et al. ${ }^{154}$ synthesized $\mathrm{MgO}-\mathrm{CaO}$ mixed metal oxides with different $\mathrm{Mg} / \mathrm{M}$ $(\mathrm{M}=\mathrm{Al}$ or $\mathrm{Ca})$ molar ratios and used it as a highly active catalyst for the transformation of 


\begin{tabular}{|c|c|c|c|c|c|}
\hline No. & Catalyst & Feedstocks & ${ }^{a}$ Conditions & Yield (\%) & Ref. \\
\hline 1. & $\mathrm{CaO}-\mathrm{CeO}_{2}$ & Rapeseed oil & $6: 1,10,60,600$ & 90 & 144 \\
\hline 2. & $\mathrm{La}_{2} \mathrm{O}_{3} / \mathrm{ZrO}_{2}$ & Sunflower oil & $30: 1,21,200,300$ & 84.9 & 145 \\
\hline 3. & $\mathrm{TiO}_{2}-\mathrm{MgO}$ & WCO & $50: 1,10,160,360$ & 92.3 & 146 \\
\hline 4. & $\mathrm{SrO} / \mathrm{SiO}_{2}$ & Olive oil & $6: 1,5,65,10$ & 95 & 147 \\
\hline 5. & $\mathrm{SrO} / \mathrm{CaO}$ & Olive oil & $6: 1,5,65,20$ & 95 & 147 \\
\hline 6. & $\mathrm{TiO}_{2}-\mathrm{ZnO}$ & Palm oil & $6: 1,14,60,300$ & 92 & 148 \\
\hline 7. & $\mathrm{ZnO}-\mathrm{La}_{2} \mathrm{O}_{3}$ & Waste oil & $6: 1,2.3,200,180$ & 96 & 149 \\
\hline 8. & $\mathrm{CaO}-\mathrm{ZnO}$ & Palm kernel oil & $30: 1,10,60,60$ & $>94$ & 150 \\
\hline 9. & $\mathrm{MgO}-\mathrm{ZrO}_{2}$ & Soybean oil & $20: 1,3,150,360$ & 99 & 151 \\
\hline 10. & $\mathrm{ZrO}_{2} @ \mathrm{SiO}_{2}$ & Stearic acid & $120: 1,10,120,180$ & 48.6 & 152 \\
\hline 11. & $\mathrm{SiO}_{2} / \mathrm{ZrO}_{2} \mathrm{NP}$ & Soybean oil & $\begin{array}{l}6.6: 1,2.8 \mathrm{mmol}, 50 \text {, } \\
180\end{array}$ & $96.2 \pm 1.4$ & 153 \\
\hline 12. & $\mathrm{MgO}-\mathrm{CaO}$ & Sunflower oil & $12: 1,2.5,60,60$ & 92 & 154 \\
\hline
\end{tabular}

906

907

908

909

910

911

912

913

914

915

916

917

sunflower oil to biodiesel in $92 \%$ yield under the optimized reaction conditions. The highest activity towards the transesterification reaction was found for a bulk $\mathrm{Mg}$ :Ca molar ratio of 3.8, whereas bare $\mathrm{CaO}$ were found to afford a lower yield of biodiesel under the same reaction conditions. The authors attributed this interesting activity to the higher BET surface area of the $\mathrm{MgO}-\mathrm{CaO}$ mixed metal oxide $\left(12.8 \mathrm{~m}^{2} \mathrm{~g}^{-1}\right)$, in comparison to $\mathrm{CaO}\left(1.2 \mathrm{~m}^{2} \mathrm{~g}^{-1}\right)$.

Table 11: Various mixed metal oxide catalyzed transesterification of vegetable oil.

${ }^{a}$ Methanol-to-oil molar ratio, Catalyst loading (wt. \%), Temperature $\left({ }^{\circ} \mathrm{C}\right)$, Reaction time (min).

\subsubsection{Biomass-based catalyst}

In recent year, bio-waste derived heterogeneous catalyst gains significant attention both in the realm of catalysis and biofuel research, and are reviewed by several authors recently ${ }^{155-}$ ${ }^{160}$ The advantages of using waste materials as a catalyst are largely due to their cheap, abundant, non-toxic, ecofriendly, economic, renewable, sustainable and easily availability. Many researchers utilized waste biomass as a catalyst for low FFA oil (edible oil) as well as in high FFA oil (edible and non-edible oils). The biomass includes plant ashes, waste shells, bones, industrial wastes and so forth. Profitably, catalysts derived from waste biomass potentially make biodiesel production highly cost-effective and environmentally benign. 


\subsubsection{Waste shells}

920

Despite several chemically synthesized heterogeneous catalysts mentioned earlier show promising and comparatively high biodiesel yield, their synthesis routes are sometimes complicated, expensive, chemically wasteful, time consuming and non-economical. Therefore, with the growing high demand for renewable energy, there is a need to search for an ideal heterogeneous catalyst which is easy to synthesize, non-toxic, low cost, widely available, biodegradable and eco-friendly in nature, yet exhibits high catalytic activity in biodiesel production. In the light of this, utilization of $\mathrm{CaO}$ (derived from high-temperature calcination of waste shells containing $\mathrm{CaCO}_{3}$ ) has been a front runner in recent times. The use of waste shells as a source of $\mathrm{CaO}$ not only make the whole production of biodiesel sustainable but also solved the problem associated with waste disposal of huge quantities of waste shell generated due to human consumption.

931

\subsection{Eggshell}

Various eggshell derived heterogeneous catalysts are available for the transformation of edible/non-edible oils to FAME as listed in Table 12. For the first time, $\mathrm{CaO}$ originated from chicken eggshell calcined at $1000{ }^{\circ} \mathrm{C}$ was utilized for biodiesel synthesis by Wei et al. ${ }^{161}$ Biodiesel yield greater than $95 \%$ was obtained. They have calcined the eggshell at different temperatures from $200{ }^{\circ} \mathrm{C}$ to $1000{ }^{\circ} \mathrm{C}$ and then tested their efficacy for the transformation of soybean oil to FAME. They observed that those calcined above $800{ }^{\circ} \mathrm{C}$ were the most active catalysts, where the XRD spectra display a crystalline $\mathrm{CaO}$ (Figure 12). Samples calcined at $700{ }^{\circ} \mathrm{C}$ for $2 \mathrm{~h}$ contain $\mathrm{CaCO}_{3}$ as the principal constituent and $\mathrm{CaO}$ as a minor one, hence medium yield (90\%) were obtained. Calcinations below $600{ }^{\circ} \mathrm{C}$ did not result in the formation of $\mathrm{CaO}$, hence, low catalytic activity was observed ( $<30 \%$ biodiesel yield). Hence, $\mathrm{CaO}$ in the catalyst is the principal basic constituent, which led to the high reactivity of the catalyst. From this experiment, it is suggested that waste shells have to be calcined at a temperature of at least $800{ }^{\circ} \mathrm{C}$ for $2 \mathrm{~h}$ to fully convert $\mathrm{CaCO}_{3}$ to $\mathrm{CaO}$, a highly basic catalyst. 


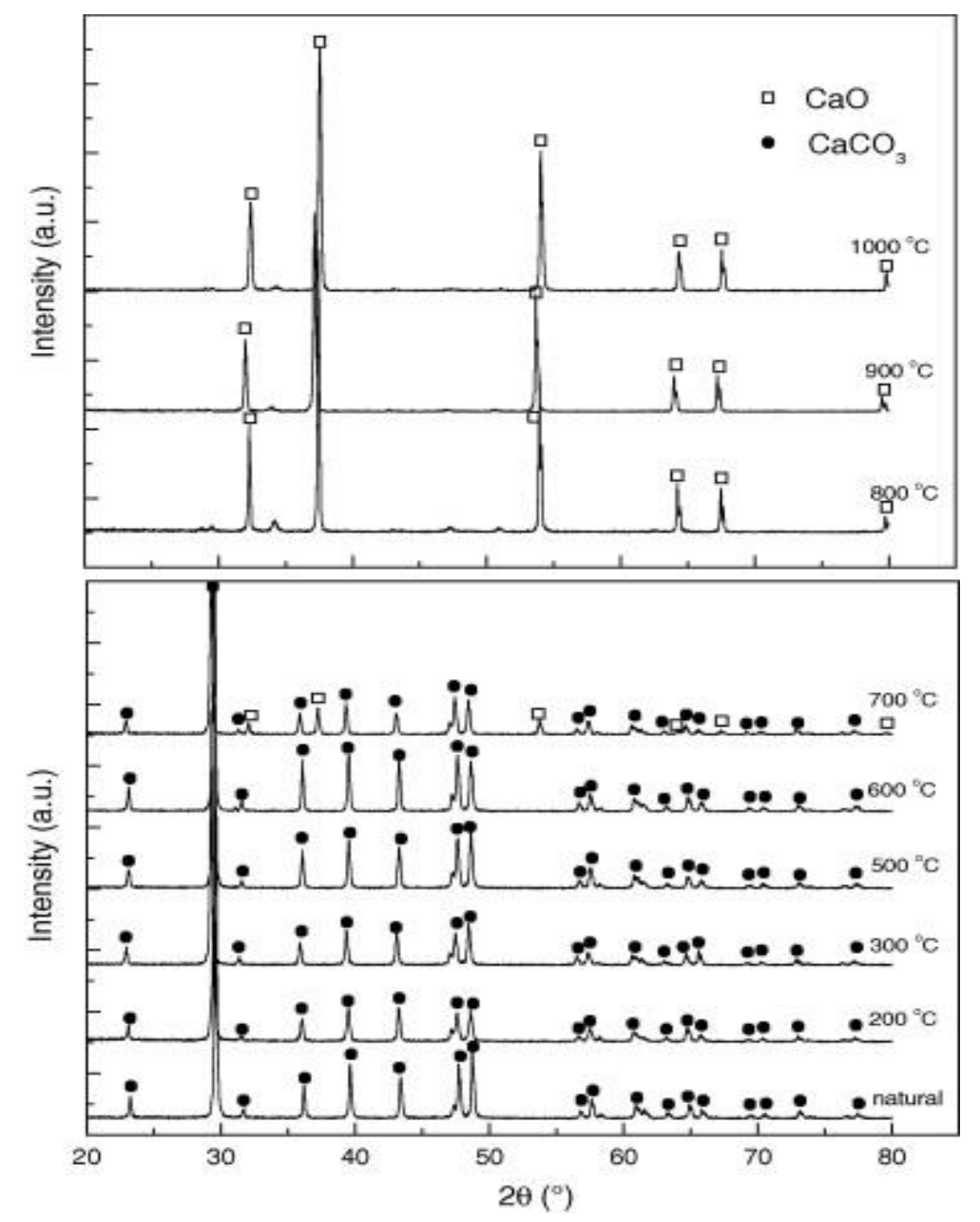

Figure 12: XRD patterns of natural eggshell and the materials obtained by calcining natural eggshell in the range of $200{ }^{\circ} \mathrm{C}-$ $1000{ }^{\circ} \mathrm{C}$. Reproduced from ref. [161].

In recent years, $\mathrm{CaO}$ derived from eggshell has been widely investigated in transformation 950 of various edible/non-edible oils such as soybean oil, ${ }^{162-164}$ karanja oil, ${ }^{165} \mathrm{WCO},{ }^{166-175}$ palm 951 oil, ${ }^{176-179}$ rapeseed oil, ${ }^{180,181}$ sunflower oil, ${ }^{182-185}$ JCO, ${ }^{186}$ microalgae oil, ${ }^{187-189}$ chicken fat, ${ }^{190}$ 952 catfish oil, ${ }^{191}$ Helianthus annuus L oil, ${ }^{192}$ cotton oil ${ }^{193}$ and sativa oil ${ }^{194}$ for FAME production. 953 In 2014, Niju et al. ${ }^{172}$ examined a highly active modified chicken eggshell derived CaO catalyst 954 for the synthesis of FAME from WFO. The authors reported that highly reactive $\mathrm{CaO}$ can be 955 obtained from eggshells via calcination-hydration-dehydration treatment. While the FAME conversion was only $67.57 \%$ for commercial $\mathrm{CaO}$ catalyst, $\mathrm{CaO}$ obtained from the eggshell calcined at $900{ }^{\circ} \mathrm{C}$ followed by hydration and dehydration at $600{ }^{\circ} \mathrm{C}$ (Eggshell-CaO-900-600) gave $94.52 \%$ conversion under the optimized reaction conditions. Calcination followed by hydration and dehydration greatly increased the surface area of the eggshell derived $\mathrm{CaO}$ as compared to those obtained with the only calcination. The high activity of the modified $\mathrm{CaO}$ 
961 (Eggshell-CaO-900-600) is attributed to the high surface area (8.6401 $\left.\mathrm{m}^{2} \mathrm{~g}^{-1}\right)$ compared to both commercial $\mathrm{CaO}\left(3.0022 \mathrm{~m}^{2} \mathrm{~g}^{-1}\right)$ and eggshell derived-CaO calcined at $900{ }^{\circ} \mathrm{C}$ (eggshell-CaO900) $\left(3.7262 \mathrm{~m}^{2} \mathrm{~g}^{-1}\right)$. The basicity of modified catalyst lies in the region $12.2<H_{-}<15.0$. Figure $13 \mathrm{~b}$ depicted the SEM image of $\mathrm{CaO}$ generated from the calcination-hydration-dehydration treatment of eggshells (i.e. egg shell-CaO-900-600) which shows a honeycomb-like porous surface. However, in the case of the eggshell-CaO-900, rod-like structure with microporous particles (size ranging from 1.29 to $2.0 \mu \mathrm{m}$ ) was observed (Figure 13a).

968

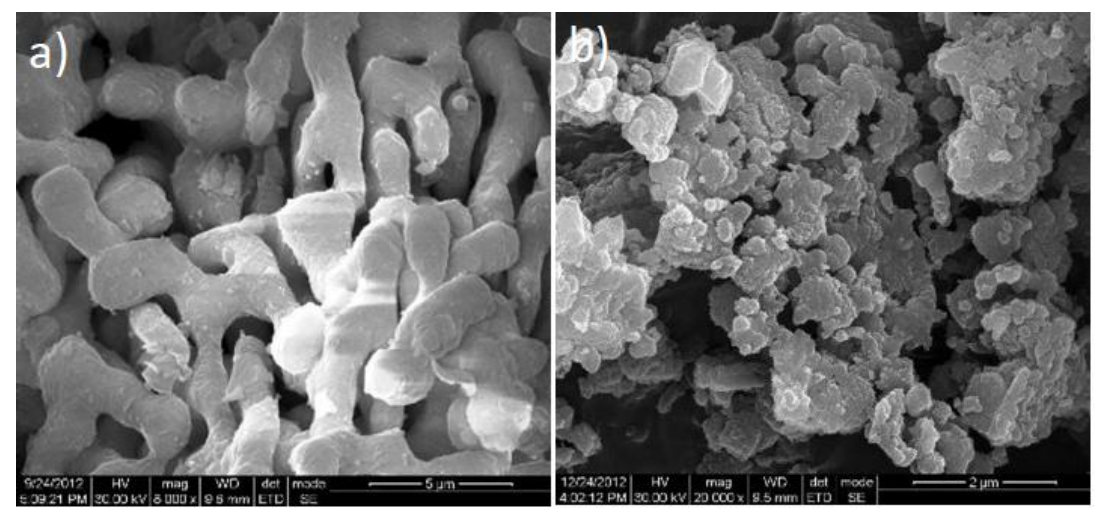

Figure 13: SEM image of a) eggshell-CaO-900. b). EggshellCaO-900-600. Reproduced from ref. [172].

969

In another work, waste chicken fat obtained from slaughterhouse was converted to FAME using calcined chicken eggshell catalyst under microwave irradiation (Figure 14). ${ }^{190}$ Esterification was carried out to lessen FFA content of the chicken oil below $1 \mathrm{mg} \mathrm{KOH} / \mathrm{g}$ of oil, followed by transesterification to yield FAME. Flow diagram of biodiesel production using chicken eggshell as a catalyst is presented in Figure 15. Optimization of transesterification process parameters by response surface methodology was performed.

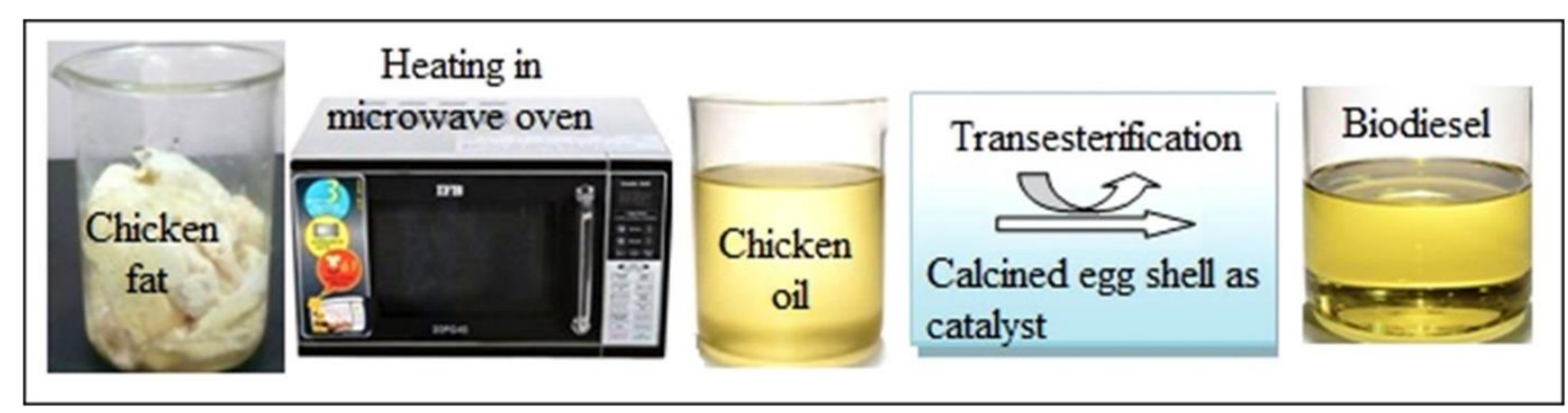


Figure 14: Microwave-assisted synthesis of FAME using an eggshell catalyst. Reproduced from ref. [190].

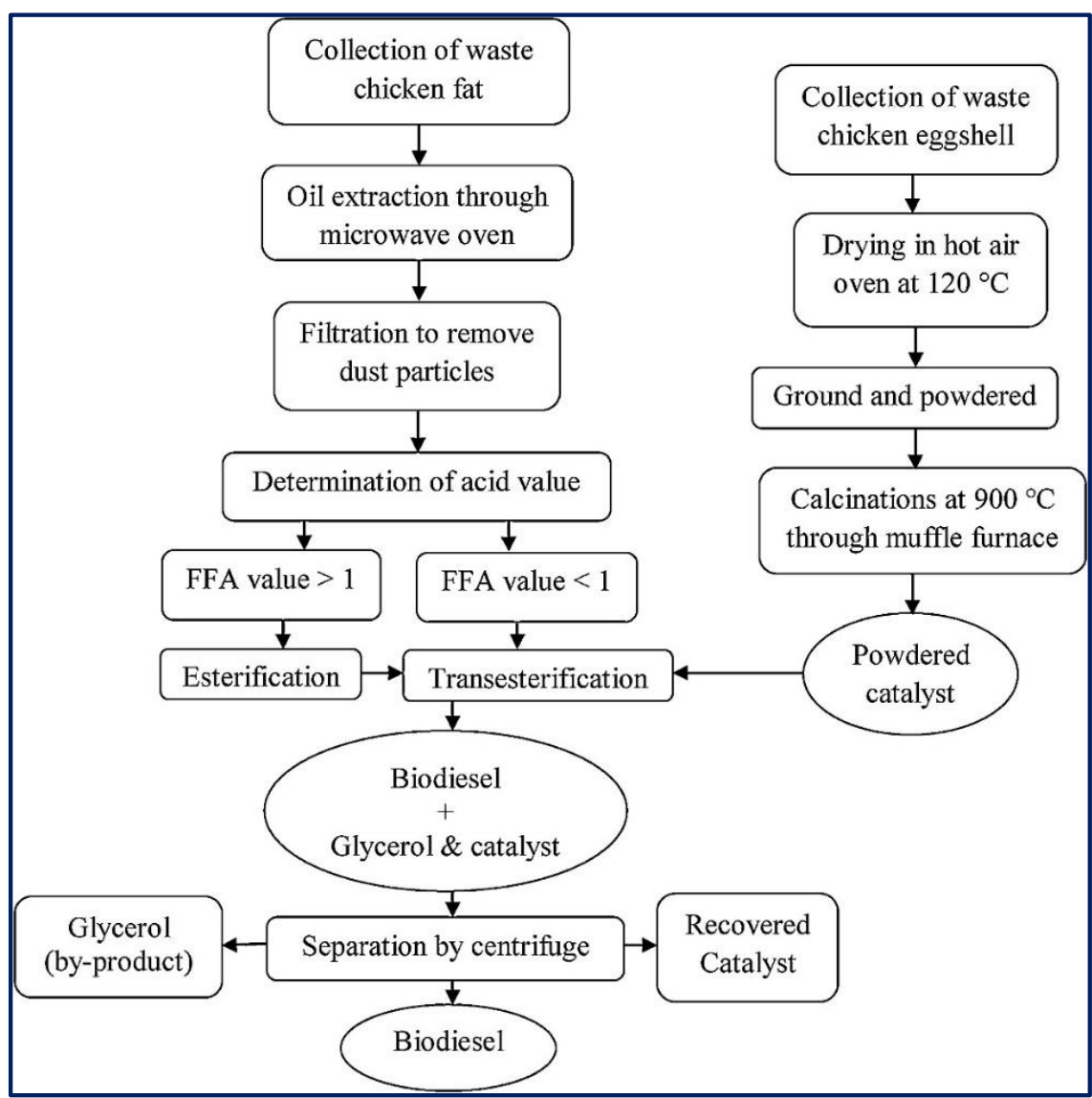

Figure 15: Flow diagram of biodiesel production utilizing chicken eggshell catalyst. Reproduced from ref. [190].

Similarly, Helianthus annuus L oil was converted to FAME using eggshell derived $\mathrm{CaO} .{ }^{192}$ The preparation route of $\mathrm{CaO}$ starting from the shell is presented in Figure 16. Under the optimized reaction conditions, $99.2 \%$ of FAME yield was achieved. The catalyst is stable up to the fourth cycle where $87.8 \%$ yield was observed. 


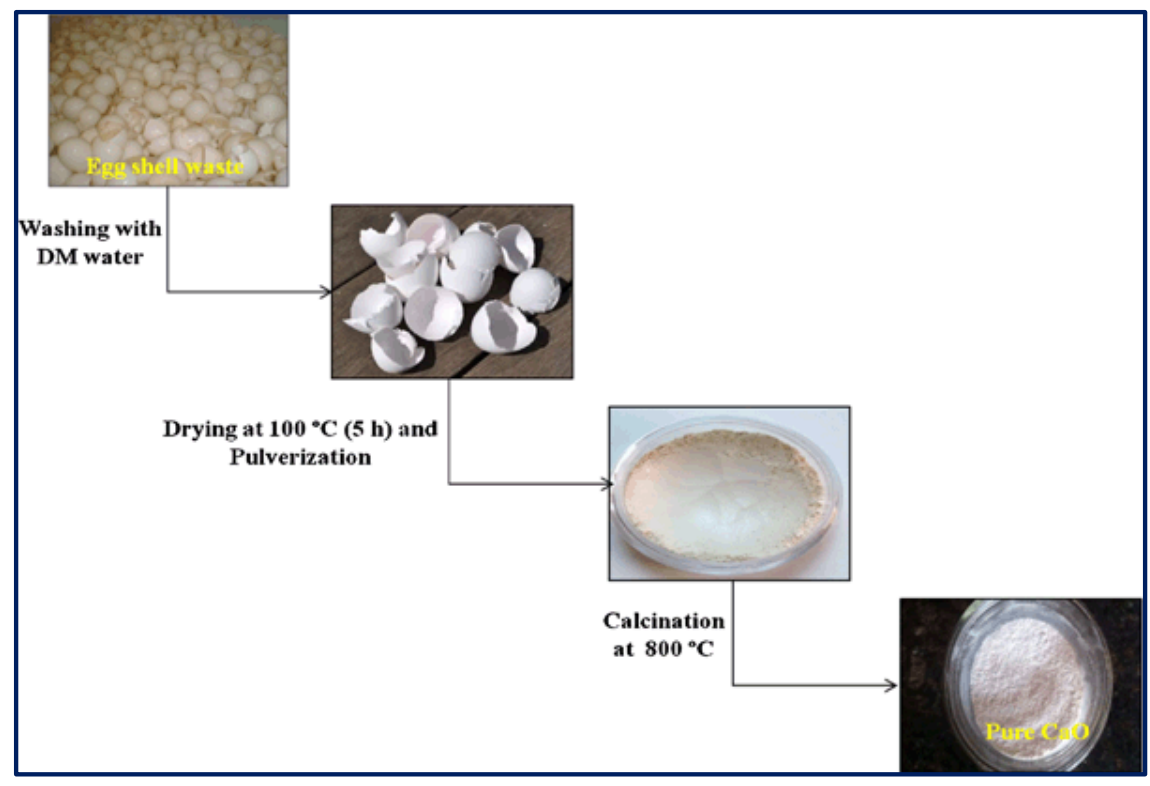

Figure 16: Schematic layout for eggshell originated $\mathrm{CaO}$ synthesis.

Reproduced from ref. [192].

Earlier, Ansori et al. ${ }^{195}$ reported a chicken shell derived $\mathrm{CaO}$ catalyzed synthesis of FAME from $C$. inophyllum $\mathrm{L}$ oil under a microwave (MW) irradiation. Initially, oil FFA content was pre-esterified utilizing $\mathrm{H}_{2} \mathrm{SO}_{4}$, which was then transesterified by utilizing the $\mathrm{CaO}$ catalyst (originated from chicken shell) and reported 98.90\% FAME yield in 12.47 min. In another work, Mansir et al. ${ }^{196}$ examined the application of $\mathrm{W} / \mathrm{Mo} / \mathrm{CaO}$ catalyst, where tungsten and molybdenum were impregnated on $\mathrm{CaO}$ derived from waste eggshell, for the transformation of WCO via concerted esterification/transesterification to produce FAME in a one-pot process. Moreover, the authors investigated the influence of $\mathrm{W}$ and $\mathrm{Mo}$ loading on $\mathrm{CaO}$ in its catalytic activity and found that catalytic activity increased when wt. \% of $\mathrm{W}$ is higher than wt. $\%$ of Mo over the range of 0.3-0.7\%. A maximum yield of $96.2 \%$ was reported under the optimum reaction conditions using $0.6 \mathrm{~W} / 0.4 \mathrm{Mo} / \mathrm{CaO}$. In addition, several literatures are available for the transesterification of WCO having FFA content in the range of 4-7.1\% to produce methyl ester using various eggshell derived $\mathrm{CaO}$ catalyst impregnated with acidic and basic compounds. Examples of such catalysts are $\mathrm{CaO} /$ anthill, ${ }^{197} \mathrm{CaO} / \mathrm{Zn},{ }^{198} \mathrm{CaO} / \mathrm{KF} / \mathrm{Fe}_{3} \mathrm{O}_{4},{ }^{199}$ $\mathrm{CaO} / \mathrm{SiO}_{2}$ based on palm empty fruit bunch (PEFB), ${ }^{200}$ and $\mathrm{Mo}-\mathrm{Zr} / \mathrm{CaO}{ }^{201}$ etc.

In 2015, Joshi et al. ${ }^{164}$ synthesized various metal oxides, for example, $\mathrm{ZnO}, \mathrm{MnO}_{2}, \mathrm{Fe}_{2} \mathrm{O}_{3}$ and $\mathrm{Al}_{2} \mathrm{O}_{3}$ impregnated on $\mathrm{CaO}$ derived from eggshell via calcination at $900{ }^{\circ} \mathrm{C}$ and exploited these catalysts in the conversion of non-edible JCO to FAME. Among all the mixed metal oxides, the surface area and pore volume of $\mathrm{ZnO}-\mathrm{CaO}$ is highest and thus showed an excellent 95.2\% JCO conversion. The authors also reported that the catalyst is very stable towards the 
transesterification of JCO and can be reused for 4 cycles. Similarly, Teo et al. ${ }^{202}$ synthesized $\mathrm{CaO}$ NPs derived from Gallus domesticus eggshell via precipitation method and utilized it for the conversion of JCO to give FAME with $97 \%$ yield under the optimal reaction conditions. TEM images and particle size distribution of waste eggshell of Gallus domesticus derived nano- $\mathrm{CaO}$ catalyst is displayed in Figure 17 (A, B, C) which revealed that the particles were regular spheroidal shape and the average particle diameter is $16-27 \mathrm{~nm}$. Figure $17 \mathrm{D}$ displays the basicity measurement of the catalyst and commercial $\mathrm{CaO}$ using $\mathrm{CO}_{2}$-TPD technique. All $\mathrm{CaO}$ catalysts showed a broad desorption peak owing to the existence of strong basic strength. The desorption peaks of both catalysts observed over the temperature ranging from 550 to 700 ${ }^{\circ} \mathrm{C}$ are attributed to the super-basic characteristics of the nanoparticles.

In 2011, Olutoye et al. ${ }^{203}$ reported a mixed metal solid catalyst, where $\mathrm{Mg}\left(\mathrm{NO}_{3}\right)_{2}$ and $\mathrm{KNO}_{3}$ were impregnated on $\mathrm{CaO}$ originated from eggshell and exploited it in the transformation of palm oil to FAME. The authors made three sets of a catalyst by changing the loading amount of $\mathrm{Mg}\left(\mathrm{NO}_{3}\right)_{2}$ and $\mathrm{KNO}_{3}$ on $\mathrm{CaO}$ with wt. \% ratio of $6: 1: 1,2: 1: 1$ and 1:1.5:1.5 and investigated their influence on the transesterification reaction and reported that the catalyst with wt. \% ratio of $6: 1: 1$ showed the maximum yield of $85.8 \%$. In addition, several works are reported in the literature regarding the transesterification of palm oil using chicken shell derived $\mathrm{CaO}$ modified solid catalyst such as $\mathrm{CaO} / \mathrm{SiO}_{2}{ }^{204,205} \mathrm{CaO} /$ rice husk ${ }^{206}$ etc. Recently, Sulaiman et al. ${ }^{207}$ successfully synthesized a mixture of calcined coconut waste and egg waste for the transformation of palm oil to biodiesel. The authors employed RSM based on CCD to study the ideal reaction conditions: coconut waste/eggshell waste ratio, M/O molar ratio, catalyst amount, reaction temperature and reaction time. After a successful investigation, they reported that 5:1 wt. \% ratio of coconut waste/eggshell waste showed the maximum yield of $81 \%$ under the optimal reaction conditions.

1031 

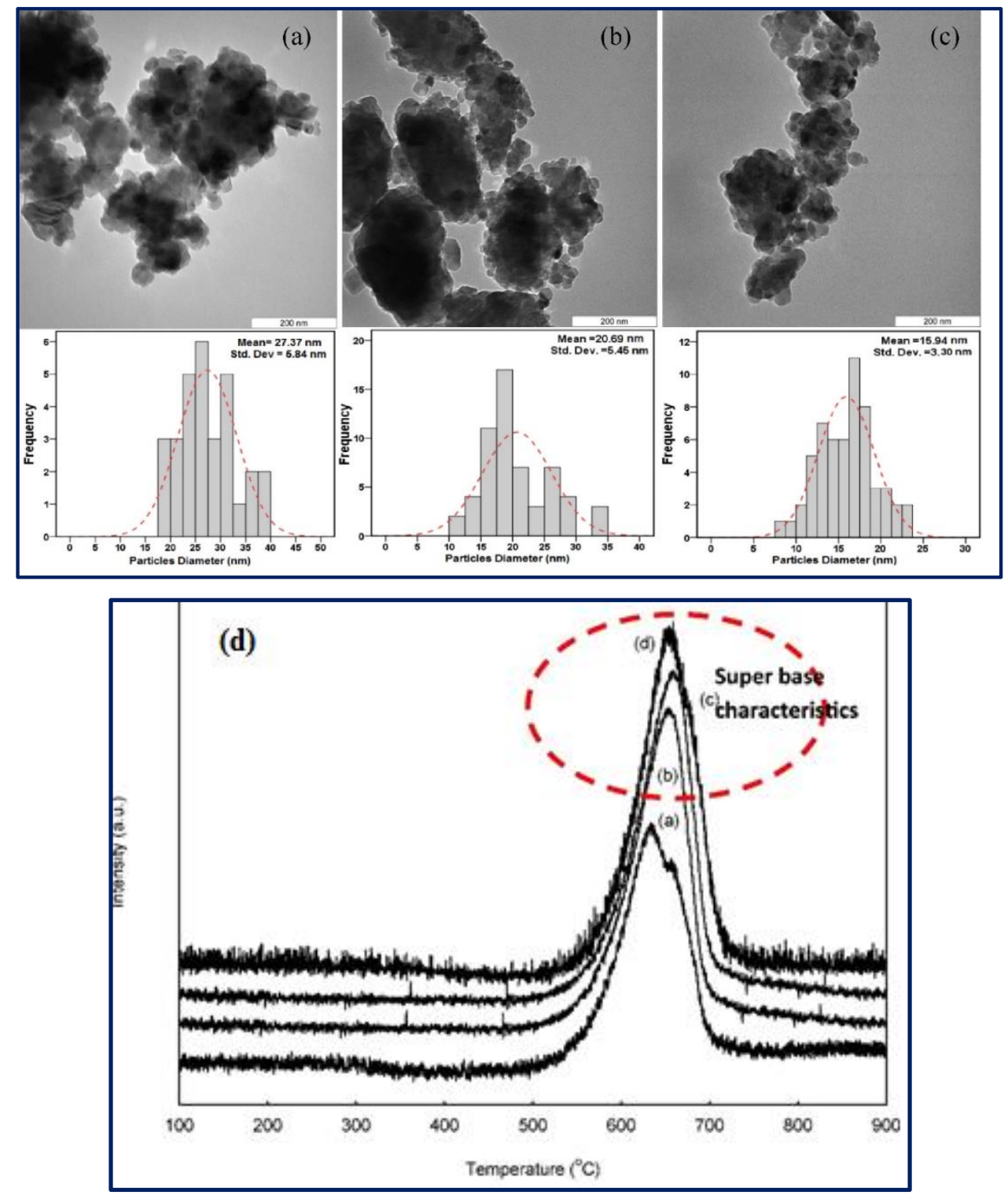

Figure 17: TEM images and particle size distributions of surfactant assistant $\mathrm{CaO}$ nanocatalysts: after $40 \mathrm{~min}(\mathrm{a})$; after $80 \mathrm{~min}$ (b) and after $120 \mathrm{~min}$ (c) and $\mathrm{CO}_{2}$ desorption performance commercial of $\mathrm{CaO}$ (a) and nano $\mathrm{CaO}$ catalysts: after $40 \mathrm{~min}$ (b); after $80 \min$ (c) and after $120 \min$ (d). Reproduced from ref. [202].

In another work, $\mathrm{A} \mathrm{Li}$ doped $\mathrm{CaO}$ catalyst derived from eggshell was examined for the transformation of nahor oil to produce FAME by Boro et al. ${ }^{208}$ They measured the FFA content in the nahor oil and found $15 \mathrm{mg} \mathrm{KOH} / \mathrm{g}$. Due to this high FFA contents, a two-step process was investigated; firstly, esterification was performed using sulfuric acid to bring down FFA amount up to $<1$ followed by transesterification reaction using $\mathrm{Li} / \mathrm{CaO}$ catalyst. They also examined the impact of Li doping on the conversion of oil to FAME and reported a maximum 
$94 \%$ conversion when the Li doping was 2 wt. \%. Recently, Rahman et al. ${ }^{209}$ modified $\mathrm{CaO}$ derived from chicken eggshell with transition metals such as $\mathrm{Zn}$ and $\mathrm{Cu}$ and applied the catalyst in the transformation of eucalyptus oil to FAME. The authors reported that the surface area and basicity of $\mathrm{Zn} / \mathrm{CaO}$ are higher than the $\mathrm{Cu} / \mathrm{CaO}$, therefore $\mathrm{Zn} / \mathrm{CaO}$ showed better result with 93.2 \% FAME yield. Moreover, the impregnation of $\mathrm{Zn}$ on $\mathrm{CaO}$ improved the stability of the catalyst and can be used for 7 consecutive cycles. In another report, a magnetically recoverable $\mathrm{KF}$ modified $\mathrm{CaO}$ derived from eggshell was prepared and employed in the transformation of neem oil to FAME. ${ }^{199}$ The author reported that the primary advantage of the catalyst is that the catalyst circumvented saponification reaction and therefore transesterification of neem oil (FFA content $4.2 \%$ ) can proceed through the one-step process, and $94.5 \%$ FAME can be achieved.

In 2010, a novel eggshell originated $\mathrm{CaO}$ impregnate on fly ash was reported for the transesterification of soybean oil to form FAME. The influence of $\mathrm{CaO}$ loading was studied by the authors and found that $30 \mathrm{wt} . \% \mathrm{CaO}$ loading showed a maximum yield of $96.97 \%$. Moreover, $\mathrm{CaO}$ supported on fly ash enhanced catalyst reusability and reactivity compared to neat eggshell originated $\mathrm{CaO}^{210} \mathrm{In}$ addition, a $\mathrm{KF}$ modified $\mathrm{CaO}$ originated from eggshell was examined for the transformation of soybean oil to FAME. The modified catalyst has higher basicity than the neat $\mathrm{CaO}$ due to the addition of $\mathrm{KOH}$ in the process. ${ }^{211}$ Recently, Chowdhury et $a .^{212}$ synthesized a Na-doped $\mathrm{CaO}$ derived from chicken eggshell and exploited it in the transesterification of Madhuca indica oil. A two-step process was employed as the oil have 45 $\%$ of FFA content. They first esterified the oil using $5 \mathrm{wt}$. \% sulfuric acid to lessen FFA content of the oil followed by transesterification using $\mathrm{Na}$-doped $\mathrm{CaO}$ catalyst. To study the influence of reaction parameters on the transformation of oil to biodiesel, Taguchi approach was used, where they observed that $\mathrm{M} / \mathrm{O}$ molar ratio and the reaction temperature have the highest impact and reaction time has the minimal impact on the transformation of oil to FAME. In 2014, Chen et al. ${ }^{213}$ demonstrated the synthesis of FAME from palm oil using $\mathrm{CaO}$ catalyst derived from ostrich egg-shell via ultrasonication. They compared the production of biodiesel using both mechanical stirring and ultrasonication process and reported that the latter case showed higher yield $(92.7 \%)$. Moreover, the catalyst can be used for 8 consecutive cycles. A transesterification process for soybean oil deodorizer distillate (SODD) to produce FAME was reported using $\mathrm{CaO}$ derived from the duck eggshell. They measured the FFA content of SODD and found $53.2 \%$, therefore to overcome the saponification problem the oil was pre-esterified with sulfuric acid and then the transesterification was performed of the pre-esterified SODD oil using $\mathrm{CaO}$ catalyst to produce FAME with an overall yield of $94.6 \% .^{2}$ In addition, $\mathrm{CaO}$ 
1080 derived from quail eggshell were also utilized for the transformation of palm oil ${ }^{214}$ and JCO 1081215 to biodiesel in high yield.

1083 Table 12: Various eggshells derived solid base catalyst for FAME production.

\begin{tabular}{|c|c|c|c|c|c|c|}
\hline No. & Catalyst source & Catalyst & Feedstock & ${ }^{a}$ Conditions & Yield $(\%)$ & Ref. \\
\hline 1. & Chicken eggshell & $\mathrm{CaO}$ & Soybean oil & $9: 1,3,65,180$ & $>95$ & 161 \\
\hline 2. & Chicken eggshell & $\mathrm{CaO}$ & Soybean oil & $\begin{array}{l}10: 1,7,57.5, \\
120\end{array}$ & 93 & 216 \\
\hline 3. & Chicken eggshell & $\mathrm{CaO}$ & Soybean oil & $8: 1,10,65,180$ & 90 & 163 \\
\hline 4. & Chicken eggshell & $\mathrm{CaO}$ & Soybean oil & $14: 1,4,60,180$ & 91 & 164 \\
\hline 5. & Ostrich eggshell & $\mathrm{CaO}$ & Karanja oil & $8: 1,2.5,65,150$ & 95 & 165 \\
\hline 6. & Chicken eggshell & $\mathrm{CaO}$ & WCO & $\begin{array}{l}22.5: 1,3.5,65, \\
330\end{array}$ & 91 & 166 \\
\hline 7. & Chicken eggshell & $\mathrm{CaO}$ & WCO & $\begin{array}{l}12: 1,1.5,65, \\
120\end{array}$ & 94 & 167 \\
\hline 8. & Chicken eggshell & $\mathrm{CaO}$ & WCO & $4: 1,2,65,120$ & NR & 168 \\
\hline 9. & Chicken eggshell & $\mathrm{CaO}$ & WFO & $9: 1,3,65,180$ & 95.05 & 169 \\
\hline 10. & Chicken eggshell & $\mathrm{CaO}$ & $\mathrm{WCO}$ & $12: 1,1.5,60,60$ & 96.23 & 191 \\
\hline 11. & Chicken eggshell & $\mathrm{CaO}$ & WCO & $24: 1,4,60,240$ & 100 & 217 \\
\hline 12. & Chicken eggshell & $\mathrm{CaO}$ & $\mathrm{WCO}$ & $12: 1,5,65,60$ & $94.52^{b}$ & 172 \\
\hline 13. & Chicken eggshell & $\mathrm{CaO}$ & WCO & $10: 1,1.5,60,50$ & 96.07 & 173 \\
\hline 14. & Chicken eggshell & $\mathrm{CaO}$ & WCO & $6: 1,3,60,30$ & 97.50 & 174 \\
\hline 15. & Chicken eggshell & $\mathrm{CaO}$ & WCO & $9: 1,5,65,165$ & 87.8 & 175 \\
\hline 16. & Chicken eggshell & $\mathrm{CaO}$ & $\mathrm{WCO}$ & $15: 1,6,65,420$ & 75.92 & 218 \\
\hline 17. & Chicken eggshell & $\mathrm{CaO}$ & Palm oil & $18: 1,10,60,90$ & $>90$ & 176 \\
\hline 18. & Chicken eggshell & $\mathrm{CaO}$ & Palm oil & $\begin{array}{l}18: 1,15,900 \mathrm{~W}, \\
4\end{array}$ & 96.7 & 177 \\
\hline 19. & Chicken eggshell & $\mathrm{CaO}$ & Palm oil & $12: 1,10,60,120$ & 94.1 & 178 \\
\hline 20. & Chicken eggshell & $\mathrm{CaO}$ & Palm oil & $6: 1,5, \mathrm{NR}, 30$ & 95 & 179 \\
\hline 21. & Chicken eggshell & $\mathrm{CaO}$ & Rape seed oil & $9: 1,3,60,180$ & 96 & 180 \\
\hline 22. & Chicken eggshell & $\mathrm{CaO}$ & Rapeseed oil & $9: 1,4,60,60$ & 95.12 & 181 \\
\hline 23. & Chicken eggshell & $\mathrm{CaO}$ & Sunflower oil & $9: 1,3,60,180$ & 96 & 182 \\
\hline
\end{tabular}




\begin{tabular}{|c|c|c|c|c|c|c|}
\hline 24. & Chicken eggshell & $\mathrm{CaO}$ & Sunflower oil & $11: 1,5,60,3$ & 83.2 & 183 \\
\hline 25. & Chicken eggshell & $\mathrm{CaO}$ & Sunflower oil & $9: 1,3,60,240$ & 97.75 & 219 \\
\hline 26. & Chicken eggshell & $\mathrm{CaO}$ & Sunflower oil & $12: 1,2,60,180$ & 100 & 185 \\
\hline 27. & Chicken eggshell & $\mathrm{CaO}$ & $\mathrm{JCO}$ & $81,2,65,150$ & 90 & 186 \\
\hline 28. & Chicken eggshell & $\mathrm{CaO}$ & $\begin{array}{l}\text { Microalgae } \\
\text { Chlorella } \\
\text { vulgaris }\end{array}$ & $\begin{array}{l}10: 1,1.39,70 \\
180\end{array}$ & 92.03 & 187 \\
\hline 29. & Chicken eggshell & $\mathrm{CaO}$ & Microalgae & $\begin{array}{l}10: 1,1.7,70 \\
216\end{array}$ & 86.41 & 188 \\
\hline 30. & Chicken eggshell & $\mathrm{CaO}$ & $\begin{array}{l}\text { Micro algae/ } \\
\text { S. armatus }\end{array}$ & $\begin{array}{l}10: 1,1.61,75, \\
240\end{array}$ & 90.44 & 189 \\
\hline 31. & Chicken eggshell & $\mathrm{CaO}$ & Chicken fat & $\begin{array}{l}13: 1,8.5,57.5, \\
300\end{array}$ & 90.41 & 190 \\
\hline 32. & Chicken eggshell & $\mathrm{CaO}$ & Catfish oil & $12: 1,1.5,60,60$ & 87.77 & 191 \\
\hline 33. & Chicken eggshell & $\mathrm{CaO}$ & $\begin{array}{l}\text { Helianthus } \\
\text { annuus L oil }\end{array}$ & $8: 1,2.5,65,120$ & 99.2 & 192 \\
\hline 34. & Chicken eggshell & $\mathrm{CaO}$ & Cotton oil & $9: 1,3,60,180$ & 98.08 & 193 \\
\hline 35. & Chicken eggshell & $\mathrm{CaO}$ & C. sativa oil & $12: 1,1,65,120$ & 97.2 & 194 \\
\hline 36. & Chicken eggshell & $\mathrm{CaO}$ & $\begin{array}{l}\text { C. } \\
\text { inophyllum } \mathrm{L} \\
\text { oil }\end{array}$ & $\begin{array}{l}9: 1,3.88, \mathrm{MW}, \\
12.47\end{array}$ & 98.90 & 195 \\
\hline 37. & Chicken eggshell & $\mathrm{CaO} / \mathrm{W} / \mathrm{Mo}$ & WCO & $15: 1,2,70,120$ & 96.2 & 196 \\
\hline 38. & Chicken eggshell & $\mathrm{CaO} /$ anthill & WCO & $6: 1,5,60,120$ & 70 & 197 \\
\hline 39. & Chicken eggshell & $\mathrm{CaO} / \mathrm{Zn}$ & WCO & $20: 1,5,65,240$ & 96.74 & 198 \\
\hline 40. & Chicken eggshell & $\begin{array}{l}\mathrm{CaO} / \mathrm{KF} / \mathrm{Fe}_{3} \\
\mathrm{O}_{4}\end{array}$ & WCO & $15: 1,6,65,120$ & 97 & 199 \\
\hline 41. & Chicken eggshell & $\begin{array}{l}\mathrm{CaO} / \mathrm{SiO}_{2} \\
\text { based on } \\
\text { PEFB }\end{array}$ & $\mathrm{WCO}$ & $14: 1,8,60,90$ & 96 & 200 \\
\hline 42. & Chicken eggshell & $\mathrm{Mo}-\mathrm{Zr} / \mathrm{CaO}$ & WCPO & $15: 1,3,80,180$ & 90.1 & 201 \\
\hline 43. & Chicken eggshell & $\mathrm{ZnO} / \mathrm{CaO}$ & $\mathrm{JCO}$ & $12: 1,5,65,60$ & 98.2 & 164 \\
\hline 44. & Chicken eggshell & $\mathrm{CaO}$ NPs & $\mathrm{JCO}$ & $6: 1,2,90,120$ & 98 & 202 \\
\hline
\end{tabular}




\begin{tabular}{|c|c|c|c|c|c|c|}
\hline 45. & Chicken eggshell & $\begin{array}{l}\mathrm{Ky}(\mathrm{MgCa})_{2 \mathrm{x}} \\
\mathrm{O}_{3}\end{array}$ & Palm oil & $\begin{array}{l}16: 1,5.53,65, \\
273\end{array}$ & 88 & 203 \\
\hline 46. & Chicken eggshell & $\mathrm{CaO} / \mathrm{SiO}_{2}$ & Palm oil & $15: 1,9,65,480$ & 80.21 & 204 \\
\hline 47. & Chicken eggshell & $\mathrm{CaO} / \mathrm{SiO}_{2}$ & Palm oil & $15: 1,3,60,120$ & 87.5 & 205 \\
\hline 48. & Chicken eggshell & $\begin{array}{l}\mathrm{CaO} / \mathrm{Rice} \\
\text { husk }\end{array}$ & Palm oil & $9: 1,7,65,240$ & 91.5 & 206 \\
\hline 49. & Chicken eggshell & $\begin{array}{l}\mathrm{CaO} / \mathrm{Cocon} \\
\text { ut waste }\end{array}$ & Palm oil & $24: 1,5,65,180$ & 81 & 207 \\
\hline 50. & Chicken eggshell & $\mathrm{Li} / \mathrm{CaO}$ & Nahor oil & $10: 1,5,65,240$ & 94 & 208 \\
\hline 51. & Chicken eggshell & $\mathrm{CaO} / \mathrm{Zn}$ & $\begin{array}{l}\text { Eucalyptus } \\
\text { oil }\end{array}$ & $6: 1,5,65,150$ & 93.2 & 209 \\
\hline 52. & Chicken eggshell & $\begin{array}{l}\mathrm{CaO} / \mathrm{KF} / \mathrm{Fe}_{3} \\
\mathrm{O}_{4}\end{array}$ & Neem oil & $15: 1,6,65,120$ & 97 & 199 \\
\hline 53. & Chicken eggshell & $\mathrm{CaO} / f l y$ ash & Soybean oil & $6.9: 1,1,70,300$ & 96.97 & 210 \\
\hline 54. & Chicken eggshell & $\mathrm{CaO} / \mathrm{KF}$ & Soybean oil & $12: 1,2,65,120$ & 99.1 & 211 \\
\hline 55. & Chicken eggshell & $\mathrm{Na} / \mathrm{CaO}$ & $\begin{array}{l}\text { Madhuca } \\
\text { indica oil }\end{array}$ & $9: 1,5,60,120$ & 81.1 & 212 \\
\hline 56. & Ostrich eggshell & $\mathrm{CaO}$ & Palm oil & $9: 1,8,60,60$ & 92.7 & 213 \\
\hline 57. & Duck eggshell & $\mathrm{CaO}$ & SODD & $10: 1,10,60,80$ & 94.6 & 2 \\
\hline 58. & Quail eggshell & $\mathrm{CaO}$ & Palm oil & $\begin{array}{l}12: 1,1.5,65 \\
120\end{array}$ & 98 & 214 \\
\hline 59. & $\begin{array}{l}\text { Quail eggshell/ } \\
\text { crab shell }\end{array}$ & $\mathrm{CaO}$ & Jatropha oil & $18: 1,4, \mathrm{MW}, 5$ & 94 & 215 \\
\hline
\end{tabular}

${ }^{a}$ Methanol-to-oil molar ratio, catalyst loading (wt. \%), temperature $\left({ }^{\circ} \mathrm{C}\right)$, reaction time (min).

$1085{ }^{b}$ Conversion

$1086 \mathrm{NR}=$ Not reported

1087 WCPO $=$ Waste cooking palm oil

\subsection{Mollusk shell and other seashells}

Mollusk shell and other seashells derived solid catalyst has been widely investigated in the transformation of edible/non-edible oils to produce biodiesel, and are listed in Table 13. Examples are a basic solid catalyst developed by impregnation of KI on the calcined oyster shell which was utilized in the transformation of soybean oil to FAME. ${ }^{116-119}$ The authors reported that impregnation and calcination increase the surface area to an extent of 32 fold and 
therefore increases the catalytic activity. The main disadvantages of the catalyst are the reusability factor and higher loading of $\mathrm{KI} \cdot{ }^{220} \mathrm{In}$ addition, there is various literature where neat $\mathrm{CaO}$ derived from oyster shell were utilized for transformation of soybean oil to FAME $^{221}$ and microwave-assisted $(800 \mathrm{~W})$ biodiesel synthesis from jatropha oil. ${ }^{222}$ Recently, a basic heterogeneous catalyst was developed from the river snail shell by calcination at $800{ }^{\circ} \mathrm{C}$ for 4 h. The catalyst was employed for the transesterification of WCO for biodiesel production. They performed $\mathrm{KOH}$ titration and found that FFA content in the $\mathrm{WCO}$ is $0.3 \%$, therefore direct transesterification was carried out and $98.19 \%$ yield was achieved under the optimal reaction conditions. ${ }^{223}$ Elsewhere other reports are also available where $\mathrm{CaO}$ derived from calcined river snail were used for the transesterification of various edible/non-edible oils, for example, palm oil, ${ }^{224}$ soybean oil ${ }^{225}$ and WFO. ${ }^{226}$

In 2016, Liu et al. ${ }^{227}$ developed a solid catalyst, where $\mathrm{KBr}$ was loaded on calcined snail shell and kaoline mixture followed by activation of the catalyst via calcination at $500{ }^{\circ} \mathrm{C}$ for $4 \mathrm{~h}$ and applied the catalyst in the transformation of soybean oil to FAME. They also investigated the effect of loading of $\mathrm{KBr}$ and wt. \% ratio of snail shell/kaoline mixture on biodiesel yield and found that the catalyst showed a maximum yield of $98.5 \%$ when the $\mathrm{KBr}$ loading and wt. \% ratio of snail shell/kaoline were $40 \mathrm{wt}$. $\%$ and $4: 1$, respectively. Mixing of snail shell and kaoline together provides the catalyst extra stability compared to their pure form ${ }^{227}$. In addition, Laskar et al. ${ }^{228}$ developed a solid basic catalyst $\mathrm{CaO}$ derived from a calcined snail shell for the conversion of soybean oil to biodiesel. Under the ideal reaction states, $98 \%$ biodiesel yield was achieved. It is reported that at $400-600{ }^{\circ} \mathrm{C}$ calcination temperature, $\mathrm{CaCO}_{3}$ of snail shell transformed to calcite. When calcination temperature was further increased to 700 and $800{ }^{\circ} \mathrm{C}$, a minor and major component of $\mathrm{CaO}$ was achieved, which was later completely transformed into $\mathrm{CaO}$ at $900{ }^{\circ} \mathrm{C}$ calcination temperature. Figure 18 reveals that $100 \%$ transformation of $\mathrm{CaCO}_{3}$ into $\mathrm{CaO}$ can be achieved above $800{ }^{\circ} \mathrm{C}$ calcination temperature. 


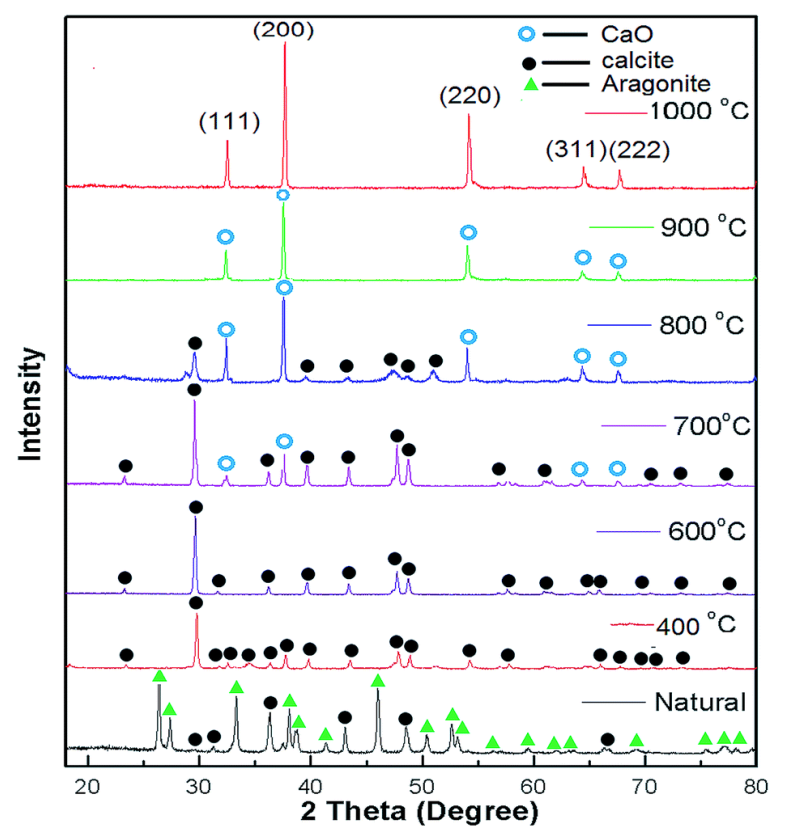

Figure 18: XRD spectra of normal and calcined (400-1000 $\left.{ }^{\circ} \mathrm{C}\right)$ snail shells.

Reproduced from ref. [228].

In another work, El-Gendy et al. ${ }^{229}$ reported $\mathrm{CaO}$ catalyst originated from snail shell calcined at $800{ }^{\circ} \mathrm{C}$ and utilized it in the transesterification reaction. RSM was utilized to investigate the influence of reaction parameters on the biodiesel production and reported that $96.76 \%$ yield was observed under the optimized reaction conditions. Similarly, various literature is available for the transesterification of WCO to FAME using $\mathrm{CaO}$ derived from snail shell collected from different sources. ${ }^{230,231}$ Very recently, Krishnamurthy et al. ${ }^{232}$ developed a solid catalyst, $\mathrm{CaO}$ nanoparticles derived from snail shell via the hydrothermal method and investigated its application in the transesterification of $H$. wightiana oil to produce FAME. However, a high FFA content $(7.57 \%)$ in the oil led the authors to follow a two-steps process: 1) pre-esterification and 2) transesterification for the production of FAME. RSM was utilized to examine the impact of reaction parameters on FAME synthesis, reported $96.92 \%$ yield under the optimal reaction conditions. In a similar vein, $\mathrm{CaO}$ derived from snail shell was also investigated for the transformation of A. africana seed oil ${ }^{233}$ and showed $85 \%$ FAME yield.

A calcined mussel/cockle/scallop shell derived $\mathrm{CaO}$ was developed for the transformation of palm oil for FAME production. The authors reported high catalyst reactivity catalytic activity with great stability towards the transesterification of palm oil with $95 \%$ conversion. ${ }^{234}$ In the meantime, Hadiyanto et al. ${ }^{235}$ developed a solid catalyst, modified $\mathrm{CaO}$ 
(derived from green mussel shell) with activated carbon (C) followed by impregnation on $\mathrm{NaOH}$ and utilized the catalyst in the transformation of palm oil. The wt. \% $\mathrm{C} / \mathrm{CaO}$ ratio of 2:3 showed the maximum yield of $95.12 \%$ under the optimal reaction conditions. Similarly, $\mathrm{KOH}$ impregnated mussel shell derived $\mathrm{CaO}$ was examined for castor oil transformation to biodiesel. The authors made a comparison between non-impregnated and $\mathrm{KOH}$ impregnated catalysts and revealed that the $\mathrm{KOH}$ impregnated catalyst displayed higher reactivity as well as basicity and reported $91.7 \%$ FAME yield using $\mathrm{KOH}$ impregnated catalyst. ${ }^{236}$ Moreover, calcined mussel shell derived catalyst were widely examined for the transformation of vegetable oils, for example, soybean oil, ${ }^{237,238}$ Chinese tallow oil, ${ }^{239}$ Camelina sativa oil ${ }^{240}$ etc., for biodiesel production.

Syazwani et al. ${ }^{241}$ examined $\mathrm{CaO}$, originated from angel wing shell (AWS) calcined at $900{ }^{\circ} \mathrm{C}$ for $2 \mathrm{~h}$, for the conversion of $N$. oculata micro-algae oil to FAME. The catalyst possessed high reactivity with great stability and can be reused for 3 consecutive cycles. Furthermore, a bifunctional catalyst was developed for conversion of palm fatty acid distillate (PFAD) to FAME. The angel wing shell was calcined to form $\mathrm{CaO}$ followed by sulfonation to afford the catalyst. The authors reported that the catalyst surface area increased to two-fold after the modification, as a result, the catalyst showed excellent activity towards the esterification of PFAD. Unfortunately, the catalyst was reusable only for two cycles as blocking of active sites occurred in each reaction cycles. Therefore to enhance the reusability of the catalyst, pretreatment of the catalyst such as washing and re-calcination are necessary before each reaction cycles. ${ }^{242}$ In 2015, Asikin-Mijan et al. ${ }^{243}$ developed a waste clam shell derived $\mathrm{CaO}$ using hydration-dehydration treatment and investigated its catalytic application in the conversion of palm oil to FAME. They also examined the effect of hydration-dehydration time on biodiesel conversion and found that higher is the hydration time higher is the catalytic activity as hydration for longer-term enhanced the formation of $\mathrm{Ca}(\mathrm{OH})_{2}$ and thus increased the basicity, reduced the crystallinity and also enhanced the surface area. They reported that the rehydration for $12 \mathrm{~h}$ showed the maximum $98 \%$ FAME yield under optimized reaction conditions. Similarly, investigation of naked $\mathrm{CaO}$ catalyst, derived from a calcined shortnecked clamshell, recorded $93 \%$ biodiesel yield under the optimal reaction conditions. ${ }^{244}$ In addition, $\mathrm{CaO}$ derived from various calcined clamshell were utilized for the transformation of diverse edible/non-edible oils, for example, palm oil, ${ }^{245,246} \mathrm{WFO}^{247}$ etc., to produce biodiesel. A solid ethanol-treated catalyst $\mathrm{CaO}$, derived from calcined abalone shell was examined for production of FAME from palm oil. The authors investigated the impact of ethanol treatment at different temperature $\left(\mathrm{RT}, 100{ }^{\circ} \mathrm{C}\right.$ and $\left.160{ }^{\circ} \mathrm{C}\right)$ and found that the catalyst treated 
with ethanol at $100{ }^{\circ} \mathrm{C}$ showed the maximum yield of $96.2 \%$ as ethanol treatment provides high basicity, high surface area and lowered the catalyst crystallinity. Moreover, comparison of modified $\mathrm{CaO}$ with naked $\mathrm{CaO}$ showed that modified $\mathrm{CaO}$ has higher reusability and provided higher biodiesel yield. ${ }^{248}$ In addition, there are several reports available in literature regarding the transesterification of palm oil to FAME utilizing $\mathrm{CaO}$ based solid catalyst originated from various waste shells such as T. jourdani shell, ${ }^{249}$ A. cristatum shell, ${ }^{250}$ cockle shell ${ }^{251}$ and obtuse horn shell ${ }^{252}$ etc.

In 2009, Xie et al. ${ }^{253}$ synthesized a solid catalyst via three-step: i) incomplete carbonization of a biont shell at $500{ }^{\circ} \mathrm{C}$, ii) $\mathrm{KF}$ impregnation and iii) catalyst activation at 300 ${ }^{\circ} \mathrm{C}$. The developed catalyst was utilized for conversion of rapeseed oil to FAME. They reported that the catalyst displayed excellent reactivity due to the formation of a higher amount of active sites during the reaction between incomplete carbonized shell and KF. The effect of KF loading was also examined and found that $25 \% \mathrm{KF}$ loading is optimal and showed $97 \%$ FAME yield under the optimized reaction conditions. Correspondingly, Boro et al. ${ }^{254}$ demonstrated the synthesis of $\mathrm{CaO}$ catalyst by calcination of Turbonilla striatula shell and utilized it for transformation of mustard oil to FAME. The effect of calcination temperature was examined and observed that the catalyst calcined at $900{ }^{\circ} \mathrm{C}$ displayed maximum $93.3 \%$ FAME yield. In addition, $\mathrm{CaO}$ derived from calcined Turbonilla striatula was modified with $\mathrm{Ba}$ in the range of 0.5-1.5 wt. \% and utilized it for the transformation of WCO to biodiesel. Due to the high acid value $22 \mathrm{mg} \mathrm{KOH} / \mathrm{g}$, the oil was pretreated with sulfuric acid to reduce the acid value $<1$. Then the pretreated oil was transesterified with $\mathrm{Ba} / \mathrm{CaO}$ catalyst. The authors also examined the effect of Ba loading and found that $1 \%$ of Ba doped showed $>98 \%$ biodiesel yield. ${ }^{255}$ In addition, Chicoreus brunneus shell was calcined above $800{ }^{\circ} \mathrm{C}$ to convert $\mathrm{CaCO}_{3}$ to $\mathrm{CaO}$ followed by hydration/dehydration to form a solid base catalyst and examined it for the transformation of rice bran oil. Calcination and hydration provide the catalyst high porosity, enhances the basicity, catalytic activity and reusability. ${ }^{256}$ In addition, shrimp shell originated catalysts has also been utilized for transformation of various edible/non-edible oils to FAME. Yang et al. ${ }^{257}$ synthesized a catalyst via a three steps processes; (i) inadequate carbonization of shrimp shell, (ii) reaction with KF and (iii) activation of the catalyst under the heating condition for the rapeseed oil transformation. The authors examined the impact of carbonization temperature, $\mathrm{KF}$ amount and activation temperature and found that $89.1 \%$ biodiesel was achieved under the reaction states: carbonization temperature of $450{ }^{\circ} \mathrm{C}, \mathrm{KF}$ amount of 25 wt. $\%$ and an activation temperature of $250{ }^{\circ} \mathrm{C}$. The excellent catalyst reactivity is attributable to the formation of active sites during the reaction between incomplete 
carbonized shrimp shell and KF. Moreover, a solid catalyst, $\mathrm{CaO}$ nanoparticles with a diameter of $66 \mathrm{~nm}$ derived from Polymedosa erosa shell via calcination-hydration-dehydration process was developed for the transformation of JCO to FAME in a two-step procedure: 1) preesterification and 2) transesterification. The influence of reaction parameters on the oil conversion was examined by RSM technique and displayed 98.54 \% FAME yield. ${ }^{258}$

In the recent past, Sivakumar et al. ${ }^{259}$ developed a solid catalyst derived from Scylla Tranquebarica crab shell calcined at $750{ }^{\circ} \mathrm{C}$ for sunflower oil transformation to FAME. The developed catalyst displayed similar reactivity to that of commercial $\mathrm{CaO}$ and reported a very high conversion of $94.2 \%$ under the optimal reaction conditions. Similarly, Shankar et al. ${ }^{260}$ prepared a solid catalyst where $\mathrm{CaO}$ (derived from crab shell calcined at $900{ }^{\circ} \mathrm{C}$ ) impregnated on Na-ZSM-5 followed by activation at $550{ }^{\circ} \mathrm{C}$ for $10 \mathrm{~h}$ and utilized it for production of FAME from neem oil. The impact of $\mathrm{CaO}$ loading was examined and found that 15 wt. \% $\mathrm{CaO}$ impregnation showed a maximum $95 \%$ biodiesel formation. Moreover, various reports are available for the transesterification of edible/non-edible oils such as palm oil ${ }^{261}$ and karanja oil ${ }^{262}$ utilizing $\mathrm{CaO}$ originated from calcined crab shells.

Table 13: Various mollusk and seashells derived solid catalyst for biodiesel production.

\begin{tabular}{|c|c|c|c|c|c|c|}
\hline No. & Catalyst source & Catalyst & Feedstock & ${ }^{a}$ Conditions & $\begin{array}{l}\text { Yield } \\
(\%)\end{array}$ & Ref. \\
\hline 1. & Oyster shell & $\mathrm{CaO} / \mathrm{KI}$ & Soybean & $\begin{array}{l}10: 1,1 \mathrm{mmol} / \mathrm{g}, \\
50,240\end{array}$ & 79.5 & 220 \\
\hline 2. & Oyster shell & $\mathrm{CaO}$ & Soybean oil & $6: 1,25,65,300$ & 73.8 & 221 \\
\hline 3. & $\begin{array}{l}\text { Oyster and } \\
\text { Pyramidella } \\
\text { shells }\end{array}$ & $\mathrm{CaO}$ & Jatropha oil & $15: 1,4, \mathrm{MW}, 6$ & 93 & 222 \\
\hline 4. & River snail shell & $\mathrm{CaO}$ & WCO & $9: 1,3,65,60$ & $92.5^{b}$ & 223 \\
\hline 5. & River snail shell & $\mathrm{CaO}$ & Palm oil & $12: 1,5,65,90$ & 98.5 & 224 \\
\hline 6. & River snail shell & $\mathrm{CaO}$ & Soybean oil & $9: 1,3^{c}, 65,180$ & 98 & 225 \\
\hline 7. & River snail shell & $\mathrm{CaO}$ & WFO & $\begin{array}{l}6.03: 1,2,60, \\
420\end{array}$ & 87.28 & 226 \\
\hline 8. & Snail shell & $\begin{array}{l}\mathrm{CaO} / \mathrm{KBr} / \mathrm{k} \\
\text { aolin }\end{array}$ & Soybean oil & $6: 1,2,65,120$ & 98.5 & 227 \\
\hline 9. & Snail shell & $\mathrm{CaO}$ & Soybean oil & $6: 1,3, \mathrm{RT}, 420$ & 98 & 228 \\
\hline
\end{tabular}




\begin{tabular}{|c|c|c|c|c|c|c|}
\hline 10 . & Snail shell & $\mathrm{CaO}$ & WFO & $6: 1,3,60,60$ & 96 & 229 \\
\hline 11. & Snail shell & $\mathrm{CaO}$ & WCO & $9: 1,9,60,180$ & 84.14 & 230 \\
\hline 12. & $\begin{array}{l}\text { Snail shell ( } S \text {. } \\
\text { canarium) }\end{array}$ & $\mathrm{CaO}$ & WCO & $12: 1,3,65,240$ & 83.5 & 231 \\
\hline 13. & Snail shell & Nano-CaO & $\begin{array}{l}\text { H. wightiana } \\
\text { oil }\end{array}$ & $\begin{array}{l}12.4: 1,0.892, \\
61.6,145.154\end{array}$ & 98.93 & 232 \\
\hline 14. & Snail shell & $\mathrm{CaO}$ & $\begin{array}{l}\text { A. africana } \\
\text { seed oil }\end{array}$ & $6: 1,1.5,55,65$ & 85 & 233 \\
\hline 15. & $\begin{array}{l}\text { Mussel/cockle/sc } \\
\text { allop shell }\end{array}$ & $\mathrm{CaO}$ & Palm oil & $9: 1,10,65,180$ & 95 & 234 \\
\hline 16. & $\begin{array}{l}\text { Mussel shell } \\
\text { (Perna varidis) }\end{array}$ & $\begin{array}{l}\mathrm{C} / \mathrm{CaO} / \mathrm{Na} \\
\mathrm{OH}\end{array}$ & Palm oil & $\begin{array}{l}0.5: 1,7.5,65 \\
180\end{array}$ & 95.12 & 235 \\
\hline 17. & Mussel shell & $\mathrm{CaO} / \mathrm{KOH}$ & Castor oil & $6: 1,2,60,180$ & 91.17 & 236 \\
\hline 18. & Mussel shell & $\mathrm{CaO}$ & Soybean oil & $24: 1,12,60,480$ & 94.1 & 237 \\
\hline 19. & Mussel shell & $\mathrm{CaO}$ & Soybean oil & $9: 1,4,65,180$ & $>98^{b}$ & 238 \\
\hline 20. & $\begin{array}{l}\text { Fresh water } \\
\text { mussel shell }\end{array}$ & $\mathrm{CaO}$ & $\begin{array}{l}\text { Chinese tallow } \\
\text { oil }\end{array}$ & $12: 1,5,70,90$ & 97.5 & 239 \\
\hline 21. & $\begin{array}{l}\text { Mussel/clamp/oys } \\
\text { ter }\end{array}$ & $\mathrm{CaO}$ & $\begin{array}{l}\text { Camelina } \\
\text { sativa oil }\end{array}$ & $12: 1,1,65,120$ & $\begin{array}{l}95 / 93 \\
/ 91\end{array}$ & 240 \\
\hline 22. & Angel wing shell & $\mathrm{CaO}$ & $\begin{array}{l}\text { N. oculata } \\
\text { (Microalgae) } \\
\text { oil }\end{array}$ & $150: 1,9,65,60$ & 84.11 & 241 \\
\hline 23. & Angel wing shell & $\mathrm{CaO}-\mathrm{SO}_{4}$ & PFAD & $15: 1,5,80,180$ & $98^{b}$ & 242 \\
\hline 24. & Clamshell & $\mathrm{CaO}$ & Palm oil & $9: 1,1,65,120$ & 98 & 243 \\
\hline 25 . & $\begin{array}{l}\text { Short necked } \\
\text { clam }(O . \\
\text { orbiculata }) \text { shell }\end{array}$ & $\mathrm{CaO}$ & $\mathrm{JCO}$ & $20: 1,4,65,360$ & 93 & 244 \\
\hline 26. & $\begin{array}{l}\text { Clamshell ( } M . \\
\text { mereterix) }\end{array}$ & $\mathrm{CaO}$ & WFO & $6.03: 1,3,60,180$ & $>89$ & 245 \\
\hline 27. & $\begin{array}{l}\text { White bivalve } \\
\text { clamshell }\end{array}$ & $\mathrm{CaO}$ & WFO & $18: 1,8,65,180$ & 95.84 & 246 \\
\hline
\end{tabular}


28. Venus clam

$\mathrm{CaO}$

Palm oil

$15: 1,5,65,360$

247

(Tapes belcheri

S.)

29. Abalon shell

$\mathrm{CaO}$

Palm oil

$9: 1,7,65,150$

$96.2 \quad 248$

30. T. jourdani shell

$\mathrm{CaO}$

Palm oil

$3: 1,10,80,420 \quad 99.33 \quad 249$

31. A. cristatum shell $\mathrm{CaO}$

Palm oil

$8: 1,3,60,360 \quad 93 \quad 250$

32. Cockleshell

$\mathrm{CaO}$

Palm oil

0.54:1,

$4.9, \quad 99.4 \quad 251$

reflux, 180

33. Obtuse horn shell $\mathrm{CaO} \quad$ Palm oil

$12: 1, \quad 5$, reflux, $86.75 \quad 252$

360

34. Biont (turtle)

$\mathrm{CaO} / \mathrm{KF} \quad$ Rape seed oil

$9: 1,3,70,180$

$97.5 \quad 253$

shell

35. Turbonilla

$\mathrm{CaO}$

Mustard oil

$9: 1,3,65 \pm 5,360 \quad 93.3$

254

striatula shell

36. Turbonilla

$\mathrm{CaO} / \mathrm{Ba} \quad \mathrm{WCO}$

$6: 1,1,65,120>98^{b}$

255

striatula shell

37. Chicoreus

$\mathrm{CaO}$

Rice bran oil

$30: 1,0.4,65,120 \quad 93$

256

brunneus shell

38. Shrimp shell

$\mathrm{CaO} / \mathrm{KF} \quad$ Rape seed oil

$9: 1,2.5,65,180$

$89.1^{b}$

257

39. P. erosa seashells

Nano-CaO Jatropha oil

5.15:1, 0.02, RT, $95.8 \quad 258$

133.1

40. Crab shell $(S . \quad \mathrm{CaO} \quad$ Sunflower oil $\quad 12: 1,8,95,75 \quad 94.2 \quad 259$ tranquebarica)

41. Crab shell

$\mathrm{CaO} / \mathrm{Na}-\quad$ Neem oil

$12: 1,15,75,360 \quad 95$

260

ZSM-5

42. Crab shell $(S$.

$\mathrm{CaO}$

Palm oil

$0.5: 1,5,65,150 \quad 98.8 \quad 261$ serrata)

43. Crab shell

$\mathrm{CaO}$

Karanja oil

$8: 1,2.5,65,120 \quad 94$

262

${ }^{a}$ Methanol-to-oil molar ratio, catalyst loading (wt. \%), temperature $\left({ }^{\circ} \mathrm{C}\right)$, reaction time (min).

${ }^{b}$ Conversion

$1226{ }^{c} \mathrm{~W} / \mathrm{W}$

$1227 \quad \mathrm{PFAD}=$ palm fatty acid distillate 


\subsubsection{Ashes of biomass}

In recent years, the application of waste plant ashes as a highly active heterogeneous catalyst has drawn increasing attention in the realm of biodiesel production. A huge amount of alkali or alkaline earth elements mostly $\mathrm{K}, \mathrm{Ca}$ and $\mathrm{Mg}$ present in the ashes of waste plant biomass acted as a highly basic catalyst in the transesterification reaction to produce biodiesel from vegetable oil with low FFA. In case of vegetable oil with high FFA, reduction of FFA to $<1 \%$ (by acid-catalyzed esterification) before transesterification reaction is mandatory to elude catalyst consumption in soap formation, which otherwise leads to low biodiesel yield. Usually, biomass is collected, washed and dried either in oven or sunlight, burnt in the open air or burnt in the air followed by calcination to produce a highly basic ash catalyst as shown in Figure 19. Different basic ash catalysts utilized and their efficacy in the synthesis of biodiesel are presented in Table 14. In a pioneering work, Chouhan et al. ${ }^{263}$ reported the use of amphibian plant L. perpusilla Torrey ash as a solid catalyst in biodiesel synthesis from JCO. The plant biomass was subjected to calcination at $550 \pm 5{ }^{\circ} \mathrm{C}$ for $2 \mathrm{~h}$ to obtain the ash catalyst. The crystallinity of the catalyst was affirmed by XRD patterns. Impact of catalyst loading revealed that 5 wt. \% (w.r.t. oil) is enough to obtain a high $89.43 \%$ biodiesel yield under the optimal reaction conditions. Nevertheless, reusability study demonstrated that the catalyst lost its reactivity in each progressive reaction cycles owing to leaching of the reactive elements in the catalyst. Thereby, the catalyst was recycled up to 3 cycles only.

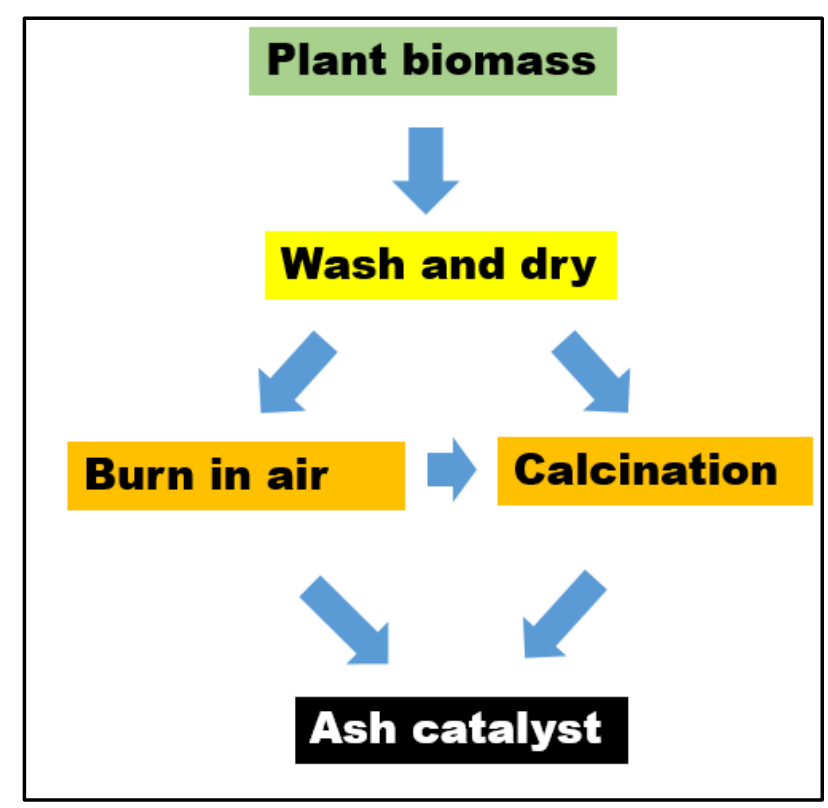

Figure 19: Flowchart for the synthesis of ash catalyst derived from plant biomass. 
In another work, oil palm ash was seen as an active catalyst for biodiesel synthesis from 1251 WCO by Chin et al. ${ }^{264}$ Figure 20 depicted the SEM micrograph of the palm ash, which 1252 displayed the porous nature of the ash catalyst, while Table 15 listed the elements exist in the 1253 palm ash determined from the EDX analysis. It was observed that the palm ash consisted of a 1254 large amount of potassium, while a relatively low quantity of aluminum, zinc, and magnesium 1255 was also found. Besides, it was seen that the $\mathrm{K}_{2} \mathrm{O}$ was the primary driver for the high basicity and catalytic activity of the catalyst towards biodiesel synthesis. CCD was utilized to 1257 investigate the impact of the optimized reaction conditions in biodiesel synthesis such as M/O ratio, reaction time and temperature and catalyst loading. Accordingly, the predicted and experimental biodiesel yields were found to be $60.07 \%$ and $71.74 \%$ respectively.

1260

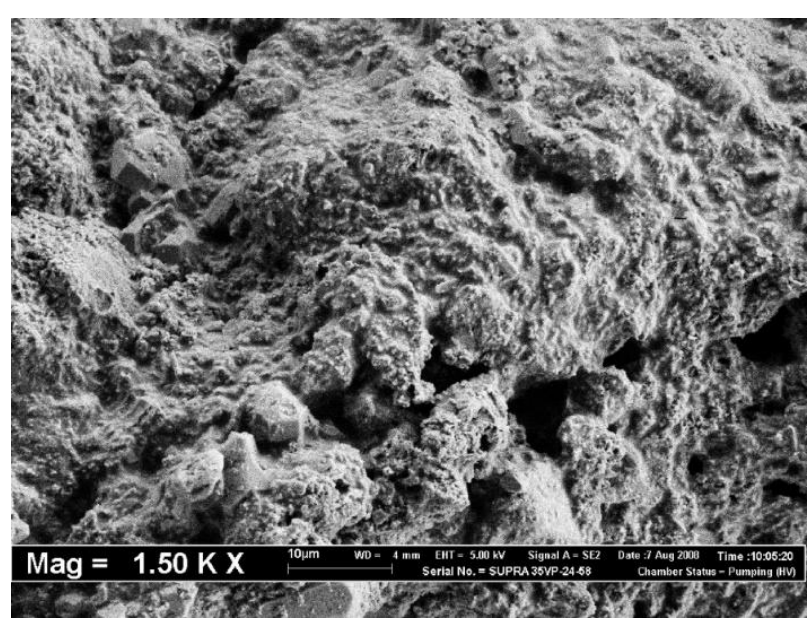

Figure 20: SEM micrograph of palm ash.

Reproduced from ref ${ }^{264}$.

Table 15. EDX data for compositions of palm ash by. Ref. [264].

\begin{tabular}{cc}
\hline Elements & Atomic wt. \% \\
\hline Potassium $(\mathrm{K})$ & 40.59 \\
Magnesium $(\mathrm{Mg})$ & 0.76 \\
Silicone $(\mathrm{Si})$ & 2.63 \\
Aluminum $(\mathrm{Al})$ & 0.50 \\
Zinc $(\mathrm{Zn})$ & 0.33 \\
Oxygen $(\mathrm{O})$ & 29.36 \\
Carbon $(\mathrm{C})$ & 14.56
\end{tabular}


In the meantime, Boey et al. ${ }^{265}$ reported a solid base, derived from boiler ash (BA) via calcination, catalyzed biodiesel synthesis from palm oil. BA effectively transformed palm oil to FAME at moderate reaction conditions and delivered 90\% FAME yield. Ironically, the ash is intolerant to the presence of moisture and FFA at $1 \mathrm{wt} . \%$ in the feedstock. Betiku et al. ${ }^{266}$ reported a process for biodiesel synthesis from Thevetia peruviana oil by utilizing calcined Musa paradisiacal (plantain) peel ash catalyst. The dried powdered plantain peels were calcined at $500{ }^{\circ} \mathrm{C}$ for $3.5 \mathrm{~h}$ to produce plantain peels ash. Biodiesel yield of $95.2 \%$ was acquired using the optimized reaction conditions. In addition, Etim et al. ${ }^{267}$ utilized ripe plantain fruit peel as a solid catalyst in biodiesel synthesis from Azadirachta indica oil. At the onset, pre-esterification of the oil was performed to diminish the FFA contents from $5.81 \mathrm{wt}$. $\%$ to 0.90 wt. \% utilizing M/O molar ratio of 2.19 v/v and 6 wt. \% of $\mathrm{Fe}_{2}\left(\mathrm{SO}_{4}\right)_{3}$. Finally, the pre-esterified oil was transformed to FAME via transesterification reaction catalyzed by plantain fruit peel ash. Coconut husk ash catalyst was also reported for biodiesel synthesis from JCO ${ }^{268}$ The husks were subjected to calcination at various temperatures ranging from $250-500$ ${ }^{\circ} \mathrm{C}$ and identified that catalyst produced at $350{ }^{\circ} \mathrm{C}$ calcination temperature was found to be the most reactive one for biodiesel synthesis giving $99.86 \%$ yield within $30 \mathrm{~min}$ at the moderate reaction temperature. XRD patterns of the catalysts are presented in Figure 21 which revealed the presence of several components of ash such as $\mathrm{KCl}, \mathrm{K}_{2} \mathrm{Si}_{2} \mathrm{O}_{5}, \mathrm{~K}_{2} \mathrm{SO}_{4}, \mathrm{~K}_{2} \mathrm{~S}_{3}, \mathrm{KAlO}_{2}$, $\mathrm{K}_{4} \mathrm{CaSi}_{3} \mathrm{O}_{9}, \mathrm{FeCa}_{2} \mathrm{Al}_{2} \mathrm{BSi}_{4} \mathrm{O}_{15} \mathrm{OH}$, etc.

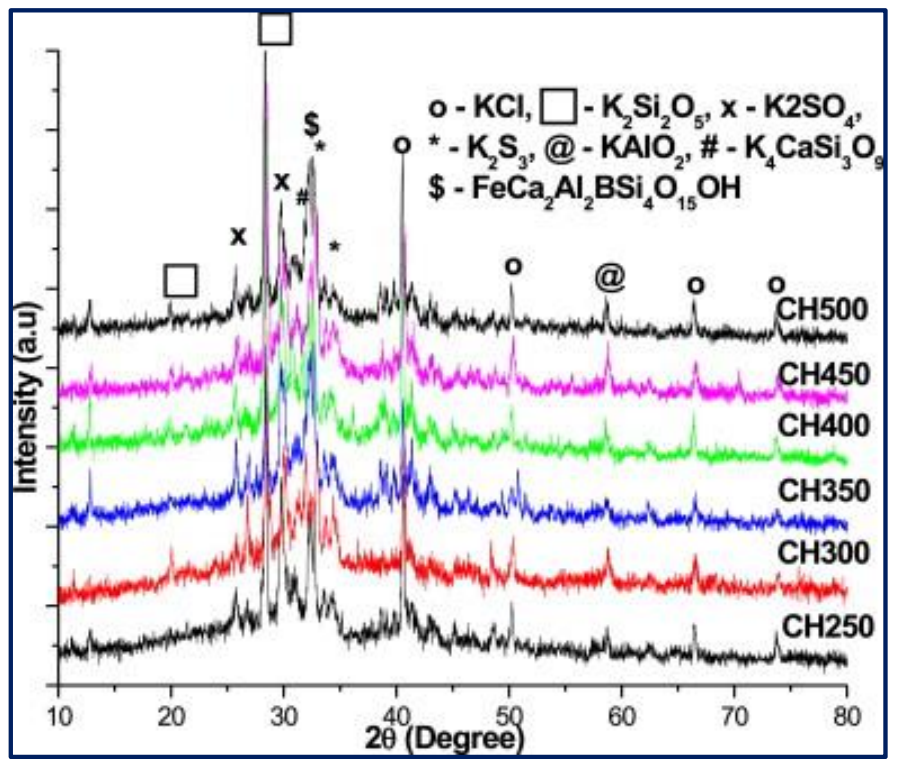


Figure 21: XRD patterns of calcined coconut husk calcined at different temperatures. Reproduced from ref $^{268}$.

1283

Cocoa pod husks (CPHs) was used as a solid catalyst for biodiesel synthesis from soybean oil by Ofori-Boateng et al. ${ }^{269}$ The authors examined the reactivity of $\mathrm{MgO}$ impregnated $\mathrm{CPH}(\mathrm{MgO} @ \mathrm{CPH})$ and bare $\mathrm{CPH}$ in biodiesel synthesis under the optimal reaction states and achieved $98.7 \%$ and $91.4 \%$ biodiesel yields respectively. Moreover, the synthesized fuel satisfies the European biodiesel quality norm (EN 14112). In another study, the production of biodiesel from yellow oleander (Thevetia peruviana) seed oil using banana (Musa balbisiana Colla) peel ash was reported. ${ }^{270} \mathrm{~K}, \mathrm{Na}, \mathrm{CO}_{3}, \mathrm{Cl}$ present in the ash are responsible for the high basicity, thus the reactivity of the catalyst. Oil transformation of $96 \%$ was demonstrated in just $3 \mathrm{~h}$ time under room temperature. The produced biodiesel conform to standards set for ASTM D6751, EN 14214 and so forth. BET surface area measurement of the catalyst revealed that the surface area is $1.487 \mathrm{~m}^{2} / \mathrm{g}$. The biodiesel was free from sulfur and has displayed a high cetane number. Meanwhile, Musa balbisiana Colla underground stem (MBCUS) ash was examined as a solid base catalyst for biodiesel synthesis from high FFA containing JCO by Sharma et al. ${ }^{271}$ Characterization of the ash catalyst revealed that it is comprised of oxides and carbonates of various alkali and alkaline earth metals, which leads to the high basicity of the catalyst and surface area is $39 \mathrm{~m}^{2} / \mathrm{g}$. It was reported that the catalyst is very effective during the biodiesel synthesis process at $275^{\circ} \mathrm{C}$ and internal pressure (4.2 $\mathrm{MPa}$ ) and resulted in $98.0 \%$ biodiesel yield.

Betiku et al. ${ }^{272}$ led an investigation on the application of banana (Musa'Gross Michel') peel waste as a catalyst for biodiesel synthesis from Bauhinia monandra (Napoleon's plume) seed oil (BMSO), with a motive to develop a low-cost fuel. The burnt ash of the banana peel was further calcined at $700{ }^{\circ} \mathrm{C}$ for $4 \mathrm{~h}$ to produce a highly active catalyst. They have utilized RSM model to determine the optimal reaction conditions for biodiesel synthesis using the ash catalyst. The RSM plot of M/O molar ratio and catalyst loading on Bauhinia monandra (Napoleon's plume) methyl ester (BMME) yield is shown in Figure 22a. It is observed that BMME yield improved from 0 to $>90 \mathrm{wt}$. $\%$ as the M/O molar ratio expanded from 7:1 to 14:1 and catalyst loading increased from 1.5 to $3.5 \mathrm{wt}$. \%. This might be ascribed to the increase in active sites number as a result of increased in catalyst loading. Besides, BMME yield diminished marginally when the catalyst loading was above 3.5 wt. \% (Figure 22a). In addition, the plot revealed a direct connection between the M/O molar ratio and catalyst loading on the 

biodiesel yield. As the two parameters increases, biodiesel yield also increased (Figure 22a). 1315 The transformation of the pre-esterified oil to biodiesel was done inside the time span of 33.79$131676.21 \mathrm{~min}$. The extended reaction time, somewhere in the range of 33.79 and $55 \mathrm{~min}$, favoured 1317 biodiesel yield; after $55 \mathrm{~min}$, the yield diminished. Figure 22b displays the impact of reaction 1318 time and catalyst loading on biodiesel yield. It is observed from the surface plot that rise in 1319 catalyst loading and reaction time leads to an increase in biodiesel yield. Moreover, the plot 1320 displayed that 90 wt. \% biodiesel yield is reached using 4.5 wt. \% catalyst loading within 80 1321 min reaction time. In addition, Figure 22c illustrates the surface plot to examine the impact of $1322 \mathrm{M} / \mathrm{O}$ molar ratio and reaction time on biodiesel yield. It is observed from the plot that increases 1323 in two parameters such as M/O molar ratio and reaction time leads to a rise in biodiesel yield. 1324 It is seen from the figure that increases in M/O molar ratio from 7:1-14:1 improved the biodiesel 1325 yield from $33 \%$ to $100 \%$. Therefore, the highest biodiesel yield was recorded at 14:1 M/O 1326 molar ratio and 80 min reaction time. 


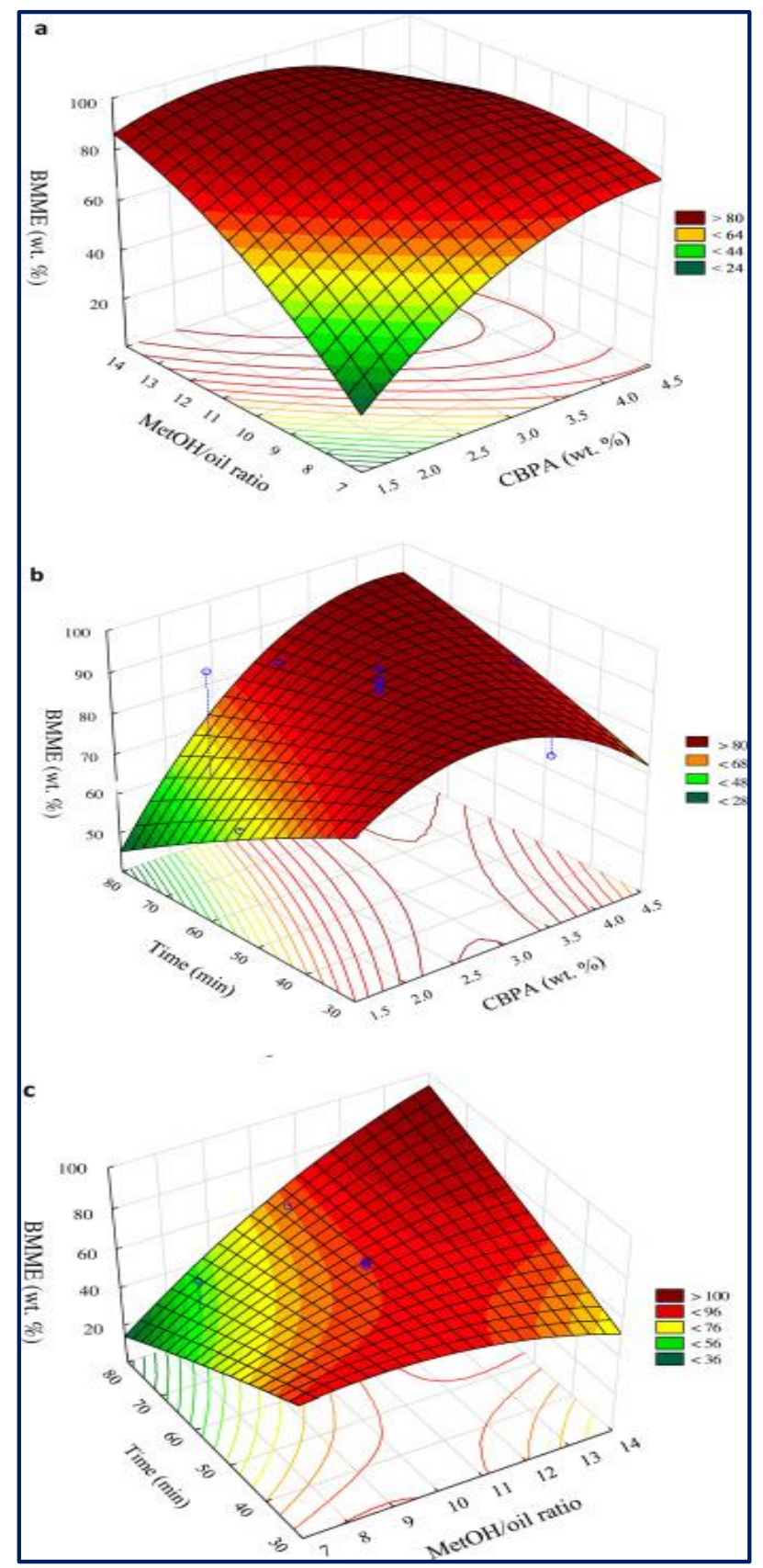

Figure 22: 3-D plots of biodiesel yield.

Reproduced from ref. [272].

Meanwhile, Onoji et al. ${ }^{273}$ built up a novel technique to utilize rubber seed shell (RSS) 1330 ash calcined at $800{ }^{\circ} \mathrm{C}$ as a solid base catalyst for the transformation of rubber seed oil to biodiesel. The high FFA content of the RSS $(9.01 \pm 0.07 \%)$ was pre-esterified using $\mathrm{H}_{2} \mathrm{SO}_{4}$ to $>1 \%$ FFA. Reusability study of the catalyst revealed that $>80 \%$ biodiesel yield was noticed after 4 successive reaction cycles. The surface area and pore size of the calcined RSS was found to be $2.29 \mathrm{~nm}$ and $352.51 \mathrm{~m}^{2} / \mathrm{g}$, respectively. Similarly, Gohain et al. ${ }^{274}$ studied the application of Musa balbisiana Colla peel ash catalyst to produce biodiesel from WCO. It was observed 
that the calcination procedure improved the mesoporous and microporous morphology of the catalyst and upgraded its surface area bringing about the higher catalytic activity. The external morphology of the catalyst examined by SEM analysis revealed aggregation of the particles and porosity in the range of micro and meso. Moreover, $100 \%$ conversion of WCO to biodiesel was confirmed by ${ }^{1} \mathrm{H}$ NMR spectra (Figure 23b) utilizing Knothe and Kenar equation (1). The ${ }^{1} \mathrm{H}$ NMR spectrum of WCO (Figure 18a) displays two peaks at 4.1 and 5.3 ppm because of the glyceridic protons (Figure 23a). The presence of peak of methoxy protons at $\sim 3.6 \mathrm{ppm}$ and vanishing of the signs of glyceridic peak close to $4-4.2 \mathrm{ppm}$ (Figure 18b) confirmed the formation of biodiesel.

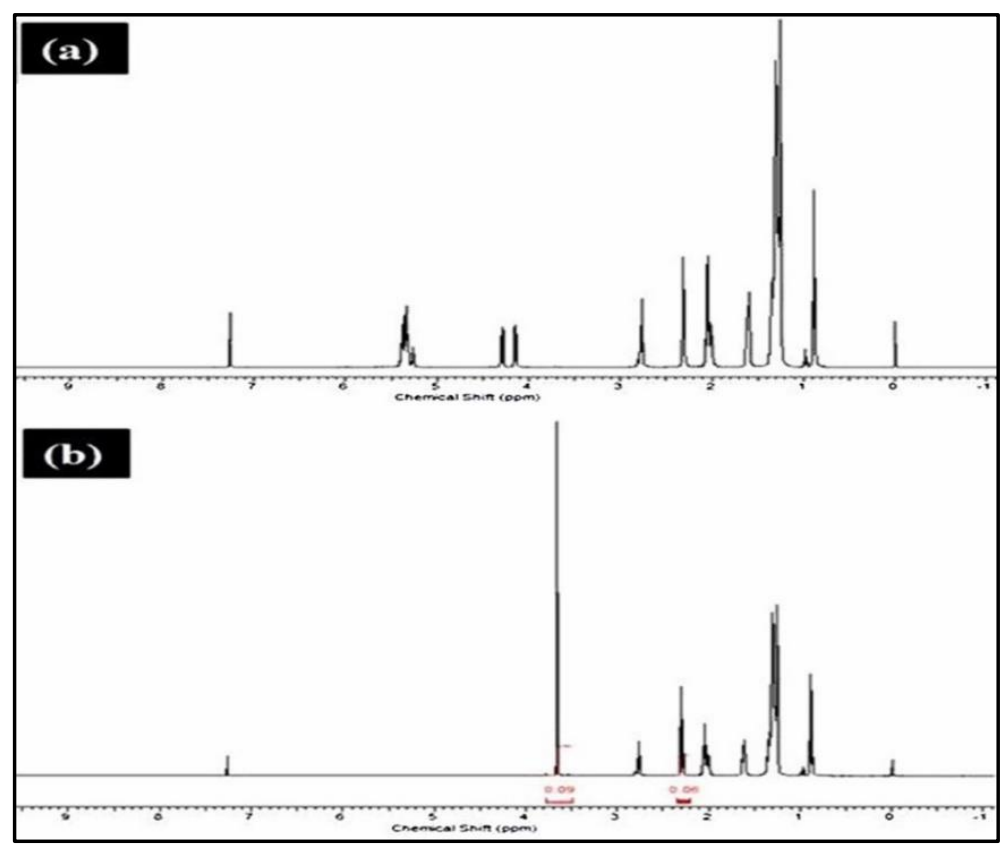

Figure 23: ${ }^{1} \mathrm{H}$ NMR Spectrum of (a) WCO and (b)

Biodiesel. Reproduced from ref. [274].

In the recent year, Pathak et al. ${ }^{275}$ utilized Musa acuminata peel ash (MAPA) catalyst for biodiesel synthesis from soybean oil at room temperature. Catalyst characterization reported the existence of various alkali and alkaline earth metals that enhance the catalyst basicity and reactivity of the ash catalyst. K (14.27\%), C (47.51\%) and O (30.27\%) are the primary/main elements exist in MAPA as revealed by the XPS data (Figure 24). The authors reported $98.95 \%$ biodiesel yield under the optimized reaction conditions. 

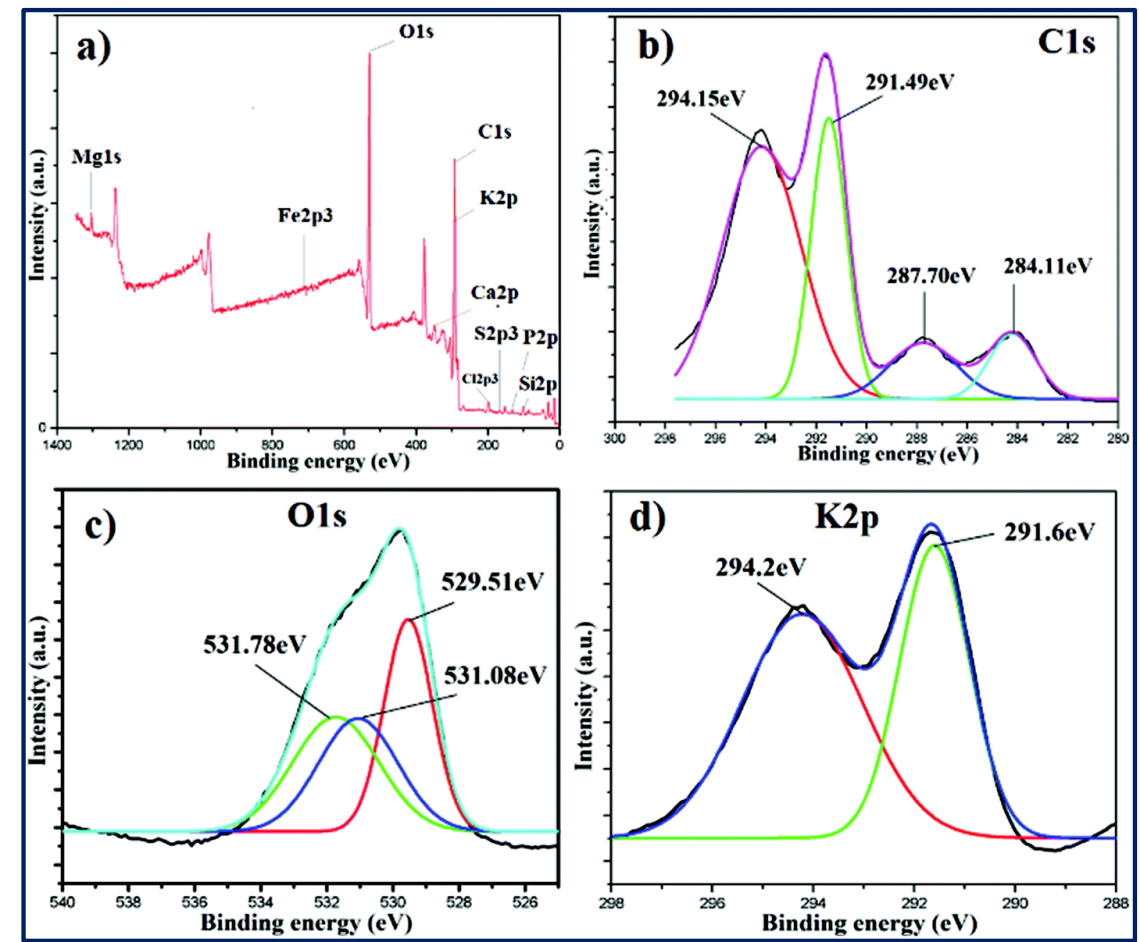

Figure 24: XPS survey (a), C 1s (b), O 1s (c), and K 2p (d) spectra of MAPA. Reproduced from ref. [275].

Sharma et al. ${ }^{276}$ investigated the reactivity of wood ash catalyst calcined at different temperature for biodiesel synthesis from JCO. Ester conversion in the range of 97-99\% could be achieved with wood ash catalysts. Wood ash calcined at $800{ }^{\circ} \mathrm{C}$ afforded $98.7 \%$ oil conversion under the ideal reaction conditions. Uprety et al. ${ }^{277}$ studied the application of wood ash derived from birch bark and fly ash blazed at $800{ }^{\circ} \mathrm{C}$ for $4 \mathrm{~h}$ synthesis of biodiesel from palm oil. Birch bark ash gave FAME yield of $88.06 \pm 0.72$, whereas, fly ash from wood pellet afforded $99.92 \pm 0.01 \%$ yield. Recently, the application of banana peduncle ash as an efficient solid base catalyst for the synthesis of biodiesel from Ceiba pentandra oil (CPO) was investigated. ${ }^{278}$ Based on the response surface methodology (RSM) study, the ideal reaction conditions for the transformation of CPO into FAME was found to be $1.978 \mathrm{wt}$ \% catalyst loading, 60 min response time, 9.20:1 M/O molar ratio with a maximum predicted FAME yield of $99.36 \%$ which was assessed experimentally as $98.69 \pm 0.18 \%$. The same research team also investigated the utilization of Musa acuminata peduncle for biodiesel preparation from CPO. ${ }^{279}$ The authors calculated the surface area and pore diameter of the calcined ash catalyst from BET analysis data and reported $45.99 \mathrm{~m}^{2} / \mathrm{g}$ and $9.77 \mathrm{~nm}$ respectively. Moreover, the catalyst consists of diverse minerals along with potassium as primary components, which leads to the 


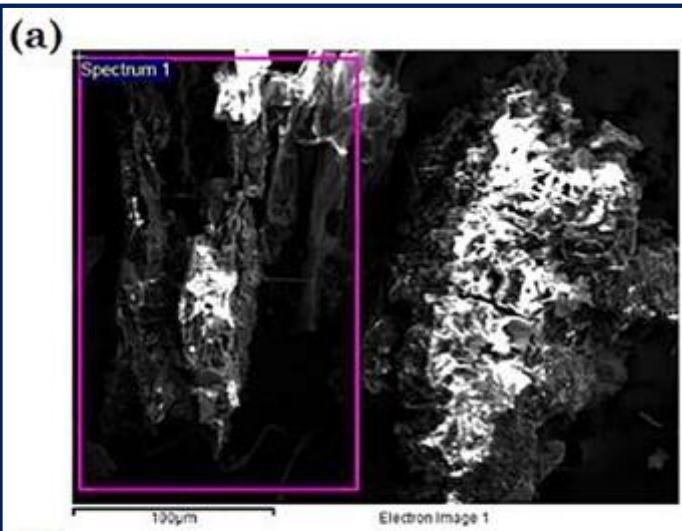

(b)

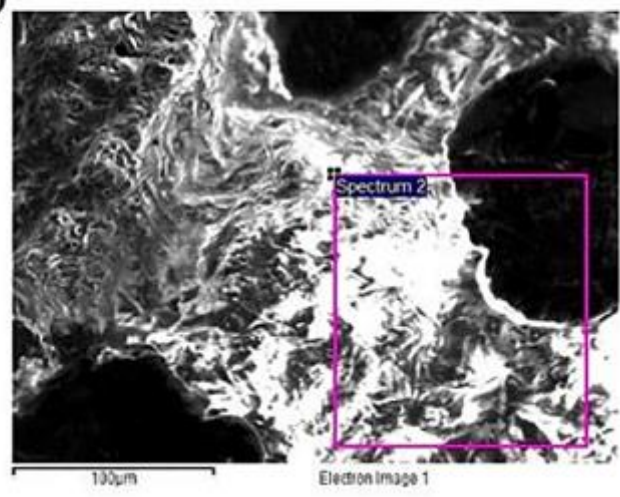

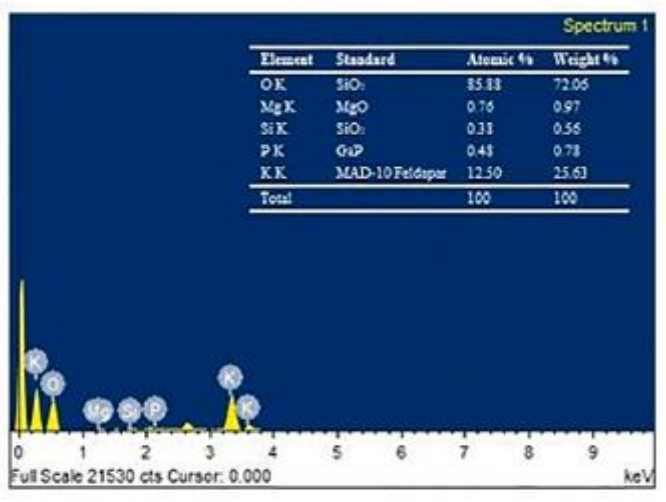

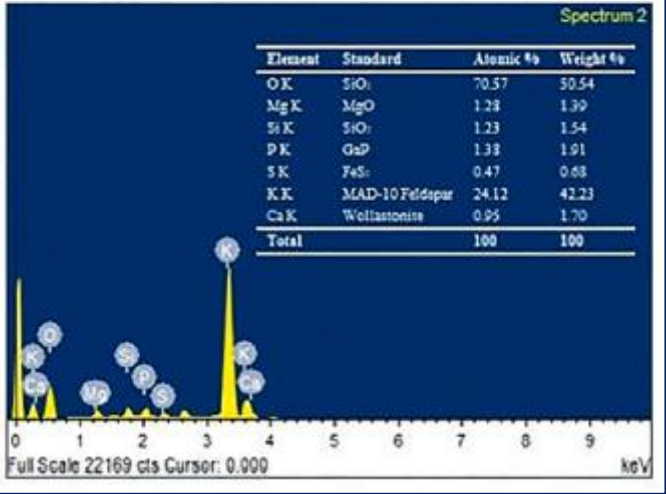

Figure 25: EDS images (a) uncalcined and b) calcined banana peduncle. Reproduced from ref. [279].

In 2019, Mendonça et al. ${ }^{280}$ reported the utilization of calcined $\left(800{ }^{\circ} \mathrm{C}\right.$ for $\left.4 \mathrm{~h}\right)$ waste cupuaçu seeds as a solid base catalyst in the synthesis of biodiesel from soybean oil and ethanol. Similarly, Nath et al. ${ }^{281}$ utilized a solid base catalyst derived from waste Brassica nigra plant for the efficient preparation of biodiesel. The SEM-EDX analysis of the catalyst revealed the existence of potassium $(56.13 \%)$ and calcium $(26.04 \%)$ in huge amount, which may be considered as key ingredients for the high basicity of the catalyst. The authors also measured the surface area pore volume of the catalyst via BET analysis and came about $7.308 \mathrm{~m}^{2} / \mathrm{g}$ and $0.011 \mathrm{~cm}^{3} / \mathrm{g}$ respectively. The catalyst possessed excellent reactivity in transforming the soybean oil to FAME and displayed $98.79 \%$ FAME yield in a short time frame of 25 min under the optimum states. Betiku et al. ${ }^{156}$ prepared ash catalyst from kola nut pod husk and used it to convert Kariya seed oil (KSO) to biodiesel, namely Kariya oil methyl esters (KOME), via transesterification process. A maximum of $98.67 \pm 0.01$ wt. \% of FAME yield was observed. 
Moreover, the reusability examination of the catalyst suggests that it can be reused for 4 progressive cycles. Recently Changmai et al. ${ }^{282}$ converted soybean oil to biodiesel using orange peel ash in $98 \%$ yield. XRF analysis showed the presence of oxide of potassium (51.64 $\%)$ and calcium. Hammet indicator strategy was employed to examine the catalyst basicity and it was seen as $9.8<H_{-}<12.2$. The author's measured catalyst pore volume and surface area from BET analysis and found $0.428 \mathrm{cc} / \mathrm{g}$ and $605.60 \mathrm{~m}^{2} / \mathrm{g}$, respectively. Moreover, GC-MS analysis (Figure 26) reveals the existence of six components in the synthesized FAME; methyl palmitate $(11.63 \%)$, methyl oleate $(25.32 \%)$ and methyl linoleate $(54.34 \%)$ are the major components.

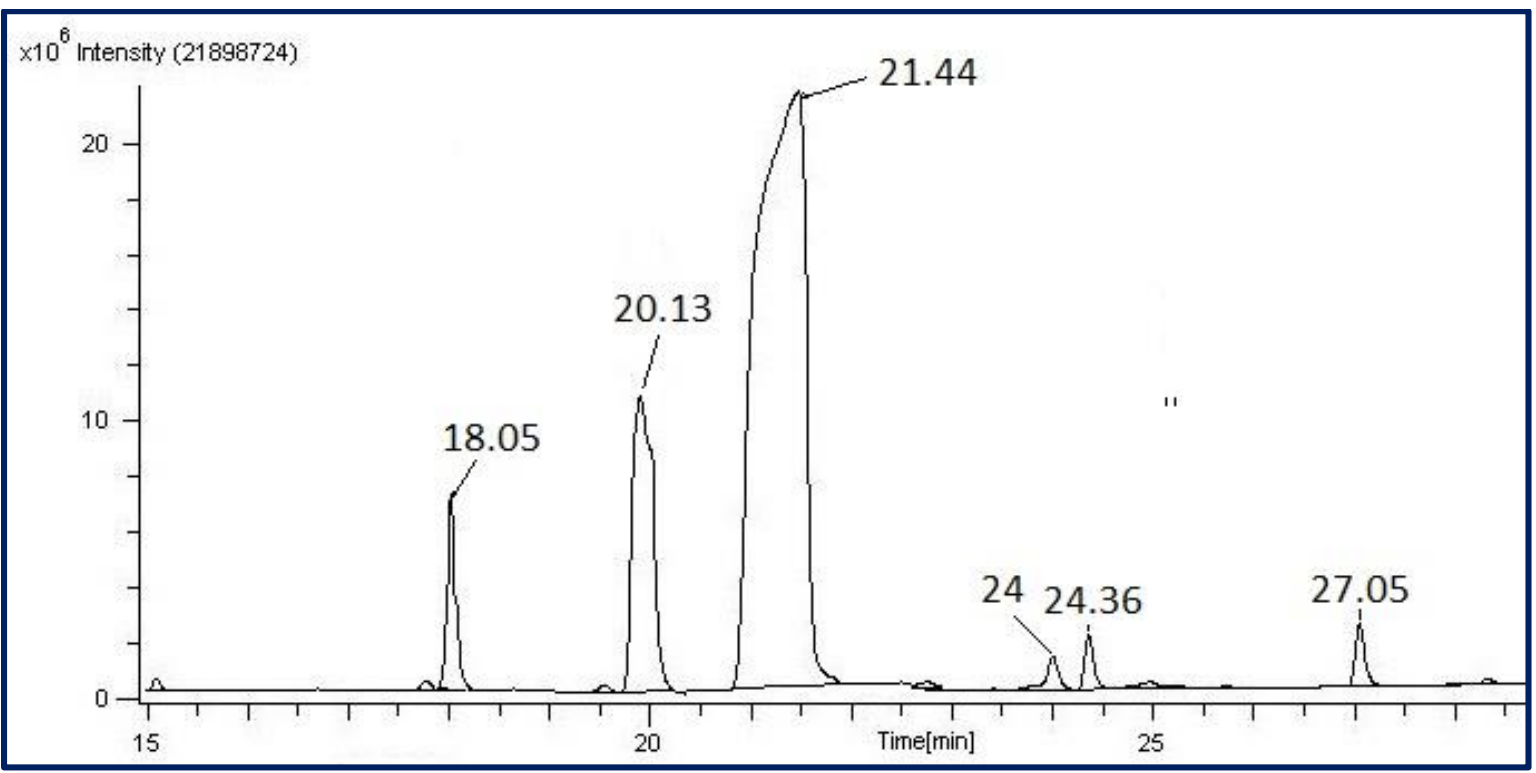

Figure 26: GC-MS spectrum of biodiesel from soybean oil. Reproduced from ref. [282].

1397

Waste Sesamum indicum plant ash catalyst was also successfully utilized for the transformation of sunflower oil to biodiesel. ${ }^{283}$ The measured surface area of the catalyst is $3.66 \mathrm{~m}^{2} / \mathrm{g}$ as obtained from the BET analysis data. A high $98.9 \%$ biodiesel yield was accomplished. They reused the catalyst up to the $3^{\text {rd }}$ cycle which yields $94.2 \%$ biodiesel. In addition, Mendonça et al. ${ }^{284}$ utilized waste tucumã peels ash catalysts for biodiesel synthesis from soybean oil. The catalyst characterization by XRF showed it was mostly composed of oxides of potassium, calcium and magnesium.. Because of its heterogeneous and non-leachable nature, the catalyst derived from tucumã peels could be reused at least 5 times. In another study, Tectona grandis leaves ash catalyst was developed and utilized for the transformation of WCO to FAME by Gohain et al. ${ }^{285}$ The measured surface area and pore size of the catalyst are $116.833 \mathrm{~m}^{2} / \mathrm{g}$ and $112.210 \AA$, respectively as calculated from BET data. $100 \%$ oil transformation to FAME was accomplished at room temperature using the optimized reaction 
conditions. Furthermore, cocoa pod husk derived solid base catalyst was employed in the transformation of neem seed oil to FAME. ${ }^{286}$ A two-step process was employed for the conversion of neem seed oil to FAME, i) pretreatment of the oil was performed using $\mathrm{Fe}_{2}\left(\mathrm{SO}_{4}\right)_{3}$ catalyst to reduce the FFA content from $28.76 \%$ to $0.39 \%$ and ii) transesterification of pretreated oil using the calcined bio waste-derived catalyst. The authors also studied the effect of reaction parameters using Box-Behnken design (BBD) and CCD of RSM was utilized to determine the optimized reaction conditions. Similarly, a walnut shell derived catalyst was developed for the transformation of sunflower oil to biodiesel. ${ }^{287}$ The catalyst was prepared from walnut shells via air combustion, thereby bringing down the cost involved in the calcination process to afford ash. The authors reported a $98 \%$ FAME yield within a brief time frame of $10 \mathrm{~min}$. Recently, the transformation of sunflower oil to synthesize FAME using calcined sugar beet generated from agro-industry waste was reported. ${ }^{288}$ The catalyst has a high amount of highly basic $\mathrm{CaO}$ and showed very high reactivity towards the transesterification process to afford about $93 \%$ FAME yield. $98.39 \%$ soybean oil transformation to FAME under room temperature was reported using M. acuminata trunk ash catalyst recently. ${ }^{289}$

Most biomass ash catalysts are usually applied for transesterification reactions of different biodiesel feedstocks and different reaction conditions. These make a comparison of the effectiveness of such catalysts under the same reaction condition impossible. Hence, to have a better insight into the activities of catalysts under the same reaction conditions and feedstock, Odude et al. ${ }^{290}$ examined the transformation of pre-esterified palm kernel oil (PKO) to FAME utilizing two diverse catalysts viz. calcined banana peel ash (CBPA) and calcined cocoa pod husk ash (CCPHA) under same reaction conditions. RSM technique was utilized for the optimization of both CBPA and CCPHA catalyzed transformation process of PKO to FAME. CCD was utilized to acquire the best possible combination of M/O ratio, catalyst loading and reaction time for the highest conversion of oil to FAME as portrayed in Figure 27. The observed FAME yields under the optimized conditions utilizing catalysts CBPA and CCPHA were 99.5 and $99.3 \mathrm{wt}$ \%, respectively. The created models when exposed to statistical assessment demonstrated that CBPA catalyzed transformation model was better than CCPHAcatalyzed transformation model. In the meantime, Carica papaya stem ${ }^{291}$ and Musa balbisiana underground stem ${ }^{292}$ was also reported as a solid catalyst to convert Scenedesmus obliquus and Mesua ferrea oil respectively, to FAME. 


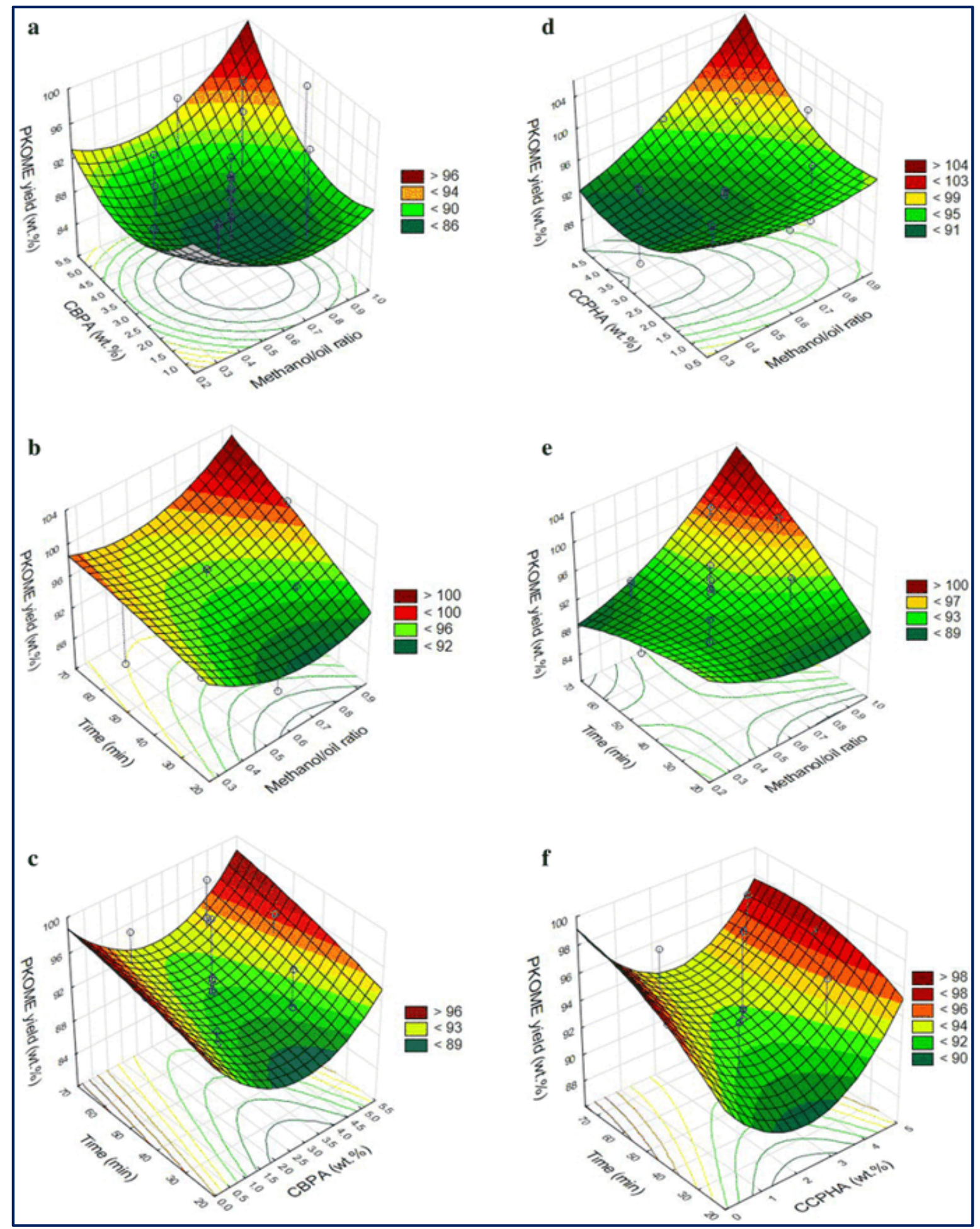

Figure 27: Contour and surface plots for PKOME synthesis. Reproduced from ref. [290].

1443 Table 14: Different plant ash catalysts in biodiesel productions

\begin{tabular}{llllll}
\hline No. & Catalyst source & Feedstock & ${ }^{a}$ Conditions & Yield (\%) & Ref. \\
\hline 1. & L. perpusilla Torrey & JCO & $9: 1,5,65 \pm 5,300$ & 89.43 & 263 \\
2. & Oil palm ash & WCO & $18: 0,5.35,60,30$ & 71.74 & 264
\end{tabular}




\begin{tabular}{|c|c|c|c|c|c|}
\hline 3. & $\begin{array}{l}\text { Oil palm ash/ boiler } \\
\text { ash (BA) }\end{array}$ & Palm olein & $15: 1,3,60,30$ & 90 & 265 \\
\hline 4. & $\begin{array}{l}\text { Musa paradisiacal } \\
\text { (plantain) peels }\end{array}$ & $\begin{array}{l}\text { Thevetia } \\
\text { peruviana oil }\end{array}$ & $3.3: 1,3,60,60$ & 95.2 & 266 \\
\hline 5. & $\begin{array}{l}\text { Ripe plantain fruit } \\
\text { peel }\end{array}$ & $\begin{array}{l}\text { Azadirachta } \\
\text { indica oil }\end{array}$ & $1: 0.73,0.65,65,57$ & 99.2 & 267 \\
\hline 6. & Coconut husk & $\mathrm{JCO}$ & $12: 1,7,45,30 \mathrm{~min}$ & 99.86 & 268 \\
\hline 7. & Cocoa pod husks & Soybean oil & $6: 1,1,60,60 / 120$ & $98.7 / 91.4$ & 269 \\
\hline 8. & Musa balbisiana & Thevetia & $20: 1^{d}, 20, \mathrm{RT}, 180$ & $96^{b}$ & 270 \\
\hline & Colla & peruviana & & & \\
\hline & peel & seed oil & & & \\
\hline 9. & Musa balbisiana & $\mathrm{JCO}$ & $9: 1,5,275,60$ & 98 & 271 \\
\hline
\end{tabular}

Colla underground

stem

10. Musa'Gross Michel’ Napoleon's $\quad 7.6: 1, \quad 2.75, \quad 65, \quad 98.5 \quad 272$

peel plume seed oil 69.02

11. Rubber seed shell $\quad$ Rubber seed $\quad 0.20: 1^{e}, 2.2,60,60 \quad 83.06 \quad 273$

12. Musa balbisiana $\quad$ WCO $\quad 6: 1,2,60,180 \quad 100^{b} \quad 274$

Colla peel

13. M. acuminata peel Soybean $6: 1,7$, RT, $240 \quad 98.95 \quad 275$

14. Wood (Acacia $\quad$ JCO 12:1, $5,65,180 \quad 98.7^{b} \quad 276$

nilotica) stem

15. Birch bark/fly ash Palm oil $\quad 12: 1,3,60,180 \quad 88.06 \pm 0.72 / \quad 277$

16. Musa spp "Pisang Ceiba 9.20:1, $1.978, \quad 65, \quad 98.69 \pm 0.18 \quad 278$ Awak" peduncle pentandra oil 60

17. Musa acuminata Ceiba 11.46:1, 2.68, 65, $98.73 \pm 0.50^{b} \quad 279$ peduncle pentandra oil 106

18. Theobroma Soybean oil $\quad 10: 1,10,80,480 \quad 98.36^{b} \quad 280$ grandiflorum seeds

19. Brassica nigra plant Soybean oil $\quad 12: 1,7,65,25 \quad 98.79 \quad 281$ 
20. Kola nut pod husk

Kariya seed

$6: 1,3,65,75$

$98.67 \pm 0.01$

156

oil (KSO)

21. Orange peel

Soybean oil

6:1, 7, RT, 420

$98^{b}$

282

22. Sesamum indicum

Sunflower oil

$12: 1,7,65,40$

98.9

283

plant

23. Tucumã peels

Soybean oil

15:1, 1, 80, 240

$97.3^{b}$

284

24. Tectona grandis

WCO

6:1, 2.5, RT, 180

$100^{b}$

285

leaves

25. Cocoa pod husk

Azadirachta

$0.73: 1^{e}, 0.65,65,57 \quad 99.3$

286

indica oil

26. Walnut shell

Soybean oil

$12: 1,5,60,10$

98

287

27. Sugar beet waste

Sunflower oil

$4.5: 1,1,75,60$

$93^{b}$

288

28. M. acuminata trunk

Soybean oil

6:1, 14, RT, 360

$98.39^{b}$

289

29. Banana peel/ cocoa

Palm kernel

$0.80: 1^{e}, 4,65,65$

$99.5 / 99.3$

290 pod husk

oil

30. Carica papaya stem

Scenedesmus

$9: 1,2,60,180$

$93.33^{b}$

291

obliquus

31. Musa balbisiana

Mesua ferrea

$9: 1,5,60,275$

$95^{b}$

292

underground stem

oil

1444

1445

1446

1447

1448

1449

1450

1451

1452

1453

1454

1455

1456

1457

1458

${ }^{\mathrm{a}^{*}}$ Methanol-to-oil molar ratio, catalyst loading (wt. \%), temperature $\left({ }^{\circ} \mathrm{C}\right)$, reaction time (min).

${ }^{b}$ Conversion

${ }^{d} \mathrm{~mL} / \mathrm{g}$

${ }^{e} \mathrm{~V} / \mathrm{V}$.

\subsection{Acid catalysts}

Acid can catalyze both transesterification and esterification reactions without soap formation. ${ }^{293}$ Hence, unlike base catalysts, an acid catalyst has the potential to afford biodiesel from poor quality oil with high FFA and high water content. In the transesterification reaction, alkaline catalysts are superior in promoting methoxide anion formation from methanol. In contrary to it, acidic catalysts are less active in methoxide anion formation, but could activate the carbonyl bonds via $\mathrm{H}^{+}$addition (Brønsted acidic sites) or via coordination of the carbonyl oxygen with the coordinatively unsaturated metal ion sites (Lewis acidic sites), and thereby promote transesterification. Hence, an increase in the number of either Brønsted or Lewis acidic sites promotes faster FAME formation via transesterification. Delightfully, 
heterogeneous acid catalysts are endorsed as a potential alternative to homogenous acids catalysts as it possesses certain advantages like it can be easily separated and reused, less corrosive and less toxic. ${ }^{294}$ In recent years, several research groups have studied the feasibility of solid acid catalysts for esterification/transesterification processes and proposed economical and environment-friendly approaches for biodiesel production. ${ }^{295-297}$

\subsubsection{Ion exchange resin}

It is a well-known fact that several catalysts have been employed for FAME production from various feedstocks. But due to the certain disadvantages of conventional catalysts, researchers are always in search of an ideal catalyst which should overcome all associated limitations such as catalyst should be active at lower temperatures, exhibits high catalytic efficacy in terms of conversion of FAME, easy availability, low cost, easy downstream processing and reusability. Such an ideal catalyst can be considered as potential and economically viable candidates for biodiesel production. ${ }^{298}$ In this context, one of them is ion exchange resin which meets most of the specifications of an ideal catalyst. Thus, many research groups have studied the role of ion exchange resins as solid catalysts in FAME product. ${ }^{299,300}$ Resin is the insoluble solid material that can retain and discharge ions simultaneously. ${ }^{301}$ Resins are broad categories into cationic and anionic resin based on functional groups and degree of cross-linkages. It possesses specific functional groups responsible for the permutation of ions. ${ }^{301}$ Having one of the important properties, the resinbased catalyst undergoes easy recovery from liquid mixtures by simple methods and are active at low temperature.

Since last few years, the cationic resins have gained considerable attention due to the advantages like functioning at soft reaction conditions, non-corrosive nature, more numbers of active sites and lower residual waters production. ${ }^{302,303}$ The cationic resin catalysts possess numerous active acid sites that play a crucial role in FAME production via esterification/transesterification reactions. ${ }^{304,305}$ Various ion exchange resin catalyst utilized for FAME production together with ideal reaction conditions are listed in Table 16. In 2007, Shibasaki-Kitakawa et al. ${ }^{302}$ in a comparative study reported that cation exchange resins showed less efficacy than anion exchange resins towards the conversion of triacylglycerols to biodiesel. Moreover, while evaluating the conversion rates of various commercial resins such as Diaion PA308, PA306, PA306S and Diaion HPA25, it was observed that highly porous resin-like Diaion HPA25 showed low conversion rate and it is believed this might be due to resistance of the resin towards the water. According to Ren et al. ${ }^{303}$ transformation of soybean 
oil to FAME reduced from $95.2 \%$ to $87.7 \%$ in the existence of D261 anion-exchange resin when the water content is enhanced from $0.0 \%$ to $1.0 \%$ by mass of oil. Similarly, in another study Deboni et al. ${ }^{304}$ also reported lowering of reaction rate due to the presence of water inside the resins.

Generally, ion exchange resins are utilized for purification and softening of water at room temperature. Recently, Kansedo et al. ${ }^{305}$ compared the catalytic efficiencies of different ion exchange resins like Amberlyst 15, Dowex DR-2030 and DR-G8 for the transformation of FFA into FAME via esterification of the sea mango oil (hydrolyzed) at RT. The results revealed that Amberlyst 15 showed maximum efficacy with the highest FAME production compared to Dowex DR-2030 and Dowex DR-G8. However, Jaya et al. ${ }^{306}$ utilized ion exchange resins catalyst at a moderately lower temperature $\left(50{ }^{\circ} \mathrm{C}\right.$ to $\left.80{ }^{\circ} \mathrm{C}\right)$ for biodiesel production which is analogous to those of homogenous catalytic process. Further, Umer and co-worker investigated the transformation of Lagenaria Vulgaris seed oil to biodiesel exploiting Amberlyst 15 resin and calcium oxide (egg cell) catalyst. The authors reported 93.2 $\%$ yield of biodiesel when Amberlyst 15 ion exchange resin was used as a catalyst with the loading of $5 \% \mathrm{w} / \mathrm{w}$ and $\mathrm{M} / \mathrm{O}$ ratio of $40 \% \mathrm{w} / \mathrm{w}$ for $40 \mathrm{~min}$ of and reaction time at $60{ }^{\circ} \mathrm{C} .{ }^{307}$ Similarly, Kansedo and Lee ${ }^{308}$ investigated the esterification of hydrolyzed sea mango oil utilizing different cationic ion exchange resins, and over $80 \%$ yield of FAME was recorded using Amberlyst 15 catalyst at a comparatively lower temperature within $1 \mathrm{hr}$ of reaction time and with catalyst loading less than $5 \% \mathrm{w} / \mathrm{w}$.

Recently, Deboni et al. ${ }^{304}$ reported $99 \%$ yield of methyl and ethyl esters from soybean oil with methanol and ethanol respectively using optimal reaction conditions. Whereas, Guzhan et al. ${ }^{309}$ recorded $63 \%$ yield of FAME from canola oil using Amberlyst-26 under the optimized reaction conditions.. Moreover, in another study, a yield of about $67 \%$ was observed for canola oil and methanol with almost similar reaction conditions. ${ }^{301,309}$ The conversion of tallow fat with methanol showed the yield of methyl and ethyl esters around $95 \%$ using Amberlyst-A26 $\mathrm{OH}$ with reaction conditions like tallow fat with methanol molar ratio of 6:1, resin loading of $2 \mathrm{~mol} / \mathrm{L}$ at $65^{\circ} \mathrm{C}$ temperature for about 8.5 hours. ${ }^{310}$

Hartono et al. ${ }^{311}$ investigated the catalytic efficacy of heterogeneous catalyst obtained from a different source like Lewatit macroporous resin, Amberlite gel resin and natural zeolite from Bayah to transform WCO to biodiesel. Authors reported the $85.94 \%$ yield of biodiesel production by Lewatit macroporous anion exchanger with $6 \mathrm{M} \mathrm{NaOH}$. Whereas, Amberlite gel with $6 \mathrm{M} \mathrm{HCl}$ displayed $65.22 \%$ biodiesel generation. Previously, Shibasaki-Kitakawa et al 312 reported the usefulness of the anion-exchange resin from their catalytic and adsorption 
Table 16: Different ion exchange resin catalyst used for the production of biodiesel.

\begin{tabular}{|c|c|c|c|c|c|}
\hline No. & Catalyst & Feedstocks & ${ }^{a}$ Conditions & Yield (\%) & Ref. \\
\hline 1 & $\begin{array}{l}\text { D261 anion-exchange } \\
\text { resin }\end{array}$ & Soybean oil & $9: 1,50.15,56$ & $95.2^{b}$ & 303 \\
\hline 2 & $\begin{array}{l}\text { Amberlyst A26 OH } \\
\text { anion } \\
\text { exchange resin }\end{array}$ & $\begin{array}{l}\text { Acid soybean } \\
\text { oil }\end{array}$ & $9: 1,2,50, \mathrm{NR}$ & 78 & 304 \\
\hline 3 & Amberlyst-15 & $\begin{array}{l}\text { Hydrolyzed sea } \\
\text { mango oil }\end{array}$ & $6: 1,30,30, \mathrm{NR}$ & $>90$ & 305 \\
\hline 4 & $\begin{array}{l}\text { Basic anion exchange } \\
\text { resin. }\end{array}$ & Pongamia oil & $9: 1,75,60$ & 85 & 306 \\
\hline 5 & $\begin{array}{l}\text { Amberlyst } 15 \text { ion } \\
\text { exchange resin }\end{array}$ & $\begin{array}{l}\text { Lagenaria } \\
\text { vulgaris seed oil }\end{array}$ & $40: 1,5,60,40$ & 93.2 & 307 \\
\hline 6 & Amberlyst & $\begin{array}{l}\text { Hydrolyzed sea } \\
\text { mango oil }\end{array}$ & $3: 12,100,60$ & $>80$ & 308 \\
\hline 7 & Amberlyst-26 & Canola oil & $6: 1,3,45,90$ & 67 & 309 \\
\hline 8 & Amberlyst-A26 OH & Tallow fat & $\begin{array}{l}6: 1,2 \mathrm{~mol} / \mathrm{L}, 65, \\
360\end{array}$ & 95 & 310 \\
\hline 9 & Amberlite gel resin & WCO & $7: 1,60,120$ & 85.94 & 311 \\
\hline 10 & Cation-exchange resin & Rice bran oil & $6: 1,20,63.83,120$ & 79.7 & 313 \\
\hline 11 & Purolite-PD206 & Corn oil & $18: 1,65,2880$ & 79.45 & 315 \\
\hline
\end{tabular}

abilities for the transformation of WCO to FAME. In their another study, Shibasaki-Kitakawa et al. ${ }^{313}$ also developed ion-exchange resin catalysts based continuous process for the production of biodiesel. FFA conversions rate was estimated for different catalysts with reactions conditions like mole ratio of $\mathrm{M} / \mathrm{O}(6: 1)$, temperature $\left(63.83{ }^{\circ} \mathrm{C}\right)$, reaction time $(2 \mathrm{~h})$ and catalyst load (20 wt. \%). The maximum FFA conversions of $79.7 \%$ were recorded for NKC-9. Whereas, for $001 \times 7$ and D61 catalysts it was found to be only $32.2 \%$ and $10.3 \%$ respectively. ${ }^{314}$ Jalilnejad-Falizi et al. ${ }^{315}$ achieved the highest FFA conversions by ion exchange resins (PD206- $\mathrm{Na}^{+}$and PD206- $\mathrm{H}^{+}$) under the optimal reation conditions. All the above-mentioned reports are enough to summarize that ion exchange resins can be employed as one the potential heterogeneous catalysts in biodiesel production. 
${ }^{b}$ Conversion

NR: Not reported

PFAD: palm fatty acid distillate

\subsubsection{Sulfated catalyst}

Among solid acid catalysts, sulfated catalysts have attracted considerable attention for transesterification due to their super-acid property. Sulfated inorganic metal oxides are reported to be chemically stable, and have super acidity comparable to $100 \%$ sulfuric acid, remarkable acid-base and redox properties. ${ }^{316}$ Different kinds of sulfated catalysts such as sulfated zirconia, tin oxide, zirconia-alumina, etc. have been successfully exploited in the production of biodiesel; but among these, sulfated zirconia is most widely studied catalyst (Table 17). Various reports are available on the transformation of oil to FAME utilizing sulfated zirconia catalyst, but there are some studies which presented certain drawbacks of these catalysts which include low catalytic activities, drastic reaction conditions, and reusability issues. Moreover, lack of uniform pore size and low surface area are the other factors which restrict their wide uses in catalyzing bulky oil molecules of biodiesel feedstocks. In this context, several attempts have been made to modify sulfated zirconia catalysts with an intention to increase their catalytic efficacy.

Xia et al. ${ }^{317}$ demonstrated the synthesis of mesoporous materials which has the potential to improve the activity of sulfated zirconia catalyst owing to their promising and outstanding properties like high surface area, uniform and controllable pore size. According to Alexander et al. ${ }^{318}$ the modification of sulfated zirconia catalyst enhanced the total acidity which basically increased catalyst active sites. In another study, Guoliang et al. ${ }^{319}$ proposed that change in phase structure of sulfated zirconia can also increase its catalytic activity and therefore, they developed tetragonal sulfated zirconia which showed enhanced catalytic activity in the FAME synthesis procedure. Moreover, some of the studies proposed the modification of sulfated zirconia on MCM-41 (Mobil Composition of Matter No. 41) support for the generation of methyl tert-butyl ether to improve its catalytic performance, the results obtained revealed that the catalytic performance of the prepared supported sulfated zirconia catalyst was 2.5-3.0 times greater than neat sulfated zirconia. ${ }^{317,320}$ Similarly, Muthu et al. ${ }^{321}$ reported the preparation of FAME from neem (Azadirochta indica) oil using sulfated zirconia catalyst. It was revealed that catalyst is highly stable to oils with high FFA concentration. The strong acid sites of this catalyst showed a considerable impact on its reactivity in the transformation of neem oil. 

exploited it for the conversion of WCO to biodiesel. Further, the authors studied the bi-metallic impact of the catalyst, in which $\mathrm{SnO}_{2}$ was blended in with $\mathrm{SiO}_{2}$ and $\mathrm{Al}_{2} \mathrm{O}_{3}$, at various weight ratios to increase the activity of $\mathrm{SnO}_{2}$. The finding confirmed that $\mathrm{SO}_{4}{ }^{2-} / \mathrm{SnO}_{2}-\mathrm{SiO}_{2}$ weight ratio of 3 showed exceptionally high reactivity with $92.3 \%$ biodiesel yield using optimal reaction conditions. Similarly, Pereira et al. ${ }^{323}$ demonstrated the application of $\mathrm{SnSO}_{4}$ catalyst for the esterification of oleic acid (as model feedstock) and acid soybean oil having high contents of FFA. It was found that model feedstock containing 70 wt. \% of FFA showed $92 \%$ FAME yield using excess ethanol, 5 wt. $\% \mathrm{SnSO}_{4}$ at $100{ }^{\circ} \mathrm{C}$ for $3 \mathrm{~h}$. Moreover, it was also reported that the catalyst is stable up to ten cycles without any significant decrease in biodiesel yield. Moreover, one of the studies involved the application of sulfated tin oxide modified with $\mathrm{SiO}_{2}\left(\mathrm{SO}_{4}{ }^{2-} / \mathrm{SnO}_{2}-\mathrm{SiO}_{2}\right)$ catalyst to produce FAME from JCO. ${ }^{324}$ The sulfated titania-based solid superacid catalysts are another kind of sulfated catalysts. Li et al. ${ }^{325}$ prepared three different titania-based solid superacid catalysts and these were exploited for the transformation of rape seed oil to FAME at $353 \mathrm{~K}$ with a 12:1 molar ratio of $\mathrm{M} / \mathrm{O}$ under atmospheric pressure. It was found that all three prepared catalysts showed a significant yield of biodiesel due to their stronger surface acidities. Moreover, Alaba et al. ${ }^{316}$ reviewed that apart from these there are various other sulfated metal oxides such as titania, silica and combination of both also showed remarkable performance. It was also proved thorough investigation led by several researchers who have applied sulfated silica as catalysts for esterification and transesterification. ${ }^{326,327}$ In this context, Gardy and co-workers demonstrated a facile preparation of sulfated doped $\mathrm{TiO}_{2}$ catalyst that has been utilized efficiently in petroleum refinery. The authors reported that the synthesized catalyst has better reactivity than other sulfated metal oxides, primarily because of the acidic properties of $\mathrm{TiO}_{2}$ particles, which was subjected to sulfonation to enhance its acidity. The catalyst displayed great efficiency in the synthesis of FAME from WCO. ${ }^{328,329}$

Table 17: Different types of sulfated catalyst reported for biodiesel production.

\begin{tabular}{llllll}
\hline No. & Catalyst & Feedstocks & ${ }^{a}$ Conditions & Yield (\%) & Ref. \\
\hline 1 & $\mathrm{SO}_{4}{ }^{2-} / \mathrm{ZrO}_{2}$ & Neem oil & $9: 1,1,65,120$ & 95 & 321 \\
2 & $\mathrm{SO}_{4}{ }^{2-} / \mathrm{SnO}_{2}-\mathrm{SiO}_{2}$ & WCO & $15: 1,3,150,180$ & 92.3 & 322 \\
3 & $\mathrm{SnSO}_{4}$ & Soybean oil & $3.5: 1,5,100,180$ & 92 & 323 \\
4 & $\mathrm{SO}_{4}{ }^{2-} / \mathrm{SnO}_{2}-\mathrm{SiO}_{2}$ & Jatropha oil & $15: 1,3,180,120$ & 97 & 324 \\
5 & $\mathrm{SO}_{4}{ }^{2-} / \mathrm{TiO}_{2}$ & Rapeseed oil & $12: 1, \mathrm{NR} .80,720$ & 51 & 325
\end{tabular}




$\begin{array}{llllll}6 & \mathrm{Ti}\left(\mathrm{SO}_{4}\right) \mathrm{O} & \text { WCO } & 9: 1,1.5,75,180 & 97.1 & 328 \\ 7 & \mathrm{TiO}_{2} / \mathrm{PrSO}_{3} \mathrm{H} & \text { WCO } & 15: 1,4.5,60,540 & 98.3 & 329\end{array}$

1599

1600

1601

1602

1603

1604

1605

1606

1607

1608

1609

1610

1611

1612

1613

1614

1615

1616

1617

1618

1619

1620

1621

1622

1623

1624

1625

1626

1627

1628

1629

1630

${ }^{a}$ Methanol-to-oil molar ratio, catalyst loading (wt. \%), temperature $\left({ }^{\circ} \mathrm{C}\right)$, reaction time (min).

NR: Not reported

\subsubsection{Mixed metal oxides}

A wide range of acidic mixed metal oxide catalysts has been utilized to overcome the problem associated with high FFA content in low-cost biodiesel feedstock employed in FAME production (Table 18). Suzuta et al. ${ }^{330}$ reported utilization of $\mathrm{Fe}_{2} \mathrm{O}_{3}-\mathrm{SiO}_{2}$ catalyst in the conversion of JCO to FAME. The catalyzed reaction displayed 95.6\% FAME yield under the optimized reaction conditions. When Fe loading was raised from 0.07 to $2.1 \mathrm{wt}$ \% , the acidity of the catalyst increased drastically. Fe-oxide species scattered over the $\mathrm{SiO}_{2}$ surface were recognized as the active sites. In the meantime, $\mathrm{ZnAl}_{2} \mathrm{O}_{4} / \mathrm{ZnFe}_{2} \mathrm{O}_{4}$ catalyst was also examined for the transformation of oil such as sunflower oil, WCO and JCO. ${ }^{331}$ During the reaction, the $\mathrm{Zn} 3 \mathrm{~d}$ electrons of $\mathrm{ZnAl}_{2} \mathrm{O}_{4}$ and $\mathrm{ZnFe}_{2} \mathrm{O}_{4}$ spinels were likely to take part in the electronic excitation, thereby $\mathrm{Zn} 3 \mathrm{~d}$ electrons are probably going to undertake a vital job to enhance the catalyst reactivity. In 2012, Xie et al. ${ }^{332}$ synthesized $\mathrm{SnO}_{2}-\mathrm{SiO}_{2}$ catalyst by loading 8 wt. \% Sn onto $\mathrm{SiO}_{2}$ followed by calcination $\left(550^{\circ} \mathrm{C}\right)$ and exploited it in the transformation of soybean to FAME yielding $81.7 \%$ under the optimal reaction conditions.

Impregnation followed by calcination $\left(600{ }^{\circ} \mathrm{C}\right)$ was used to synthesize Fe-Mn$\mathrm{MoO}_{3} / \mathrm{ZrO}_{2}$ catalyst, which could provide a high $95.6 \pm 0.15 \%$ yield of FAME ${ }^{33}$ It is interesting to observe that $\mathrm{ZrO}_{2}$ and $\mathrm{MoO}_{3} / \mathrm{ZrO}_{2}$ gave a lower FAME yield of $48.6 \pm 1.14$ and $73.0 \pm 0.25 \%$ respectively. The high activity of $\mathrm{Fe}-\mathrm{Mn}-\mathrm{MoO}_{3} / \mathrm{ZrO}_{2}$ catalyst is attributed to high surface area $\left(49.5 \mathrm{~m}^{2} \mathrm{~g}^{-1}\right)$ and availability of huge active sites $\left(2411 \mu \mathrm{molg}^{-1}\right)$ in the catalyst. Moreover, catalyst reusability examination revealed that it is stable up to 6 progressive reaction cycles of transesterification of WCO without loss in its efficiency. On the other hand, enhanced catalytic activity was observed in a mixed metal oxide of $\mathrm{WO}_{3} / \mathrm{SnO}_{2}$ in the soybean oil transformation in comparison with the individual $\mathrm{WO}_{3}$ and $\mathrm{SnO}_{2}$ species. ${ }^{334}$ The bonding of $\mathrm{WO}_{3}$ with $\mathrm{SnO}_{2}$ was believed to upgrade $\mathrm{WO}_{3} / \mathrm{SnO}_{2}$ acidity. The catalyst is highly stable and was reused up to 4 times without much depreciation in the biodiesel yield.

Further, Xie et al. ${ }^{335}$ studied 30 wt. \% $\mathrm{WO}_{3}$ loading on $\mathrm{AlPO}_{4}$ catalyst and recorded a good $72.5 \%$ conversion to biodiesel under the optimized reaction condition. The high catalyst reactivity was attributed to the existence of $\mathrm{WO}_{3}$ that enhanced the surface acid sites. Similarly, Amani et al. ${ }^{336}$ reported a series of $\mathrm{Mn}_{3.5 \mathrm{x}} \mathrm{Zr}_{0.5 \mathrm{y}} \mathrm{Al}_{\mathrm{x}} \mathrm{O}_{3}$ catalyst for the transformation of WCO 
to FAME. The $\mathrm{Mn}_{1.4} \mathrm{Zr}_{0.35} \mathrm{Al}_{0.6} \mathrm{O}_{3}$ catalyst demonstrates better catalyst reactivity as far as FAME yield (>93 \%) than the $\mathrm{Mn}_{1.4} \mathrm{Zr}_{0.35} \mathrm{O}_{3}$ catalyst (52.8\%). The bonding between metals in the crystal structure efficiently influenced the catalyst reactivity. It was observed that the amphoteric component of the $\mathrm{Al}$ developed the surface region of the catalyst and framed a complex structure with other metal oxides, though Mn alternated the morphology and catalyst basic site density. In the meantime, Zhang et al. ${ }^{337}$ reported Zr-Mo mixed metal oxide functionalized with various carboxylic acids, for example, lauric acid, stearic acid, palmitic acid and myristic acid for biodiesel production from oleic acid. The modification of $\mathrm{Zr}-\mathrm{Mo}$ metal oxide using such monofunctional carboxylic acids enhances the catalyst acidity and surface area, thus upgraded the rate of the reaction. They also reported that among all, stearic acid-functionalized Zr-Mo metal oxide showed the best result with the maximum oleic acid conversion of $94.2 \%$. Catalyst reusability test revealed that the catalyst is stable up to 6 progressive cycles. Similarly, WCO was utilized for the FAME production using ferricmanganese doped tungstate molybdena nanoparticles (FMWMo). ${ }^{338}$ The dopants Fe-Mn enhances the surface area, density of acidic sites and the stability towards the esterification of WCO. A maximum yield of $92.3 \pm 1.12 \%$ methyl ester was achieved under the optimized reaction conditions.

Table 18: Different types of solid acid catalysts for FAME production.

\begin{tabular}{|c|c|c|c|c|c|}
\hline No. & Catalyst & Feedstocks & ${ }^{a}$ Conditions & Yield (\%) & Ref. \\
\hline 1. & $\mathrm{Fe}_{2} \mathrm{O}_{3}-\mathrm{SiO}_{2}$ & Jatropha oil & $218: 1,15,220,180$ & 95.6 & 330 \\
\hline 2. & $\mathrm{ZnA}_{12} \mathrm{O}_{4} / \mathrm{ZnFe}_{2} \mathrm{O}_{4}$ & $\begin{array}{l}\text { Sunflower } \\
\text { oil, WCO, } \\
\text { Jatropha oil }\end{array}$ & $9: 1,5,180,600$ & $>90$ & 331 \\
\hline 3. & $\mathrm{SnO}_{2}-\mathrm{SiO}_{2}$ & Soybean oil & $24: 1,5,180,300$ & 81.7 & 332 \\
\hline 4. & $\mathrm{Fe}-\mathrm{Mn}-\mathrm{MoO}_{3} / \mathrm{ZrO}_{2}$ & WCO & $25: 1,4,200,300$ & $95.6 \pm 0.15$ & 333 \\
\hline 5. & $\mathrm{WO}_{3}-\mathrm{SnO}_{2}$ & Soybean oil & $30: 1,5,110,300$ & 79.2 & 334 \\
\hline 6. & $\begin{array}{l}\mathrm{WO}_{3}(30 \mathrm{wt} . \\
\%) / \mathrm{AlPO}_{4}\end{array}$ & Soybean oil & $30: 1,5,180,300$ & 72.5 & 335 \\
\hline 7. & $\mathrm{Mn}_{1.4} \mathrm{Zr}_{0.35} \mathrm{Al}_{0.6} \mathrm{O}_{3}$ & WCPO & $14: 1,2.5,150,300$ & $>93$ & 336 \\
\hline 8. & $\mathrm{Zr}-\mathrm{Mo}$ & Oleic acid & $10: 1,4,180,120$ & $94.2^{b}$ & 337 \\
\hline 9. & FMWMo & WCO & $25: 1,6,200,480$ & $92.3 \pm 1.12$ & 338 \\
\hline
\end{tabular}




\subsubsection{Sulfonated carbon-based catalyst}

In the last few decades, various carbon materials with different shape, size, and structures have been developed by several research groups and utilized as low-cost catalysts for diverse industrial processes including transesterification. ${ }^{339}$ Currently, sulfonated carbons i.e. $\mathrm{SO}_{3} \mathrm{H}$-functionalized acidic carbon materials are considered as a new group of the metalfree solid acid catalyst described by their original carbon structure and Brønsted acidity equivalent to concentrated $\mathrm{H}_{2} \mathrm{SO}_{4}$. Sulfonated carbon acid catalysts can be easily prepared by processes like incomplete carbonization of aromatic compounds in concentrated $\mathrm{H}_{2} \mathrm{SO}_{4}{ }^{340}$ or sulfonation of incompletely carbonized natural organic matter, such as sugar ${ }^{341-343}$ and cellulosic materials. ${ }^{34,345}$ Sulfonation can also be achieved by treating carbon material with a sulfonating reagent such as gaseous $\mathrm{SO}_{3}, \mathrm{ClSO}_{3} \mathrm{H}$, p-toluenesulfonic acid, 4-benzenediazonium sulfonate or $\mathrm{SO}_{3} \mathrm{H}$-containing aryl diazoniums etc. ${ }^{346-349}$ These materials possess promising features such as biogenic, environment-friendly, lower production costs, distinctive surface chemistry, high chemical and thermal stability.

The acid-catalyzed chemical reactions such as saccharification, esterification, transesterification and acetylation are vital operations commonly used for the valorization of biomass or their components to useful products in various food, fuel and chemical industries. ${ }^{350}$ The functionalized acidic carbons from inexpensive sources including natural organic carbon matter such as sugars, carbohydrates, cellulosic materials, lignin have been achieved by several researchers. ${ }^{351-353,341}$ Besides this, agro waste such as husk, straw, seed cover, cow manure, corn $\operatorname{cob}^{342,343,354,355 \text {, }}$ carbonaceous waste from industries (char, oil pitch, coke, glycerol, etc.) 356,357,346,348 and polymer resins ${ }^{349,358,359}$ were also used. Various carbon supports (e.g. zeolitetemplated carbons, mesoporous carbons, active carbon, etc) ${ }^{352,353,360,361}$ and more recently nanostructured carbons such as graphene, graphene oxide, carbon nanotubes, and carbon dots) ${ }^{362-367}$ have been exploited for the same purpose.

Over the last few years, there is growing interest from researchers towards the application of sulfonated carbon-based catalysts due to their noteworthy efficacies mentioned earlier. Many reports are available which demonstrated the efficient nature of sulphonic acidfunctionalized catalyst in biodiesel production using various feedstocks. ${ }^{362,356,367}$ One of the reports presented the synthesis of organosulfonic acid (i.e. propylsulfonic and arenesulfonic groups) functionalized mesoporous silicas through a simple one-step process. The synthesized novel catalysts that possessed propylsulfonic groups and arenesulfonic groups were further evaluated for their catalytic efficacy in the esterification of fatty acid with methanol to produce methyl esters and the authors also compared the efficacy of these heterogeneous catalysts with 
a variety of commercially available catalysts such as sulfuric acid, p-toluene sulfonic acid, Nafion NR50, Amberlyst-15, etc. The obtained results indicated that the organosulfonic acidfunctionalized mesoporous silica catalysts showed the highest reactivity compared to all the above mentioned commercial solid acid catalysts in fatty acid esterification process. Moreover, it was also recorded that the efficiency of these catalysts was largely depended on important factors such as the median pore diameter of the catalyst and the acidic strength of the organosulfonic acid group present over this catalyst. Considering these findings, it can be proposed that there is a huge potential to developed catalysts using organic-inorganic mesoporous materials. ${ }^{363}$ In general, the activity of carbon-based catalysts upon fatty acid (C16-C18) esterification to produce biodiesel primarily depends on three primary factors: (i) $\mathrm{SO}_{3} \mathrm{H}$ group density, (ii) total acid density, and (iii) porosity. Different sulfonated carbon-based acid catalyst utilized for FAME production are listed in Table 19. Numerous reported catalysts demonstrated promising outcome in the (trans)esterification of biodiesel feedstocks with high FFA and afforded $>85 \%$ FAME yield. In the meantime, several investigations had been conducted using model acids (e.g. palmitic acid, oleic acid, etc. which are the major components of vegetable oil as reactant) that mainly focused on esterification reaction.

In a pioneering work towards the preparation of biomass-based sulfonated carbon catalyst, Toda et al. ${ }^{364}$ synthesized sulfonated carbon catalyst by partial carbonization of sugar followed by sulfonation in fuming $\mathrm{H}_{2} \mathrm{SO}_{4}$. The prepared catalyst consists of sheets of indistinctive carbon having a high amount of sulfonic groups along with hydroxyl and carboxyl as a minor group (Figure 28). The highly active bio-based carbon catalyst was utilized for transformation of oleic and stearic acid to FAME via esterification. Apart from $-\mathrm{SO}_{3} \mathrm{H}$ group, presence of $-\mathrm{OH}$ and $\mathrm{COOH}$ groups in the catalyst greatly enhance the catalytic activity and make it highly water tolerant. The successful incorporation of $-\mathrm{SO}_{3} \mathrm{H}$ group and formation of carbonized materials are can be easily confirmed by using FT-IR and ${ }^{13} \mathrm{C}$ MAS NMR analysis respectively, as depicted in Figure 33. ${ }^{368}$ FT-IR spectra (Figure 29a) displayed two bands at 1040 and $1377 \mathrm{~cm}^{-}$ 1 (in $\mathrm{SO}_{3} \mathrm{H}$ ), ascribed to $\mathrm{SO}_{3}$ and $\mathrm{O}=\mathrm{S}=\mathrm{O}$ stretching vibration, respectively, suggests the existence of $-\mathrm{SO}_{3} \mathrm{H}$ groups. ${ }^{13} \mathrm{C}$ MAS NMR (Figure 29b) depicted three major peaks at 130, 155 , and $180 \mathrm{ppm}$, ascribed to polycyclic aromatic carbon atoms, phenolic $\mathrm{OH}$, and $\mathrm{COOH}$ groups, respectively.

In another work, Hara et al. ${ }^{356}$ examined sulfonated carbon catalyst in biodiesel synthesis. The findings showed that amorphous carbon material containing sulfonic acid groups enhances the catalytic performance, thus displayed extraordinary reactivity in esterification/transesterification reactions in comparison to the ordinary solid acid catalyst. 


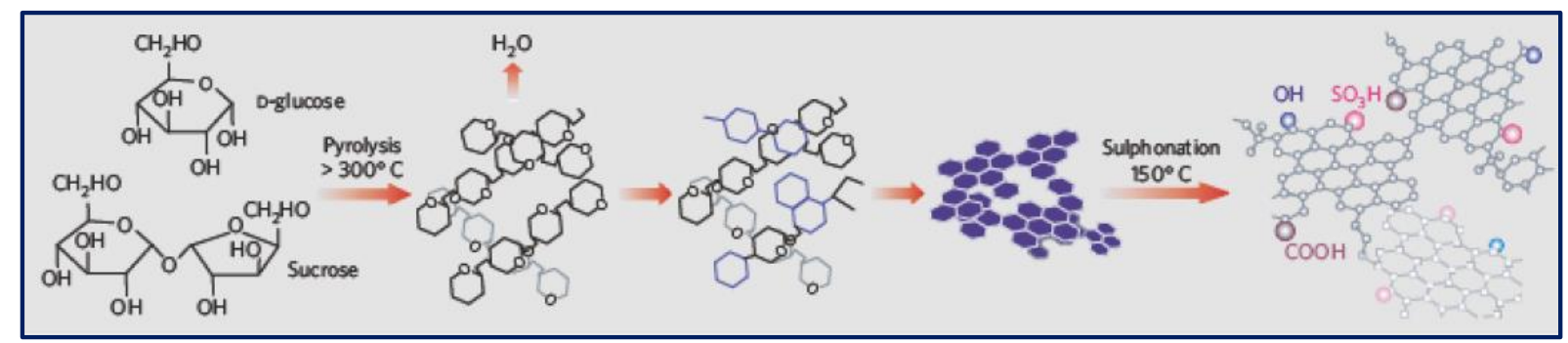

Figure 28: Synthesis of sulfonated carbon catalyst from sucrose and D-glucose.

Reproduced from ref. [364].

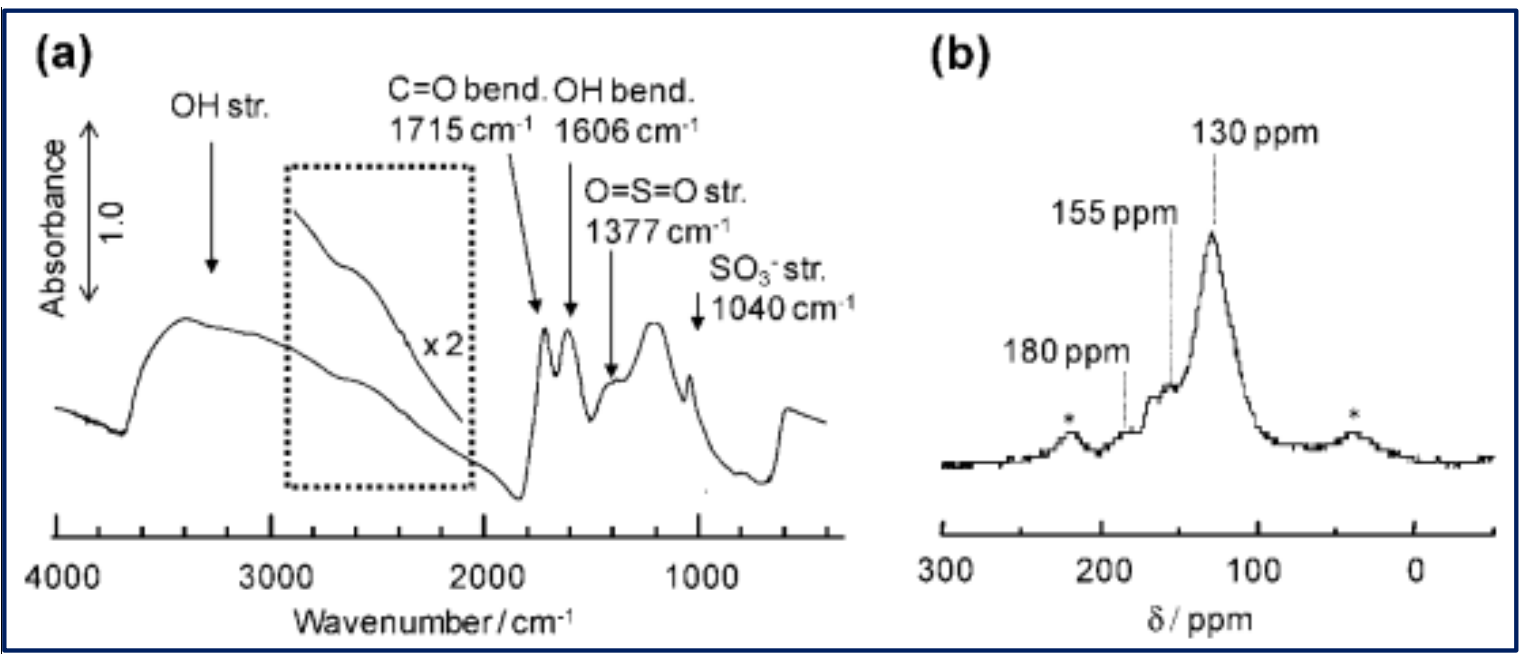

Figure 29: FT-IR (a) and 13C MAS NMR (b) spectrum for the sulfonated carbon catalyst originated from cellulose. Reproduced from ref. [368].

Likewise, Nakajima et al. ${ }^{365}$ synthesized amorphous cellulose-originated carbon solid acid (CCSA) catalyst and exploited it in the transformation of oleic acid to FAME, and observed a $99.9 \%$ yield under the optimized conditions. The carbon material displayed much

1723 higher catalytic activity in esterification reaction in comparison to ordinary solid acid catalysts 1724 examined, such as niobic acid, Amberlyst-15 and Nafion NR50. Interestingly, those CCSA catalyst prepared at a lower carbonization temperature before subjected to sulfonation gave a lot better biodiesel yield as compared to those prepared at higher carbonization temperature.

1727 This is attributed to the huge amount of $-\mathrm{OH}$ and $-\mathrm{COOH}$ groups in the former which enhanced 1728 its acidic nature, thereby its catalytic activities (Figure 30). The catalyst reactivity remains intact after 10 progressive cycles. 


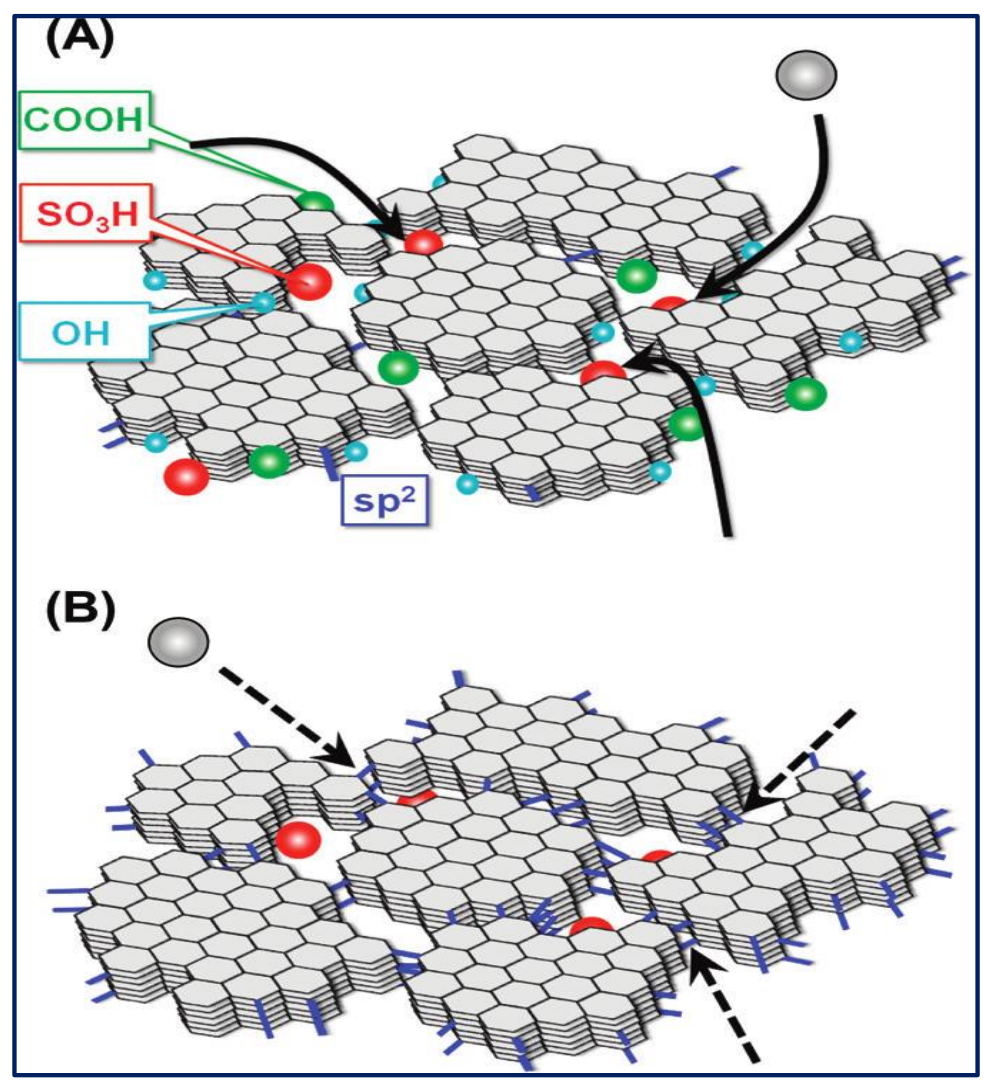

Figure 30: Schematic structures of $\mathrm{SO}_{3} \mathrm{H}$-bearing CCSA materials carbonized at below $723 \mathrm{~K}$ (A) and (B) above 823

K. Reproduced from ref. [365].

Simultaneous carbonization and sulfonation in a one-pot synthesis of solid acid catalyst directly from biomass have also been explored by various experts as it is straight forward, cost and time-efficient. Malins et al. ${ }^{366}$ synthesized $\mathrm{C}-\mathrm{SO}_{3} \mathrm{H}$ via simultaneous carbonizationsulfonation and utilized it for FAME production. The $\mathrm{C}-\mathrm{SO}_{3} \mathrm{H}$ catalysts with the highest density of $\mathrm{SO}_{3} \mathrm{H}$ groups $(0.81 \mathrm{mmol} \mathrm{Hp} / \mathrm{g})$ were prepared using optimal reaction conditions. It was noted that under optimized reaction conditions $96.5 \%$ of FAME was recorded. Interestingly, the catalyst has great stability and can be easily recovered and reused for subsequent reaction cycles. Moreover, in the comparative study of esterification reactions of rapeseed oil fatty acids, the prepared catalyst exhibited similar reactivity to Amberlyst-15.

Another recent report proposed a synthesis of the heterogeneous sulfonated catalyst using activated carbon to overcome several problems like drastic reaction conditions such as very high temperature, pressure, longer reaction time and expensive overall process cost. The above-mentioned activated carbon catalyst was prepared from corncobs as a precursor and utilized in the microwave-assisted conversion of soybean oil with ethanol to FAME. In this 
study, about $88.7 \%$ yield of pure biodiesel was reported at $0-600 \mathrm{~W}$ of microwave power. Moreover, the catalyst was reused up to 5 cycles. ${ }^{355}$ Figure 31 represents the schematic illustration of the application of activated carbon-based catalyst in the transesterification of various oils using methanol.

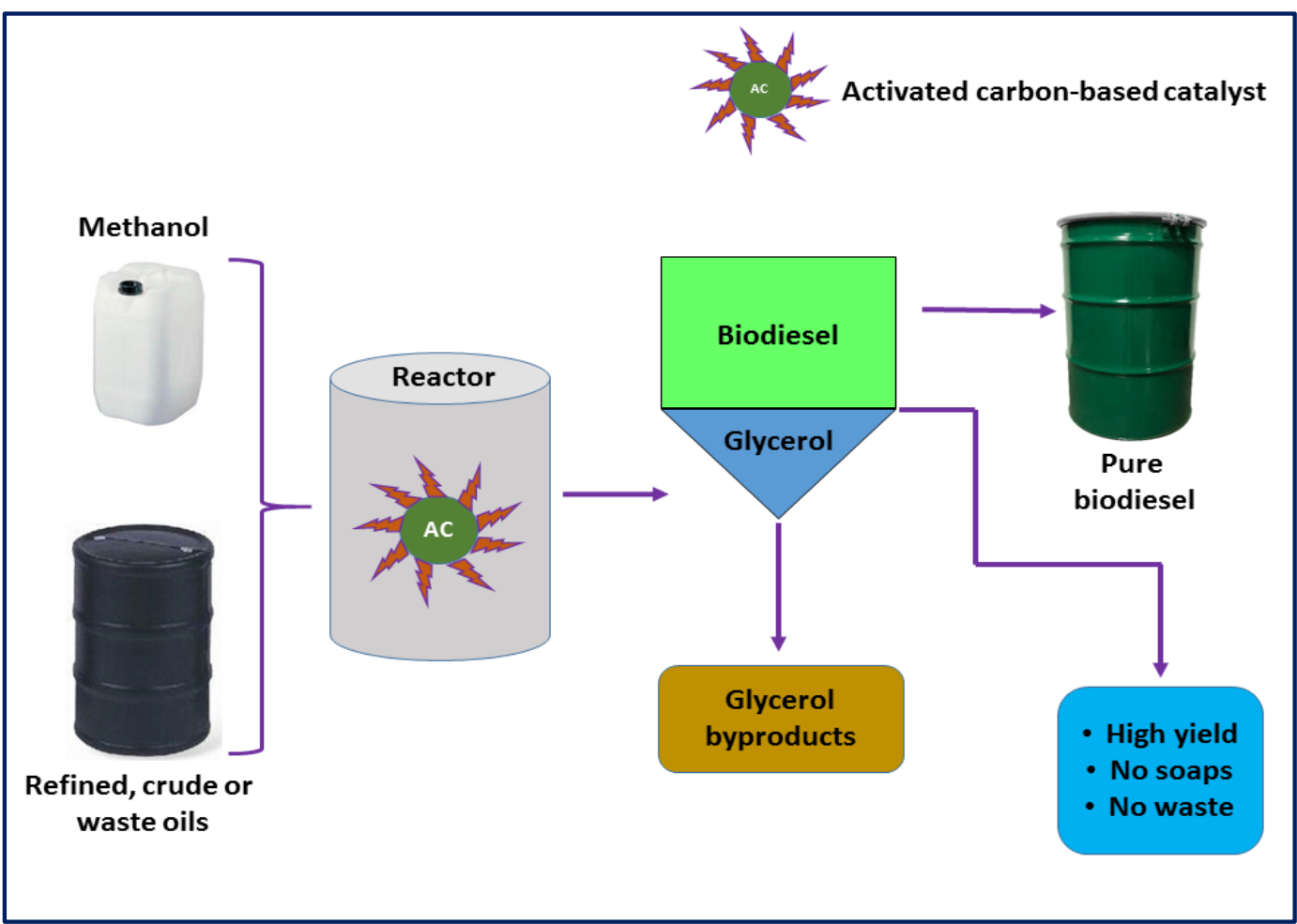

Figure 31: Schematic representation of transesterification of various oils using activated carbon-based catalysts.

In 2009, Yuan et al. ${ }^{369}$ examined the application of solid acid catalyst originated from sulfonated activated carbon $\left(\mathrm{H}_{2} \mathrm{SO}_{4} / \mathrm{C}\right)$ for catalyzing transesterification of castor oil and methanol as feedstock. Melero et al. ${ }^{370}$ synthesized sulfonic acid-modified mesostructured (SAM) catalyst and studied their efficacy in crude vegetable oils transformation to FAME. The results obtained noted that this catalyst has the ability to yield 95 wt. \% pure FAME and oil transformation close to $100 \%$. Despite the presence of FFAs, this catalyst displayed significantly high activity toward simultaneous esterification and transesterification reactions. Similarly, Zuo et al. ${ }^{371}$ developed various sulfonic acid functionalized mesoporous SBA-15 catalysts and tested their catalytic activity in the microwave-assisted conversion of soybean oil and 1-butanol to biodiesel. The authors observed that the catalytic efficacy of these catalysts mainly depends on the acid strength and not on the number of acid sites. Further, propyl- $\mathrm{SO}_{3} \mathrm{H}$ and arene- $\mathrm{SO}_{3} \mathrm{H}$ functionalized SBA-15 catalysts found to have comparatively better reactivity 
in the transesterification process. However, perfluoro- $\mathrm{SO}_{3} \mathrm{H}$ functionalized SBA-15 catalyst displayed leaching of the active sites in each progressive cycles, thus reactivity decreased. Shah et al. ${ }^{372}$ demonstrated esterification of FFAs in acid oil (which is a byproduct of oil refining) using sulfonic acid-functionalized silica $\left(\mathrm{SiO}_{2}-\mathrm{Pr}-\mathrm{SO} 3 \mathrm{H}\right)$ catalyst to prepare biodiesel. Further, the authors optimized various reaction conditions such as temperature, reaction time, catalyst concentration, and $\mathrm{M} / \mathrm{O}$ molar ratio, etc. which usually affects the conversion to FAME. A high conversion (i.e. $96.78 \%$ conversion after $8 \mathrm{~h}$ was reported at optimized conditions) can be achieved using these solid acid catalysts.

Moreover, in recent past Varyambath et al. ${ }^{373}$ developed different sulfonic acidfunctionalized organic knitted porous polyaromatic microspheres $\left(\mathrm{OPPSO}_{3} \mathrm{H}\right)$ utilizing pyrene, anthracene, and naphthalene as monomers via Friedel-Crafts alkylation, followed by crosslinking reactions. Further, these heterogeneous catalysts were utilized for the transformation of long-chain fatty acids and triglycerides to biodiesel. These solid acid catalysts were found to be very promising for biodiesel synthesis as they showed excellent surface acidity. In addition, several other sulphonic acid-functionalized catalysts were successfully developed and exploited in the production of biodiesel. In this context, Shagufta et al. ${ }^{374}$ reviewed all such sulphonic acid-functionalized in catalysts esterification and transesterification reactions. This review can be consulted for more detail information.

Yu et al. ${ }^{375}$ studied biodiesel production by exploiting coal-based acid catalysts and reported an oleic acid conversion of $97.6 \%$ under the optimal reaction conditions. Similarly, Tang and Niu ${ }^{376}$ investigated the synthesis of carbon-based solid acid catalysts from bamboo through partial carbonization and sulfonation approach. The microstructure of catalyst was activated by phosphoric acid impregnation. The catalyst afforded biodiesel yield $97.3 \%$ at optimum conditions which decreased to $83.7 \%$ in fourth reaction cycles. In addition, biodiesel production from oleic acid was reported using sulfonated activated carbon from bamboo. ${ }^{377} \mathrm{~A}$ sulfonated carbonaceous material synthesized via single-step hydrothermal sulfonation of glucose has also been used as a catalyst for esterification of waste cooking oil to produce biodiesel. ${ }^{378}$ FESEM images of the carbonaceous material (C) (Figure 32a) and the sulfonated carbonaceous material $\left(\mathrm{C}-\mathrm{SO}_{3} \mathrm{H}\right)$ (Figure 32b) showed microsphere and microsphere with an attached sulfonic group on the surface respectively. The catalyst showed great stability with 93.4 \% FAME yield under the optimized reaction conditions. 


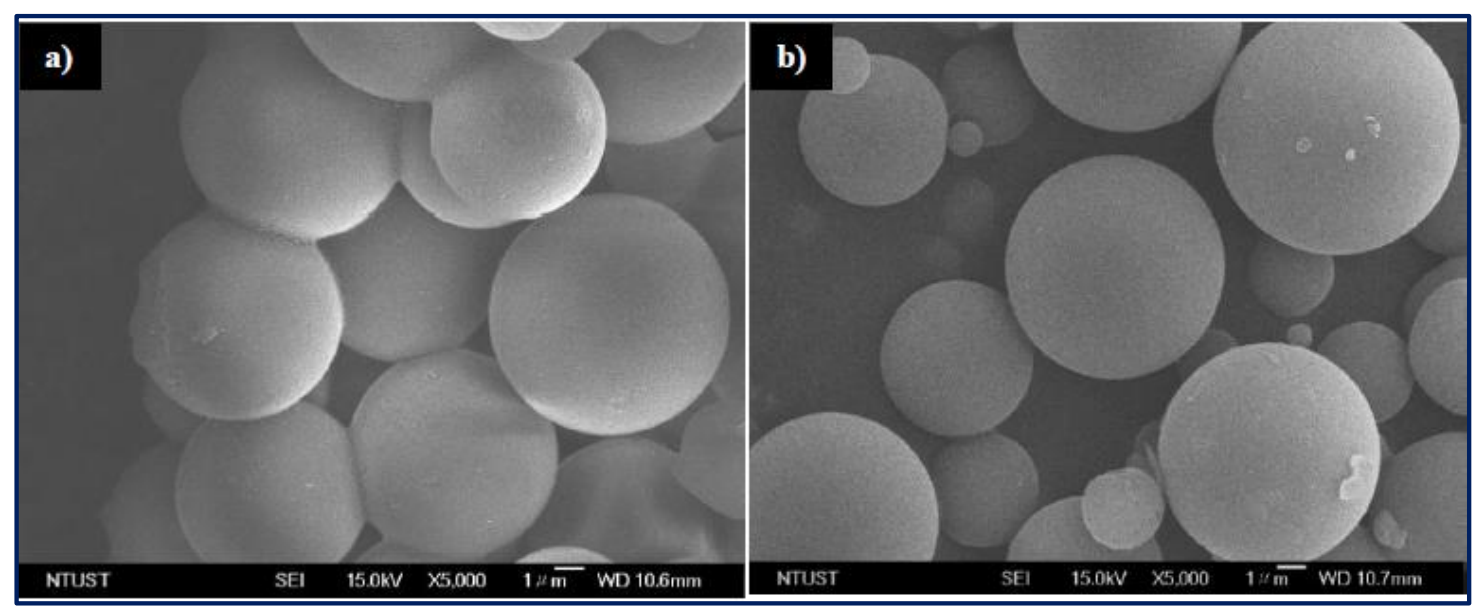

Figure 32: FESEM images of a) $\mathrm{C}$ and b) C-SO3H. Reproduced from ref. [378].

Guan et al. ${ }^{379}$ synthesized sulfonated multi-walled carbon nanotube (S-MWCNT) for the conversion of triglyceride to FAME in $97.8 \%$. The high catalytic reactivity is because of high surface area $\left(198.9 \mathrm{~m}^{2} \mathrm{~g}^{-1}\right)$, high porosity $(10-15 \mathrm{~nm})$ and high acid sites. Similarly, sulfonated carbonaceous material from starch was utilized as a solid catalyst for esterification of PFAD. ${ }^{380}$ A novel, efficient, inexpensive and environment-friendly acid catalyst was synthesized from coconut meal residue (CMR). CMR-DS- $\mathrm{SO}_{3} \mathrm{H}$ catalyst was prepared by a one-step direct in-situ carbonization in concentrated $\mathrm{H}_{2} \mathrm{SO}_{4}$ and reported for the transformation of waste palm oil (WPO) to biodiesel. The prepared sulfonated catalyst has acid density 3.8 $\mathrm{mmol} / \mathrm{g}$, surface area $1.33 \mathrm{~m}^{2} / \mathrm{g}$ and means pore volume $0.31 \mathrm{~cm}^{3} / \mathrm{g}$. The results obtained recorded a high yield of $92.7 \%$ biodiesel from WPO. ${ }^{381}$ Moreover, Wang et al. ${ }^{382}$ investigated the application of monodispersed hollow carbon/silica solid acid catalyst $\mathrm{HS} / \mathrm{C}-\mathrm{SO}_{3} \mathrm{H}$, which was prepared by chemical activation approach, in the esterification of oleic acid with methanol to produce biodiesel.

Besides this, another kind of sulfonated functionalized carbon material i.e. sulfonated ordered mesoporous carbon (SOMC) catalyst showed promising biodiesel production (73.59\% yield). ${ }^{383}$ Recently, sulfonated acid catalyst obtained from corncob $\left(\mathrm{SO}_{4}{ }^{2-}\right.$ /corncob), has been reported as an excellent catalyst for conversion of oleic acid to obtain methyl oleate in good yield (> $80 \%$ after $8 \mathrm{~h}$ at $60{ }^{\circ} \mathrm{C}$ ). ${ }^{384}$ Mahdavi and Darabi ${ }^{385}$ prepared sulfonated carbon catalyst by treatment of sucrose and concentrated $\mathrm{H}_{2} \mathrm{SO}_{4}$ at high temperature (sulfonation and carbonization approach). The synthesized $\mathrm{C}-\mathrm{SO}_{3} \mathrm{H}$ catalyst was further utilized for the conversion of oleic acid to FAME in $93.04 \%$ yield. Moreover, a solid acid catalyst generated from sulfonation of microcrystalline cellulose powder was successfully applied for oleic acid esterification, showed $99.9 \%$ biodiesel yield under the optimized reaction 
conditions. ${ }^{386}$ In another investigation, waste cooking oil was transformed to produce biodiesel utilizing an environmentally benign sulfonated carbon microsphere catalyst. ${ }^{387}$ The catalyst with surface area $86 \mathrm{~m}^{2} / \mathrm{g}$ and acidity $1.38 \mathrm{mmol} / \mathrm{g}$ was developed by consecutive hydrothermal carbonization and sulfonation of xylose. Using this catalyst, biodiesel yield of $89.6 \%$ was recorded at optimal reaction conditions. Catalyst reusability report revealed that in each cycle biodiesel yield was reduced by $9 \%$. Furthermore, sulfonated carbon-based solid acid catalyst was also utilized for the transformation of PFAD ${ }^{388}$ and Mesua Ferrea Linn oil ${ }^{389}$ to biodiesel.

To bring down the cost of biodiesel production, several sulfonated raw biomass has been prepared and investigated for their catalytic activities. In this line, a sulfonated solid-acid catalyst obtained from coconut shells $\left(\mathrm{SO}_{4}{ }^{2-} /\right.$ coconut shell) reported $88.03 \%$ biodiesel yield. ${ }^{390}$ In the same vein, oil palm trunk/ sugarcane bagasse, ${ }^{391}$ corn straw, ${ }^{392}$ bamboo, ${ }^{393}$ Jatropha curcas seed, ${ }^{394}$ bio-glycerol,${ }^{395}$ glycerol, ${ }^{396}$ microalgae residue, ${ }^{397}$ oil cake waste,${ }^{398,399}$ de-oiled waste cake, ${ }^{400}$ de-oiled canola meal- $\mathrm{SO}_{3} \mathrm{H},{ }^{401}$ pine chip char ${ }^{402}$ and biochar ${ }^{403,404}$ are reported as a catalysts for FAME production.

Table 19: Different sulfonated carbon-based acid catalyst used for biodiesel production.

\begin{tabular}{|c|c|c|c|c|c|}
\hline No. & Catalyst & Feedstock & ${ }^{a}$ Conditions & Yield (\%) & Ref. \\
\hline 1. & $\begin{array}{l}\text { Sulfonated } \\
\text { sugar }\end{array}$ & Oleic acid & $10: 1^{f}, 7.4,80,240$ & NR & 364 \\
\hline 2. & $\begin{array}{l}\text { Sulfonated } \\
\text { carbon }\end{array}$ & Oleic acid & $\begin{array}{l}2.92: 1^{c}, 17.2,95, \\
240\end{array}$ & 99.9 & 365 \\
\hline 3. & $\mathrm{ACPhSO}_{3} \mathrm{H}$ & Rapeseed oil & $20: 1,10,65,420$ & 95 & 366 \\
\hline 4. & Sulfonated AC & Soybean oil & $6: 1,20,75,20$ & 88.7 & 355 \\
\hline 5. & $\mathrm{H}_{2} \mathrm{SO}_{4} / \mathrm{C}$ & Castor oil & $12: 1,5,65,60$ & 94 & 369 \\
\hline 6. & SAM & Vegetable oil & $10: 1,6,180,120$ & 95 & 370 \\
\hline 7. & $\mathrm{SO}_{3} \mathrm{H} / \mathrm{SBA}-15$ & Soybean oil & $6: 1,5,190,30$ & 90 & 371 \\
\hline 8. & $\begin{array}{l}\mathrm{SiO}_{2}-\mathrm{Pr}- \\
\mathrm{SO}_{3} \mathrm{H}\end{array}$ & Acid oil & $15: 1,4,100,480$ & $96.78^{b}$ & 372 \\
\hline 9. & $\mathrm{OPPSO}_{3} \mathrm{H}$ & Soybean oil & $50: 1^{c}, 10,70,600$ & $93^{b}$ & 373 \\
\hline 10. & $\begin{array}{l}\text { Coal based } \\
\text { solid acid }\end{array}$ & Oleic acid & $10: 1,8,240,67$ & $97.6^{b}$ & 375 \\
\hline
\end{tabular}


11. Sulfonated $\quad$ Oleic acid $\quad 10: 1,10,65,120 \quad 97.3 \quad 376$

carbon-based

solid acid

12. Sulfonated Oleic acid $7: 1^{f}, 12,180,85 \quad 96^{b}$

activated

carbon

13. $\mathrm{C}-\mathrm{SO} 3 \mathrm{H}$

Waste cooking $20: 1,10,60,180 \quad 93.6$

378

oil

14. Sulfonated Triglycerides $10: 1^{f}, 3.7,60,150 \quad 97.8^{b}$

379

multiwalled

carbon

nanotube

15. ICS-SO3H Palm fatty acid $10: 1,2,180,75 \quad 90$.

380

distillate

16. CMR-DS- Waste palm oil $12: 1,5,65,72$

381

$\mathrm{SO}_{3} \mathrm{H}$

17. $\mathrm{HS} / \mathrm{C}-\mathrm{SO}_{3} \mathrm{H} \quad$ Oleic acid $\quad 5: 1,3.5,80,300 \quad 96.9^{b} \quad 382$

18. SOMC Oleic acid $\quad 10: 1,3.5,80,600 \quad 73.59^{b} \quad 383$

19. $\mathrm{SO}_{4}{ }^{2-} /$ corncob $\quad$ Oleic acid $\quad 15: 1,5,60,480 \quad>80 \quad 384$

20. ${\mathrm{C}-\mathrm{SO}_{3} \mathrm{H}} \quad$ Oleic acid $\quad 10: 1,1.5,67,120 \quad 93.04 \quad 385$

21. ${\mathrm{C}-\mathrm{SO}_{3} \mathrm{H}} \quad$ Oleic acid $\quad 16: 1,17,95,240 \quad 99.9 \quad 386$

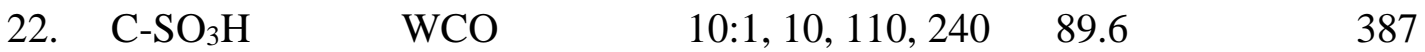

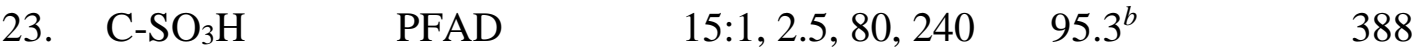

24. ${\mathrm{C}-\mathrm{SO}_{3} \mathrm{H}}^{2}$ Mesua Ferrea $40: 1,5,120,1440 \quad 97.79$

Linn oil

25. Coconut shell- Palm oil 30:1, 6, 60,360 390 $\mathrm{SO}_{3} \mathrm{H}$

26. Oil palm Waste Oil $\quad 1.17 \mathrm{~mL} / \mathrm{min}, 12, \quad 80.6 / 83.2 \quad 391$

trunk/

130,240

Sugarcane

bagasse- $\mathrm{SO}_{3} \mathrm{H}$

27. Corn straw- Oleic acid $3: 1,3,60,240$

$92 \quad 392$

$\mathrm{SO}_{3} \mathrm{H}$ 


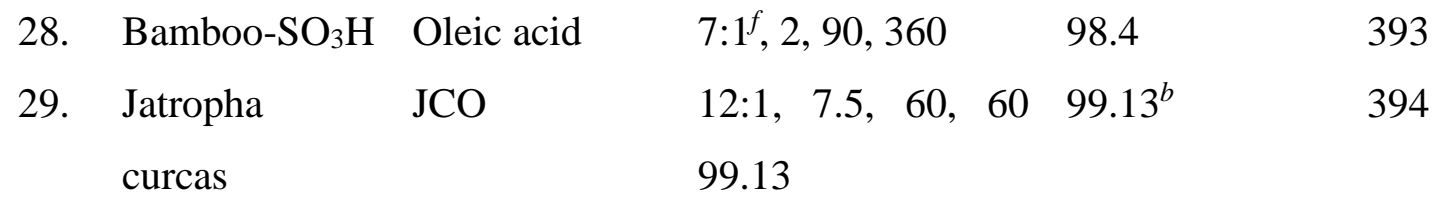
Seed- $\mathrm{SO}_{3} \mathrm{H}$

30. Bio-glycerol Karanja oil 45:1, 20, 160, $240 \quad 99.5 \quad 395$

31. Glycerol Palmitic acid $9.7: 1^{c}, 10,65,240 \quad 99^{b} \quad 396$

32. Microalgae $\quad$ Oleic acid $\quad$ NR,5, 80, $720 \quad 98^{b} \quad 397$ residue

33. Oil cake JCO/ $M . \quad 43: 1,5,80,480 \quad 99 \quad 398$ waste- $\mathrm{SO}_{3} \mathrm{H} \quad$ ferrea

L. oil

34. Oil cake $\quad$ Oleic acid $\quad 12: 1,20,60,120 \quad 94^{b} \quad 399$ waste- $\mathrm{SO}_{3} \mathrm{H}$

35. De-oiled waste Oleic acid $\quad 20: 1,3,64,600 \quad 97^{b} \quad 400$ cake

36. De-oiled $\quad$ Oleic acid $\quad 60: 1,7.5,65,1440 \quad 93.8^{b} \quad 401$ canola Meal- $\mathrm{SO}_{3} \mathrm{H}$

37. Pine chip char Palmitic acid 6:1,5,55-60,300 $97 \quad 402$

38. Biochar Canola oil 15:1 $f, 5,65,1440 \quad 92403$

39. Biochar Canola oil, $30: 1,5,315,180 \quad 48 \quad 404$ oleic acid ${ }^{b}$ Conversion

$1836{ }^{f}$ Ethanol to oil molar ratio

1837 NR: Not reported.

\subsection{Enzyme catalyst}

In recent years, enzyme catalysts are widely examined for the production of biodiesel 1841 as they produce high-quality biodiesel, improve the product separation process, mild reaction 1842 conditions and most importantly their ecological benignness (Table 20). ${ }^{405,406}$ Besides, they do 1843 not form soap with FFA contrary to the alkaline catalyst and hence can be utilized in the 1844 biodiesel production in industrial scale. 
In biocatalyst mediated reactions, usually enzymes can be used in free form or can be immobilized on a matrix, i.e. immobilized lipase. ${ }^{407}$ The free enzymes are more sensitive towards the $\mathrm{pH}$, temperature and impurities of reactants which may create obstacle in bioprocesses. However, these problems can be overcome by immobilizing enzyme onto different types of support materials. ${ }^{408}$ The commonly adopted immobilization methods for biological processes include entrapment, adsorption and covalent bonding. Among these techniques, entrapment found to be effective offering greater advantages such as ease of process scale up, higher stability of enzyme and longer enzymatic activity retention. ${ }^{409,410}$ Mostly lipase enzymes obtained from microbial sources have been used for biodiesel production ${ }^{411}$ proposed the method for large scale production of bacterial or fungal lipases due to their extracellular nature. Moreover, lipases obtained from diverse plant sources are also considered as the potential substitute for catalysing the transesterification process. ${ }^{412}$ The advantages associated with lipase catalyst over the other catalyst used in biodiesel production are superior quality and higher yield of biodiesel, free from soap formation, lower reaction temperature and can work on variety of feedstock. ${ }^{413}$

Compared to homogeneous and heterogeneous catalysts, enzymatic catalysts are less studied hence scanty of literature is available when compared with reports on above-mentioned two catalysts. However, the high cost of the free lipase catalyst along with the limited longterm use has led to the exploitation of immobilized lipase catalyst to reduce the cost of the catalyst and its reusability. Apart from that, immobilized lipase catalyst showed greater tolerance to $\mathrm{pH}$ variation, high thermal stability and high substrate selectivity. ${ }^{414,415}$ To date, large number of literature are available in the field of biodiesel production using both free ${ }^{416-}$ 418 and immobilized ${ }^{419-422}$ enzyme catalyst.

demonstrated the lipase enzyme mediated transesterification of waste cooking oil (WCO) and reported $88 \%$ of biodiesel yield. MarínSuárez et al. ${ }^{424}$ demonstrated the lipase-catalyzed transesterification of low quality fish oil through the process optimization, moreover, the reusability of enzyme was also studied. Authors evaluated the efficacy of commercially available immobilized enzymes such as Liposome RM IM, Lipozyme TL IM and Novozym $435^{425}$ for biodiesel production from waste fish oil. The results obtained revealed that Novozym 435 showed maximum catalytic activity resulting in highest yield of FAME i.e. $82.91 \mathrm{wt}$ \% and enzyme can be reused for about ten successive cycles. In another study, it was reported that immobilized lipase (Epobond $P$. cepacia) employed in transesterification of waste vegetable oil reported to achieve ester yield of $46.32 \%{ }^{426}$ Similarly, the Candida cylindracea lipase immobilised on the functionalised 
activated carbon was tested as a catalyst in the transesterification of Jatropha curcas oil. It was found that free fatty acid yield of $78 \%$ was achieved at optimized reaction conditions and further biocatalyst was found stable up to four consecutive cycles of transesterification. ${ }^{427}$ Beside, lipase obtained from plant source like rice bran lipase produced $83.4 \mathrm{wt}$ \% FAME yield from rice bran oil under optimized conditions. ${ }^{428}$

Moreover, Muanruksa and Kaewkannetra ${ }^{429}$ examined the biodiesel production from

Table 20: Different enzyme catalysts reported for the production of biodiesel.

\begin{tabular}{|c|c|c|c|c|c|}
\hline $\begin{array}{l}\text { Sl. } \\
\text { No }\end{array}$ & Catalyst & Feedstock & ${ }^{a}$ Conditions & Yield & Ref. \\
\hline 1 & $\begin{array}{l}\text { Lipase immobilized on } \\
\text { biosupport beads }\end{array}$ & $\begin{array}{l}\text { Hybrid non } \\
\text { edible oils }\end{array}$ & $6: 1^{\mathrm{c}}, 10,50,1440$ & $\sim 78$ & 407 \\
\hline 2 & Lipase & WCO & $3: 1,1.5,65,240$ & 88 & 423 \\
\hline 3 & $\begin{array}{l}\text { Thermomysis } \\
\text { Lanugonosus Lipase }\end{array}$ & $\begin{array}{l}\text { Rubber seed } \\
\text { oil }\end{array}$ & $4: 1,5, \mathrm{NR}, 65$ & 92.83 & 416 \\
\hline 4 & $\begin{array}{l}\text { CalleraTM Trans L } \\
\text { lipase }\end{array}$ & Soybean oil & $\begin{array}{l}4.51: 1, \quad 1.45, \quad 35 \\
1440\end{array}$ & 96.9 & 417 \\
\hline 5 & Lipase@AC & Sardine oil & $9: 1,10,30,600$ & 94.5 & 418 \\
\hline 6 & $\begin{array}{l}\text { Lipase@APTES- } \\
\mathrm{Fe}_{3} \mathrm{O}_{4}\end{array}$ & $\begin{array}{l}\text { Aspergillus } \\
\text { lipid }\end{array}$ & $4: 1,300^{b}, 45,240$ & 84 & 419 \\
\hline 7 & Lipase@ZIF-67 & Soybean oil & $6: 1,10,45,3600$ & 78 & 420 \\
\hline 8 & Lipase@[bmim] $]\left[\mathrm{PF}_{6}\right]$ & $\begin{array}{l}\text { Food } \\
\text { compost }\end{array}$ & $6: 1,40,50,840$ & 72 & 421 \\
\hline
\end{tabular}


compost

10 Lipase@Immobead

Blended

$7.64: 1, \quad 3.55, \quad 36, \quad 94$

422

non-edible

120

oils

$11 \quad$ Novozym 435 lipase

Waste fish

$35.45: 1$

$50, \quad 35, \quad 82.91$

424

oil

480

wt \%

12 Novozym 435 lipase

BSFL fat

14.64: $1^{\mathrm{e}}$,

96.97

425

$17.58,39.5,720$

13 Immobilized lipase Waste

$3: 1^{\mathrm{d}}, 3,37,90$

46.32

426

(Epobond-

vegetable

Pseudomonas cepacia)

oil

14 Immobilized Candida

Jatropha

HR, 8,40,1440

78

427

cylindracea lipase

curcas oil

15 Immobilised Rhizopus

sludge palm $3: 1,5,40,240$

91.30

428

oryzae lipase

oil (SPO)

16 Lipase (from rice bran)

\section{Rice Bran}

6:1, NR,40, 17280

83.4

429

oil

wt $\%$

1896

1897

1898

1899

1900

1901

1902

1903

1904

1905

1906

1907

1908

${ }^{a}$ Methanol-to-oil molar ratio, catalyst loading (wt. \%), temperature $\left({ }^{\circ} \mathrm{C}\right.$ ), reaction time (min).NR: Not reported.

${ }^{b}$ miligram

\subsection{Bifunctional solid catalysts}

Despite the high reactivity of the basic solid catalyst towards biodiesel production, they are not an effective catalyst for transesterification of oils having a high amount of FFA as such catalyst are highly sensitive to the FFA, which leads to soap generation and thus interfere in the separation process of glycerol from biodiesel. On the other hand, solid acid catalysts are insensitive to the FFA content and esterify waste oils or low-cost oils without any requirement of pretreatment. However, water formed during the course of the reaction may lead to the decomposition of triglycerides to diglycerides, resulting in the formation of more FFA and catalyst leaching. ${ }^{430}$ Taking these difficulties into account, developing a new type of solid 
catalysts that possess dual characteristics such as solid acidic character to tackle the FFA and solid basic character for easy transesterification of triglycerides to FAME has been a recent interest in the realm of biodiesel research. To date, numerous bifunctional catalysts are reported for the FAME production (Table 21), which will be discussed in this section. Faroog et al. ${ }^{78}$

1913 developed a bifunctional $\mathrm{Mo}-\mathrm{Mn} / \gamma-\mathrm{Al}_{2} \mathrm{O}_{3}-\mathrm{MgO}$ catalyst and utilized it for the simultaneous 1914 esterification/transesterification of WCO having FFA content of $3.27 \mathrm{mg} \mathrm{KOH} / \mathrm{g}$. The authors 1915 investigated the effect of $\mathrm{MgO}$ loading (5-20 wt. \%) on its catalytic activity and found that 15 1916 wt. \% MgO loading showed highest catalytic activity with $91.4 \%$ biodiesel yield under the 1917 ideal reaction conditions. Moreover, the catalyst showed excellent stability towards the 1918 biodiesel production from WCO as it is stable up to 8 progressive reaction cycles without any major loss of its activity. In another study, $\mathrm{Cu} / \mathrm{Zn} / \gamma-\mathrm{Al}_{2} \mathrm{O}_{3}$ catalyst was utilized for the 1920 simultaneous esterification/transesterification of WCO for production of FAME via RSM. ${ }^{431}$ 1921 The effect of $\mathrm{Cu} / \mathrm{Zn}$ wt. \% ratio and calcination temperature on the catalytic reactivity was also 1922 examined and found that $10: 90 \mathrm{Cu} / \mathrm{Zn}$ wt. $\%$ ratio and $800{ }^{\circ} \mathrm{C}$ calcination temperature showed $192388.82 \%$ FAME yield. The authors also studied the structure and particle size of the synthesized 1924 catalyst via TEM micrographs (Figure 33). Figure 33a displayed that the average diameter of the particles lies in between 4-6 nm. The lattice fringes measured from Figure 33b, $\mathrm{c}$ and $\mathrm{d}$ are $0.201,0.282$ and $0.242 \mathrm{~nm}$, matched with the hkl planes (400), (220) and (311) of alumina respectively. The lattice fringes in Figure $33 \mathrm{e}$ is $0.240 \mathrm{~nm}$ fitted with the hkl plane (200) of $1928 \mathrm{CuO}$ and lattice fringes $0.281 \mathrm{~nm}$ (Figure 33f) fitted with the $\mathrm{ZnO}$ plane (100). Similarly, 1929 biodiesel production from WCO was reported using diverse bifunctional solid catalysts such 1930 as $\mathrm{Mg} / \mathrm{MCM}-41,{ }^{432} \gamma-\mathrm{Al}_{2} \mathrm{O}_{3}-\mathrm{CeO}_{2},{ }^{433} \mathrm{KAcZX}{ }^{434}$ and $\mathrm{Sr} / \mathrm{ZrO}_{2}{ }^{435}$ etc. 


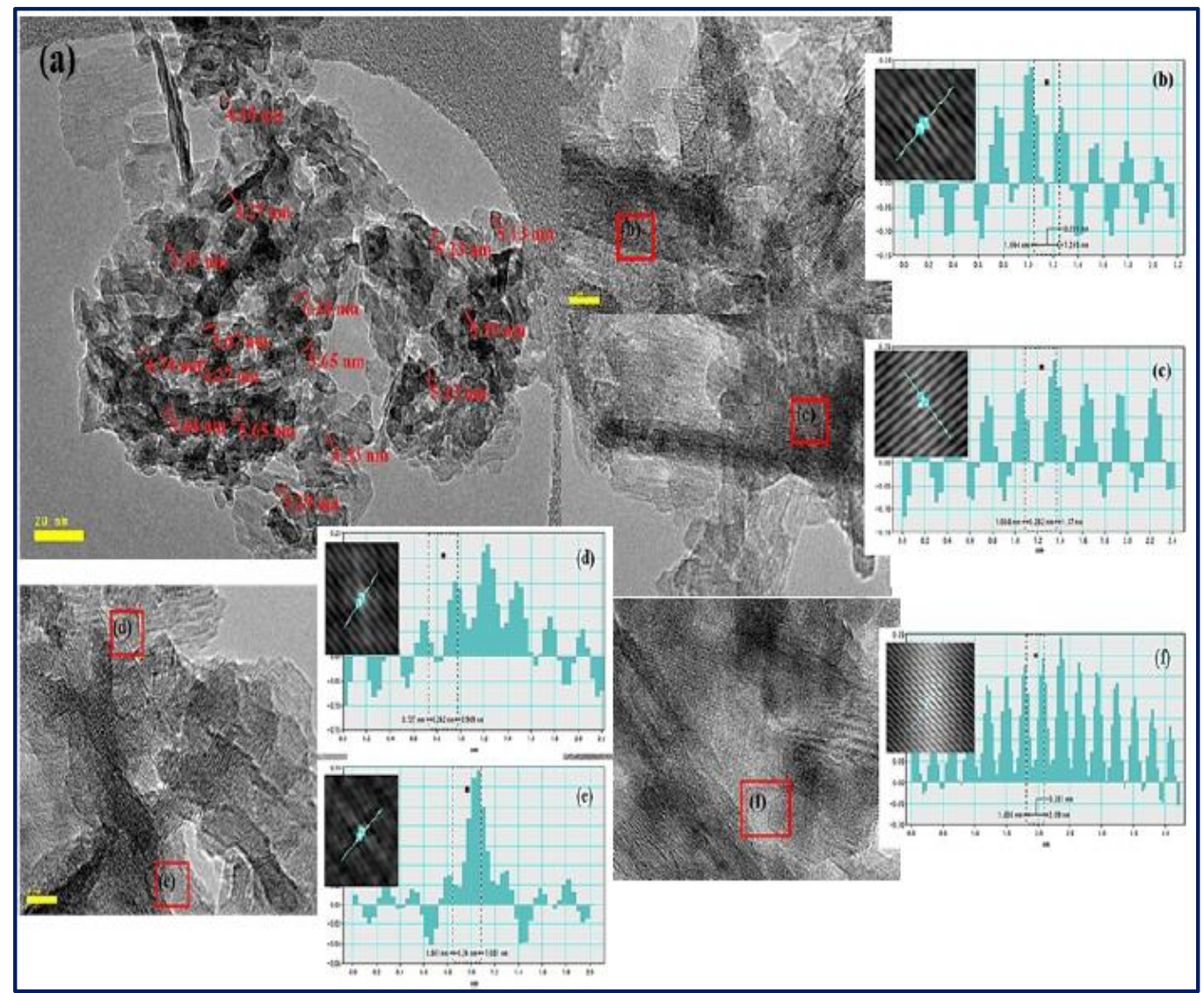

Figure 33: TEM micrograph for $\mathrm{Cu} / \mathrm{Zn}(10: 90) / \gamma-\mathrm{Al}_{2} \mathrm{O}_{3}-800{ }^{\circ} \mathrm{C}$ (a) HRTEM displayed the lattice fringes of (b) $\mathrm{Al}_{2} \mathrm{O}_{3}$ (400), (c) $\mathrm{Al}_{2} \mathrm{O}_{3}$ (220), (d) $\mathrm{Al}_{2} \mathrm{O}_{3}$ (311), (e) $\mathrm{CuO}(200)$ and (f) $\mathrm{ZnO}$ (100). Reproduced from ref. [431].

Nizah et al. ${ }^{436}$ synthesized a bifunctional catalyst $\mathrm{Bi}_{2} \mathrm{O}_{3}-\mathrm{La}_{2} \mathrm{O}_{3}$ via wet impregnation procedure and employed it for one-pot esterification/transesterification of JCO having FFA content of $6.1 \mathrm{mg} \mathrm{KOH} / \mathrm{g}$. The authors investigated the influence of $\mathrm{Bi}_{2} \mathrm{O}_{3}$ impregnation on $\mathrm{La}_{2} \mathrm{O}_{3}$ support by varying the wt. $\%$ of $\mathrm{Bi}_{2} \mathrm{O}_{3}$ in the range of $1-7$ wt. $\%$ and found that 5 wt. $\%$ $\mathrm{Bi}_{2} \mathrm{O}_{3}$ impregnated on $\mathrm{La}_{2} \mathrm{O}_{3}$ showed maximum biodiesel yield of $94 \%$. The high catalyst reactivity is attributed to the well dispersion of $\mathrm{Bi}_{2} \mathrm{O}_{3}$ on $\mathrm{La}_{2} \mathrm{O}_{3}$ support, that directly enhanced the surface area and thus increases selectivity and rate of the reaction. Similarly, biodiesel production from JCO having a high amount of FFA was reported by using a bifunctional solid catalyst $\mathrm{CaO}-\mathrm{La}_{2} \mathrm{O}_{3}{ }^{437}$ The esterification/transesterification was performed in a hightemperature reactor (Figure 34). The effect of $\mathrm{Ca} / \mathrm{La}$ atomic ratio on the catalytic activity was examined and observed that 0.8 atomic ratio of $\mathrm{Ca} / \mathrm{La}$ showed maximum biodiesel yield of $98.76 \%$ under the optimized reaction conditions. The high catalytic reactivity is because of well dispersion of $\mathrm{CaO}$ on the surface of $\mathrm{La}_{2} \mathrm{O}_{3}$, that led to an increase in catalyst surface area. 
Moreover, the synthesized catalyst is chemically stable and can be used for 4 consecutive cycles.

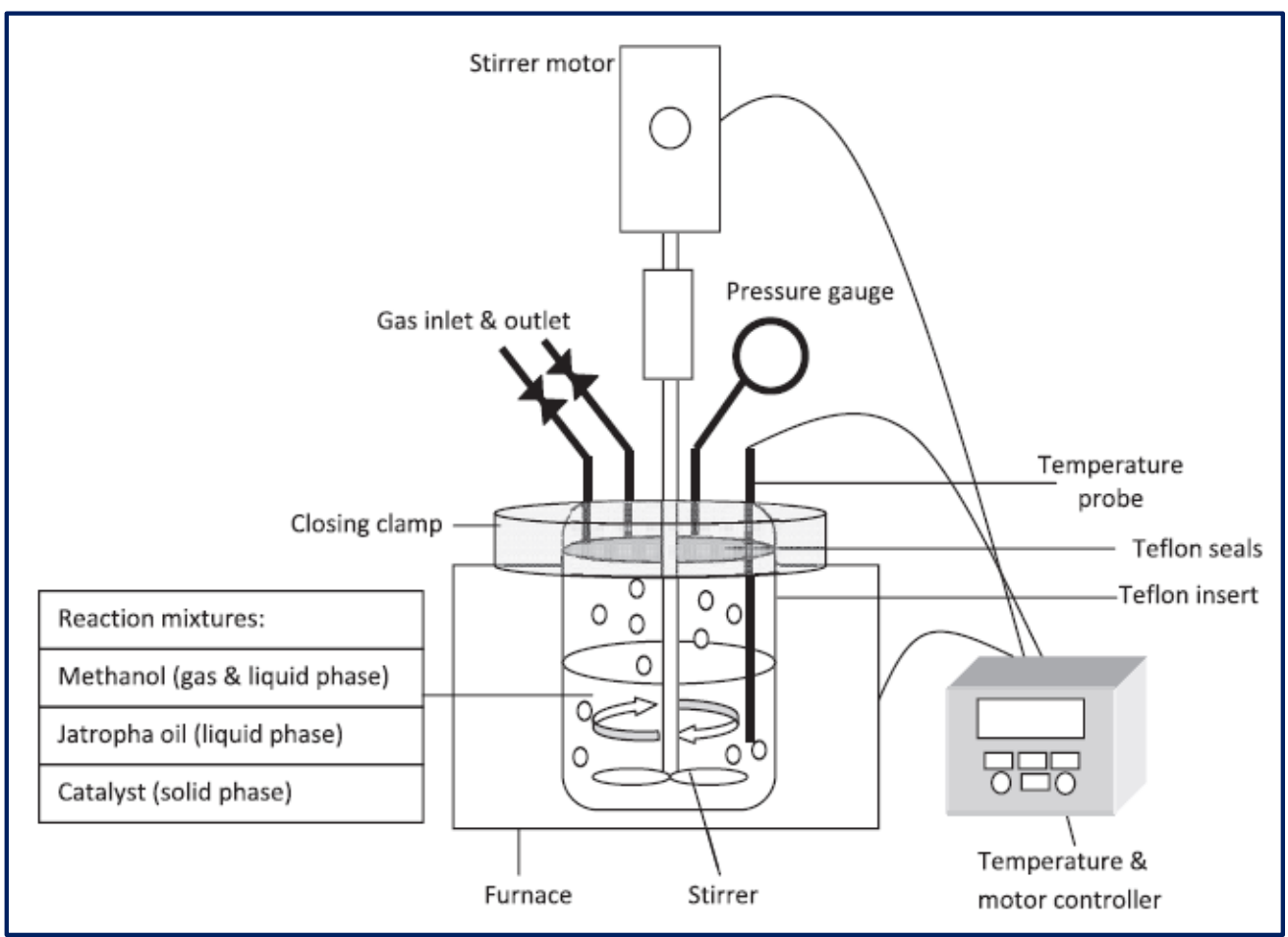

Figure 34: Schematic diagram of a high-temperature reactor. Reproduced from ref. [437].

Another study revealed the synthesis of mixed metal oxide $\mathrm{Mn} @ \mathrm{MgO}-\mathrm{ZrO}_{2}$ via coprecipitation and impregnation method and utilization of the catalyst in the FAME production from kernel oil. ${ }^{438}$ The efficiency of the catalyst in FAME production was tested by changing the $\mathrm{Mg} / \mathrm{Zr}$ ration from $0.2-05$ and found that $0.4 \mathrm{Mg} / \mathrm{Zr}$ has the optimal active sites followed by impregnation of $4 \mathrm{wt}$. $\% \mathrm{Mn}$ to $\mathrm{MgO}-\mathrm{ZrO}_{2}$ composite to enhance its reactivity and displayed $96.4 \%$ biodiesel yield. The high catalyst reactivity is due to a large number of active sites and the mesoporous nature of the catalyst. Jeon et al. ${ }^{439}$ synthesized heteropolyacid (HPA) functionalized ZIF-8 (zeolite imidazole framework-8) to form a bifunctional catalyst for the production of biodiesel from rapeseed oil in a batch reactor. The catalyst possesses core-shell nanostructure as displayed by the TEM micrograph (Figure 35), where the rhombic dodecahedral ZIF-8 core was surrounded by thin-wrinkled HPA shell, thus enhances the surface area and catalyst reactivity. Moreover, the effect of concentration of HPA for the functionalization was also tested by varying the amount of HPA such as $0.05,0.1,0.3$ and 0.5 and found that $0.1 \mathrm{~g}$ HPA functionalized ZIF-8 showed maximum FAME conversion of 98.02 
$\%$ under the optimized reaction conditions. Similarly, another bifunctional catalyst organotriphosphonic acid-functionalized ferric alginate (ATMP-FA) was developed for the oleic acid esterification to produce biodiesel. ${ }^{440}$ The reaction conditions are optimized by using Box-Behnken model of RSM. Moreover, the catalyst is very stable towards the esterification reaction and can be reused for 5 consecutive cycles.

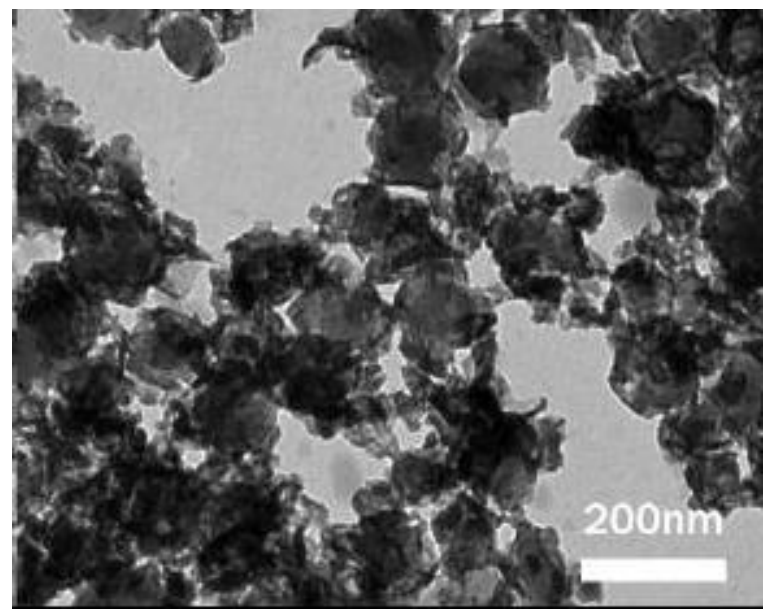

Figure 35: TEM image of HPA-ZIF-8.

Reproduced from ref. [439].

Recently, a solid bifunctional catalyst originated from bio-waste angel wing shell (AWS) via two-step processes-i) calcination of angel wing shell and ii) sulfonation of the calcined angel wing shell to produce sulfonated angel wing shell ( $\mathrm{AWS} / \mathrm{SO}_{4}{ }^{2-}$ ) was reported for esterification of PFAD to produce biodiesel. ${ }^{441}$ The sulfonation procedure increases the surface area of bare AWS from 3.88 to $6.53 \mathrm{~m}^{2} \mathrm{~g}^{-1}$, thus enhanced the catalytic reactivity. The authors tested the influence of sulfuric acid concentration by varying the sulfuric acid amount from 3-11 $\mathrm{M}$ and found that sulfonation with 7M sulfuric acid showed $98 \%$ FAME yield. The authors also checked the reusability of the catalyst and observed blockage of the active sites of the catalyst after $2^{\text {nd }}$ consecutive cycles; which necessitate pretreatment of the spent catalyst to increase its reusability. In addition, a coordinated polymer of $\mathrm{Zn},\left[\mathrm{Zn}\left(4,4^{\prime}-\text { bipy }\right)(\mathrm{OAc})_{2}\right]_{\mathrm{n}}$ was tested for the soybean oil transformation to FAME. ${ }^{442}$ The catalyst showed excellent reactivity and showed $98 \%$ FAME yield under the optimized reaction conditions. The authors reported that the high reactivity of the catalyst is attributed to the bipyridine present in the catalyst. In another study, the conversion of canola oil to FAME was reported using potassium impregnated titania $\left(\mathrm{K} / \mathrm{TiO}_{2}\right) .{ }^{443}$ The addition of $\mathrm{K}$ on the surface of titania increases the surface 
energy from 86 to $102 \mathrm{~m}^{2} / \mathrm{g}$, thus enhanced the catalytic activity. The authors investigated the effect of $\mathrm{K}$ loading on catalytic activity and found that $20 \mathrm{wt}$. \% $\mathrm{K}$ loaded titania was optimum and showed $100 \%$ conversion of canola oil to biodiesel.

Table 21: Different bifunctional solid catalyst reported for biodiesel production.

\begin{tabular}{|c|c|c|c|c|c|}
\hline No & Catalyst & Feedstocks & ${ }^{a}$ Conditions & $\begin{array}{l}\text { Yield } \\
(\%)\end{array}$ & Ref. \\
\hline 1 & $\begin{array}{l}\mathrm{Mo}-\mathrm{Mn} / \gamma-\mathrm{Al}_{2} \mathrm{O}_{3-} \\
15 \% \mathrm{MgO}\end{array}$ & $\mathrm{WCO}$ & $27: 1,3,100,240$ & 91.4 & 78 \\
\hline 2 & $\begin{array}{l}\mathrm{Cu} / \mathrm{Zn}(10: 90) / \gamma- \\
\mathrm{Al}_{2} \mathrm{O}_{3}-800{ }^{\circ} \mathrm{C}\end{array}$ & WCO & $18: 1,6,65 \pm 5,180$ & 88.82 & 431 \\
\hline 3 & Mg/MCM-41 & WCO & $8: 1,10,80,180$ & 94 & 432 \\
\hline 4 & $\gamma-\mathrm{Al}_{2} \mathrm{O}_{3}-\mathrm{CeO}_{2}$ & WCO & $30: 1,7,110,270$ & 81.1 & 433 \\
\hline 5 & KAcZX & WCO & $48: 1,6,120,180$ & 80.8 & 434 \\
\hline 6 & $\mathrm{Sr} / \mathrm{ZrO}_{2}$ & WCO & $29: 1,2.7,115.5,169$ & 79.7 & 435 \\
\hline 7 & $\mathrm{Bi}_{2} \mathrm{O}_{3}-\mathrm{La}_{2} \mathrm{O}_{3}$ & $\mathrm{JCO}$ & $15: 1,2,150,240$ & 94 & 436 \\
\hline 8 & $\mathrm{CaO}-\mathrm{La}_{2} \mathrm{O}_{3}$ & $\mathrm{JCO}$ & $25: 1,3,160,180$ & 98.76 & 437 \\
\hline 9 & $\mathrm{Mn} @ \mathrm{MgO}-\mathrm{ZrO}_{2}$ & Kernel oil & $15: 1,3,90,240$ & 96.4 & 438 \\
\hline 10 & HPA@ZIF-8 & Rapeseed oil & $10: 1,4,240,300$ & $98.02^{b}$ & 439 \\
\hline 11 & $\mathrm{AWS} / \mathrm{SO}_{4}{ }^{2-}$ & PFAD & $15: 1,5,80,180$ & 98 & 441 \\
\hline 12 & $\begin{array}{l}{\left[\mathrm{Zn}\left(4,4^{\prime}-\right.\right.} \\
\left.\text { bipy })(\mathrm{OAc})_{2}\right]_{\mathrm{n}}\end{array}$ & Soybean oil & $3.2 / 5(\mathrm{v} / \mathrm{v}), 2,180,120$ & 98 & 442 \\
\hline 13 & $\mathrm{~K} / \mathrm{TiO}_{2}$ & Canola oil & $36: 1,6,70,180$ & $100^{b}$ & 443 \\
\hline
\end{tabular}

${ }^{a}$ Methanol-to-oil molar ratio, catalyst loading (wt. \%), temperature $\left({ }^{\circ} \mathrm{C}\right)$, reaction time $(\mathrm{min})$.

\section{Biodiesel production process}

Biodiesel can be produced by (trans)esterification, thermal cracking and pyrolysis. ${ }^{444-}$ 447 Amongst all these methods, transesterification is generally utilized for the synthesis of biodiesel. ${ }^{447}$ The generalized diagram for biodiesel production process is presented in Figure 36 which consists of synthesis and purification steps. ${ }^{448}$ Alkali, acid and enzyme are routinely exploited as a catalyst for the transesterification reactions. These catalysts had their own merits and demerits as compiled in Table $22 .{ }^{449}$ Till now, homogeneous base catalysts such as $\mathrm{NaOH}$, $\mathrm{KOH}$ are normally utilized for biodiesel synthesis in industrial scale. In the meantime, owing 
to their capacity to catalyze both esterification/transesterification reactions, a homogeneous acid catalyst such as $\mathrm{H}_{2} \mathrm{SO}_{4}$ and $\mathrm{HCl}$ are generally picked for feedstock having high FFA such as non-edible vegetable oil, WCO and animal fats. Recently, the heterogeneous catalyst has attracted interest to a great extent for biodiesel synthesis because of their easy recyclability and reusability for successive reaction cycles.

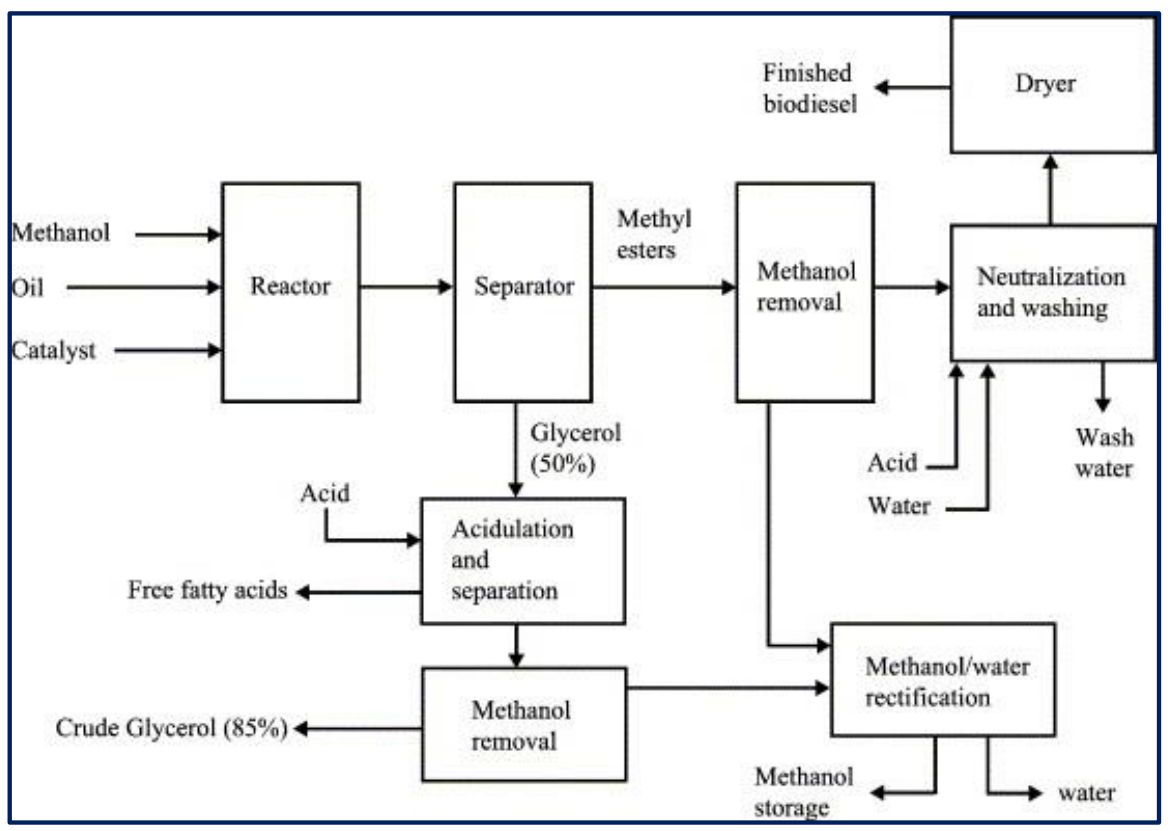

Figure 36: Representative diagram for biodiesel production.

Reproduced from ref. [447].

Table 22: Points of interest and detriments of different catalyst utilized for transesterification/esterification reaction (Reproduced from ref. [449]).

\begin{tabular}{|c|c|c|c|}
\hline Catalyst types & Examples & Advantages & Disadvantages \\
\hline \multicolumn{4}{|l|}{ Homogeneous } \\
\hline Alkali & $\begin{array}{l}\mathrm{NaOH}, \\
\mathrm{KOH}\end{array}$ & $\begin{array}{l}\text { - High reactivity } \\
\text { - } \text { Faster reaction rate } \\
\text { - } \text { Minimum cost } \\
\text { - Encouraging kinetics } \\
\text { - Moderate working } \\
\text { conditions }\end{array}$ & $\begin{array}{l}\text { Inappropriate for high } \\
\text { FFA in feedstocks } \\
\text { of moisture and FFA. } \\
\text { - Requirement of high } \\
\text { amount of waste water }\end{array}$ \\
\hline
\end{tabular}


- Saponication occurs as a side reaction.

- Non-recyclable

- Corrosive in nature

Acid

$\begin{array}{ll}\mathrm{H}_{2} \mathrm{SO}_{4}, \mathrm{HCl}, \quad & \text { Non-reactive to } \\ \mathrm{HF} \text { etc. } & \text { moisture and FFA } \\ & \text { content in oil. } \\ & =\text { Catalyzed simultaneous } \\ & \text { esterification/transester } \\ & \text { ification reactions. } \\ = & \text { Avoid formation of } \\ & \text { soap. }\end{array}$

- Slow reaction rate

- Long reaction time

- Equipment corrosion

- Higher reaction temperature and pressure

- High alcohol/oil requirement

- Weak catalytic activity

- Catalyst is difficult to recycle

\section{Heterogeneous}

\begin{tabular}{|c|c|c|c|c|}
\hline Alkali & $\begin{array}{l}\mathrm{CaO}, \mathrm{SrO}, \\
\mathrm{MgO}, \\
\text { mixed oxide } \\
\text { and } \\
\text { hydrotalcite }\end{array}$ & & $\begin{array}{l}\text { Non-corrosive } \\
\text { Environmentally } \\
\text { benign } \\
\text { Recyclable } \\
\text { Fewer disposal } \\
\text { problems } \\
\text { Easy separation } \\
\text { Higher selectivity } \\
\text { Longer catalyst life }\end{array}$ & $\begin{array}{l}\text { - Slow reaction rate } \\
\text { compared to } \\
\text { homogeneous one } \\
\text { - Low FFA requirement in } \\
\text { the feedstock }(<1 \mathrm{wt} . \%) \\
\text { - Highly sensitive to water } \\
\text { and FFA } \\
\text { - Saponification as side } \\
\text { reaction } \\
\text { - Soap formation } \\
\text { High volume of } \\
\text { wastewater } \\
\text { Leaching of active } \\
\text { catalyst sites } \\
\text { Diffusion limitations, } \\
\text { Complex and expensive } \\
\text { synthesis route }\end{array}$ \\
\hline
\end{tabular}




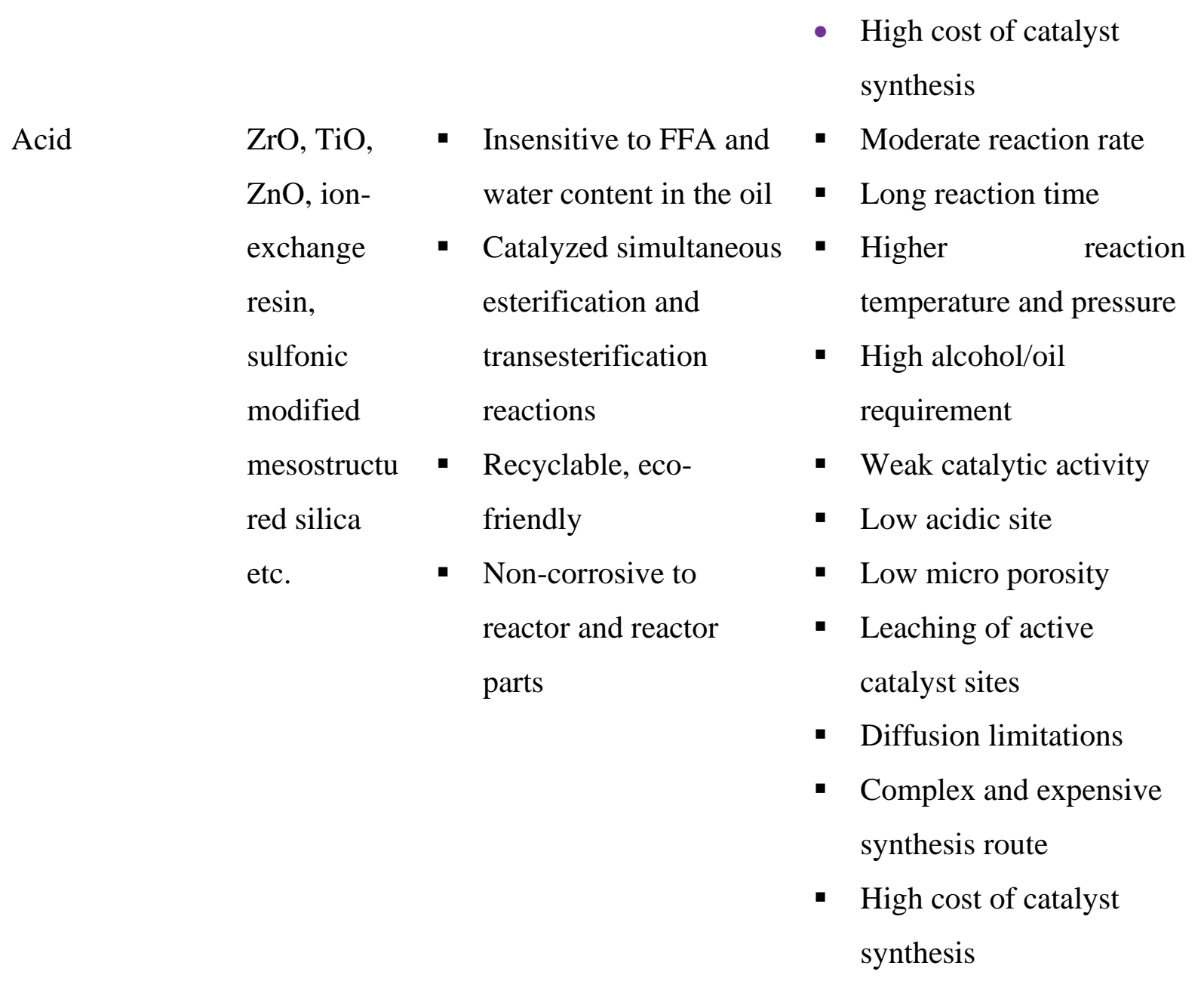

\section{Catalyst comparison}

It is seen from the literature that the reactivity of both homogeneous base and acid catalysts are very high compared to heterogeneous catalysts. ${ }^{61,70}$ Despite the high reactivity, homogeneous catalysts have some serious shortfalls such as low quality of glycerol produced, the catalyst cannot be regenerated and the lengthy process involves in the purification of biodiesel; thereby makes the whole process labour-intensive and uneconomical. ${ }^{76}$ To overcome these shortfalls, solid catalysts have been widely investigated. Alkaline earth, basic metal oxides and supported solid base catalyst shows excellent activity towards biodiesel production, however, their low stability, high sensitivity against the FFA limits its industrial application, ${ }^{143}$ whereas, their acid counterparts are not efficient towards the transesterification reactions. Recently, mixed metal oxides are gaining immense attentions in the field of biodiesel production due to their generally high surface area, excellent thermal and chemical stability, tailored acid-base properties and hence can be used prominently utilized for (trans)esterification of vegetable oil having high FFA. ${ }^{145}$ 
Literatures revealed that enzyme-based catalyst have various advantages over other catalyst such as environmentally benign, operate at mild reaction conditions and display high specificity. ${ }^{432}$ Unfortunately, due to their sensitivity towards heat, poor operational stability and narrow $\mathrm{pH}$ range, the use of such catalyst for industrial scale production of biodiesel is not a wise choice. ${ }^{433}$ However, immobilized lipase has various advantages compared to free lipase such as cost-effective, high thermal stability and greater tolerance to $\mathrm{pH}$ change. ${ }^{435}$ Thus, it has a scope for utilization in industrial scale biodiesel production. Besides, the present study suggests that bio-waste derived catalyst can be used potentially in the industrial scale production of biodiesel as they are easily available, cost-effective and most importantly environmentally benign. ${ }^{161}$ The main limitation is their reusability due to the leaching of the active sites. ${ }^{165}$ Apart from that, metal free carbon based solid acid catalyst is also a promising candidate for industrial scale production of biodiesel as these materials possess promising features such as biogenic, environment-friendly, lower production costs, distinctive surface chemistry, high chemical and thermal stability. ${ }^{383}$ Bifunctional catalyst has been a recent interest in the realm of biodiesel research as it possess dual characteristics such as solid acidic character to tackle the FFA and solid basic character for easy transesterification of triglycerides to FAME and hence can be utilized for the (trans)esterification of diverse oil systems. Apart from that, bifunctional catalyst are highly reusable, thermostable and insensitive to the moisture. ${ }^{438}$ Thus, bifunctional solid catalyst can be utilized in the successful production of industrial scale biodiesel.

\section{Conclusion and outlook}

The exponential growth in the human population around the globe and industrial globalization tremendously increases the demand for petroleum fuels like diesel for various purposes. However, considering the limited resources of fossil fuels, searching for a novel, renewable and sustainable alternative fuel was required. In this context, researchers focused on FAME production from different renewable sources as an effective way. A variety of methods have been proposed for biodiesel production however, among all the existing methods, transesterification is considered as the foremost choice.

Transesterification reaction involves the use of a basic catalysts such as homogeneous and heterogeneous catalysts. The use of homogeneous catalysts is found to be promising as far as rate of biodiesel production is concerned; but it is associated with certain limitations. The homogeneous catalysts based transesterification reaction involves the consumption of high energy, moreover, the treatment of wastewater generated is essential due to the presence of 
unreacted chemicals. These limitations created the need for the development of efficient catalysts which was completed in terms of heterogeneous catalysts. These catalysts attracted a great of attention from the scientific community all over the world because of its several advantages over homogeneous catalysts such as the simple realization of continuous reactors, production of cleaner glycerol, and the absence of both the alkaline catalyst neutralization step and the necessity to replace the consumed catalyst. Due to these advantages, heterogeneous catalysts have opened up the chance for another powerful pathway for FAME production. However, the reactivity of the solid catalyst is dependent on several variables which mainly involve the oil type, alcohol to oil molar ratio, temperature, type of reactor, etc. therefore, selection of these variables at an optimum level is a crucial step. The heterogeneous catalysts are considered comparatively promising because only external-surface active species of porous solid support involved in the reaction and these catalysts can be recovered in some cases. However, in case of certain catalysts like $\mathrm{CaO}$, leaching was reported which adversely influences the reaction and hence, researchers are looking at nanotechnology as new hope.

Nanotechnology is the most emerging branch of science having promising applications in catalysis. Moreover, it reported to have the ability to fabricate the catalyst surface in order to meet the prerequisites of explicit applications and beat the different issues related to both homogeneous and heterogeneous catalysts. Nanocatalysts can act as an interface between homogeneous and heterogeneous catalysts having the possibility to develop promising solidacid or solid-base catalysts which can be easily recovered using conventional filtration and centrifugation techniques. The development and use of magnetic nanoparticle-supported catalysts is a path-breaking research because such catalysts can be easily recovered by using a simple magnetic field and reused for progressive reaction cycles which helps to reduce the overall process cost involved in biodiesel production which is the ultimate aim.

It is well proven that the application of biological catalyst (enzyme) is more effective over all kinds of chemical catalysts, but the involvement of expensive enzyme increases the overall cost of the FAME production process. In this context, immobilization of such enzymes on the surface of various magnetic nanoparticles was found to be a novel concept because of the easy recovery of the immobilized enzyme along with magnetic nanoparticles and its reusability. Moreover, it also solves the problem of leaching of the enzymes during the reaction due to immobilization. Although nanocatalysts reported to have promising applications, the toxicological concerns associated with nanoparticles is a topic of debate because there are mixed opinions from the scientific community. 
The present study revealed that the properties of the catalyst such as basicity and acidity play a pivotal role in the biodiesel production. Several literatures suggest the basicity of the catalyst directly proportional to the transesterification activity. ${ }^{171,195}$ Similarly, acidity of the catalyst decides the esterification activity of the catalyst. ${ }^{383,} 390$ Higher the acidity of the catalyst, higher is the esterification activity. Apart from basicity and acidity, catalytic activity of the solid catalyst depends on its surface area and porosity. Literatures revealed that high surface area of the catalyst enhances the rate of biodiesel production. ${ }^{184,225}$

It is believed that several newly introduced catalysts will take a central position in the near future and help to produce biodiesel through eco-friendly and economically viable processes. The development of novel heterogeneous catalysis having both acid and basic sites on its surface will have promising future in biodiesel production technologies because they have ability to overcome the issues usually caused because of the utilization of homogeneous catalysts. The application of bifunctional solids can be a novel way in heterogeneous catalysts mediated biodiesel production, because they showed the capability to accomplish simultaneous esterification and transesterification reactions in one-pot. In addition, the development and application of nanocatalysts will be a milestone in biodiesel production. These nanocatalysts will be the next generation catalysts which will help to develop most effective, sensitive, sustainable and economically viable technology for the FAME production in the near future. Although recent advances in the developments various homogeneous, heterogeneous and nanocatalyst showed promising future for biodiesel industries or biorefineries, more efforts are required to develop even more effective and cheap catalysts which will help to overcome the present issues all the above-mentioned catalysts and increase the efficiency of biodiesel production sustainably.

\section{Acknowledgement}

Science and Engineering Research Board (SERB), India is thankfully acknowledged for the research fund (Grant No. SB/FT/CS-103/2013 and SB/EMEQ-076/2014).

21171 G. Ciarrocchi, A. Montecucco, G. Pedrali-Noy and S. Spadari, Biochem. Pharmacol., $2118 \quad 1988,37,1803-1804$.

21192 X. Yin, X. Duan, Q. You, C. Dai, Z. Tan and X. Zhu, Energy Convers. Manag., 2016, $2120 \quad$ 112, 199-207.

21213 International Renewable Energy Agency (IRENA), Global Energy Transformation: A 
21234 IEA, Int. Energy Agency, Peris, 2016, 1-77.

21245 M. G. Kulkarni and A. K. Dalai, Ind. Eng. Chem. Res., 2006, 45, 2901-2913.

21256 S. Chatterjee, Dhanurdhar and L. Rokhum, Renew. Sustain. Energy Rev., 2017, 72, $2126 \quad 560-564$.

21277 A. da Silva César, M. A. Conejero, E. C. Barros Ribeiro and M. O. Batalha, Renew. $2128 \quad$ Energy, 2019, 133, 1147-1157.

21298 M. T. Lund, T. K. Berntsen and J. S. Fuglestvedt, Environ. Sci. Technol., 2014, 48, $2130 \quad 14445-14454$.

21319 F. C. De Oliveira and S. T. Coelho, Renew. Sustain. Energy Rev., 2017, 75, 168-179.

213210 J. Ling, S. Nip, W. L. Cheok, R. A. de Toledo and H. Shim, Bioresour. Technol., 2014, $2133 \quad \mathbf{1 7 3}, 132-139$.

213411 L. E. Singer and D. Peterson, International energy outlook 2010, 0484.

213512 D. Y. C. Leung, X. Wu and M. K. H. Leung, Appl. Energy, 2010, 87, 1083-1095.

213613 G. Pathak, D. Das and L. Rokhum, RSC Adv., 2016, 6, 93729-93740.

213714 G. Pathak and L. Rokhum, ACS Comb. Sci., 2015, 17, 483-487.

213815 B. Mallesham, P. Sudarsanam and B. M. Reddy, Ind. Eng. Chem. Res., 2014, 53, 2139 18775-18785.

214016 B. H. Hameed, L. F. Lai and L. H. Chin, Fuel Process. Technol., 2009, 90, 606-610.

214117 D. R. Lathiya, D. V. Bhatt and K. C. Maheria, Bioresour. Technol. Reports, 2018, 2, $2142 \quad 69-76$.

214318 J. M. Encinar, N. Sánchez, G. Martínez and L. García, Bioresour. Technol., 2011, 102, $2144 \quad 10907-10914$.

214519 L. Li, W. Du, D. Liu, L. Wang and Z. Li, J. Mol. Catal. B Enzym., 2006, 43, 58-62.

214620 J. Kansedo, K. T. Lee and S. Bhatia, Biomass and Bioenergy, 2009, 33, 271-276.

214721 M. N. Nabi, M. M. Rahman and M. S. Akhter, Appl. Therm. Eng., 2009, 29, 226521482270 .

214922 S. V. Ghadge and H. Raheman, Biomass and Bioenergy, 2005, 28, 601-605.

215023 X. Meng, G. Chen and Y. Wang, Fuel Process. Technol., 2008, 89, 851-857.

215124 S. A. Shaban, Egypt. J. Chem., 2012, 55, 437-452.

215225 H. N. Bhatti, M. A. Hanif, M. Qasim and Ata-ur-Rehman, Fuel, 2008, 87, 2961-2966.

215326 P. Cao, M. A. Dubé and A. Y. Tremblay, Biomass and Bioenergy, 2008, 32, 102821541036.

215527 H. Y. Shin, S. H. Lee, J. H. Ryu and S. Y. Bae, J. Supercrit. Fluids, 2012, 61, 134- 
2156

$2157 \quad 28$

$2158 \quad 29$

$2159 \quad 30$

$2160 \quad 31$

2161

$2162 \quad 32$

$2163 \quad 33$

2164

2165

2166

$2167 \quad 35$

2168

2169

2170

$2171 \quad 37$

$2172 \quad 38$

2173

$2174 \quad 39$

2175

2176

2177

2178

2179

2180

2181

2182

2183

2184

2185

2186

$2187 \quad 47$

2188

2189

138.

M. Gürü, A. Koca, Ö. Can, C. Çinar and F. Şahin, Renew. Energy, 2010, 35, 637-643.

E. Alptekin and M. Canakci, Fuel, 2010, 89, 4035-4039.

C. Y. Lin and R. J. Li, Fuel Process. Technol., 2009, 90, 130-136.

J. F. Costa, M. F. Almeida, M. C. M. Alvim-Ferraz and J. M. Dias, Energy Convers. Manag., 2013, 74, 17-23.

2 S. H. A.B.M and S. Aishah, Am. J. Biochem. Biotechnol., 2008, 4, 250-254.

3 G. Najafi, B. Ghobadian and T. F. Yusaf, Renew. Sustain. Energy Rev., 2011, 15, 3870-3876.

34 L. Chen, T. Liu, W. Zhang, X. Chen and J. Wang, Bioresour. Technol., 2012, 111, 208-214.

5 U. Zur and R. V. O. N. Oel-proteinpflanzen, Union Zur Förderung Von Oel- Und Proteinpflanzen E.V., 2017, 51.

36 I. M. Atadashi, M. K. Aroua, A. R. Abdul Aziz and N. M. N. Sulaiman, J. Ind. Eng. Chem., 2013, 19, 14-26.

7 S. P. Singh and D. Singh, Ren. Sus. Energ. Rev., 2010, 14, 200-216.

S. D. A. P. Apptanaidu, A. M. Ali and M. H. Alias, J. Ekon. Malaysia, 2014, 48, 2940 .

B. Flach, S. Lieberz, M. Rondon, B. Williams and C. Teiken, GAIN Report: EU-28 Biofuels Annual, 2015, 14-21.

40 R. Delzeit, T. Heimann, F. Schuenemann and M. Soeder. GTAP, 2019.

41 U. Zur and R. V. O. N. Oel-proteinpflanzen, Union Zur Förderung Von Oel- Und Proteinpflanzen E.V. 2015.

42 J. L. Shumaker, C. Crofcheck, S. A. Tackett, E. Santillan-Jimenez and M. Crocker, Catal. Letters, 2007, 115, 56-61.

43 K. Bélafi-Bakó, F. Kovács, L. Gubicza and J. Hancsók, Biocatal. Biotransformation, 2002, 20, 437-439.

44 S. Yan, H. Lu and B. Liang, Energy and Fuels, 2008, 22, 646-651.

45 D. A. G. Aranda, R. T. P. Santos, N. C. O. Tapanes, A. L. D. Ramos and O. A. C. Antunes, Catal. Letters, 2008, 122, 20-25.

46 M. R. Avhad and J. M. Marchetti, Renew. Sustain. Energy Rev., 2015, 50, 696-718.

7 A. Karmakar, S. Karmakar and S. Mukherjee, Bioresour. Technol., 2010, 101, 72017210.

48 M. M. Gui, K. T. Lee and S. Bhatia, Energy, 2008, 33, 1646-1653. 
219049 K. Shikha and C. Y. Rita, J. Chem. Pharm. Res., 2012, 4, 4219-4230.

$219150 \quad$ A. L. Ahmad, N. H. M. Yasin, C. J. C. Derek and J. K. Lim, Renew. Sustain. Energy $2192 \quad$ Rev., 2011, 15, 584-593.

219351 S. L. Dmytryshyn, A. K. Dalai, S. T. Chaudhari, H. K. Mishra and M. J. Reaney, 2194 Bioresour. Technol., 2004, 92, 55-64.

219552 S. Yusup and M. A. Khan, Biomass and Bioenergy, 2010, 34, 1500-1504.

$219653 \quad$ J. M. Dias, M. C. M. Alvim-Ferraz and M. F. Almeida, Fuel, 2008, 87, 3572-3578.

219754 U. Rashid and F. Anwar, Fuel, 2008, 87, 265-273.

$219855 \quad$ J. M. Encinar, J. F. González and A. Rodríguez-Reinares, Fuel Process. Technol., $2199 \quad 2007, \mathbf{8 8}, 513-522$.

220056 A. A. Refaat, N. K. Attia, H. A. Sibak, S. T. El Sheltawy and G. I. ElDiwani, Int. J. $2201 \quad$ Environ. Sci. Technol., 2008, 5, 75-82.

220257 M. P. Dorado, E. Ballesteros, M. Mittelbach and F. J. López, Energy and Fuels, 2004, $2203 \quad 18,1457-1462$.

220458 O. J. Alamu, S. O. Jekayinfa and T. a Akintola, Agric. Eng., 2007, 9, 1-11.

220559 K. H. Chung, J. Kim and K. Y. Lee, Biomass and Bioenergy, 2009, 33, 155-158.

220660 S. K. Karmee and A. Chadha, Bioresour. Technol., 2005, 96, 1425-1429.

220761 P. Felizardo, M. J. Neiva Correia, I. Raposo, J. F. Mendes, R. Berkemeier and J. M. 2208 Bordado, Waste Manag., 2006, 26, 487-494.

220962 B. B. Uzun, M. Kiliç, N. Özbay, A. E. Pütün and E. Pütün, Energy, 2012, 44, 347-351.

221063 D. Y. C. Leung and Y. Guo, Fuel Process. Technol., 2006, 87, 883-890.

221164 U. Rashid, F. Anwar, B. R. Moser and S. Ashraf, Biomass and Bioenergy, 2008, 32, $2212 \quad 1202-1205$.

221365 Z. Ilham, Malaysian J. Biochem. Mol. Biol., 2009, 17, 5-9.

221466 S. T. Keera, S. M. El Sabagh and A. R. Taman, Fuel, 2011, 90, 42-47.

221567 U. Rashid, F. Anwar, T. M. Ansari, M. Arif and M. Ahmad, J. Chem. Technol. 2216 Biotechnol., 2009, 84, 1364-1370.

221768 K. S. Chen, Y. C. Lin, K. H. Hsu and H. K. Wang, Energy, 2012, 38, 151-156.

221869 K. Jacobson, R. Gopinath, L. C. Meher and A. K. Dalai, Appl. Catal. B Environ., 2008, $2219 \quad \mathbf{8 5}, 86-91$.

222070 Y. Wang, S. Ou, P. Liu, F. Xue and S. Tang, J. Mol. Catal. A Chem., 2006, 252, 107$2221 \quad 112$.

222271 M. Canakci and J. Van Gerpen, 1999, 42, 1203-1210.

$222372 \quad$ X. Miao, R. Li and H. Yao, Energy Convers. Manag., 2009, 50, 2680-2684. 
75

79

M. J. Nye, T. W. Williamson, W. Deshpande, J. H. Schrader, W. H. Snively, T. P. Yurkewich and C. L. French, J. Am. Oil Chem. Soc., 1983, 60, 1598-1601.

74 2009, 355, 94-99.

3

Moreno-Tost, J. Santamaría and J. L. G. Fierro, Appl. Catal. B Environ., 2007, 73, $317-326$. 1825 .

A. Kawashima, K. Matsubara and K. Honda, Bioresour. Technol., 2009, 100, 696-700.

C. Y. Cao and Y. H. Zhao, Int. J. Green Energy, 2013, 10, 219-229.

H. Mootabadi, B. Salamatinia, S. Bhatia and A. Z. Abdullah, Fuel, 2010, 89, 1818-

87 J. Jitputti, B. Kitiyanan, P. Rangsunvigit, K. Bunyakiat, L. Attanatho and P. Jenvanitpanjakul, Chem. Eng. J., 2006, 116, 61-66.

M. Stöcker, J. Mol. Catal., 1985, 29, 371-377.

S. J. Yoo, H. shik Lee, B. Veriansyah, J. Kim, J. D. Kim and Y. W. Lee, Bioresour. Technol., 2010, 101, 8686-8689.

90 R. B. da Silva, A. F. Lima Neto, L. S. Soares dos Santos, J. R. de Oliveira Lima, M. H. Chaves, J. R. dos Santos, G. M. de Lima, E. M. de Moura and C. V. R. de Moura, Bioresour. Technol., 2008, 99, 6793-6798.

91 G. Baskar, A. Gurugulladevi, T. Nishanthini, R. Aiswarya and K. Tamilarasan, Renew. Energy, 2017, 103, 641-646.

92 S. Nakagaki, A. Bail, V. C. dos Santos, V. H. R. de Souza, H. Vrubel, F. S. Nunes and L. P. Ramos, Appl. Catal. A Gen., 2008, 351, 267-274. 
225893 M. Di Serio, M. Cozzolino, R. Tesser, P. Patrono, F. Pinzari, B. Bonelli and E. Santacesaria, Appl. Catal. A Gen., 2007, 320, 1-7.
B. Rongxian, T. Yisheng and H. Yizhuo, Fuel Process. Technol., 2004, 86, 293-301. A. P. S. Chouhan and A. K. Sarma, Renew. Sustain. Energy Rev., 2011, 15, 43784399.

W. Xie, X. Huang and H. Li, Bioresour. Technol., 2007, 98, 936-939.

Q. Shu, B. Yang, H. Yuan, S. Qing and G. Zhu, Catal. Commun., 2007, 8, 2159-2165.

M. J. Ramos, A. Casas, L. Rodríguez, R. Romero and Á. Pérez, Appl. Catal. A Gen., 2008, 346, 79-85.

99 H. Wu, J. Zhang, Q. Wei, J. Zheng and J. Zhang, Fuel Process. Technol., 2013, 109, $13-18$.

100 M. Feyzi and G. Khajavi, Ind. Crops Prod., 2014, 58, 298-304.

101 N. Narkhede and A. Patel, Ind. Eng. Chem. Res., 2013, 52, 13637-13644.

102 O. Babajide, N. Musyoka, L. Petrik and F. Ameer, Catal. Today, 2012, 190, 54-60.

103 M. C. Manique, L. V. Lacerda, A. K. Alves and C. P. Bergmann, Fuel, 2017, 190, $268-273$.

104 N. Al-Jammal, Z. Al-Hamamre and M. Alnaief, Renew. Energy, 2016, 93, 449-459.

105 L. Du, S. Ding, Z. Li, E. Lv, J. Lu and J. Ding, Energy Convers. Manag., 2018, 173, 728-734.

106 S. Semwal, A. K. Arora, R. P. Badoni and D. K. Tuli, Bioresour. Technol., 2011, 102, 2151-2161.

107 A. Bohlouli and L. Mahdavian, Biofuels, 2019, 0, 1-14.

108 W. Xie and H. Li, J. of Mol. Cat. A: Chemical, 2006, 255, 1-9.

109 J. Paulo, A. Duarte, L. Di and A. Souza, Renew. Sustain. Energy Rev., 2016, 59, 887894.

110 H. Ma, S. Li, B. Wang, R. Wang and S. Tian, JAOCS, 2008, 263-270.

111 Y. Chen, Y. Huang, R. Lin, N. Shang and C. Chang, J. Taiwan Inst. Chem. Eng., 2011, 42, 937-944.

112 X. Zhang, Q. Ma, B. Cheng, J. Wang, J. Li and F. Nie, J. Nat. Gas Chem., 2012, 21, $774-779$.

113 E. S. Umdu, M. Tuncer and E. Seker, Bioresour. Technol., 2009, 100, 2828-2831.

114 M. Zabeti, W. Mohd, A. Wan and M. K. Aroua, Fuel Process. Technol., 2010, 91, 243-248.

115 C. Samart, C. Chaiya and P. Reubroycharoen, Energy Convers. Manag., 2010, 51, 
1428-1431.

116 T. Witoon, S. Bumrungsalee, P. Vathavanichkul and S. Palitsakun, Bioresour. Technol., 2014, 156, 329-334.

117 H. Wu, J. Zhang, Y. Liu, J. Zheng and Q. Wei, Fuel Process. Technol., 2014, 119, 114-120.

118 B. Narowska, M. Kułażyński, M. Łukaszewicz and E. Burchacka, Renew. Energy, 2019, 135, 176-185.

119 A. Buasri, B. Ksapabutr, M. Panapoy and N. Chaiyut, Korean J. Chem. Eng., 2012, 29, $1708-1712$.

120 L. J. Konwar, J. Boro and D. Deka, Energy Sources, Part A Recover. Util. Environ. Eff., 2018, 40, 601-607.

121 B. H. Hameed, C. S. Goh and L. H. Chin, Fuel Process. Technol., 2009, 90, 1532 1537.

122 S. Baroutian, M. K. Aroua, A. Aziz, A. Raman, N. Meriam and N. Sulaiman, Fuel Process. Technol., 2010, 91, 1378-1385.

123 X. Li, Y. Zuo, Y. Zhang, Y. Fu and Q. Guo, Fuel, 2013, 113, 435-442.

124 A. Buasri, N. Chaiyut, V. Loryuenyong and C. Rodklum, Sci. Asia, 2012, 38, 283-288.

125 Z. Wan and B. H. Hameed, Bioresour. Technol., 2011, 102, 2659-2664.

126 A. B. Fadhil, A. M. Aziz and M. H. Altamer, Fuel, 2016, 170, 130-140.

127 H. Liu, L. Su, Y. Shao and L. Zou, Fuel, 2012, 97, 651-657.

128 I. B. Laskar, L. Rokhum, R. Gupta and S. Chatterjee, Environ. Prog. Sustain. Energy, 2019, 39, 1-11.

129 Taslim, O. Bani, Iriany, N. Aryani and G. S. Kaban, Key Eng. Mater., 2018, 777, $262-$ 267.

130 S. Abelló, F. Medina, D. Tichit, J. Pérez-Ramírez, J. C. Groen, J. E. Sueiras, P. Salagre and Y. Cesteros, Chem. - A Eur. J., 2005, 11, 728-739.

131 D. P. Debecker, E. M. Gaigneaux and G. Busca, Chem. - A Eur. J., 2009, 15, 39203935 .

132 A. Navajas, I. Campo, A. Moral, J. Echave, O. Sanz, M. Montes, J. A. Odriozola, G. Arzamendi and L. M. Gandía, Fuel, 2018, 211, 173-181.

133 H. yan Zeng, Z. Feng, X. Deng and Y. qin Li, Fuel, 2008, 87, 3071-3076.

134 Y. Ma, Q. Wang, L. Zheng, Z. Gao, Q. Wang and Y. Ma, Energy, 2016, 107, 523-531.

135 H. Y. Zeng, S. Xu, M. C. Liao, Z. Q. Zhang and C. Zhao, Appl. Clay Sci., 2014, 9192, 16-24. 
136 W. Trakarnpruk and S. Porntangjitlikit, Renew. Energy, 2008, 33, 1558-1563.

137 Q. Liu, B. Wang, C. Wang, Z. Tian, W. Qu, H. Ma and R. Xu, Green Chem., 2014, 16, 2604-2613.

138 L. Gao, G. Teng, G. Xiao and R. Wei, Biomass and Bioenergy, 2010, 34, 1283-1288.

139 Y. Liu, E. Lotero, J. G. Goodwin and X. Mo, Appl. Catal. A Gen., 2007, 331, 138-148.

140 Z. Helwani, N. Aziz, M. Z. A. Bakar, H. Mukhtar, J. Kim and M. R. Othman, Energy Convers. Manag., 2013, 73, 128-134.

141 C. S. Cordeiro, G. G. C. Arizaga, L. P. Ramos and F. Wypych, Catal. Commun., 2008, 9, 2140-2143.

142 J. Tantirungrotechai, P. Chotmongkolsap and M. Pohmakotr, Microporous Mesoporous Mater., 2010, 128, 41-47.

143 H. Hattori, Chem. Rev., 1995, 95, 537-558.

144 A. Kawashima, K. Matsubara and K. Honda, Bioresour. Technol., 2008, 99, 34393443.

145 H. Sun, Y. Ding, J. Duan, Q. Zhang, Z. Wang, H. Lou and X. Zheng, Bioresour. Technol., 2010, 101, 953-958.

146 Z. Wen, X. Yu, S. T. Tu, J. Yan and E. Dahlquist, Bioresour. Technol., 2010, 101, 9570-9576.

147 C. L. Chen, C. C. Huang, D. T. Tran and J. S. Chang, Bioresour. Technol., 2012, 113, $8-13$.

148 R. Madhuvilakku and S. Piraman, Bioresour. Technol., 2013, 150, 55-59.

149 S. Yan, S. O. Salley and K. Y. Simon Ng, Appl. Catal. A Gen., 2009, 353, 203-212.

150 C. Ngamcharussrivichai, P. Totarat and K. Bunyakiat, Appl. Catal. A Gen., 2008, 341, $77-85$.

151 J. Su, Y. Li, H. Wang, X. Yan and D. Pan, Chem. Phys. Lett., 2016, 663, 61-65.

152 M. M. Ibrahim, H. R. Mahmoud and S. A. El-molla, Catal. Commun., 2019, 122, 10 15.

153 E. A. Faria, I. M. Dias, P. A. Z. Suarez and A. G. S. Prado, J. Brazillian Chem. Soc., 2009, 20, 1732-1737.

154 M. C. G. Albuquerque, J. Santamaría-González, J. M. Mérida-Robles, R. MorenoTost, E. Rodríguez-Castellón, A. Jiménez-López, D. C. S. Azevedo, C. L. Cavalcante and P. Maireles-Torres, Appl. Catal. A Gen., 2008, 347, 162-168.

155 K. Rajkumari, D. Das, G. Pathak and L. Rokhum, New J. Chem., 2019, 43, 2134 2140 . 
156 E. Betiku, A. A. Okeleye, N. B. Ishola, A. S. Osunleke and T. V. Ojumu, Catal. Letters, 2019, 149, 1772-1787.

157 R. Shan, L. Lu, Y. Shi, H. Yuan and J. Shi, Energy Convers. Manag., 2018, 178, 277289.

158 G. Pathak, K. Rajkumari and L. Rokhum, Nanoscale adv., 2019, 1, 1013-1020.

159 B. Changmai, I. B. Laskar and L. Rokhum, J. Taiwan Inst. Chem. Eng., 2019, 102, 276-282.

160 C. Xu, M. Nasrollahzadeh, M. Sajjadi, M. Maham, R. Luque and A. R. PuenteSantiago, Renew. Sustain. Energy Rev., 2019, 112, 195-252.

161 Z. Wei, C. Xu and B. Li, Bioresour. Technol., 2009, 100, 2883-2885.

162 J. Goli and O. Sahu, Renew. Energy, 2018, 128, 142-154.

163 A. A. Ayodeji, M. E. Ojewumi, B. Rasheed and J. M. Ayodele, Data Br., 2018, 19, $1466-1473$.

164 G. Joshi, D. S. Rawat, B. Y. Lamba, K. K. Bisht, P. Kumar, N. Kumar and S. Kumar, Energy Convers. Manag., 2015, 96, 258-267.

165 Y. C. Sharma, B. Singh and J. Korstad, Energy and Fuels, 2010, 24, 3223-3231.

166 N. Tshizanga, E. F. Aransiola and O. Oyekola, South African J. Chem. Eng., 2017, 23, $145-156$.

167 Y. H. Tan, M. O. Abdullah, C. Nolasco-Hipolito and N. S. Ahmad Zauzi, Renew. Energy, 2017, 114, 437-447.

168 Y. C. Wong and R. X. Ang, Open Chem., 2018, 16, 1166-1175.

169 P. Suwannasom, R. Sriraksa, P. Tansupo and C. Ruangviriyachai, Energy Sources, Part A Recover. Util. Environ. Eff., 2016, 38, 3221-3228.

170 G. Santya, T. Maheswaran and K. F. Yee, SN Appl. Sci., 2019, 1, 152-160.

171 P. Parthasarathy and S. K. Narayanan, Environ. Prog. Sustain. Energy, 2014, 33, 676680 .

172 S. Niju, M. M. M. S. Begum and N. Anantharaman, J. Saudi Chem. Soc., 2014, 18 , 702-706.

173 A. R. Gupta and V. K. Rathod, Waste Manag., 2018, 79, 169-178.

174 N. S. El-Gendy, S. F. Deriase, A. Hamdy and R. I. Abdallah, Egypt. J. Pet., 2015, 24, $37-48$.

175 Y. P. Peng, K. T. T. Amesho, C. E. Chen, S. R. Jhang, F. C. Chou and Y. C. Lin, Catalysts, 2018, 8, 81-91.

176 N. Viriya-Empikul, P. Krasae, W. Nualpaeng, B. Yoosuk and K. Faungnawakij, Fuel, 
2012, 92, 239-244.

177 P. Khemthong, C. Luadthong, W. Nualpaeng, P. Changsuwan, P. Tongprem, N. Viriya-Empikul and K. Faungnawakij, Catal. Today, 2012, 190, 112-116.

178 N. Viriya-empikul, P. Krasae, B. Puttasawat, B. Yoosuk, N. Chollacoop and K. Faungnawakij, Bioresour. Technol., 2010, 101, 3765-3767.

179 A. Annam Renita, P. P. Chowdhury, P. Sultana, P. Phukan and A. Hannan, Int. J. Pharm. Pharm. Sci. 2016, 8, 143-146.

180 A. a Jazie, H. Pramanik and a S. K. Sinha, Spec. Issue Int. J. Sustain. Dev. Green Econ., 2013, 2, 2315-4721.

181 F. Yasar, Fuel, 2019, 255, 115828.

182 K. Kara, F. Ouanji, M. El Mahi, E. M. Lotfi, M. Kacimi and Z. Mahfoud, Biofuels, 2019, 24, 1-7.

183 E. Fayyazi, B. Ghobadian, H. H. Van De Bovenkamp, G. Najafi, B. Hosseinzadehsamani, H. J. Heeres and J. Yue, Ind. Eng. Chem. Res.,2018, 38, $12742-$ 12755.

184 L. M. Correia, R. M. A. Saboya, N. de Sousa Campelo, J. A. Cecilia, E. RodríguezCastellón, C. L. Cavalcante and R. S. Vieira, Bioresour. Technol., 2014, 151, 207-213.

185 I. Reyero, F. Bimbela, A. Navajas, G. Arzamendi and L. M. Gandía, Fuel, 2015, 158, $558-564$

186 S. B. Chavan, R. R. Kumbhar, D. Madhu, B. Singh and Y. C. Sharma, RSC Adv.,2015, 5, 63596-63604.

187 P. R. Pandit and M. H. Fulekar, J. Environ. Manage., 2017, 198, 319-329.

188 P. R. Pandit and M. H. Fulekar, Renew. Energy, 2019, 136, 837-845.

189 P. R. Pandit and M. H. Fulekar, in Materials Today: Proceedings, 2019, 10, 75-86.

190 K. Kirubakaran and V. Arul Mozhi Selvan, J. Environ. Chem. Eng., 2018, 6, 44904503.

191 G. Santya, T. Maheswaran and K. F. Yee, SN Appl. Sci., 2019, 1, 152-160.

192 M. L. Savaliya, M. S. Bhakhar and B. Z. Dholakiya, Catal. Letters,2016, 146, 2313 2323.

193 L. Da Silva Castro, A. G. Barañano, C. J. G. Pinheiro, L. Menini and P. F. Pinheiro, Green Process. Synth., 2019, 8, 235-244.

194 Y. Hangun-Balkir, J. Chem., 2016.

195 A. Ansori, S. A. Wibowo, H. S. Kusuma, D. S. Bhuana and M. Mahfud, Open Chem., 2019, 17, 1185-1197. 
196 N. Mansir, S. Hwa Teo, M. Lokman Ibrahim and T. Y. Yun Hin, Energy Convers. Manag., 2017, 151, 216-226.

197 A. S. Yusuff, O. D. Adeniyi, M. A. Olutoye and U. G. Akpan, Int. J. Technol., 2018, 1, $1-11$.

198 M. J. Borah, A. Das, V. Das, N. Bhuyan and D. Deka, Fuel, 2019, 242, 345-354.

199 A. S. Oladipo, O. A. Ajayi, A. A. Oladipo, S. L. Azarmi, Y. Nurudeen, A. Y. Atta and S. S. Ogunyemi, Comptes Rendus Chim., 2018, 21, 684-695.

200 M. D. Putra, Y. Ristianingsih, R. Jelita, C. Irawan and I. F. Nata, RSC Adv., 2017, 7, $55547-55554$.

201 N. Mansir, S. H. Teo, U. Rashid and Y. H. Taufiq-Yap, Fuel, 2018, 211, 67-75.

202 S. H. Teo, A. Islam, H. R. F. Masoumi, Y. H. Taufiq-Yap, J. Janaun, E. S. Chan and M. A. khaleque, Renew. Energy, , DOI:10.1016/j.renene.2017.04.039.

203 M. A. Olutoye, S. C. Lee and B. H. Hameed, Bioresour. Technol., 2011, 102, $10777-$ 10783.

204 G. Chen, R. Shan, S. Li and J. Shi, Fuel, 2016, 143, 110-117.

205 N. S. Lani, N. Ngadi, N. Y. Yahya and R. A. Rahman, J. Clean. Prod., 2018, 164, 210218.

206 G. Y. Chen, R. Shan, J. F. Shi and B. B. Yan, Fuel Process. Technol., 2015, 133, 8-13.

207 S. Sulaiman and N. I. F. Ruslan, Energy Sources, Part A Recover. Util. Environ. Eff., 2017, 39, 154-159.

208 J. Boro, L. J. Konwar and D. Deka, Fuel Process. Technol., 2014, 122, 72-78.

209 W. U. Rahman, A. Fatima, A. H. Anwer, M. Athar, M. Z. Khan, N. A. Khan and G. Halder, Process Saf. Environ. Prot., 2019, 122, 313-319.

210 R. Chakraborty, S. Bepari and A. Banerjee, Chem. Eng. J., 2010, 165, 798-805.

211 D. Zeng, Q. Zhang, S. Chen, S. Liu, Y. Chen, Y. Tian and G. Wang, J. Environ. Chem. Eng., 2015, 3, 560-564.

212 S. Chowdhury, S. H. Dhawane, B. Jha, S. Pal, R. Sagar, A. Hossain and G. Halder, Biomass Convers. Biorefinery, 2019, 1-11.

213 G. Chen, R. Shan, J. Shi and B. Yan, Bioresour. Technol., 2014, 171, 428-432.

214 Y. B. Cho and G. Seo, Bioresour. Technol., 2010, 22, 8515-8519.

215 A. Buasri and V. Loryuenyong, in Materials Today: Proceedings, 2017, 4, 6051-6059.

216 J. Goli and O. Sahu, Renew. Energy, 2018, 128, 142-154.

217 S. Niju, K. M. M. S. Begum and N. Anantharaman, Environ. Prog. Sustain. Energy, 2015, 34, 248-254. 
218 N. P. Asri, B. Podjojono, R. Fujiani and Nuraini, IOP Conf. Ser. Earth Environ. Sci., $2017,67,1-7$.

219 L. M. Correia, R. M. A. Saboya, N. de Sousa Campelo, J. A. Cecilia, E. RodríguezCastellón, C. L. Cavalcante and R. S. Vieira, Bioresour. Technol., 2014, 151, 207-213.

220 S. Jairam, P. Kolar, R. Sharma-Shivappa Ratna, J. A. Osborne and J. P. Davis, Bioresour. Technol., 2012, 104, 329-335.

221 N. Nakatani, H. Takamori, K. Takeda and H. Sakugawa, Bioresour. Technol., 2009, 100, 1510-1513.

222 A. Buasri, T. Rattanapan, C. Boonrin, C. Wechayan and V. Loryuenyong, J. Chem., 2015.

223 S. Kaewdaeng, P. Sintuya and R. Nirunsin, Energy Procedia, 2017, 138, 937-942.

224 W. Roschat, T. Siritanon, T. Kaewpuang, B. Yoosuk and V. Promarak, Bioresour. Technol., 2016, 209, 343-350.

225 X. Liu, H. Bai, D. Zhu and G. Cao, Advanced Materials Research, 2011, 148, 794798.

226 A. Birla, B. Singh, S. N. Upadhyay and Y. C. Sharma, Bioresour. Technol., 2012, 106, 95-100.

227 H. Liu, H. shuang Guo, X. jing Wang, J. zhong Jiang, H. Lin, S. Han and S. peng Pei, Renew. Energy, 2016, 93, 648-657.

228 I. B. Laskar, K. Rajkumari, R. Gupta, S. Chatterjee, B. Paul and L. Rokhum, RSC $A d v ., 2018, \mathbf{8}, 20131-20142$.

229 N. S. El-Gendy, S. F. Deriase and A. Hamdy, Energy Sources, Part A Recover. Util. Environ. Eff., 2014, 36, 623-637.

230 Sani. J, Samir. S, Rikoto. II, Tambuwal. AD, Sanda. A, Maishanu. SM and Laden. MM, Innov. Energy Res. 2017, 6, 1-4.

231 V. A. Fabiani, R. O. Asriza, A. R. Fabian and M. Kafillah, in IOP Conference Series: Earth and Environmental Science, 2019, 353, 12012.

232 K. N. Krishnamurthy, S. N. Sridhara and C. S. Ananda Kumar, Renew. Energy, 2020, 146, 280-296.

233 A. A. Otori, A. Mann, M.A.T. Suleiman and E. C. Egwimvol. Nigerian J. Chem. Res., $2011,23,837-846$.

234 A. Buasri, N. Chaiyut, V. Loryuenyong, P. Worawanitchaphong and S. Trongyong, Sci. World J., 2013.

235 H. Hadiyanto, A. H. Afianti, U. I. Navi'A, N. P. Adetya, W. Widayat and H. Sutanto, 
J. Environ. Chem. Eng., 2017, 5, 4559-4563.

236 S. Nurdin, N. A. Rosnan, N. S. Ghazali, J. Gimbun, A. H. Nour and S. F. Haron, in Energy Procedia, 2015, 79, 576-583.

237 R. Rezaei, M. Mohadesi and G. R. Moradi, Fuel, 2013, 109, 534-541.

238 Y. Zhang, X. Shen, H. Bai and S. Liu, World Automation Congress Proceedings, 2012, $1-4$.

239 S. Hu, Y. Wang and H. Han, Biomass and Bioenergy, 2011, 35, 3627-3635.

240 A. Perea, T. Kelly and Y. Hangun-Balkir, Green Chem. Lett. Rev., 2016, 9, 27-32.

241 O. Nur Syazwani, U. Rashid and Y. H. Taufiq Yap, Energy Convers. Manag., 2015, 101, 749-756.

242 O. N. Syazwani, U. Rashid, M. S. Mastuli and Y. H. Taufiq-Yap, Renew. Energy, 2019, 131, 187-196.

243 N. Asikin-Mijan, H. V. Lee and Y. H. Taufiq-Yap, Chem. Eng. Res. Des., 2015, 102, $368-377$.

244 Y. Taufiq-Yap, H. Lee and P. Lau, Energy Explor. Exploit., 2012, 30, 853-866.

245 P. Nair, B. Singh, S. N. Upadhyay and Y. C. Sharma, J. Clean. Prod., 2012, 29, 82-90.

246 N. Girish, S. P. Niju, K. M. Meera Sheriffa Begum and N. Anantharaman, Fuel, 2013, 111, 653-658.

247 O. N. Syazwani, S. H. Teo, A. Islam and Y. H. Taufiq-Yap, Process Saf. Environ. Prot., 2017, 105, 303-315.

248 G. Y. Chen, R. Shan, B. B. Yan, J. F. Shi, S. Y. Li and C. Y. Liu, Fuel Process. Technol., 2016, 143, 110-117.

249 S. Boonyuen, S. M. Smith, M. Malaithong, A. Prokaew, B. Cherdhirunkorn and A. Luengnaruemitchai, J. Clean. Prod.,2018, 177, 925-929.

250 W. Suryaputra, I. Winata, N. Indraswati and S. Ismadji, Renew. Energy, 2013, 50, 795799.

251 P. L. Boey, G. P. Maniam, S. A. Hamid and D. M. H. Ali, Fuel, 2011, 88, 283-288.

252 S. L. Lee, Y. C. Wong, Y. P. Tan and S. Y. Yew, Energy Convers. Manag., 2015, 93, $282-288$.

253 J. Xie, X. Zheng, A. Dong, Z. Xiao and J. Zhang, Green Chem., 2009, 11, 355-364.

254 J. Boro, A. J. Thakur and D. Deka, Fuel Process. Technol., 2011, 92, 2061-2067.

255 J. Boro, L. J. Konwar, A. J. Thakur and D. Deka, Fuel, 2014, 129, 182-187.

256 H. Mazaheri, H. C. Ong, H. H. Masjuki, Z. Amini, M. D. Harrison, C. T. Wang, F. Kusumo and A. Alwi, Energy, 2018, 144, 10-19. 
L. Yang, A. Zhang and X. Zheng, Energy and Fuels, 2009, 23, 3859-3865.

258 R. Anr, A. A. Saleh, M. S. Islam, S. Hamdan and M. A. Maleque, Energy and Fuels, 2016, 30, 334-343.

259 P. Sivakumar, P. Sivakumar, K. Anbarasu, R. Mathiarasi and S. Renganathan, Int. J. Green Energy, 2014, 11, 886-897.

260 V. Shankar and R. Jambulingam, Sustain. Environ. Res., 2017, 27, 273-278.

261 P. L. Boey, G. P. Maniam and S. A. Hamid, Bioresour. Technol., 2011, 168, 15-22.

262 D. Madhu, S. B. Chavan, V. Singh, B. Singh and Y. C. Sharma, Bioresour. Technol.,2016, 214, 210-217.

263 A. P. S. Chouhan and A. K. Sarma, Biomass and Bioenergy, 2013, 55, 386-389.

264 L. H. Chin, B. H. Hameed and A. L. Ahmad, Energy and Fuels, 2009, 23, 1040-1044.

265 P. L. Boey, S. Ganesan, S. X. Lim, S. L. Lim, G. P. Maniam and M. Khairuddean, Energy, 2011, 36, 5791-5796.

266 E. Betiku and S. O. Ajala, Ind. Crops Prod., 2014, 53, 314-322.

267 A. O. Etim, E. Betiku, S. O. Ajala, P. J. Olaniyi and T. V. Ojumu, Sustain., 2018, 10, 707-715.

268 V. Vadery, B. N. Narayanan, R. M. Ramakrishnan, S. K. Cherikkallinmel, S. Sugunan, D. P. Narayanan and S. Sasidharan, Energy, 2014, 70, 588-594.

269 C. Ofori-Boateng and K. T. Lee, Chem. Eng. J., 2013, 220, 395-401.

270 D. C. Deka and S. Basumatary, Biomass and Bioenergy, 2011, 35, 1797-1803.

271 A. K. Sarma, P. Kumar, M. Aslam and A. P. S. Chouhan, Catal. Letters, 2014, 144, $1344-1353$

272 E. Betiku, A. M. Akintunde and T. V. Ojumu, Energy, 2016, 103, 797-806.

273 S. E. Onoji, S. E. Iyuke, A. I. Igbafe and M. O. Daramola, Energy and Fuels, 2017, 31, 6109-6119.

274 M. Gohain, A. Devi and D. Deka, Ind. Crops Prod., 2017, 109, 8-18.

275 G. Pathak, D. Das, K. Rajkumari and L. Rokhum, Green Chem., 2018, 20, 2365-2373.

276 M. Sharma, A. A. Khan, S. K. Puri and D. K. Tuli, Biomass and Bioenergy, 2012, 41, 94-106.

277 B. K. Uprety, W. Chaiwong, C. Ewelike and S. K. Rakshit, Energy Convers. Manag., 2016, 115, 191-199.

278 M. Balajii and S. Niju, Renew. Energy, 2020, 146, 2255-2269.

279 M. Balajii and S. Niju, Energy Convers. Manag., 2019, 189, 118-131.

280 I. M. Mendonça, F. L. Machado, C. C. Silva, S. Duvoisin Junior, M. L. Takeno, P. J. 
de Sousa Maia, L. Manzato and F. A. de Freitas, Energy Convers. Manag., 2019, 200, 112095.

281 B. Nath, B. Das, P. Kalita and S. Basumatary, J. Clean. Prod., 2019, 239, 118112.

282 B. Changmai, P. Sudarsanam and L. Rokhum, Ind. Crops Prod., 2019, 145, 111911 111919.

283 B. Nath, P. Kalita, B. Das and S. Basumatary, Renew. Energy, 2020, 151, 295-310.

284 I. M. Mendonça, O. A. R. L. Paes, P. J. S. Maia, M. P. Souza, R. A. Almeida, C. C. Silva, S. Duvoisin and F. A. de Freitas, Renew. Energy, 2019, 130, 103-110.

285 M. Gohain, K. Laskar, H. Phukon, U. Bora, D. Kalita and D. Deka, Waste Manag., 2020, 102, 212-221.

286 E. Betiku, A. O. Etim, O. Pereao and T. V. Ojumu, Energy and Fuels, 2017, 31, 61826193.

287 M. R. Miladinović, M. V. Zdujić, D. N. Veljović, J. B. Krstić, I. B. Banković-Ilić, V. B. Veljković and O. S. Stamenković, Renew. Energy, 2020, 147, 1033-1043.

288 H. H. Abdelhady, H. A. Elazab, E. M. Ewais, M. Saber and M. S. El-Deab, Fuel, 2020, 261, 116481

289 K. Rajkumari and L. Rokhum, Biomass Conversion and Biorefinery, 2020, 1-10.

290 V. O. Odude, A. J. Adesina, O. O. Oyetunde, O. O. Adeyemi, N. B. Ishola, A. O. Etim and E. Betiku, Waste and Biomass Valorization, 2019, 10, 877-888.

291 M. Gohain, K. Laskar, A. K. Paul, N. Daimary, M. Maharana, I. K. Goswami, A. Hazarika, U. Bora and D. Deka, Renew. Energy, 2020, 147, 541-555.

292 M. Aslam, P. Saxena and A. K. Sarma, Energy and Environment Research. 2014, 4, 1927-0569.

293 M. Di Serio, R. Tesser, L. Pengmei and E. Santacesaria, Energy and Fuels, 2008, 22, 207-217.

294 N. S. Talha and S. Sulaiman, ARPN J. Eng. Appl. Sci., 2016, 11, 439-442.

295 F. Allioux, B. J. Holland, L. Kong and L. F. Dumée, 2017, 4, 1-10.

296 K. L. T. Rodrigues, V. M. D. Pasa and É. C. Cren, J. Environ. Chem. Eng., 2018, 6, $4531-4537$.

297 L. Ma, Y. Han, K. Sun, J. Lu and J. Ding, J. Energy Chem., 2015, 000, 1-7.

298 S. Xia, X. Guo, D. Mao, Z. Shi, G. Wu and G. Lu, RSC Adv., 2014, 4, 51688-51695.

299 N. Shibasaki-kitakawa, K. Hiromori, T. Ihara, K. Nakashima and T. Yonemoto, FUEL, 2015, 139, 11-17.

300 M. Banchero and G. Gojjelino, Energies, 2018, 11, 1843-1851. 
301 D. R. Radu and G. A. Kraus, Heterogeneous Catalysis for Today's Challenges. 2015. $117-130$

302 N. Shibasaki-kitakawa, H. Honda, H. Kuribayashi and T. Toda, 2007, 98, 416-421.

303 Y. Ren, B. He, F. Yan, H. Wang, Y. Cheng, L. Lin, Y. Feng and J. Li, Bioresour. Technol., 2012, 113, 19-22.

304 M. Tubino, A. José and D. A. Meirelles, Chem. Eng. J., 2018, 333, 686-696.

305 J. Kansedo, Y. X. Sim and K. T. Lee, IOP Conf. Ser. Mater. Sci. Eng., 2019, 495, 012050-012060.

306 N. Jaya, B. K. Selvan and S. J. Vennison, Ecotoxicol. Environ. Saf., 2015, 121, 3-9.

307 A. Umar, A. Uba, M. L. Mohammed, M. N. Almustapha, C. Muhammad and J. Sani, Niger. J. Basic Appl. Sci., 2019, 26, 88.

308 J. Kansedo and K. T. Lee, Energy Sci. Eng., 2014, 2, 31-38.

309 O. Ilgen, A. N. Akin and N. Boz, Turkish J. Chem., 2009, 33, 289-294.

310 B. Vafakish and M. Barari, Kem. u Ind. Chem. Chem. Eng., 2017, 66, 47-52.

311 R. Hartono, B. Mulia, M. Sahlan, T. S. Utami, A. Wijanarko and H. Hermansyah, AIP Conf. Proc., 2017, 1826, 020020.

312 N. Shibasaki-Kitakawa, T. Tsuji, M. Kubo and T. Yonemoto, Bioenergy Res., 2011, 4, 287-293.

313 N. Shibasaki-Kitakawa, T. Tsuji, K. Chida, M. Kubo and T. Yonemoto, Energy and Fuels, 2010, 24, 3634-3638.

314 Y. Feng, B. He, Y. Cao, J. Li, M. Liu, F. Yan and X. Liang, Bioresour. Technol., 2010, 101, 1518-1521.

315 N. Jalilnejad Falizi, T. Güngören Madenoğlu, M. Yüksel and N. Kabay, Int. J. Energy Res., 2019, 43, 2188-2199.

316 P. A. Alaba, Y. M. Sani, W. Mohd and A. Wan, RSC Adv., 2016, 6, 78351-78368.

317 Q. H. Xia, K. Hidajat and S. Kawi, Chem. Commun., 2000, 22, 2229-2230.

318 A. V. Ivanov, S. V. Lysenko, S. V. Baranova, A. V. Sungurov, T. N. Zangelov and E. A. Karakhanov, Microporous Mesoporous Mater., 2006, 91, 254-260.

319 S. H. I. Guo-liang, Y. U. Feng, Y. A. N. Xiao-liang and L. I. Rui-feng, J. Fuel Chem. Technol., 2017, 45, 311-316.

320 Q. H. Xia, K. Hidajat and S. Kawi, J. Catal., 2002, 205, 318-331.

321 H. Muthu, V. S. Selvabala, T. K. Varathachary, D. K. Selvaraj, J. Nandagopal and S. Subramanian, Brazilian J. Chem. Eng., 2010, 27, 601-608.

322 M. K. Lam, K. T. Lee and A. R. Mohamed, Appl. Catal. B Environ., 2009, 93, 134 
139.

323 C. O. Pereira, M. F. Portilho, C. A. Henriques and F. M. Z. Zotin, J. Braz. Chem. Soc., 2014, 25, 2409-2416.

324 G. Kafuku, K. T. Lee and M. Mbarawa, Chem. Pap., 2010, 64, 734-740.

325 X. Li and W. Huang, Energy Sources, Part A Recover. Util. Environ. Eff., 2009, 31, $1666-1672$.

326 M. L. Testa, V. La Parola, L. F. Liotta and A. M. Venezia, J. Mol. Catal. A Chem., 2013, 367, 69-76.

327 M. L. Testa, V. La Parola and A. M. Venezia, Catal. Today, 2010, 158, 109-113.

328 J. Gardy, A. Hassanpour, X. Lai and M. H. Ahmed, Appl. Catal. A Gen., 2016, 527, $81-95$.

329 J. Gardy, A. Hassanpour, X. Lai, M. H. Ahmed and M. Rehan, Appl. Catal. B Environ., 2017, 207, 297-310.

330 T. Suzuta, M. Toba, Y. Abe and Y. Yoshimura, JAOCS, J. Am. Oil Chem. Soc., 2012, 89, 1981-1989.

331 K. Thirunavukkarasu, T. M. Sankaranarayanan, A. Pandurangan, R. Vijaya Shanthi and S. Sivasanker, Catal. Sci. Technol., 2014, 4, 851-860.

332 W. Xie, H. Wang and H. Li, Ind. Eng. Chem. Res., 2012, 51, 225-231.

333 F. H. Alhassan, U. Rashid and Y. H. Taufiq-Yap, J. Oleo Sci., 2015, 64, 505-514.

334 W. Xie and T. Wang, Fuel Process. Technol., 2013, 109, 150-155.

335 W. Xie and D. Yang, Bioresour. Technol., 2012, 119, 60-65.

336 H. Amani, Z. Ahmad, M. Asif and B. H. Hameed, J. Ind. Eng. Chem., 2014, 20, 44374442.

337 Q. Zhang, H. Li, X. Liu, W. Qin, Y. Zhang, W. Xue and S. Yang, Energy Technol., 2013, 1, 735-742.

338 F. H. Alhassan, U. Rashid and Y. H. Taufq-Yap, J. Oleo Sci., 2015, 64, 91-99.

339 A. Mahajan and P. Gupta, Environ. Chem. Lett., 2020, 18, 299-314.

340 M. Hara, T. Yoshida, A. Takagaki, T. Takata, J. N. Kondo, S. Hayashi and K. Domen, Angew. Chemie - Int. Ed., 2004, 43, 2955-2958.

341 S. P. Adhikari, Z. D. Hood, S. Borchers and M. Wright, Chemistry select, 2020, 5, $1534-1538$.

342 R. A. Arancon, H. R. Barros, A. M. Balu, C. Vargas and R. Luque, Green Chem., 2011, 13, 3162-3167.

343 A. Sandouqa, Z. Al-Hamamre and J. Asfar, Renew. Energy, 2019, 132, 667-682. 
344 K. Malins, J. Brinks, V. Kampars and I. Malina, Appl. Catal. A Gen., 2016, 519, 99106.

345 M. Kacem, G. Plantard, N. Wery and V. Goetz, Cuihua Xuebao/Chinese J. Catal., 2014, 35, 1571-1577.

346 Q. Shu, J. Gao, Z. Nawaz, Y. Liao, D. Wang and J. Wang, Appl. Energy, 2010, 87, 2589-2596.

347 M. Goncìalves, V. C. Souza, T. S. Galhardo, M. Mantovani, F. C. A. Figueiredo, D. Mandelli and W. A. Carvalho, Ind. Eng. Chem. Res., 2013, 52, 2832-2839.

348 Y. Zhong, Q. Deng, P. Zhang, J. Wang, R. Wang, Z. Zeng and S. Deng, Fuel, 2019, 240, 270-277.

349 V. Trombettoni, D. Lanari, P. Prinsen, R. Luque, A. Marrocchi and L. Vaccaro, Prog. Energy Combust. Sci., 2018, 65, 136-162.

350 M. Otadi, A. Shahraki, M. Goharrokhi and F. Bandarchian, Procedia Eng., 2011, 18, $168-174$.

351 K. Rajkumari, I. B. Laskar, A. Kumari, B. Kalita and L. Rokhum, React. Funct. Polym., 2020, 149, 104519.

352 P. P. Upare, J. M. Lee, D. W. Hwang, S. B. Halligudi, Y. K. Hwang and J. S. Chang, J. Ind. Eng. Chem., 2011, 17, 287-292.

353 K. Fukuhara, K. Nakajima, M. Kitano, S.Hayashic and M. Hara, Phys. Chem. Chem. Phys.,2013, 15, 9343.

354 T. S. Galhardo, N. Simone, M. Gonçalves, F. C. A. Figueiredo, D. Mandelli and W. A. Carvalho, ACS Sustain. Chem. Eng., 2013, 1, 1381-1389.

355 P. D. Rocha, L. S. Oliveira and A. S. Franca, Renew. Energy, 2019, 143, 1710-1716.

356 M. Hara, Energy Environ. Sci., 2010, 3, 601-607.

357 L. J. Konwar, P. Mäki-Arvela and J. P. Mikkola, Chem. Rev., 2019, 119, 1157611630.

358 I. B. Laskar, K. Rajkumari, R. Gupta and L. Rokhum, Energy and Fuels, 2018, 32, $12567-12576$.

359 K. Rajkumari, I. B. Laskar, A. Kumari, B. Kalita and L. Rokhum, React. Funct. Polym., 2020, 149, 104519.

360 M. M. Alam, M. A. Hossain, M. D. Hossain, M. A. H. Johir, J. Hossen, M. S. Rahman, J. L. Zhou, A. T. M. K. Hasan, A. K. Karmakar and M. B. Ahmed, Processes, 2020, 8, 203.

361 X. J. Zhang, Y. Y. Wang, Z. C. Jiang, P. T. Wu, Y. M. Jin and Y. Q. Hu, Xinxing Tan 
Cailiao/New Carbon Mater., 2013, 28, 484-488.

362 Q. Zhang, Y. Zhang, T. Deng, F. Wei, J. Jin and P. Ma, Sustainable production of biodiesel over heterogeneous acid catalysts, Elsevier B.V., 2020, 407-432.

363 I. K. Mbaraka, D. R. Radu, V. S. Y. Lin and B. H. Shanks, J. Catal., 2003, 219, 329336.

364 M. Toda, A. Takagaki, M. Okamura, J. N. Kondo. S. Hayashi, K. Domen and M. Hara, Nature, 2005, 438, 178.

365 K. Nakajima, M. Hara, B. Hu, Q. Lu, Y. ting Wu, Z. xi Zhang, M. shu Cui, D. jia Liu, C. qing Dong, Y. ping Yang, V. Aniya, A. Kumari, D. De, D. Vidya, V. Swapna, P. K. Thella, B. Satyavathi, H. Zhang, X. Meng, C. Liu, Y. Wang and R. Xiao, J. Anal. Appl. Pyrolysis, 2018, 2, 1296-1304.

366 K. Malins, V. Kampars, J. Brinks, I. Neibolte and R. Murnieks, Applied Catalysis B: Environmental, 2015, 176, 553-558.

367 S. Pandian, A. Sakthi Saravanan, P. Sivanandi, M. Santra and V. K. Booramurthy, Refining Biomass Residues for Sustainable Energy and Bioproducts. Academic Press, 2020. 87-109.

368 M. Kitano, D. Yamaguchi, S. Suganuma, K. Nakajima, H. Kato, S. Hayashi and M. Hara, Langmuir, 2009, 25, 5068-5075.

369 H. Yuan, B. L. Yang and G. L. Zhu, Energy and Fuels, 2009, 23, 548-552.

370 J. A. Melero, L. F. Bautista, G. Morales, J. Iglesias and D. Briones, Energy and Fuels, 2009, 23, 539-547.

371 D. Zuo, J. Lane, D. Culy, M. Schultz, A. Pullar and M. Waxman, Appl. Catal. B Environ., 2013, 129, 342-350.

372 K. A. Shah, J. K. Parikh and K. C. Maheria, Res. Chem. Intermed., 2015, 41, 10351051 .

373 A. Varyambath, M. R. Kim and I. Kim, New J. Chem., 2018, 42, 12745-12753.

374 Shagufta, I. Ahmad and R. Dhar, Catal. Surv. from Asia, 2017, 21, 53-69.

375 H. Yu, S. Niu, C. Lu, J. Li and Y. Yang, Fuel, 2017, 208, 101-110.

376 X. Tang and S. Niu, J. Ind. Eng. Chem., 2019, 69, 187-195.

377 S. Niu, Y. Ning, C. Lu, K. Han, H. Yu and Y. Zhou, Energy Convers. Manag., 2018, $163,59-65$.

378 I. F. Nata, M. D. Putra, C. Irawan and C. K. Lee, J. Env. Chem. Eng, 2017, 5, 21712175 .

379 Q. Guan, Y. Li, Y. Chen, Y. Shi, J. Gu, B. Li and R. Miao, RSC Adv., 2017, 7, 7250- 
7258.

380 I. M. Lokman, Arab. J. Chem., 2016, 9, 179-189.

381 I. Thushari and S. Babel, Bioresour. Technol., 2018, 248, 199-203.

382 Y. Wang, D. Wang, M. Tan, B. Jiang, J. Zheng, N. Tsubaki and M. Wu, ACS Appl. Mater. Interfaces, 2015, 7, 26767-26775.

383 R. Liu, X. Wang, X. Zhao and P. Feng, Carbon N. Y., 2008, 46, $1664-1669$.

384 S. Dechakhumwat, P. Hongmanorom, C. Thunyaratchatanon, S. M. Smith, S. Boonyuen and A. Luengnaruemitchai, Renew. Energy, 2020, 148, 897-906.

385 M. Mahdavi, Iranian Journal of Catalysis, 2019, 9, 27-35.

386 M. Hara, Top. Catal., 2010, 53, 805-810.

387 T. T. V. Tran, S. Kaiprommarat, S. Kongparakul, P. Reubroycharoen, G. Guan, M. H. Nguyen and C. Samart, Waste Manag., 2016, 52, 367-374.

388 S. Hosseini, J. Janaun and T. S. Y. Choong, Process Saf. Environ. Prot., 2015, 98, $285-295$.

389 L. J. Konwar, J. Wärnå, P. Mäki-Arvela, N. Kumar and J. P. Mikkola, Fuel, 2016, 166, $1-11$.

390 A. Endut, S. Hanis, Y. Sayid, N. Hanis, M. Hanapi, S. Hajar, A. Hamid, F. Lananan, M. Khairul, A. Kamarudin, R. Umar and H. Khatoon, International Biodeterioration \& Biodegradation, 2017, 124, 250-257.

391 F. Ezebor, M. Khairuddean, A. Z. Abdullah and P. L. Boey, Energy Convers. Manag., 2014, 88, 1143-1150.

392 T. Liu, Z. Li, W. Li, C. Shi and Y. Wang, Bioresour. Technol., 2013, 133, 618-621.

393 Y. Zhou, S. Niu and J. Li, Energy Convers. Manag., 2016, 114, 188-196.

394 H. H. Mardhiah, H. C. Ong, H. H. Masjuki, S. Lim and Y. L. Pang, Energy Convers. Manag., 2017, 144, 10-17.

395 B. L. A. Prabhavathi Devi, T. Vijai Kumar Reddy, K. Vijaya Lakshmi and R. B. N. Prasad, Bioresour. Technol., 2014, 153, 370-373.

396 B. L. A. P. Devi, K. N. Gangadhar, P. S. S. Prasad, B. Jagannadh and R. B. N. Prasad, ChemSusChem, 2009, 2, 617-620.

397 X. Fu, D. Li, J. Chen, Y. Zhang, W. Huang, Y. Zhu, J. Yang and C. Zhang, Bioresour. Technol., 2013, 146, 767-770.

398 L. J. Konwar, R. Das, A. J. Thakur, E. Salminen, P. Mäki-Arvela, N. Kumar, J. P. Mikkola and D. Deka, J. Mol. Catal. A Chem., 2014, 388-389, 167-176.

399 E. M. Santos, A. P. D. C. Teixeira, F. G. Da Silva, T. E. Cibaka, M. H. Araújo, W. X. 
C. Oliveira, F. Medeiros, A. N. Brasil, L. S. De Oliveira and R. M. Lago, Fuel, 2015, 150, 408-414.

400 L. J. Konwar, P. Mäki-Arvela, E. Salminen, N. Kumar, A. J. Thakur, J. P. Mikkola and D. Deka, Appl. Catal. B Environ., 2015, 176-177, 20-35.

401 B. V. S. K. Rao, K. Chandra Mouli, N. Rambabu, A. K. Dalai and R. B. N. Prasad, Catal. Commun., 2011, 14, 20-26.

402 J. R. Kastner, J. Miller, D. P. Geller, J. Locklin, L. H. Keith and T. Johnson, Catal. Today, 2012, 190, 122-132.

403 A. M. Dehkhoda, A. H. West and N. Ellis, Appl. Catal. A Gen., 2010, 382, 197-204.

404 A. M. Dehkhoda and N. Ellis, Catal. Today, 2013, 207, 86-92.

405 L. Fjerbaek, K. V. Christensen and B. Norddahl, Biotechnol. Bioeng., 2009, 102, $1298-1315$.

406 F. Moazeni, Y. C. Chen and G. Zhang, J. Clean. Prod., 2019, 216, 117-128.

407 D. Kumar, T. Das, B. S. Giri, E. R. Rene and B. Verma, Fuel, 2019, 255, 115801.

408 D. Kumar, T. Das, B. S. Giri and B. Verma, New J. Chem., 2018, 42, 15593-15602.

409 K. C. Badgujar, K. P. Dhake and B. M. Bhanage, Process Biochem., 2013, 48, 13351347.

410 N. R. Mohamad, N. H. C. Marzuki, N. A. Buang, F. Huyop and R. A. Wahab, Biotechnol. Biotechnol. Equip., 2015, 29, 205-220.

411 Z. Amini, Z. Ilham, H. C. Ong, H. Mazaheri and W. H. Chen, Energy Convers. Manag., 2017, 141, 339-353.

412 R. W. M. Mounguengui, C. Brunschwig, B. Baréa, P. Villeneuve and J. Blin, Prog. Energy Combust. Sci., 2013, 39, 441-456.

413 S. V. Ranganathan, S. L. Narasimhan and K. Muthukumar, Bioresour. Technol., 2008, 99, 3975-3981.

414 A. Gusniah, H. Veny and F. Hamzah, Ind. Eng. Chem. Res., 2019, 58, 581-589.

415 K. H. Kim, O. K. Lee and E. Y. Lee, Catalysts, 2018, 8, 68.

416 J. Sebastian, C. Muraleedharan and A. Santhiagu, Int. J. Green Energy, 2017, 14, 687693.

417 J. H. C. Wancura, D. V. Rosset, M. V. Tres, J. V. Oliveira, M. A. Mazutti and S. L. Jahn, Can. J. Chem. Eng., 2018, 96, 2361-2368.

418 A. Arumugam and V. Ponnusami, Heliyon, 2017, 3, 486.

419 R. Jambulingam, M. Shalma and V. Shankar, J. Clean. Prod., 2019, 215, 245-258.

420 S. Rafiei, S. Tangestaninejad, P. Horcajada, M. Moghadam, V. Mirkhani, I. 
Mohammadpoor-Baltork, R. Kardanpour and F. Zadehahmadi, Efficient biodiesel production using a lipase@ZIF-67 nanobioreactor, 2018, vol. 334.

421 H. Taher, E. Nashef, N. Anvar and S. Al-Zuhair, Biofuels, 2019, 10, 463-472.

422 R. S. Malani, S. B. Umriwad, K. Kumar, A. Goyal and V. S. Moholkar, Energy Convers. Manag., 2019, 188, 142-150.

423 J. Jayaraman, K. Alagu, P. Appavu, N. Joy, P. Jayaram and A. Mariadoss, Renew. Energy, 2020, 145, 399-407.

424 M. Marín-Suárez, D. Méndez-Mateos, A. Guadix and E. M. Guadix, Renew. Energy, 2019, 140, 1-8.

425 H. C. Nguyen, S. H. Liang, S. S. Chen, C. H. Su, J. H. Lin and C. C. Chien, Energy Convers. Manag., 2018, 158, 168-175.

426 C. G. Lopresto, S. Naccarato, L. Albo, M. G. De Paola, S. Chakraborty, S. Curcio and V. Calabrò, Ecotoxicol. Environ. Saf., 2015, 121, 229-235.

427 N. A. Kabbashi, N. I. Mohammed, M. Z. Alam and M. E. S. Mirghani, J. Mol. Catal. B Enzym., 2015, 116, 95-100.

428 N. Choi, Y. Kim, J. S. Lee, J. Kwak, J. Lee and I. H. Kim, J. Am. Oil Chem. Soc., 2016, 93, 311-318.

429 P. Muanruksa and P. Kaewkannetra, Renew. Energy, 2020, 146, 901-906.

430 N. Choi, D. S. No, H. Kim, B. H. Kim, J. Kwak, J. S. Lee and I. H. Kim, Ind. Crops Prod., 2018, 120, 140-146.

431 N. F. Sulaiman, W. Azelee, W. Abu, S. Toemen, N. M. Kamal and R. Nadarajan, Renew. Energy, 2019, 135, 408-416.

432 M. Pirouzmand, M. Mahdavi and Z. Ghasemi, Fuel, 2018, 216, 296-300.

433 A. Ramli and M. Farooq, Malaysian Journal of Analytical Sciences, 2015, 19, 8-19.

434 M. E. Borges and A. Brito, International Journal of Chemical Reactor Engineering, 2011, 9, 1-20.

435 W. Nor, N. Wan, N. Aishah and S. Amin, Fuel Process. Technol., 2011, 92, $2397-$ 2405.

436 M. F. R. Nizah, Y. H. Taufiq-yap, U. Rashid, S. Hwa and Z. A. S. Nur, Energy Convers. Manag., 2014, 88, 3-8.

437 H. V Lee, J. C. Juan and Y. H. Tau, 2015, 74, 124-132.

438 F. Jamil, A. H. Al-muhatseb, M. Tay, Z. Myint, M. Al-hinai, L. Al-haj, M. Baawain, M. Al-abri, G. Kumar and A. E. Atabani, Energy Convers. Manag., 2018, 155, 128137. 
439 Y. Jeon, W. S. Chi, J. Hwang, D. H. Kim, J. H. Kim and Y. Shul, "Applied Catal. B, Environ., 2019, 242, 51-59.

440 W. Liu, P. Yin, X. Liu and R. Qu, Bioresour. Technol., 2014, 173, 266-271.

441 O. Nur, U. Rashid and M. Sufri, Renew. Energ., 2019, 131, 187-196.

442 F. Farzaneh and F. Moghzi, React. Kinet. Mech. Catal., 2016, 118, 509-521.

443 D. Salinas, S. Guerrero and P. Araya, Catal. Commun., 2010, 11, 773-777.

444 K. Srilatha, N. Lingaiah, B. L. A. P. Devi, R. B. N. Prasad, S. Venkateswar and P. S.

S. Prasad, Appl. Catal. A Gen., 2009, 365, 28-33.

445 C. M. R. Prado and N. R. Antoniosi Filho, J. Anal. Appl. Pyrolysis, 2009, 86, 338-347.

446 A. Wisniewski, V. R. Wiggers, E. L. Simionatto, H. F. Meier, A. A. C. Barros and L. A. S. Madureira, Fuel, 2010, 89, 563-568.

447 J. Van Gerpen, Fuel Process. Technol., 2005, 86, 1097-1107.

448 S. H. Y. S. Abdullah, N. H. M. Hanapi, A. Azid, R. Umar, H. Juahir, H. Khatoon and A. Endut, Renew. Sustain. Energy Rev., 2017, 70, 1040-1051.

449 S. Hanis, Y. Sayid, N. Hanis, M. Hanapi and A. Azid, 2017, 70, 1040-1051. 